\title{
Performance Assessment of Solar Absorption Cooling for Ontario Housing
}

\author{
by \\ Courtney Edwards \\ B.Eng., Environmental Engineering \\ Carleton University, 2009
}

A thesis submitted to the Faculty of Graduate and Postdoctoral Affairs in partial fulfillment of the requirements for the degree of

Master of Applied Science in Mechanical Engineering

Ottawa-Carleton Institute for Mechanical and Aerospace Engineering Department of Mechanical and Aerospace Engineering

Carleton University

Ottawa, Ontario

August, 2011

(C) Copyright 2011

Courtney Edwards 
Library and Archives

Canada

Published Heritage

Branch

395 Wellington Street

Ottawa ON K1A ON4

Canada
Bibliothèque et

Archives Canada

Direction du

Patrimoine de l'édition

395, rue Wellington

Ottawa ON K1A ON4

Canada
Your file Votre référence

ISBN: 978-0-494-83056-7

Our file Notre référence

ISBN: 978-0-494-83056-7

\section{NOTICE:}

The author has granted a nonexclusive license allowing Library and Archives Canada to reproduce, publish, archive, preserve, conserve, communicate to the public by telecommunication or on the Internet, loan, distribute and sell theses worldwide, for commercial or noncommercial purposes, in microform, paper, electronic and/or any other formats.

The author retains copyright ownership and moral rights in this thesis. Neither the thesis nor substantial extracts from it may be printed or otherwise reproduced without the author's permission.
AVIS:

L'auteur a accordé une licence non exclusive permettant à la Bibliothèque et Archives Canada de reproduire, publier, archiver, sauvegarder, conserver, transmettre au public par télécommunication ou par l'Internet, prêter, distribuer et vendre des thèses partout dans le monde, à des fins commerciales ou autres, sur support microforme, papier, électronique et/ou autres formats.

L'auteur conserve la propriété du droit d'auteur et des droits moraux qui protège cette thèse. $\mathrm{Ni}$ la thèse ni des extraits substantiels de celle-ci ne doivent être imprimés ou autrement reproduits sans son autorisation.
In compliance with the Canadian Privacy Act some supporting forms may have been removed from this thesis.

While these forms may be included in the document page count, their removal does not represent any loss of content from the thesis.
Conformément à la loi canadienne sur la protection de la vie privée, quelques formulaires secondaires ont été enlevés de cette thèse.

Bien que ces formulaires aient inclus dans la pagination, il n'y aura aucun contenu manquant. 


\begin{abstract}
Residential energy consumption from space-cooling has more than doubled in Canada in the last two decades, and accounts for a large portion of summer electricity usage peaks. Presently, the most common space-cooling technology in use is electrically driven vapour compression systems. These systems place a large strain on the central electricity system. Furthermore, the marginal power required to supply space-cooling is often supplied by non-renewable sources of energy, such as coal and natural gas. Solar thermal energy can be used as the driving source for a residential absorption cooling system, removing the bulk of the energy demand of the cooling system from the electricity grid while continuing to provide comfortable living conditions. In order to assess the suitability of solar absorption cooling for residential space-cooling in Ontario (Canada), simulations of the thermal and electrical performance of the technology have been completed. The goal of the research is to determine whether a solar absorption cooling system could meet the cooling loads of typical Ontario single, detached houses given the climate and housing characteristics of the region.
\end{abstract}

A TRNSYS model was constructed to dimension key system components. Two custom Types were created for this model: a controller and an absorption chiller. The size of the solar thermal array and the volumes of the hot and cold stores were established based upon a series of sensitivity analyses. Following this, an ESP-r model was configured to represent the entire energy system: the house, the occupant electrical loads, the solar thermal collectors, absorption chiller, hot and cold stores, and all ancillary equipment. To meet the goals of this research progamme it was necessary to develop a calibrated model of an absorption chiller suitable for building performance simulation. A set of experimentally acquired absorption chiller performance data has been used to calibrate an absorption chiller model in ESP-r.

A control function was created in ESP-r to provide added flexibility in the execution of the plant system. Models of typical Ontario houses were selected for building performance simulation in conjunction with the plant model, and different system strategies and climates, using ESP-r. The simulations of the solar absorption cooling system demonstrate that the application of the technology is feasible for cooling Ontario houses, and results in significant reduction of residential greenhouse gas emissions. 
To my husband, Jonathan James Stuart Edwards. 


\section{Acknowledgments}

I would first like to express my gratitude for the support and guidance of my research supervisors Dr. Ian Beausoleil-Morrison and Dr. Cynthia Cruickshank. I would not have even begun this research without Dr. Beausoleil-Morrison's support, and I am ever thankful for his rare balance of both challenging me and providing encouragement. I am grateful for the steady mentorship and encouragement from Dr. Cruickshank, and feel privileged to be her first graduating student, as I am certain that incredible research and teaching are to follow in her career.

I would like to acknowledge the funding and support of this research by the Natural Sciences and Engineering Research Council as part of the Solar Buildings Research Network, and through my supervisors' Discovery Grants. Great thanks to David Bradley for helping me in my work with TRNSYS and for responding with patience and thoroughness. I am also thankful to have been able to apply the excellent work done by Dr. Lukas Swan, and to have received his helpful advice and guidance. A big thanks to Geoff Johnson for his perseverance in acquiring data for the absorption chiller, without it my research would have been much less fruitful.

A special thanks to Andrea Pietila, Briana Kemery, and Neil Saldhana who showed me great kindness and patience as I began this endeavour. Our shared laughs, frustrations, and problem-solving are what allowed this research to come to fruition. Great thanks to Ryan Dickinson, Phil Drouillard, Geoff Johnson, John Kopf, Stephen McMurtry, Stephanie Seemel, and Adam Wills, who took the time to review sections of this thesis, and who were always at hand for brainstorming and tea breaks. I could not ask for a better team, which I believe is a testament to the strong culture of mutual support and friendship fostered by my supervisors.

Thank you to my parents and brothers for instilling within me an appreciation for education, and a willingness to face and conquer challenges. The love of family is a precious gift that I feel honoured and blessed to hold. A special thanks to all my family and friends who have been understanding and supportive throughout this endeavour, spurring me on with encouragement and acts of love.

Finally, and most importantly, I wish to express my sincerest appreciation for my husband, Jonathan Edwards. His encouragement and complete faith in my ability to excel in this work was an integral part of my success. His graphics for the polar area charts are beautiful, and it brings me great joy to see his work intertwined in my own. His unfailing love and commitment enabled me to maintain balance despite the demands of this research, and also helped me to grow emotionally, spiritually, and academically. Thank you, my love, for demonstrating daily that "love bears all things, believes all things, hopes all things, endures all things. Love never ends." 


\section{Table of Contents}

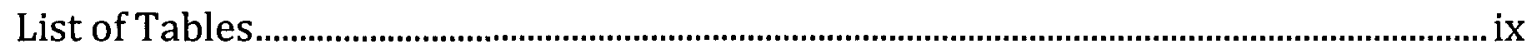

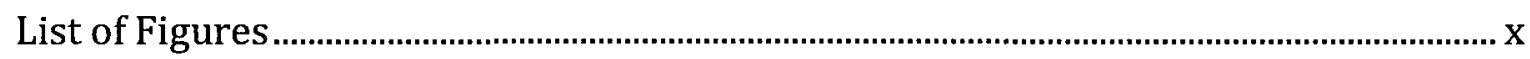

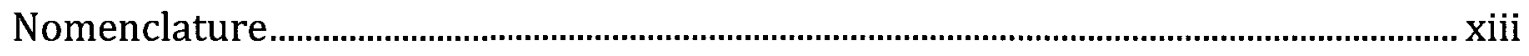

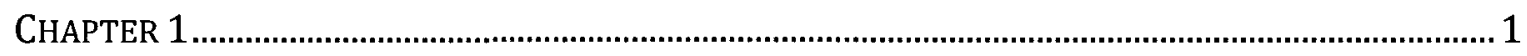

1.0 Introduction and Literature Review........................................................................ 1

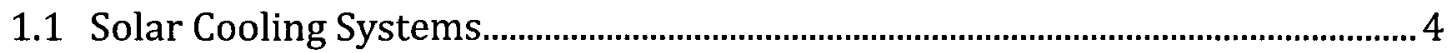

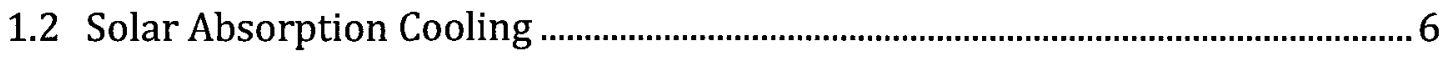

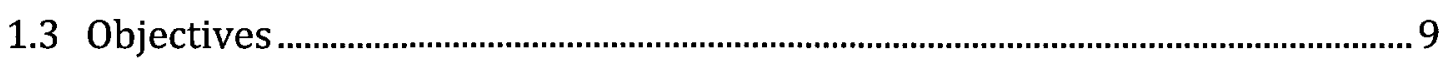

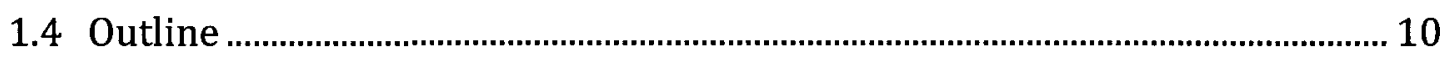

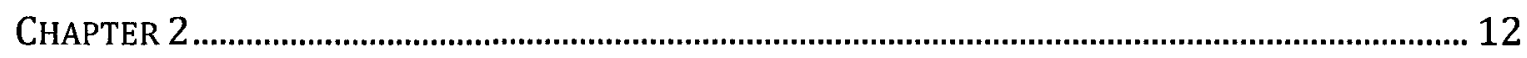

2.0 System Configuration and Modelling ................................................................ 12

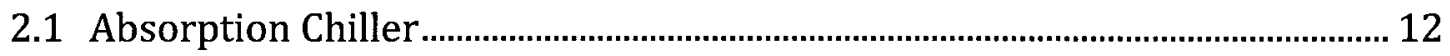

2.2 Heat Medium Production Sub-System ................................................................ 13

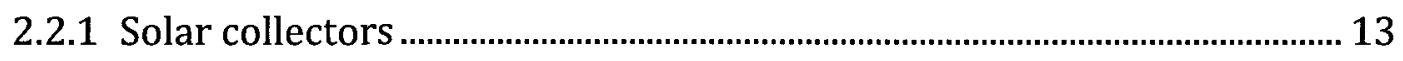

2.2.2 Auxiliary heat production ............................................................................... 16

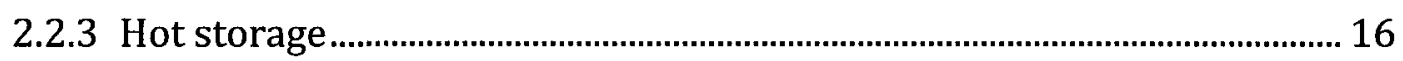

2.3 Cold Medium Production Sub-System................................................................ 17

2.4 Heat Rejection Sub-System................................................................................ 18

2.5 Load Sub-System .............................................................................................. 19

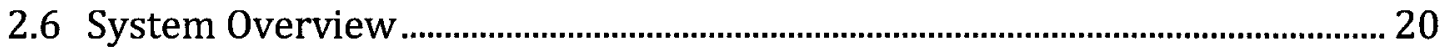

2.7 Building Performance Simulation......................................................................... 20

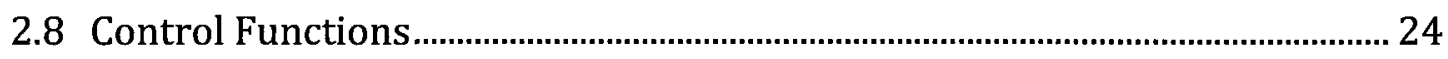

2.8.1 Solar collector loop control ........................................................................... 24

2.8.2 Zone cooling loop control................................................................................ 25

2.8.3 Absorption chiller control......................................................................... 27 
3.0 Sizing of System Components .................................................................................. 30

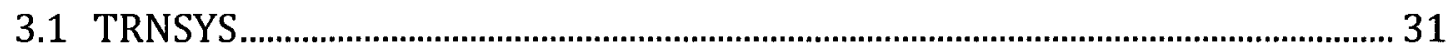

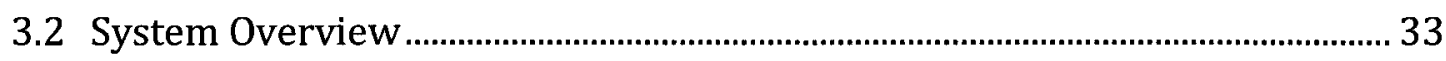

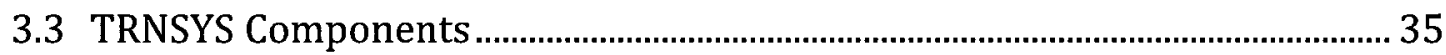

3.3.1 Type 198 - absorption chiller......................................................................... 36

3.3.2 Type 199 - absorption chiller controller ………………………………...... 39

3.3.3 Type 71 - evacuated tube collector.................................................................. 41

3.3.4 Type 4a - storage tank; fixed inlets, uniform losses..................................... 45

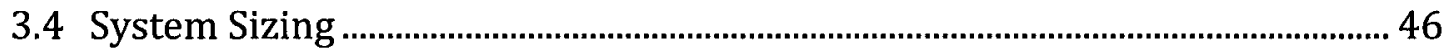

3.4.1 Sensitivity of the solar collector flow rate ................................................. 51

3.4.2 Hot loop flow rate......................................................................................... 52

3.4.3 Cold loop flow rate ........................................................................................... 53

3.4.4 Component sizing........................................................................................... 54

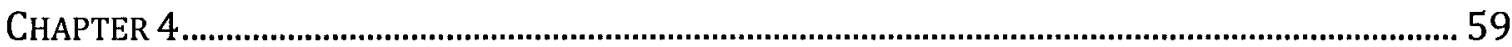

4.0 ESP-r Building Performance Simulation Software...............................................59

4.1 The ESP-r Building Thermal Network ...............................................................6

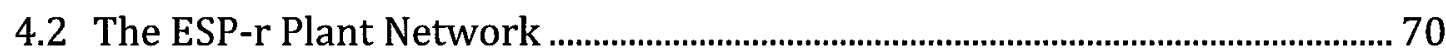

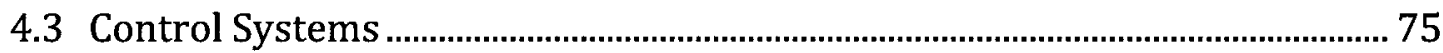

4.4 Climatic Considerations ................................................................................................ 77

CHAPTER 5

5.0 ESP-r Modelling Methods ...................................................................................... 79

5.1 Plant Network Description .............................................................................. 81

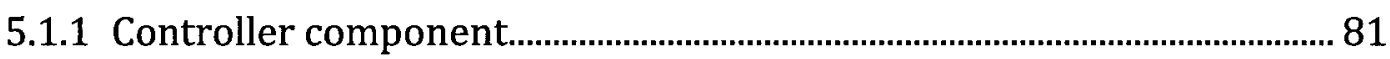

5.1.2 Absorption chiller component ................................................................... 83

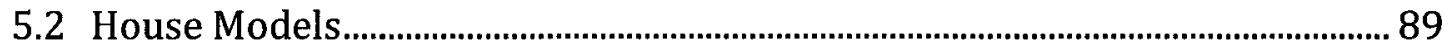

5.2.1 Geometry and envelope characteristics ....................................................... 91

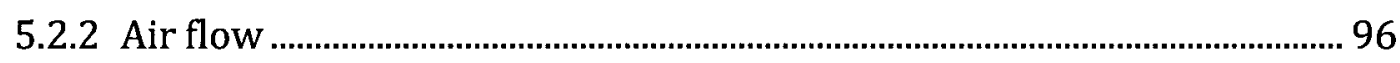

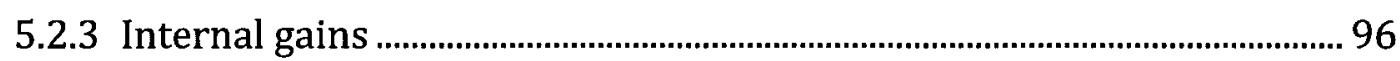




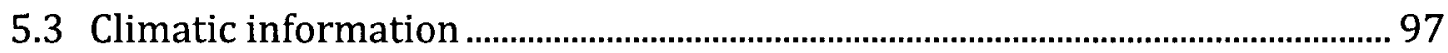

5.4 System Configuration ............................................................................................ 97

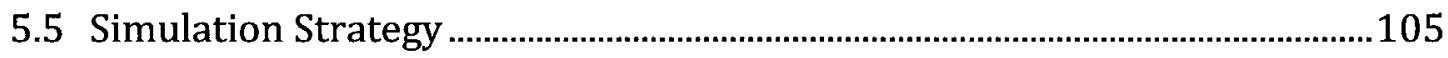

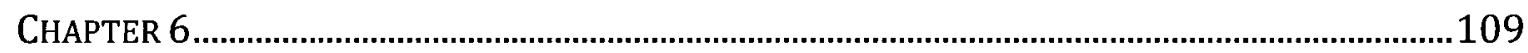

6.0 Results and Analysis ........................................................................................109

6.1 Comparison to Free Floating Conditions ……………………………………...110

6.2 System Performance .........................................................................................112

6.2.1 Summary of findings ...................................................................................130

6.3 Significance of Housing Construction and Geometry .......................................131

6.3.1 Summary of findings .....................................................................................138

6.4 Effect of Climate and Weather Conditions......................................................139

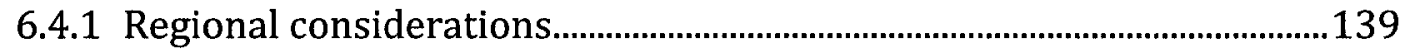

6.4.2 Temporal considerations ..............................................................................147

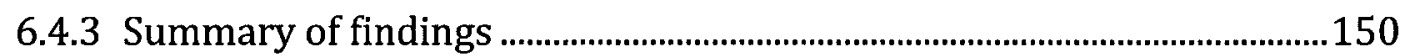

6.5 Control Strategies................................................................................................150

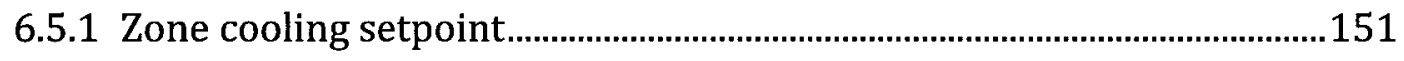

6.5.2 Minimum generator inlet temperature........................................................152

6.5.3 Summary of findings ........................................................................................154

6.6 Summary of Results............................................................................................154

CHAPTER 7

7.0 Electrical Results and Greenhouse Gas Emissions...............................................156

7.1 System Electrical Loads..........................................................................................156

7.2 Electrical Performance .............................................................................................159

7.3 Determination of Greenhouse Gas Emissions ...................................................161

7.4 Greenhouse Gas Emission Results..........................................................................164

CHAPTER 8

8.0 Conclusions and Recommendations for Future Work........................................168

8.1 Recommendations for System Optimization ...................................................169 
APPENDIX A: TRNSYS Deck File......................................................................................182

APPENDIX B: ESP-r Plant Network Description and Inputs ...............................................191

APPENDIX C: Experimental Data Used for Regression Analysis ........................................197

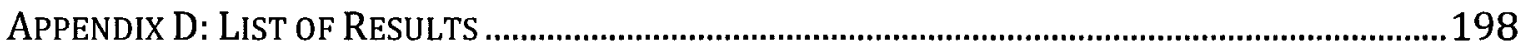




\section{List of Tables}

Table 1-1: Cooling system stock in Ontario ........................................................................... 2

Table 2-1: Yazaki specifications ....................................................................................... 28

Table 3-1: Thermal performance coefficients of Wikora tubes .......................................... 45

Table 3-2: IAM data for Wikora tubes ................................................................................... 45

Table 3-3: Initial variable conditions ................................................................................... 48

Table 3-4: Final component sizing …………………………………………….......... 57

Table 5-1 Temperature ranges for chiller experimental data........................................... 82

Table 5-2: Generator heat transfer coefficients .................................................................... 86

Table 5-3: Evaporator heat transfer linear expression coefficients ................................ 88

Table 5-4: Criteria for house model selection ................................................................... 90

Table 5-5: House characteristics ........................................................................................... 93

Table 5-6: Tank and solar collector sizing ........................................................................104

Table 5-7: Simulation cases ............................................................................................106

Table 6-1: Summary of performance characteristics .....................................................112

Table 6-2: Average performance indicators for the SAC system on July $4^{\text {th }} \ldots \ldots . . . . . . . .120$

Table 6-3: Monthly performance summary of base case ................................................121

Table 6-4: System performance at different operating conditions for two hot days

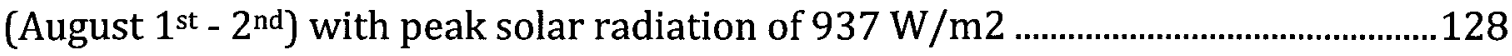

Table 6-5: Summary of results for four houses................................................................131

Table 6-6: Summary of results for Toronto, Windsor, and Ottawa simulations .......140

Table 6-7: Summary of weather and performance variables for Toronto Pearson International Airport for 1999-2008...............................................................................149

Table 6-8: Summary of results for different zone cooling setpoints .............................151

Table 6-9: Summary of results for different minimum generator inlet temperatures

Table 7-1: Electrical consumption by component of SAC system.

Table 7-2: Total summer electrical draw for four houses with conventional and solar absorption cooling systems

Table 7-3: Marginal greenhouse gas intensity factors (Farhat \& Ugursal, 2010).....164

Table 7-4: Monthly greenhouse gas emission reduction

Table 7-5: Approximation of annual Ontario central air space-cooling GHG emission reduction for different levels of SAC adoption 


\section{List of Figures}

Figure 1-1: Schematic diagram of solar cooling................................................................

Figure 1-2: Schematic of a single-effect solar absorption chiller......................................... 8

Figure 1-3: Schematic of a solar absorption cooling system ............................................. 9

Figure 2-1 Collector characteristic curves.......................................................................... 15

Figure 2-2: Selected solar absorption cooling system schematic ..................................... 21

Figure 2-3: Solar collector loop control logic.................................................................... 25

Figure 2-4: Zone cooling loop control................................................................................ 26

Figure 2-5: Absorption chiller control logic ......................................................................... 29

Figure 3-1: Schematic of the solar absorption cooling system ......................................... 34

Figure 3-2: TRNSYS Simulation Studio SAC system schematic......................................... 35

Figure 3-3: Coefficient of performance as a function of solar heat supply temperature for LiBr-water absorption chillers ...................................................................... 37

Figure 3-4: Solar collector area definition ............................................................................... 42

Figure 3-5: Bi-axial incidence angle modifier definitions.................................................... 44

Figure 3-6: Sensitivity of unmet cooling loads to solar collector flow rate ................... 52

Figure 3-7: Sensitivity of unmet cooling loads to hot loop flow rate............................... 53

Figure 3-8: Sensitivity of unmet cooling loads to cold loop flow rate ............................. 54

Figure 3-9: Sizing of the solar collectors ……………………………………………..... 55

Figure 3-10: Sizing of the hot storage tank................................................................................. 56

Figure 3-11: Sizing of the cold storage tank .................................................................... 56

Figure 3-12: Relationship between storage tank sizes and unmet cooling loads ...... 57

Figure 4-1: Control volume discretisation of an opaque surface ..................................... 61

Figure 4-2: Heat and mass transfer processes .................................................................... 62

Figure 4-3: Heat and mass transfer processes in an opaque surface .............................. 63

Figure 4-4: Control volume for an intra-constructional node............................................. 65

Figure 4-5: Control volume for an internal surface node.................................................... 67

Figure 4-6: Zone air control volume..................................................................................... 68

Figure 4-7: Solar collector control volume ......................................................................... 72

Figure 4-8 Control loop methodology in ESP-r............................................................ 75

Figure 5-1: Schematic of ESP-r plant network representing the SAC system.............. 80 
Figure 5-2: Comparison of the predicted and experimental generator heat transfer rates.

Figure 5-3: Comparison of the predicted and experimental evaporator heat transfers

Figure 5-4: Wireframe diagram of the 1955 house.

Figure 5-5: Wireframe diagram of the 1976 house............................................................ 94

Figure 5-6: Wireframe diagram of the 1976-LW house .................................................. 95

Figure 5-7: Wireframe diagram of the 2000 house........................................................... 95

Figure 5-8: Percentage of unmet cooling loads by month for different solar collector tilt angles..........................................................................................................................

Figure 5-9: Monthly solar collector efficiency for different tilt angles .........................101

Figure 5-10: Percentage of cooling loads unmet with various cold tank and solar collector sizes

Figure 5-11: Maximum main living zone temperature for various solar collector and cold tank sizes 103

Figure 5-12: Percentage of monthly unmet cooling loads for various cold tank sizes with a solar collector area of $50 \mathrm{~m}^{2}$

Figure 6-1: Maximum daily temperature in Zone 1 for July and August.......................110

Figure 6-2: Average daily temperature in Zone 1 for July and August ..........................111

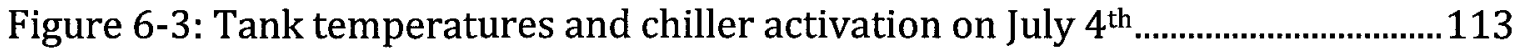

Figure 6-4: Zone and ambient temperatures on July $4^{\text {th }}$....................................................113

Figure 6-5: Tank temperatures and chiller activation on August $4^{\text {th }}$.............................115

Figure 6-6: Hot tank temperature variation on August $4^{\text {th }}$................................................115

Figure 6-7: Zone and ambient temperatures on August $4^{\text {th }}$...............................................116

Figure 6-8: Tank temperatures and chiller activation on May $17^{\text {th }}$................................117

Figure 6-9: Zone and ambient temperatures on May 17th..............................................117

Figure 6-10: Zone temperature and ambient conditions during time of unmet cooling setpoint from July $6^{\text {th }}$ to July $10^{\text {th }}$

Figure 6-11: Zone temperature and ambient conditions during time of unmet cooling setpoint from August $3^{\text {rd }}$ to August $7^{\text {th }}$

Figure 6-12: Chiller performance parameters from 9:30 am-5:30 pm over a two week period

Figure 6-13: System performance parameters from 9:30 am-5:30 pm over a two week period

Figure 6-14: Energy flow for the SAC system on a typical day (July $4^{\text {th }}$ ) 
Figure 6-15: Histogram of the evaporator heat transfer on August 1st, a typical hot day

Figure 6-16: Maximum monthly Zone 1 temperature for different house models..133 Figure 6-17: Average monthly temperature for Zone 1 for different house models

Figure 6-18: Breakdown of unmet cooling loads by time period ..................................135

Figure 6-19: Temperature fluctuation of the 1976 house on July 30th........................136

Figure 6-20: Temperature fluctuation of the 1976-LW house on July $30^{\text {th }} \ldots . . . \cdots \cdots . . . . . . .136$

Figure 6-21: Monthly energy flow for each house ............................................................138

Figure 6-22: Breakdown of unmet cooling loads across four hour periods in three climates

Figure 6-23: Maximum monthly Zone 1 temperature for three Ontario climates ...143 Figure 6-24: Average monthly Zone 1 temperatures across three Ontario climates

Figure 6-25: Component temperatures on hottest day (July 20 th) in Ottawa............145

Figure 6-26: Storage tank temperatures for three Ontario climates on August $1^{\text {st }} .146$ Figure 6-27: Unmet cooling loads and maximum and average zone temperatures in Toronto from 1999-2008

Figure 6-28: Cold storage tank and zone temperatures for different cooling setpoints on August $4^{\text {th }}$ 152

Figure 7-1: Electrical breakdown for 2000 house 161 


\section{Nomenclature}

A

$\mathrm{AL}$

AIM-2

BPS

C

$\bar{c}$

$\mathrm{CH}_{4}$

$\mathrm{CO}_{2}$

$\mathrm{CO}_{2 \text { eq }}$

COP

CSDDRD

CWEC

CWEEDS

DHW

E

$F^{\prime}$

$F_{R}$

$\mathrm{G}_{\mathrm{T}}$

GHG
Area

$\mathrm{m}^{2}$

Appliance and lighting

Alberta Infiltration Model

Building performance simulation

Specific heat capacity

$\mathrm{J} / \mathrm{kg}^{\circ} \mathrm{C}$

Average specific heat capacity

$\mathrm{J} / \mathrm{kg}^{\circ} \mathrm{C}$

Methane

Carbon dioxide

Equivalent $\mathrm{CO}_{2}$

Coefficient of performance

$(-)$

Canadian stock of single-detached double,

and row houses database

Canadian weather for energy calculations

Canadian weather energy and engineering

datasets

Domestic hot water

Energy

MJ

Collector efficiency factor

$(-)$

Collector heat removal factor

$(-)$

Incoming solar energy

$\mathrm{W} / \mathrm{m}^{2}$

Greenhouse gas 


\begin{tabular}{|c|c|c|}
\hline GHGIF & Greenhouse gas intensity factor & \\
\hline GTA & Greater Toronto area & \\
\hline GWP & Global warming potential & $(-)$ \\
\hline $\mathrm{h}$ & Heat transfer coefficient & $\mathrm{W} / \mathrm{mK}$ \\
\hline $\mathrm{H}_{2} \mathrm{O}$ & Water & \\
\hline I & Current node & \\
\hline$I+1$ & Next node in space & \\
\hline $\mathrm{I}-1$ & Previous node in space & \\
\hline IESO & Independent Electricity System Operator & \\
\hline HVAC & Heating, ventilation and air conditioning & \\
\hline IAM & Incidence angle modifier & \\
\hline $\mathrm{J}$ & Linear heat loss coefficient & $\mathrm{W} / \mathrm{m}^{2} \mathrm{~K}$ \\
\hline $\mathrm{k}$ & Thermal conductivity & $\mathrm{W} / \mathrm{mK}$ \\
\hline $\mathrm{K}_{\alpha \tau}$ & Incidence angle modifier & $(-)$ \\
\hline $\mathrm{K}_{1}$ & Transversal IAM & $(-)$ \\
\hline $\mathrm{K}_{2}$ & Longitudinal IAM & $(-)$ \\
\hline L & Quadratic heat loss coefficient & $\mathrm{W} / \mathrm{m}^{2} \mathrm{~K}^{2}$ \\
\hline $\mathrm{LiBr}$ & Lithium Bromide & \\
\hline M & Number of adjoining zones & $(-)$ \\
\hline $\mathrm{m}$ & Mass & $\mathrm{kg}$ \\
\hline$\dot{m}$ & Mass flow rate & $\mathrm{kg} / \mathrm{s}$ \\
\hline MSF & Modified solar fraction & $(-)$ \\
\hline $\mathrm{n}$ & Number of zones & $(-)$ \\
\hline
\end{tabular}


Nitrous oxide

$\Delta \mathrm{p}$

Pressure Loss

$\mathrm{Pa}$

$\mathrm{P}$

Power

kW

q

Heat transfer

W

q"

Heat transfer per unit area

$\mathrm{W} / \mathrm{m}^{2}$

q"'

Heat transfer per unit volume

$\mathrm{W} / \mathrm{m}^{3}$

Q

Energy transferred by heat

$\dot{Q}$

Heat transfer rate

W

$\dot{Q}_{u}$

Useful energy gain

W

RSI

R-value

$\mathrm{m}^{2} \mathrm{~K} / \mathrm{W}$

SAC

Solar absorption cooling

SF

Solar fraction

$\delta t$

Time step

S

$t$

Time, or current time step

S

$\Delta \mathrm{t}$

Change in time

S

$\mathrm{t}+\Delta \mathrm{t}$

Future time step

S

$\mathrm{T}$

Temperature

${ }^{\circ} \mathrm{C}$

$\Delta \mathrm{T}$

Temperature difference

${ }^{\circ} \mathrm{C}$

TAC

Thermal air conditioning

$\mathrm{U}_{\mathrm{L}}$

Collector heat loss coefficient

$\mathrm{W} / \mathrm{m}^{2} \mathrm{~K}$

V

Volume

$\mathrm{m}^{3}$

X

Energy density 
$\Delta \mathrm{x}$

$\Delta y$

Z

$\Delta \mathrm{z}$

Greek Constants

$\alpha$

$\delta$

$\eta$

$\theta$

$\rho$

$\tau \alpha$

$\Psi$

$\Omega$

\section{Latin Symbols}

2

N

\section{Subscripts}

a

absorbed

aux

availon $_{\text {on }}$

captured
Width of control volume

m

Height of control volume m

Height

$\mathrm{m}$

Length of control volume

$\mathrm{m}$

Explicit weighting

$(-)$

Differential change

Thermal efficiency

$(-)$

Temperature

${ }^{\circ} \mathrm{C}$

Density

$\mathrm{kg} / \mathrm{m}^{3}$

Effective transmittance-absorptance

$(-)$

Longitudinal angle

Transversal angle

Percentage of time steps where the system was

$\%$

unable to maintain the cooling setpoint

Percentage of time steps above $25^{\circ} \mathrm{C}$

$\%$

Ambient

Absorbed

Auxiliary

Available solar energy when solar collector loop is activated

Captured solar energy 


\begin{tabular}{|c|c|}
\hline casual & Casual gains \\
\hline cas-rad & Radiative casual gain \\
\hline cas-conv & Convective casual gain \\
\hline chill & Chilled water stream \\
\hline chill_in & Chilled water inlet \\
\hline chill_out & Chilled water outlet \\
\hline coll & Collector \\
\hline con & Condenser \\
\hline cond & Conduction \\
\hline conv & Convection \\
\hline cooling & Cooling \\
\hline cooling_load & Cooling load \\
\hline $\mathrm{e}, \theta$ & Effective at angle $\theta$ \\
\hline$e, n$ & Effective at normal incidence \\
\hline elec-chiller & Chiller Electrical \\
\hline elec-system & System Electrical \\
\hline evap & Evaporator \\
\hline $\mathrm{fi}$ & Inlet fluid \\
\hline $\mathrm{fm}$ & Mean fluid \\
\hline gen & Generator \\
\hline heat_rejection & Heat rejection stream \\
\hline high & High \\
\hline hot & Heat medium stream \\
\hline
\end{tabular}




$\begin{array}{ll}\text { in } & \text { Inlet } \\ \text { losses } & \text { Losses } \\ \text { low } & \text { Low } \\ \text { out } & \text { Outlet } \\ \text { p } & \text { At constant pressure } \\ \text { peak } & \text { Peak } \\ \text { plant } & \text { Plant components } \\ \text { rad } & \text { Radiation } \\ \text { room } & \text { Room containing zone node } \\ \text { s } & \text { Surface number } \\ \text { sc } & \text { Solar collector } \\ \text { setpoint } & \text { Setpoint } \\ \text { solar } & \text { Solar } \\ \text { stored } & \text { Stored } \\ \text { th } & \text { Thermal } \\ \text { u } & \text { Useful } \\ \text { water } & \text { Water } \\ \text { wb } & \text { Wet bulb } \\ & \end{array}$




\section{Chapter 1}

\subsection{Introduction and Literature Review}

Residential energy use in Canada increased by $9 \%$ between 1990 and 2005, accounting for $17 \%$ of the nation's total secondary energy consumption in 2005 . During the same time period, the energy demand from space-cooling in residential units increased by 215\%, to reach a total of 37 PJ in 2005 (NRCan, 2008a). Presently, the most common space-cooling technology in use is electrically driven vapour compression systems. These systems place a large strain on the central electricity system during the summer months, and in Ontario these marginal loads are typically powered by non-renewable sources of energy. While improvements are being realized in the thermal envelope of households, space-cooling remains a significant component of residential energy use in summer months.

With air conditioning systems in over 6.5 million households in Canada, spacecooling resulted in the emission of $1.2 \mathrm{Mt}$ of $\mathrm{CO}_{2}$ equivalent $\left(\mathrm{CO}_{2 \mathrm{eq}}\right)$ in 2008 , with 1.0 Mt resulting from central systems. Ontario accounted for $70 \%$ of national spacecooling energy use in 2008 (NRCan, 2010), and was responsible for the majority of the cooling-related greenhouse gas (GHG) emissions. The annual air conditioning system stock in Ontario (NRCan, 2010) can be seen in Table 1-1. The number of central cooling systems has increased, though steadily remaining between $70 \%$ and $75 \%$ of the total cooling stock in Ontario. 
Table 1-1: Cooling system stock in Ontario

\begin{tabular}{|l|l|l|l|l|l|l|l|l|l|l|l|}
\hline & 1990 & 2000 & 2001 & 2002 & 2003 & 2004 & 2005 & 2006 & 2007 & 2008 \\
\hline $\begin{array}{l}\text { Central } \\
\text { Cooling } \\
\begin{array}{l}\text { Systems } \\
\text { (thousands) }\end{array}\end{array}$ & 997 & 1,938 & 2,007 & 2,060 & 2,210 & 2,397 & 2,511 & 2,615 & 2,614 & 2,818 \\
\hline $\begin{array}{l}\text { Total } \\
\text { cooling } \\
\text { systems } \\
\text { (thousands) }\end{array}$ & 1,638 & 2,689 & 2,783 & 2,905 & 3,006 & 3,187 & 3,338 & 3,600 & 3,606 & 3,762 \\
\hline
\end{tabular}

As an alternative, solar power can be used as the energy source in a residential cooling system, removing the bulk of the energy demand of the cooling system from the electricity grid. The addition of this renewable energy source can reduce the load on the electricity system, and therefore decrease the GHG contributions from cooling systems. Solar energy is a nearly limitless resource, and provides an immense amount of energy to the earth. For example, the solar radiation captured by the earth within a single month corresponds to the sum of all of the energy on the planet stored in all of the coal, petroleum, and natural gas (Vanek \& Albright, 2008).

In 2003, the Solar Air Conditioning in Europe Project investigated 54 solar cooling projects across Europe. Of the projects surveyed, $40 \%$ were at the research stage, $40 \%$ were in the development stage, and only $20 \%$ of projects were in the production stage (Balaras et al., 2007).

This research has shown solar cooling to result in primary energy savings of 4050\% (Balaras et al., 2007). However, solar insolation fluctuates considerably with 
latitude, and studies have shown that climate is a strong factor in the performance of solar cooling systems (Mateus \& Oliveira, 2009), which establishes the need for studies in a Canadian climate. While research concerning the application of solar cooling in buildings has been completed in a number of countries, research on applications in Canada has been limited. In 2007, while there were 81 large scale solar cooling systems documented in academic literature, the only system installed in North America was in Mexico, a country with a significantly different climate than Canada (Sparber et al., 2007). Solar cooling has begun to emerge across the United States, for example at the Audubon Environmental Centre in Los Angeles (LA Audubon, 2008). Over 25 companies provide systems for purchase (SEIA, 2010), but little data is available on the performance of the systems.

In addition, while much research has been completed in the area of building spacecooling, for example for the Shanghai Institute of Building Science in China (Zhai \& Wang, 2009b) and the General Hospital of Sitia in Greece (Tsoutsos et al., 2010), research concerning the application of solar cooling in residential housing has been less prevalent. Kim and Ferreira (2008) presented an overview of solar absorption studies, some of which were designed for residential application, and Florides et al. (2002b) used a domestic-size $11 \mathrm{~kW}$ cooling capacity absorption chiller in their assessment. These studies highlighted hurdles to the application of solar cooling to residential houses, including the limited number of small capacity $(<50 \mathrm{~kW})$ chillers available on the market, high initial cost, and the large collector area required per unit of installed cooling capacity 
(Zhai \& Wang, 2009a). While small-size water chillers are still scarce, several companies have begun the development of chillers in the range of 5-50 kW (Henning, 2007a).

Investigations on solar cooling can be completed through design testing and evaluation, as well as by using building performance simulation (BPS). Simulations are advantageous as they avoid the expense of prototype creation and allow for optimization of components and predictions for different housing styles and iterations (Florides et al., 2002b). In the last decade, a number of simulation tools have been used for BPS. The Solar Air Conditioning in Europe Project created a multimedia tool to aid in the selection of appropriate technology and techniques based on climate and other constraints (Balaras et al., 2007). Another commonly used software tool for the assessment of building systems, TRNSYS, has been employed in a number of solar cooling investigations (Mateus \& Oliveira, 2009; Florides et al., 2002a; Balghouthi et al., 2005). ESP-r is a further modelling tool which is used for simulating the thermal performance of buildings and can be utilized for assessing the energy use within domestic houses (ESRU, 2002).

\subsection{Solar Cooling Systems}

Solar cooling combines decades of experience in space-cooling with the high solar energy resource available at the times when cooling is most needed. This combination allows for the reduction of peak electricity loads in the summer months, while also reducing the residential GHG production through the use of a 
renewable energy resource. Solar cooling can be accomplished through solar thermal systems, such as 'sorption' systems, or through solar mechanical systems, such as photovoltaic technologies. Solar thermal systems are typically much less expensive (Zhai \& Wang, 2009a) and avoid the requirement of converting the captured solar energy into mechanical energy for a conventional cooling system (Dincer et al., 1996).

Solar cooling systems are generally composed of solar thermal collectors, a form of heat storage, a thermally driven cooling device, the distribution system, and a backup system (Balaras et al., 2007). Figure 1-1 provides a schematic diagram of a simple solar cooling system with an absorption chiller.

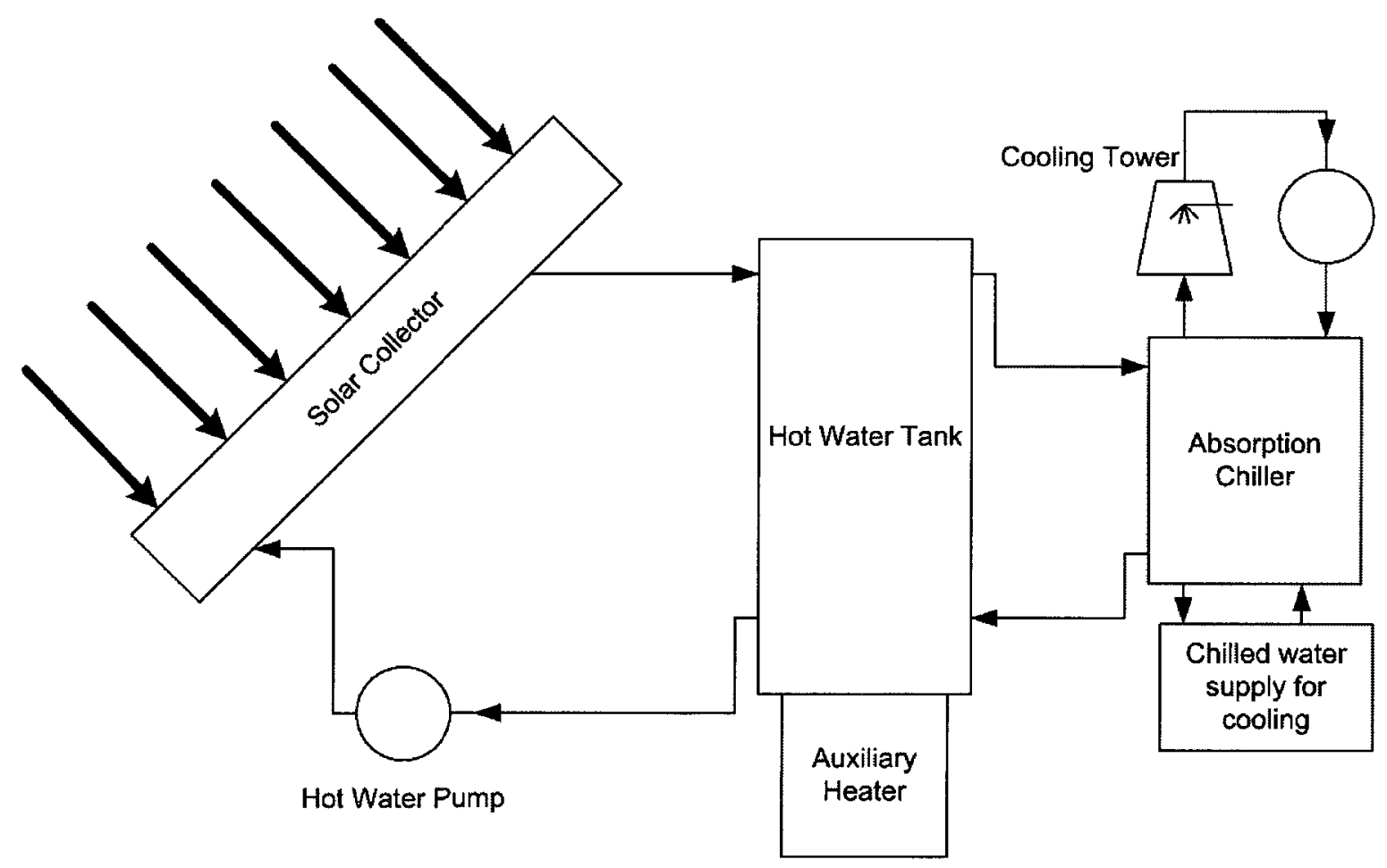

Figure 1-1: Schematic diagram of solar cooling 
Solar thermal collectors use the available solar resource to heat a fluid which can then serve as the heat input to a thermodynamic cycle. There are two common types of solar thermal collectors used for cooling: flat-plate solar collectors, and evacuated-tube solar collectors. These will be described in greater detail in Section 2.2.1.

Two of the most common approaches to solar thermal cooling are through the use of chillers and dessicant systems. Chillers produce chilled water which is then utilized for direct heat transfer from the indoor air to the fluid. Common chillers for solar applications include absorption and adsorption chillers (Henning, 2007b). Dessicant cooling systems are designed to produce conditioned air by means of cooling and dehumidifying fresh air, and must be coupled with equipment that supplies conditioned ventilation air (Henning, 2007b). A study completed in 2006 showed that $67 \%$ of systems in place in Europe were based on solar absorption cooling technology (ESTIF, 2006), making it one of the more prominent solar cooling technologies currently in use (Mateus \& Oliveira, 2009; Balaras et al., 2007).

\subsection{Solar Absorption Cooling}

Solar absorption cooling (SAC) utilizes harmless working fluids (refrigerants) such as water to produce chilled fluid for the removal of heat through space-cooling (Balghouthi et al., 2005). The thermal coefficient of performance ( $\mathrm{COP}_{\text {th }}$ ) of an absorption cooling system varies with operating conditions, including change in temperature levels and load. The $\mathrm{COP}_{\text {th }}$ can be defined as (Henning, 2007b): 


$$
\operatorname{COP}_{\text {th }}=\frac{\dot{Q}_{\text {low }}}{\dot{Q}_{\text {high }}}=\frac{\text { Heat flux extracted at a low temperature level }}{\text { Driving heat flux supplied to cooling equipment }}
$$

The typical COP th of a single-effect absorption system is $0.5-0.8$ (Henning, 2007b). Absorption systems consist of a generator, a condenser, an evaporator, and an absorber. The working fluid is a mixture of a refrigerant and absorbent, for example water and lithium-bromide (LiBr). A typical system is shown in Figure 1-2. Heat (e.g., solar input) is transferred to vapourize the refrigerant from the solution entering the generator. The vapourized working fluid is then passed through a condenser, exiting as a liquid. Heat is rejected at an intermediate temperature from the condensing process to a heat rejection water stream. The fluid then expands through a throttling valve to lower the pressure, and enters an evaporator, where it removes heat from an incoming stream to produce chilled water. This produces the useful cooling effect, as the chilled water is used for space-cooling in the distribution portion of the air conditioning system.

The vapourized refrigerant is absorbed by a dilute solution within the absorber. The mixing heat and the latent heat of condensation resulting from the absorption process are extracted by a heat rejection medium, typically water. The absorbent, now rich in refrigerant (strong solution), is pumped through a heat exchanger to a generator, where it is heated above the boiling point of the solution, which causes the refrigerant to desorb. This heat is provided by the solar-heated fluid from the solar collectors. The absorbing solution, now with renewed absorbing capacity, 
returns to the absorber, while the vapourized refrigerant flows to the condenser (Solair, 2003; Henning, 2007).

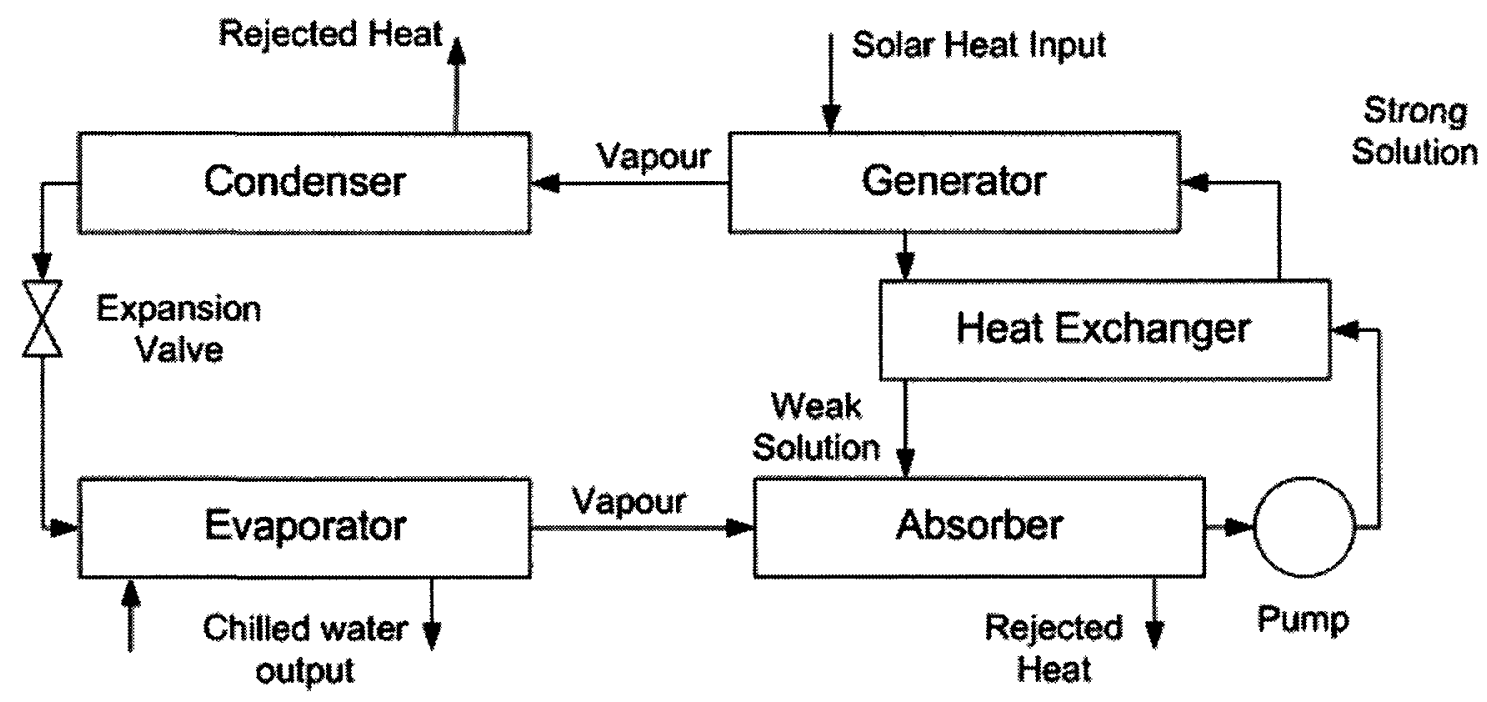

Figure 1-2: Schematic of a single-effect solar absorption chiller Modified from (Florides et al., 2002a)

A schematic of an absorption chiller integrated into a solar-driven system is shown in Figure 1-3. Additional variations to this system setup will be provided in Chapter 2. 


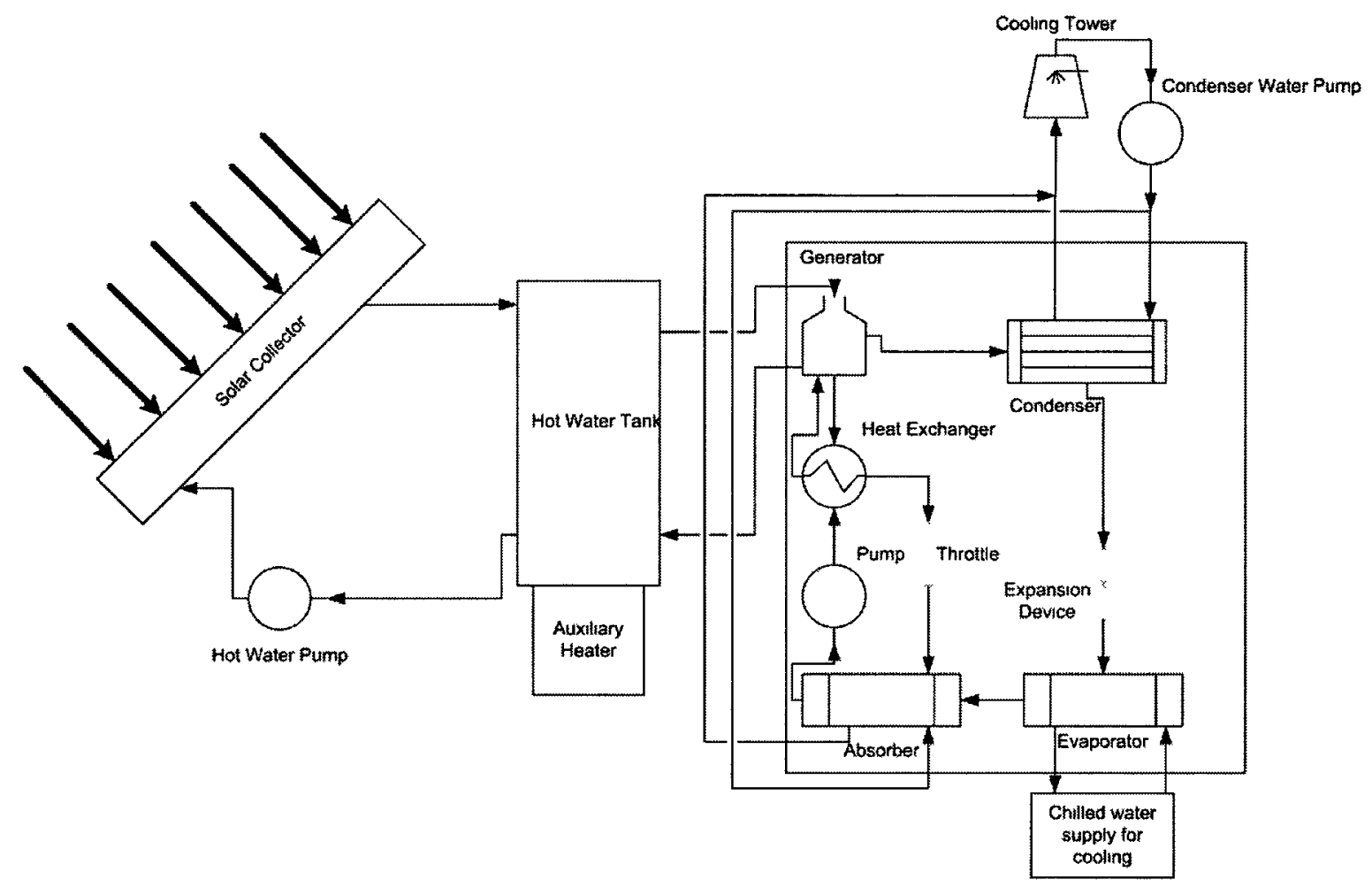

Figure 1-3: Schematic of a solar absorption cooling system

Modified from Fong et al. (2010)

\subsection{Objectives}

The following research objectives are the second phase of a performance assessment of SAC for Canadian housing. The research builds upon the first phase of research completed by Geoffrey Johnson (a Carleton M.A.Sc graduate) which involved the testing of a small-scale absorption chiller suitable for residential use (Johnson, 2011). 
The overall purpose of the research is to assess the feasibility of SAC for Ontario houses. To this end, the research objectives are as follows:

- Establish appropriate control schemes for a residential solar absorption chiller system;

- Conduct initial simulations of the absorption chiller system to dimension system components using TRNSYS;

- Calibrate and refine an existing ESP-r thermal air conditioning (TAC) model using data from Johnson's (2011) absorption chiller study;

- Develop a complete SAC system in ESP-r using the refined TAC model and other appropriate system components;

- Develop detailed models of representative Canadian houses;

- Perform an assessment of the solar absorption cooling system in houses with different operating conditions and for different climatic regions; and

- Determine the viability of the system based on the energy and greenhouse gas performance of the system.

\subsection{Outline}

The use of multiple building simulation software programs required a well-defined system setup. The system and its components are described in Chapter 2, along with an overview of building performance simulation and the selected control strategies. Chapter 3 then describes the TRNSYS simulation engine, and the initial sizing of the system components undertaken using TRNSYS. The ESP-r simulation 
environment, including the building simulation and plant network simulation components, are described in Chapter 4. Following this, the description of the building performance simulation completed in ESP-r is described in Chapter 5. This description includes the calibration of the absorption chiller system, the selection of the modelled houses, and an overview of the simulations undertaken.

Following these sections, Chapter 6 presents the thermal results and analysis of the simulations undertaken. This analysis includes an overview of each of the simulation sets, their associated parameters, and the significance of the results achieved with respect to SAC in Ontario. Chapter 7 describes the electrical performance and the greenhouse gas emissions impact of the system. Finally, Chapter 8 provides an overview of the conclusions resulting from the research, and recommendations for future work. 


\section{ChAPTER 2}

\subsection{System Configuration and Modelling}

The feasibility of solar cooling in Ontario was assessed through the use of building simulation software programs, which necessitated a thorough system description. Multiple variations of solar absorption cooling systems exist (for example, see Asrubali et al., 2009 and Cristina et al., 2010). The systems are generally comprised of the absorption chiller itself and four additional sub-systems: heat medium production, cold medium production, heat rejection, and load (Henning, 2007b). The following sections describe the various system components selected for the solar absorption cooling system (Sections 2.1 through 2.5), a brief introduction to the simulation environments employed (Section 2.7), and the overall system control strategies (Section 2.8).

\subsection{Absorption Chiller}

Absorption chillers used for solar cooling can be driven by various refrigerant/absorbent solutions. For applications such as air conditioning with chilled water temperatures above $5^{\circ} \mathrm{C}$, water-cooled water- $\mathrm{LiBr}$ is the most common pairing. Lithium Bromide remains water-soluble when it comprises less than $30 \%$ of the solution by mass. For chilled water temperatures below $5^{\circ} \mathrm{C}$, ammonia-water is a more prevalent pairing (IEA/SCH Task 25, 2002). 
For the present research, experimental results were obtained from Johnson (2011), who used a Yazaki $35 \mathrm{~kW}$ (10 Ton) chiller (Aroace, 2010) with a water-LiBr working pair. The Yazaki $35 \mathrm{~kW}$ chiller was thus selected as the basis for both the TRNSYS and ESP-r simulations described in Chapters 3 and 5, respectively.

\subsection{Heat Medium Production Sub-System}

The heat medium production sub-system is responsible for the production and storage, if applicable, of the heat medium which drives the absorption chiller. The heat medium can be generated through the use of solar collectors (Ghaddar et al., 1997), auxiliary heaters (Riley \& Probert, 1998), or a combination of both (Cristina et al., 2010; Muneer \& Uppal, 1985). Excess heat can be passed to a domestic hot water system (Asrubali et al., 2009), or stored for future use (Florides et al., 2002b).

\subsubsection{Solar collectors}

Given that the design of a solar absorption cooling system was core to the objectives of this research, the inclusion of solar collectors as the main driving energy for the generation of the heat medium was vital to the system design.

The two most common solar collectors in use for thermally-driven cooling are flat plate collectors and evacuated tube collectors. Flat plate collectors are generally less expensive, are easier to maintain, and make up a large majority of collectors globally (Duffie \& Beckman, 2006). Flat-plate solar collectors use a coated heat conducting metal sheet to absorb incident solar energy and glazing to transmit 
radiation to the plate and reduce convective heat loss. The incident energy is transmitted to a series of pipes, typically made of copper, filled with a heat transfer medium fluid (in many cases, a water-glycol mix). Flat-plate collectors are most frequently designed for applications requiring moderate delivery temperatures, up to around $100^{\circ} \mathrm{C}$, and they utilize both diffuse and beam solar radiation (Duffie \& Beckman, 2006). For use with an absorption chiller in a climate with an ambient air temperature of $30^{\circ} \mathrm{C}$ and radiation ranging between $400-1000 \mathrm{~W} / \mathrm{m}^{2}$, such as Toronto (Environment Canada, 2010b), flat plate collectors average an output temperature of $95^{\circ} \mathrm{C}$ with an efficiency of $20-60 \%$ (Henning, 2007b).

Evacuated tube collectors represent $10 \%$ of the covered solar collectors market in International Energy Association member countries. Evacuated tube solar collectors are formed by an array of concentric glass tubes connected in parallel, within which are absorbers. The evacuated tubes impede convective and conductive heat loss from the absorber, which results in higher efficiency than flatplate collectors at high temperatures (Henning, 2007b).

Despite their higher cost, evacuated tube collectors are commonly selected in place of flat plate collectors for solar cooling due to their lower heat exchange surface requirement (Assilzadeha, et al., 2005; Chasapis, 2009). For example, Fong et al. (2010) found evacuated tube collectors resulted in a higher solar fraction and $81 \%$ more solar radiation absorbed for SAC than flat plate collectors. 


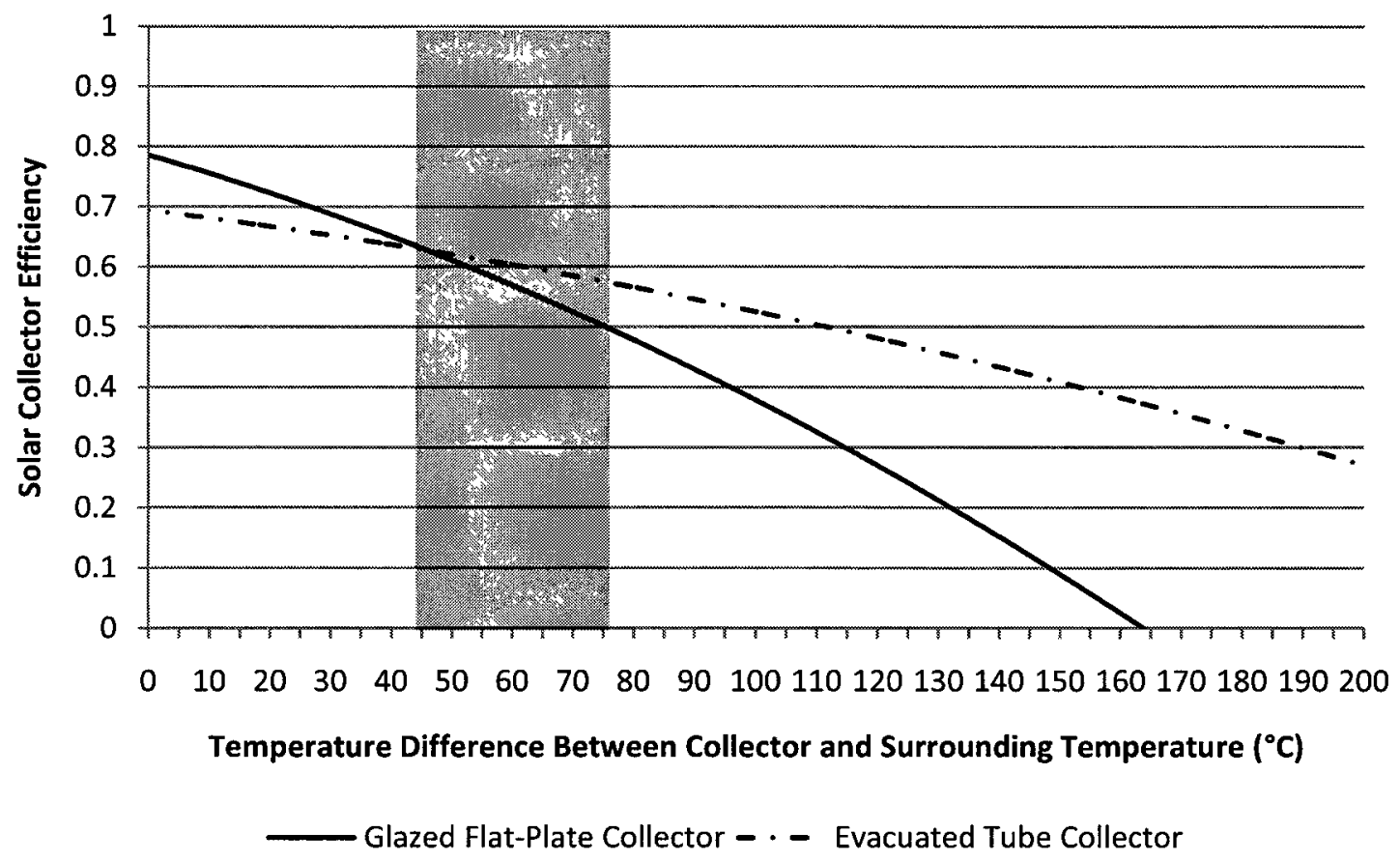

Figure 2-1 Collector characteristic curves Adatped from German Solar Energy Society (DGS) (2005)

The present research demands a solar collector outlet temperature in the range of $80-95^{\circ} \mathrm{C}$, with an ambient temperature of approximately $20-35^{\circ} \mathrm{C}$. The resulting temperature difference between the collector and surrounding temperature is in the range of $45-75^{\circ} \mathrm{C}$, shown as the shaded area on Figure 2-1. For this range of temperature difference, research by the German Solar Energy Society displayed on Figure 2-1, indicates that evacuated tube collectors have efficiencies up to $10 \%$ higher than that of glazed flat-plate collectors. Due to their efficiency at the high working fluid temperatures demanded by solar absorption cooling, an evacuated tube collector was chosen as the thermal input unit for the present research. 


\subsubsection{Auxiliary heat production}

Due to the unpredictable nature of solar radiation, back-up heat sources are occasionally employed in solar cooling systems to ensure that sufficient heat is always available to meet the cooling loads. Auxiliary heat production components are particularly beneficial on humid days with high cloud coverage, where a large latent load and low direct radiation exist (Henning, 2007b). Additionally, during the heating season, auxiliary heating systems can be used for space heating.

The objective of the present research was to determine the feasibility of solar absorption cooling for Ontario residential houses. In order to accurately assess the suitability of the technology to the climate and housing style in Ontario, it was desirable to assess the performance of solar absorption cooling without auxiliary heat production.

\subsubsection{Hot storage}

Thermal storage can be used in an absorption cooling system to increase the effectiveness of the system. Two different strategies exist for thermal storage:

1. A hot storage tank stores excess solar heat, which is then procured if the present solar heat is not sufficient.

2. A cold storage tank allows the storage of excess cooling potential and is procured if the present cold production of the chiller is not sufficient to meet the cooling load. 
These two strategies can be used individually or in combination. The average $\operatorname{COP}_{\text {th }}$ of a LiBr chiller is below 1.0 (Henning, 2007b), which means that storage upstream of the chiller (hot tank) is necessarily larger than an equivalent storage downstream of the chiller (cold tank). Practically, this means that a hot storage tank must be larger than a cold storage tank to provide equivalent cooling energy storage. Cold storage will be discussed further in Section 2.3.

Most frequently, hot storage is accomplished using a hot water storage tank, in order to reduce losses in conversion of thermal energy. The use of a hot storage tank has several advantages, though its primary benefit is in addressing the fluctuating heat availability by allowing the storage of excess heat for future use when little heat is available. This strategy also reduces the need for auxiliary heating devices (Henning, 2007b). Hot storage tanks have also been used for domestic hot water on off-cooling times, when the temperature of the tank is above $60^{\circ} \mathrm{C}$ but below the driving temperature of the chiller (Asrubali et al., 2009). A hot water storage tank has been included in the present research to better meet the cooling demands given the fluctuating solar radiation patterns during Ontario summers.

\subsection{Cold Medium Production Sub-System}

Once hot water has been produced through the hot medium sub-system, the cold medium sub-system can be initialized. The cold medium production sub-system includes the chilled stream from the absorption chiller and can also include cold storage. Similarly to the addition of a hot storage tank, cold storage can be 
integrated in order to store energy at times of high radiation for use at times when the available solar energy is not sufficient to meet the cooling demand. Solar gains reach a peak at solar noon, while the typical cooling load patterns peak in the afternoon or evening. The storage system is thus designed to cover the load for a number of hours (Henning, 2007b).

There are multiple cold storage options including eutectic salt, ice, and chilled water. The use of a solution of eutectic salt/water capitalizes on phase change for the storage of energy. This strategy only works well with low dehumidification needs, as the tank will only cool the distribution water to $8-10^{\circ} \mathrm{C}$. Ice may be used for thermal storage, but it requires additional ice-making equipment or chillers which are designed for low-temperature distribution (Henning, 2007b).

Chilled water can also be stored in a tank in the same way as the storage of the heat medium. The storage density of a tank is determined by the heat capacity of water as well as the difference between the supply and return temperatures. A typical system may have a temperature difference of $10^{\circ} \mathrm{C}$, which would provide a storage density of $41.9 \mathrm{MJ} / \mathrm{m}^{3}$ without dehumidification (Henning, 2007b). Due to the lower complexity and the suitable storage characteristics, a cold water tank was selected for use in the present research.

\subsection{Heat Rejection Sub-System}

In addition to the hot medium and cold medium production sub-systems, a heat rejection sub-system is integrated in the SAC system. The most common heat 
rejection method for absorption cooling is the use of a cooling tower. A cooling tower is a form of heat exchanger which allows the rejection of energy from a warm working fluid to the ambient air. Cooling towers can be either open-circuit systems or closed-circuit systems. Open-circuit systems involve direct contact between the air and cooling-water. Around $2-3 \%$ of the circulating water is evaporated during this contact, which produces the useful cooling effect. Closed-circuit systems involve indirect contact between the cooling-water and the air through heat exchanger walls. Closed circuit systems have larger fans, which increase the electricity consumption and are generally less efficient (Henning, 2007). A cooling tower was selected for use in the present research, but was not modelled explicitly, as described in Sections 3.3.1 and 5.1.

\subsection{Load Sub-System}

A variety of options exist for the load sub-system, which is responsible for meeting the cooling load. A water/air system allows both the latent \& sensible cooling loads to be met and was therefore selected in this case. The system was simplified to include a cooling coil for exchange of energy between the chilled water loop and an air loop. The air side of the cooling coil was then connected to a circulation fan for distribution to the house. 


\subsection{System Overview}

The complete SAC system described in Sections 2.1 through 2.5 is shown in Figure 2-2. State points have been numbered for reference in future sections. The system includes three controls, which are described in Section 2.8 .

\subsection{Building Performance Simulation}

Once a standardized system design has been selected, building simulation programs can then be used to assess the performance of buildings and their related plant networks under a variety of control scenarios. For the present research, BPS software was used to determine the appropriate sizing of a residential SAC system. In addition, BPS was used to simulate the performance of the system in a variety of house designs and climatic conditions.

Building simulation programs primarily utilize one of two simulation approaches: response function methods or numerical methods. Response function methods for building simulation were proposed by Stephenson and Mitalas (1967) in order to add robustness to manual methods by introducing dynamic considerations. The response function method is founded on the principle of superposition, whereby responses are summed independently of the system's component parts. This process results in the decoupling of the building and the heating, ventilation, and air conditioning (HVAC) system, as well as other interrelated networks such as building thermal processes and cross-room air movement (Clarke, 2001). 


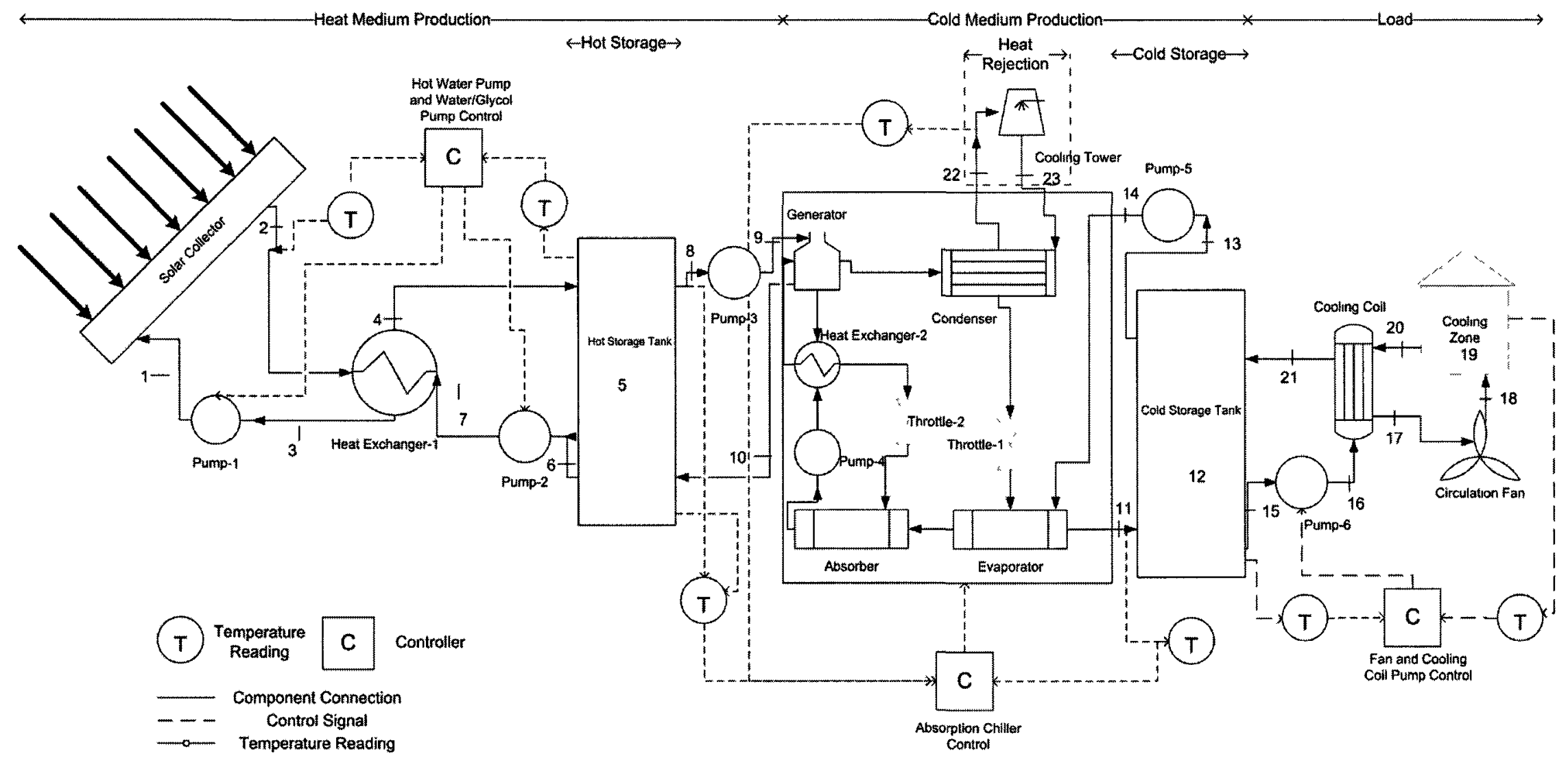

Figure 2-2: Selected solar absorption cooling system schematic 
Numerical methods in finite difference for building simulation emerged following the response function method when computing power became more vigorous. Numerical methods can be used for complex systems involving multiple interactions by representing relatively small regions by discrete control volumes that can be characterized by thermal properties. Numerical methods involve the discretisation and simultaneous solution of characteristic equations for each control volume (Clarke, 2001).

For initial designs, the response function and numerical modelling approaches are both able to provide reasonable results. However, when a realistic model is desired for BPS, response function methods prove to have significant limitations. The advantage of numerical methods is the ability to solve non-linear, time varying equation sets simultaneously. The benefit of this approach is the ability to solve complex flow path interactions and systems which have significantly different time constraints for different components. Additionally, the ability to couple all interacting networks of a model ensures both spatial and temporal accuracy (Clarke, 2001). The response function method, on the other hand, is unsuitable in situations when recirculation loops or complex control schemes are present, and does not provide accurate results for complex building models due to the decoupling of systems such as heat and moisture transfers within the building envelope (Abadie et al., 2005).

The present research required two consecutive uses of BPS. Initially, BPS was used for the dimensioning of the SAC system. This process required short simulation 
times, ease in component design, and robust cooling component simulation. The second phase of the research required the use of BPS for entire building simulation with the incorporated SAC system. This phase required accurate simulation of both the building and cooling components.

The TRNSYS simulation environment (University of Wisconsin, 2010) utilizes the response factor method to solve heat transfer equations and perform an overall zone energy balance in building simulation (Abadie et al., 2005). The TRNSYS software employs a sequential approach to HVAC. The outputs of one component are provided as inputs to the subsequent component, followed by iteration of component solutions. Due to its ability to rapidly prototype and design, along with the ease in adding and redesigning components, TRNSYS was selected for the initial sizing of the solar absorption cooling system. TRNSYS is described further in Section 3.1.

For the overall BPS of houses with the integrated SAC system, a program which utilized a more robust numerical method in finite difference was desired. The ESP-r simulation environment (ESRU, 2002) utilizes numerical methods for mass and thermal energy balances in the solution of its building and plant networks, and is described further in Sections 4.1 and 4.2. The ESP-r simulation environment has been extensively validated (e.g. Strachan, 2008), and is an open-source software platform. For this study, ESP-r was selected for the final modelling of the plant network and its integration into Ontario houses with different control strategies and climatic conditions. 


\subsection{Control Functions}

Due to the complexity of the total SAC system, three distinct control strategies were employed in the management of the system. The control of the addition of energy to the system from the solar collectors is described in Section 2.8.1. The control of the withdrawal of heat from the conditioned living space is described in Section 2.8.2. Finally, the control of the absorption chiller is described in Section 2.8.3. The state points in the control descriptions refer to Figure 2-2.

\subsubsection{Solar collector loop control}

The solar collector loop control logic is shown in Figure 2-3 and operates as follows. The temperature at the outlet of the solar collector $\left(\mathrm{T}_{2}\right)$ is compared to the temperature at the base of the hot storage tank $\left(\mathrm{T}_{5_{-} \text {base }}\right)$. If $\mathrm{T}_{2}$ is at least $4{ }^{\circ} \mathrm{C}$ greater than $T_{5}$, the controller moves on to the next step, otherwise pump- 1 and pump-2 are deactivated. In order to keep the hot tank within the temperature range accepted by the absorption chiller $\left(70^{\circ} \mathrm{C}\right.$ to $\left.95^{\circ} \mathrm{C}\right)$, the controller then checks whether the hot storage tank temperature $\left(\mathrm{T}_{5_{-} \text {base }}\right)$ is at or below $94^{\circ} \mathrm{C}$. If $\mathrm{T}_{5_{-} \text {base }}$ is below $94^{\circ} \mathrm{C}$, pump-1 and pump-2 are actuated. The four degree temperature difference is in line with other experimental chiller controls (Bong et al., 1987), and is not an influential parameter in this modelling because once solar radiation is available, the solar collector outlet temperature is significantly higher than the hot storage tank temperature. 


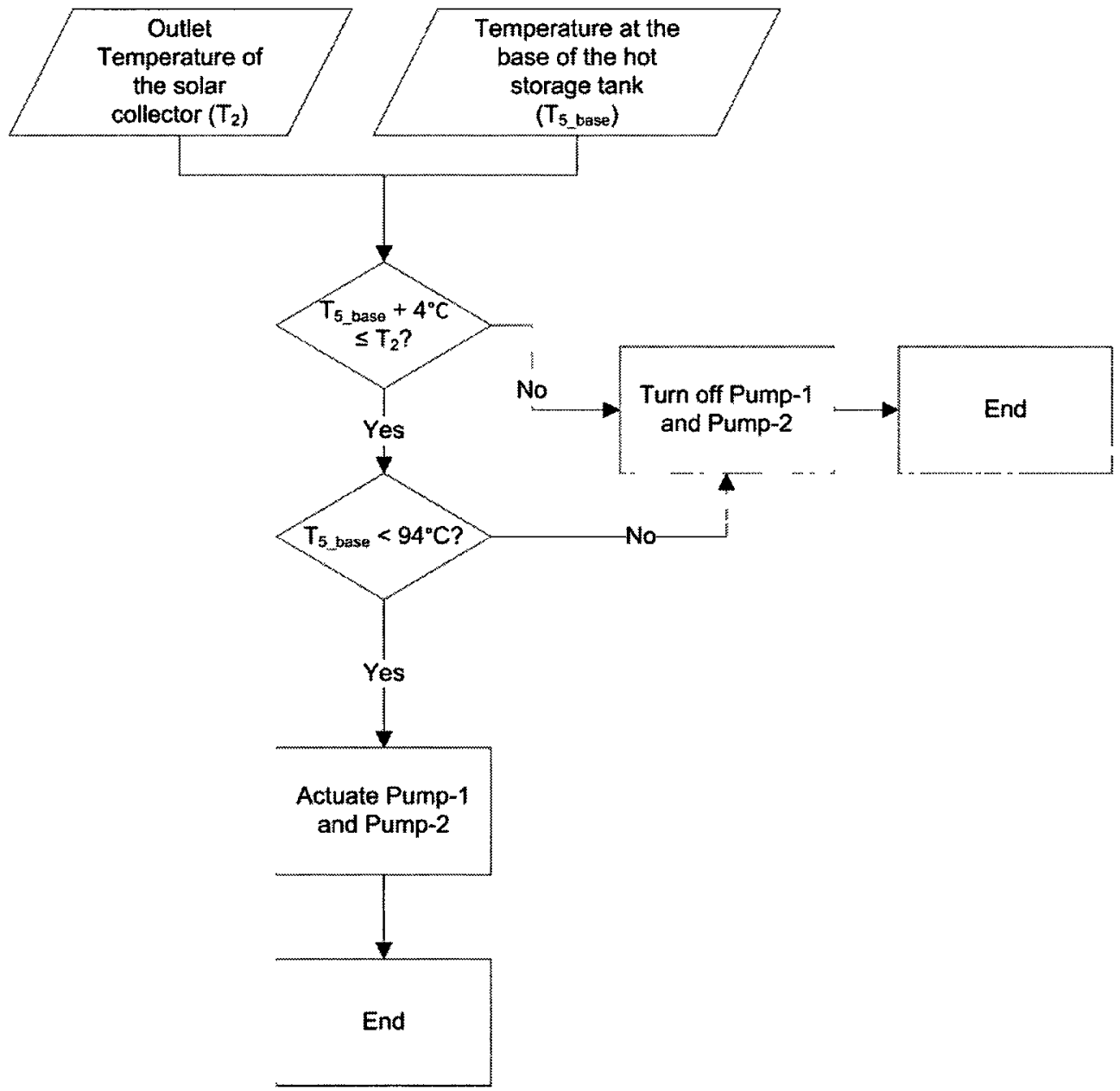

Figure 2-3: Solar collector loop control logic

\subsubsection{Zone cooling loop control}

The control strategy managing the cooling of the living space (zone) is determined by the zone temperature and the cooling availability in the cold storage tank, with an objective to maintain the zone temperature at $24+/-0.5^{\circ} \mathrm{C}$ (Beausoleil-Morrison et al., 2004). The zone cooling loop control logic is described in Figure 2-4. 


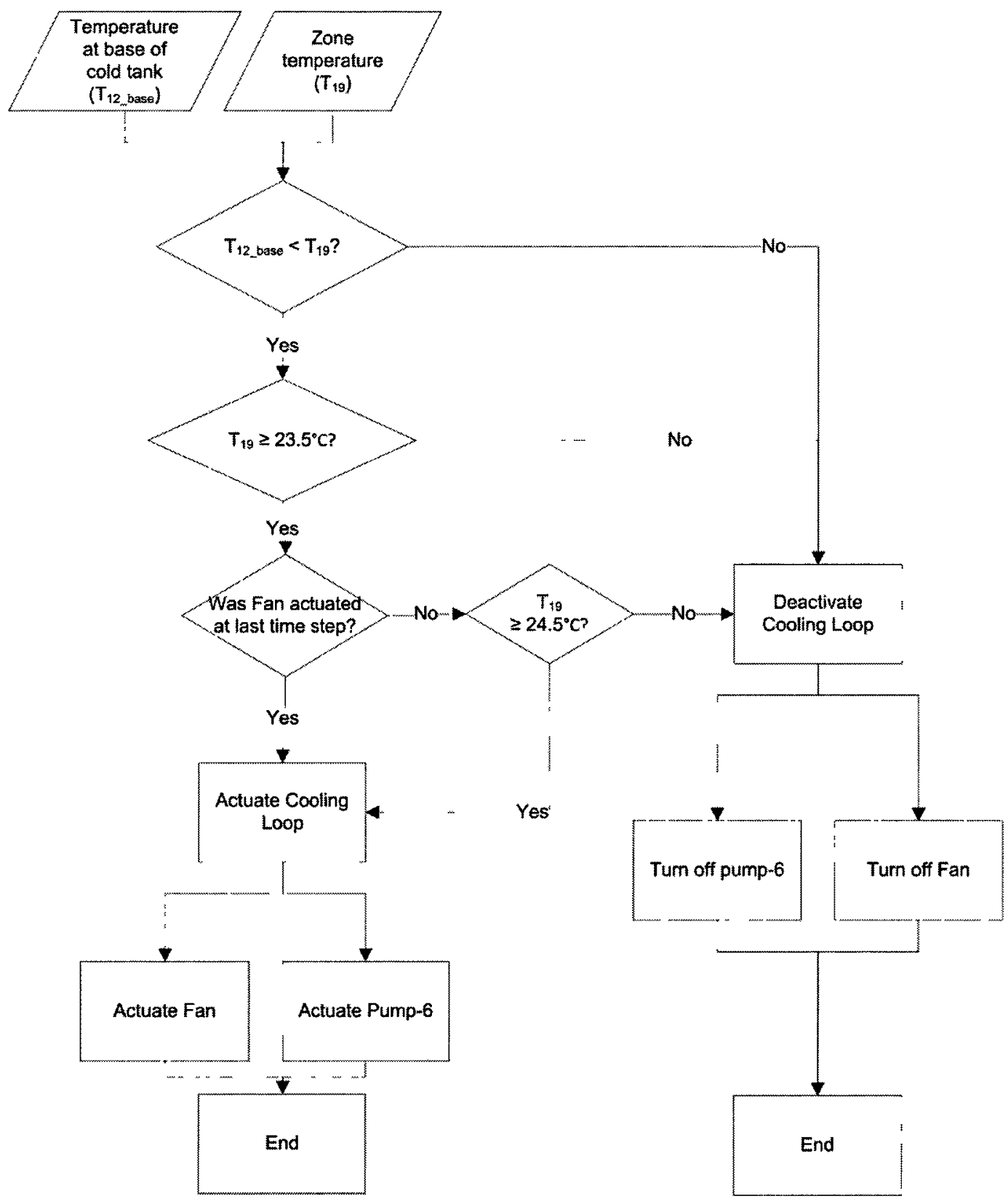

Figure 2-4: Zone cooling loop control

First, the temperature of the zone of interest $\left(\mathrm{T}_{19}\right)$ and the temperature at the base of the cold tank ( $T_{12_{-} \text {base }}$ ) are sensed. If $T_{12 \text { _base }}$ is greater than or equal to $T_{19}$, the fan and pump- 6 are deactivated. Otherwise, if the zone temperature is equal to or above $23.5^{\circ} \mathrm{C}$, it is determined whether the fan was actuating in the last time step, 
which indicates that the cooling system is currently in operation. If $\mathrm{T}_{19}$ is above $24.5^{\circ} \mathrm{C}$, or it is above $23.5^{\circ} \mathrm{C}$ and the system was already in operation, then the fan and pump- 6 are both actuated. Otherwise, the fan and pump- 6 are both deactivated. In this way, the cooling coil and fan actuate when the temperature of the zone surpasses $24.5^{\circ} \mathrm{C}$, and continues to operate until the zone temperature is brought to $23.5^{\circ} \mathrm{C}$.

\subsubsection{Absorption chiller control}

The control of the absorption chiller is defined by the operating conditions of the Yazaki Chiller, as described in Table 2-1 (Aroace, 2010). The chiller requires a hot medium temperature between $70^{\circ} \mathrm{C}$ and $95^{\circ} \mathrm{C}$ in order to operate, and the standard heat rejection temperature is $31^{\circ} \mathrm{C}$. To this end, the absorption chiller control logic, as described in Figure 2-5, begins with the determination of the temperature at the top of the hot storage tank $\left(\mathrm{T}_{5_{-} \text {base }}\right)$, which serves as the heat medium for the chiller ( $\mathrm{T}_{9}$ ). If $\mathrm{T}_{5}$ base is between $70^{\circ} \mathrm{C}$ and $95^{\circ} \mathrm{C}$, the logic flows to the next decision point. The treatment of the experimental data for the heat medium and chilled water streams is further described in Section 5.1.

The temperature at the top of the cold storage tank ( $\left.\mathrm{T}_{12 \_t o p}\right)$, which serves as the chilled water inlet $\left(\mathrm{T}_{14}\right)$, is then determined. If $\mathrm{T}_{12 \text { top }}$ is greater than the setpoint temperature, $7^{\circ} \mathrm{C}$, then the logic flows to the final decision point. The incoming heat rejection stream temperature $\left(\mathrm{T}_{23}\right)$ is determined with respect to the ambient wet bulb temperature conditions. If $\mathrm{T}_{23}$ is less than or equal to $31.0^{\circ} \mathrm{C}$, the chiller, pump- 3 and pump- 5 are actuated. This final logical step is treated differently in the 
control strategies in TRNSYS and ESP-r, as described in Section 3.3.2 and Section 4.3, respectively. If any of the three sensed temperatures are not in the prescribed range, then the chiller and the associated pumps are deactivated.

Table 2-1: Yazaki specifications (Aroace, 2010)

\begin{tabular}{|c|c|c|}
\hline Component & Parameter & Specification \\
\hline \multirow{3}{*}{ Chilled Water } & Outlet Temperature & $7^{\circ} \mathrm{C}$ \\
\cline { 2 - 3 } & Rated Water Flow & $5,496 \mathrm{Lph}$ \\
\hline \multirow{3}{*}{ Heat Rejection Water } & Inlet Temperature & $31^{\circ} \mathrm{C}$ (Standard) \\
\cline { 2 - 3 } & Rated Water Flow & $18,352 \mathrm{Lph}$ \\
\hline \multirow{3}{*}{ Heat Medium } & Inlet Temperature & $88^{\circ} \mathrm{C}($ Standard) \\
\cline { 2 - 3 } & & $70^{\circ} \mathrm{C}(\min )-95^{\circ} \mathrm{C}(\max )$ \\
\cline { 2 - 3 } & Rated Water Flow & $8,631 \mathrm{Lph}$ \\
\hline Electrical & Consumption & $210 \mathrm{~W}$ \\
\hline
\end{tabular}

In the initial sizing of the system in TRNSYS, the solar collector and zone cooling control loops were treated together in one control component, while the absorption chiller control logic was integrated into the absorption chiller component, as described in Chapter 3. The final simulations undertaken in ESP-r included a distinct control file which managed all three control loops, as described in Chapter 4. 


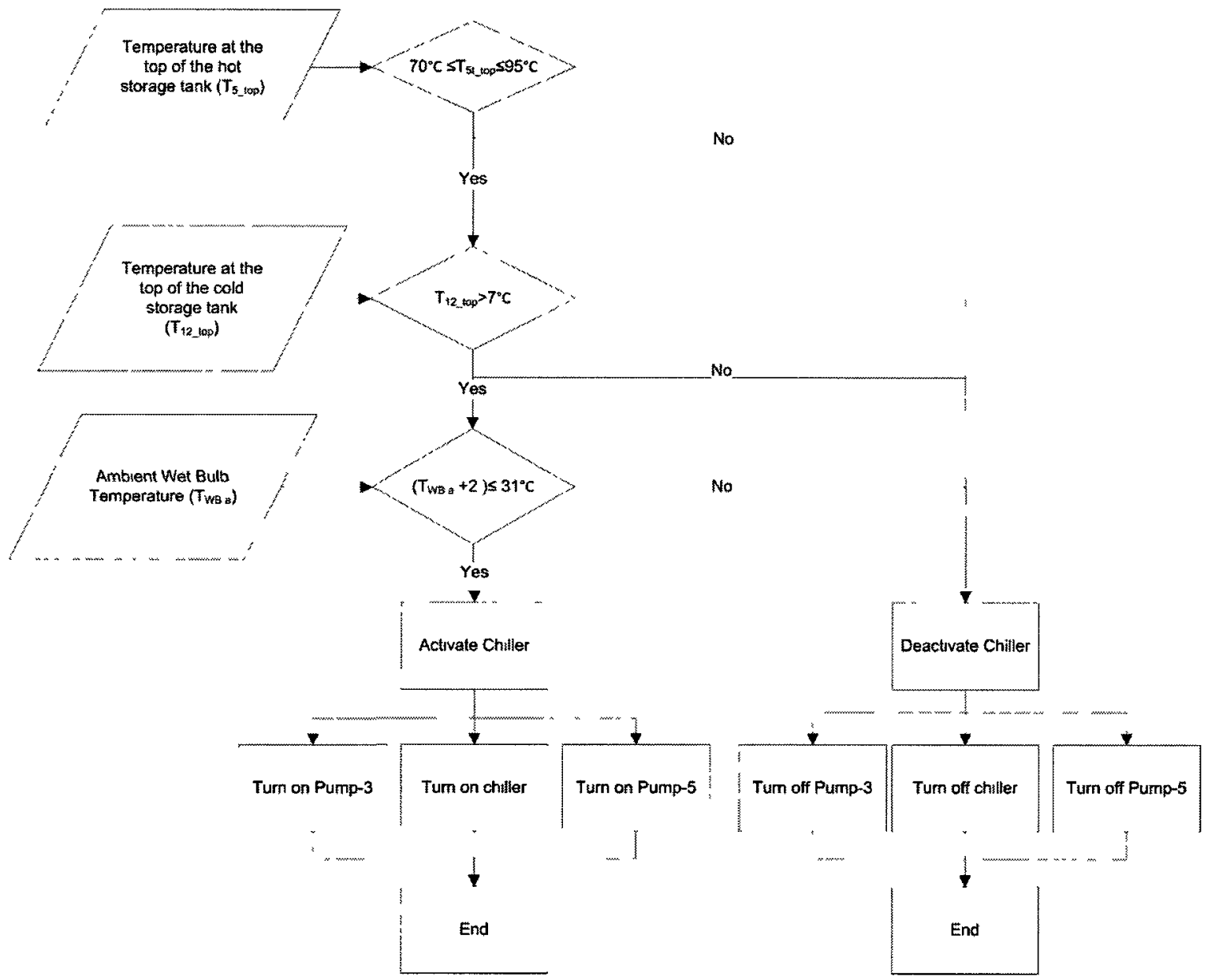

Figure 2-5: Absorption chiller control logic

The determination of a common system definition and control strategies allowed for the simulation of the solar absorption cooling system in BPS software. The system was first sized in TRNSYS, as described in Chapter 3, and was then fully implemented into the ESP-r simulation environment, as described in Chapter 4. 


\section{Chapter 3}

\subsection{Sizing of System Components}

The previous chapter provided an overview of the SAC system to be modelled. This system includes multiple components whose sizes affect the performance of the system. The sizing of the SAC system components can be achieved using a variety of building simulation tools (Bongs et al., 2010). The system components were initially sized using TRNSYS 17, and the results were then used in the BPS environment ESP-r, as described in Chapter 4. TRNSYS was selected to size the components due to its flexibility in component creation, and its ability to robustly model both plant modules and controls (Underwood, 1997). A solar absorption cooling system was created in TRNSYS which included an absorption chiller, two storage tanks, evacuated tube collectors and other associated components. The system is described in further detail in Section 3.1.

The objective of the simulations was to find the appropriate sizing of the following components: hot storage tank volume, cold storage tank volume, and solar collector area. The constraints on the system were defined by the specified flow and temperature requirements of the Yazaki Chiller, as well as the control strategies described in Section 2.8. The required cooling loads used for the sizing of the components were from a two-storey Toronto house (Swan et al., 2009b), and are further described further in Section 3.4. The cooling loads used represent base 
cooling loads, which are appropriate for the initial dimensioning of the system. Houses with diverse geometries and other variations to resultant loads were further explored using ESP-r, as described in Chapter 4.

\subsection{TRNSYS}

TRNSYS is a simulation environment for transient simulation which employs an open modular structure that allows the user to build a representative model of a physical system. Users are provided with the source code of the kernel and component models, allowing for rapid prototyping and customization of components and entire systems (University of Wisconsin, 2010).

TRNSYS projects can be setup by use of the graphical interface in the 'Simulation Studio', or by manual coding of the model's input file (referred to as the 'deck file'). The desired system is broken into individual components, each of which is referred to as a unit. Each unit in a system is characterized by a 'Type' (for example Type 4 is a stratified storage tank), and multiple instances of a Type can occur in a system. The Types are interconnected with one another to model the flow of energy, matter, or other variables. Each Type has a matching set of 'proformas' which describe the components' inputs, outputs, and parameters. Inputs are the time-dependent characteristics of the inlets to the Type (e.g., flow rate of inlet flow 1, temperature of inlet flow 1). Similarly, outputs describe the time-dependent characteristics of the outlets of the Type (e.g., flow rate of outlet 1, temperature of outlet flow 1). Parameters are the time-independent governing characteristics of the Type, e.g., the total component mass, and mass-weighted average specific heat 
for a pump (University of Wisconsin, 2010). Each of the Types has an underlying mathematical model coded in FORTRAN or $\mathrm{C}++$, which allows the user to program additional Types not currently available in the TRNSYS library (Vidal et al., 2009).

TRNSYS utilizes the transfer function methodology determined by Stephenson and Mitalas (1967) for the heat transfer calculations in building simulation (Abadie et al., 2005). At equal time intervals, the Mitalas \& Arsenault relationships are evaluated numerically (Bansal \& Bhandari, 1996). Due to the limitations of the transfer function method, the TRNSYS multizone building model (Type 56) was not used for building performance simulation in the present research, as described in Section 2.7.

Due to the high level of customization and control definition in TRNSYS, it is well suited to plant and control modelling (Underwood, 1997). The plant modelling in TRNSYS is accomplished through sequential explicit systems simulation, which involves successive substitution. At each time step, the outputs of the first unit are determined based on its parameters and inputs. The unit's outputs are then passed as the inputs to the succeeding units. The result of the successive substitutions is then used as the base for the following iteration to achieve convergence of the plant solution. This sequential method is different from the simultaneous approach used by ESP-r, described in Section 4.2.

The sequential method is advantageous for plant modelling due to the ability to rapidly prototype models, as system complexity can be increased progressively. New models can be added without impacting the overall solution, 
allowing again for high levels of customization and model iteration. The limitation of the sequential method is seen in the instability of systems with little or no energy storage, and of systems which have multiple discrete states which rapidly change (Keiholz et al., 2003). The system created in TRNSYS is described in further detail in the following sections.

\subsection{System Overview}

The SAC system developed in TRNSYS includes three loops: the hot loop, the chilled loop, and the load loop. The hot loop and the chilled loop are connected through a custom absorption chiller Type, which is further discussed in Section 3.3.1. Figure 3-1 shows the schematic of the SAC system. The incoming solar radiation heats a water-glycol mixture (1) in an evacuated tube solar collector, which then flows through the source side of a heat exchanger (2). Water flows from the bottom of the hot storage tank (5) to the load-side of the heat exchanger (7), which then exits the heat exchanger (4) and returns to the first port at the top of the hot storage tank. The outlet of the second port at the top of the hot storage tank (8) then serves as the incoming hot stream for the absorption chiller before returning to the bottom inlet of the storage tank (10). Chilled water exiting the absorption chiller (11) is stored in a cold storage tank (12). The chilled water contained in the cold storage tank can then be accessed to meet a house's cooling demand (16). 


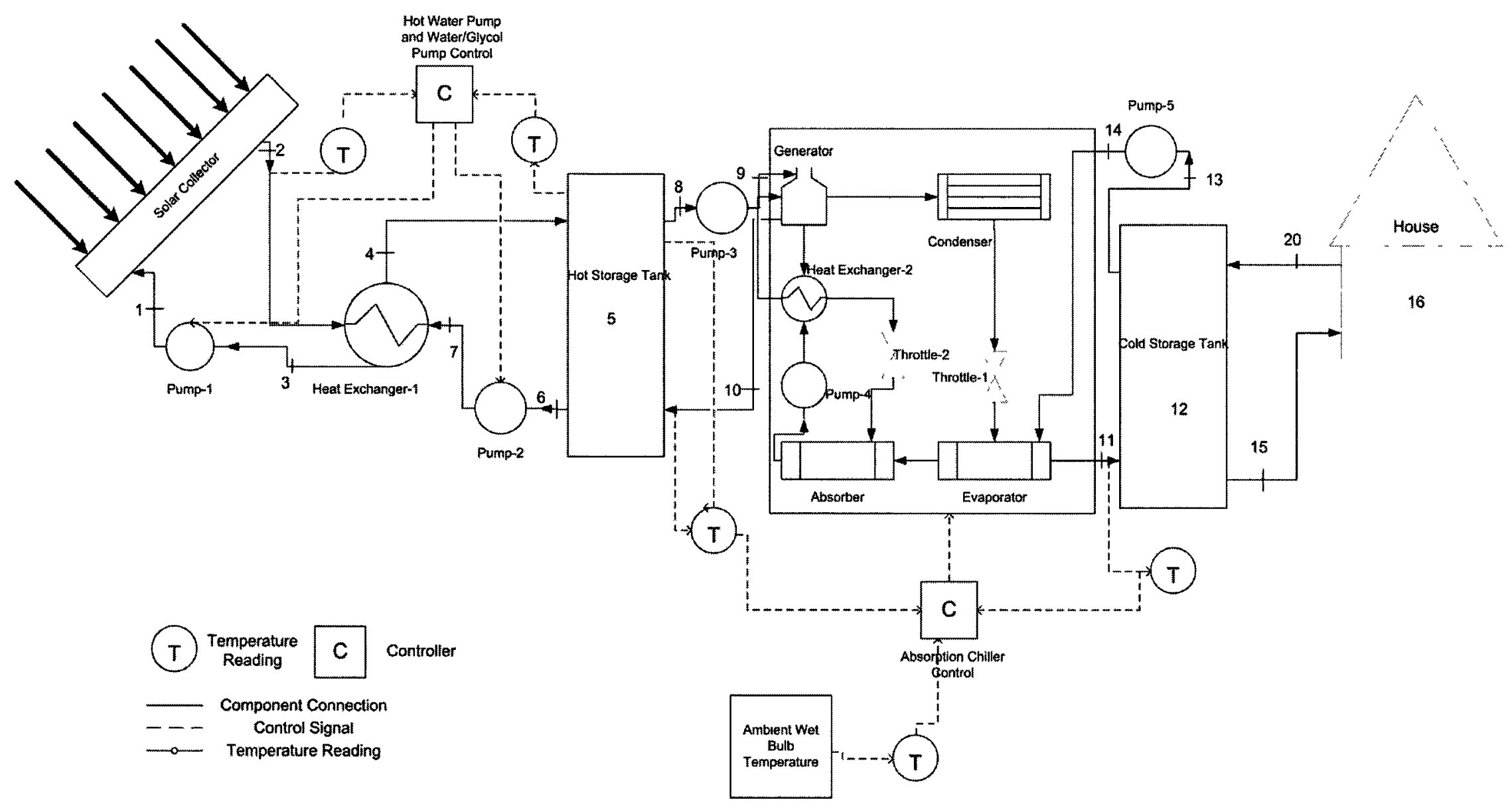

Figure 3-1: Schematic of the solar absorption cooling system 


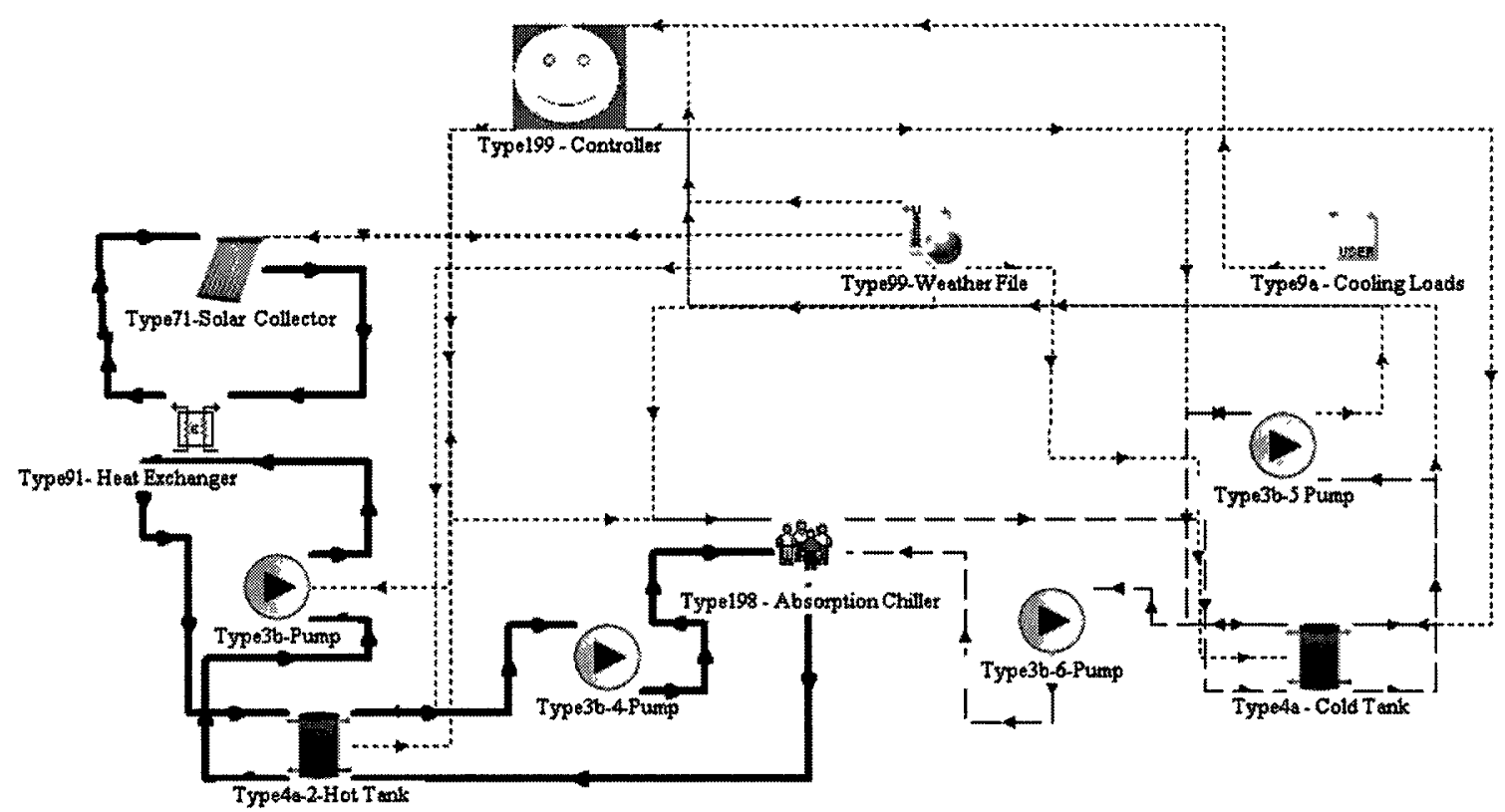

Figure 3-2: TRNSYS Simulation Studio SAC system schematic

Figure 3-2 provides the schematic of the system model developed in TRNSYS within the Simulation Studio. The Types connected by the thick lines represent the hot loop; those connected by the dashed lines represent the chilled loop; and those connected by dotted lines represent the flow of data from the weather file, cooling load file, and the controller inputs and outputs. The components will be described further in the following sections.

\subsection{TRNSYS Components}

In order to accurately model this system, two custom Types were created for use in TRNSYS: Type 198 - Absorption Chiller (see Section 3.3.1), and Type 199 Absorption Chiller Controller (see Section 3.3.2). In addition to the created Types, existing TRNSYS Types were used for the remaining components. The evacuated tube collector (see Section 3.3.3) and storage tanks (see Section 3.3.4) are described 
below, while inputs and parameters for all other Types may be found in Appendix A. Finally, the mathematical model for each of the components from the standard TRNSYS library can be found in Chapter 4 of the TRNSYS documentation (University of Wisconsin, 2010).

\subsubsection{Type 198 - absorption chiller}

The custom absorption chiller Type is a simple component which performs an energy balance on the given input flows based off of a control strategy. The work completed by Johnson (2011), further discussed in Chapter 5, was not available at the time when the sizing was being undertaken. For the initial dimensioning of the system, a constant $\mathrm{COP}_{\text {th }}$ was selected for simplicity as an appropriate baseline for the sizing of the system. For this study, a constant $\mathrm{COP}_{\text {th }}$ of 0.6 was selected based on previous experiments such as Grossman (2002). Figure 3-3 shows the resulting $\mathrm{COP}_{\text {th }}$ from multiple experiments completed with a water- $\mathrm{LiBr}$ absorption chiller with a chilled water setpoint of $7^{\circ} \mathrm{C}$. From this figure, it can be seen that a $\mathrm{COP}_{\text {th }}$ of 0.6 is an appropriate conservative value for the initial sizing of the single-effect system. 


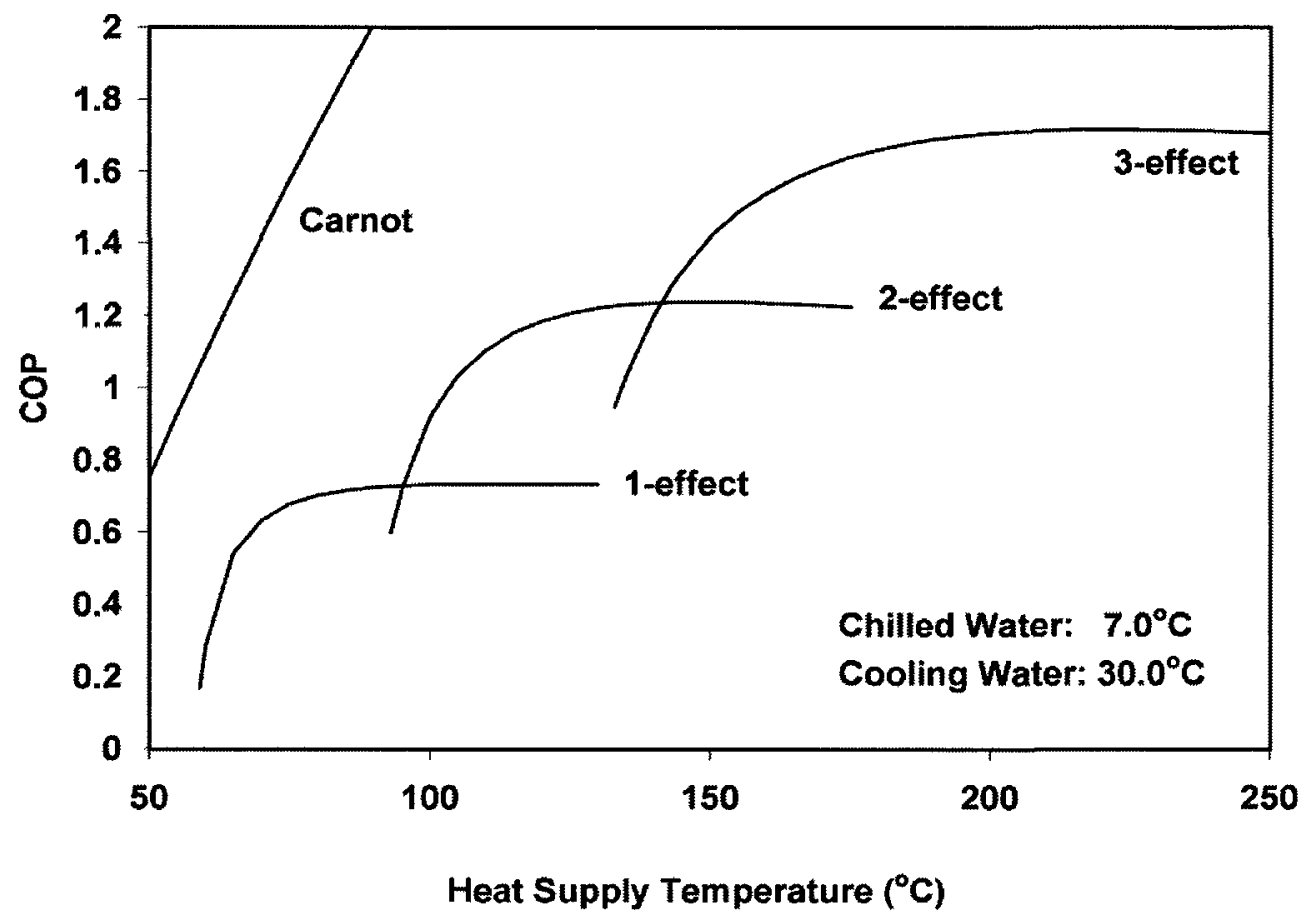

Figure 3-3: Coefficient of performance as a function of solar heat supply temperature for LiBr-water absorption chillers

(Grossman, 2002, with permission)

The control strategy for Type 198 took into consideration the Yazaki specifications described in Table 2-1 for each of the three flow loops. The logic utilized by Type 198 in determining whether the chiller should actuate is shown in Figure 2-5 and described in Section 2.8.3.

A logical variable was output from the Type at each time step which indicated whether the chiller had actuated at that time step. When not actuating, the flow rate and temperature of each of the water streams flowing into the chiller remained unchanged. This strategy was equivalent to implementing a control on the pump which would only allow the water streams to flow to the chiller when actuated. When the chiller was actuated, a simple energy balance was used to determine the 
outlet temperature of each of the streams. The first calculation performed by Type 198 was to determine the required heat rejection energy to reduce the chilled water stream to the chilled setpoint. Equation 3-1 describes this relationship:

$$
\dot{\mathrm{Q}}_{\text {Chill }}=\left(\mathrm{T}_{\text {Chll lin }}-\mathrm{T}_{\text {SetPont }}\right) * \dot{\mathrm{m}}_{\text {Ch.ll }} * \mathrm{C}_{\text {Chll }}
$$

where $\dot{\mathrm{Q}}_{\text {Chll }}$ is the energy removed from the chilled water stream in $\mathrm{W}$, $\mathrm{T}_{\text {Chil_In }}$ is the temperature of the chilled water inlet in ${ }^{\circ} \mathrm{C}, \mathrm{T}_{\text {SetPont }}$ is the setpoint temperature of the chilled water outlet in ${ }^{\circ} \mathrm{C}$, $\dot{\mathrm{m}}_{\text {Chlll }}$ is the flow rate of the chilled water in $\mathrm{kg} / \mathrm{s}$, and $\mathrm{C}_{\text {Chill }}$ is the heat capacity of the chilled fluid in $\mathrm{J} / \mathrm{kg}^{\circ} \mathrm{C}$ (in this case water). Type 198 then checked to ensure that $\dot{Q}_{\text {chll }}$ was below the rated capacity of the chiller $(35 \mathrm{~kW})$. If the required energy was above the rated capacity, then $\dot{Q}_{\text {chlll }}$ was set to $35 \mathrm{~kW}$, and the outlet temperature of the chilled stream ( $\mathrm{T}_{\text {Chill_out }}$ ) was calculated using Equation 3-2.

$$
\mathrm{T}_{\text {Chill_out }}=\mathrm{T}_{\text {Chlll_In }}-\left(\frac{\dot{\mathrm{Q}}_{\text {Ch.ll }}}{\dot{\mathrm{m}}_{\text {Chill }} * \mathrm{C}_{\text {Ch.ll }}}\right)
$$

If the required energy was below the rated capacity, the calculated value of $\dot{\mathrm{Q}}_{\text {chll }}$ was retained and the outlet temperature of the chilled stream was set to the chiller setpoint. The energy removed from the chilled water stream was then used to calculate the required energy from the heated stream $\left(\dot{\mathrm{Q}}_{\mathrm{Hot}}\right)$, as described by Equation 3-3. 


$$
\dot{\mathrm{Q}}_{\mathrm{Hot}}=\frac{\dot{\mathrm{Q}}_{\text {Chll }}}{\mathrm{COP}_{\text {th }}}
$$

The coefficient of performance $\left(\mathrm{COP}_{\text {th }}\right)$ and auxiliary power $\left(\mathrm{P}_{\text {Aux }}\right)$ were both parameters input by the user. As previously stated, the $\mathrm{COP}_{\text {th }}$ was considered to remain constant at 0.6 , and the auxiliary power provided by the Yazaki guidelines (Aroace, 2010) was $210 \mathrm{~W}$. The outlet temperature of the hot stream was then calculated using Equation 3-2, replacing all the chilled water values with those of the hot water stream.

The heat transferred to the heat rejection stream $\left(\dot{\mathrm{Q}}_{\text {Heat_Rejection }}\right)$ was calculated using Equation 3-4. The outlet flow rates of each of the streams were equated to the incoming flow rates.

$$
\dot{\mathrm{Q}}_{\text {Heat_Rejection }}=\dot{\mathrm{Q}}_{\mathrm{Hot}}+\mathrm{P}_{\mathrm{Aux}}+\dot{\mathrm{Q}}_{\text {Chlll }}
$$

Equation 3-1 through 3-4 provided the mathematical model for the absorption chiller Type, which was then used in conjunction with other system components and controls.

\subsubsection{Type 199 - absorption chiller controller}

The absorption chiller controller was created in order to control when the hot and cold cycle pumps would actuate. Additionally the controller was designed to estimate the temperature exiting the house being cooled. The details of the controller were modelled after the description in Section 2.8.3. The cold cycle was 
uniquely treated in TRNSYS to account for the use of existing cooling loads rather than modelling a full building.

The cold cycle controller was used to emulate the use of the stored chilled water to meet the cooling loads of the house. If a cooling load existed in the house, the pump would actuate, circulating the chilled water from the storage tank to meet the load. Equation 3-5 was then used to determine the exiting water temperature, assuming the cooling load was fully met by the chilled water and the flow rate ( $\dot{\mathrm{m}}_{\text {House }}$ ) remained constant.

$$
\mathrm{T}_{20}=\frac{\dot{\mathrm{Q}}_{\text {Cooling_Load }}}{\mathrm{C}_{\text {Chll }} * \dot{\mathrm{m}}_{\text {House }}}+\mathrm{T}_{15}
$$

In this equation, $\mathrm{C}_{\text {Chill }}$ is the heat capacity of the water in $J / \mathrm{kg}^{\circ} \mathrm{C}, \dot{\mathrm{Q}}_{\text {Coolng_Load }}$ is the cooling load of the house in $\mathrm{W}$, and $\mathrm{T}_{20}$ and $\mathrm{T}_{15}$ are the temperatures of the outlet and inlet water flows respectively, in ${ }^{\circ} \mathrm{C}$. In order to determine whether the cooling load could be sufficiently met by the cooling system, the outlet temperature of the house $\mathrm{T}_{20}$ was monitored. If $\mathrm{T}_{20}$ was above the upper deadband temperature of the house $\left(24.5^{\circ} \mathrm{C}\right)$, the load was considered to be unmet. Due to the simplistic nature of this initial sizing, unmet loads in one time step were not considered to affect the cooling load in the following time steps. 


\subsubsection{Type 71 - evacuated tube collector}

The existing evacuated tube collector Type (Type 71) was selected from the TRNSYS component library for use in the modelled system. Type 71 uses a text file containing a list of transverse and longitudinal incidence angle modifiers (IAM) to determine the thermal performance of the collector. The user is required to provide the results from standard efficiency tests based on the fluid temperature.

The thermal efficiency ( $\eta$ ) of an evacuated tube solar collector can be determined using the thermal performance expression represented by Equation 3-6 (Harrison et al., 1993), and is equal to the ratio of the collected useful energy $\left(\dot{Q}_{U}\right)$ to the solar energy incident on the collector. The solar energy incident on the collector is equivalent to the incoming energy per square metre, $\mathrm{G}_{\mathrm{T}}\left(\mathrm{W} / \mathrm{m}^{2}\right)$, multiplied by the collector area, $A\left(\mathrm{~m}^{2}\right)$. The collector area can be defined as the gross area (GR), the aperture area (AP), or the absorber area (AB), each leading to different coefficient definitions. Figure 3-4 shows these three area definitions.

$$
\eta=\frac{\dot{Q}_{U}}{G_{T} A}=F^{\prime}\left((\tau \alpha)_{e}-U_{L} \frac{\left(\mathrm{T}_{\mathrm{fm}}-\mathrm{T}_{\mathrm{a}}\right)}{G_{T}}\right)
$$

The term $\mathrm{F}^{\prime}$ is unitless and is called the collector efficiency factor. This factor is an attribute of the collector, and allows for the determination of a quadratic characteristic equation for the thermal efficiency of the collector. The collector efficiency factor is based on the temperature difference determined by the average temperature of the fluid in the collector, $\mathrm{T}_{\mathrm{fm}}\left({ }^{\circ} \mathrm{C}\right)$, and the ambient temperature, 
$\mathrm{T}_{\mathrm{a}}\left({ }^{\circ} \mathrm{C}\right)$, and is primarily used in European markets. An alternate expression of Equation 3-6 is to replace $F^{\prime}$ with the collector heat removal factor, $F_{R}$. The term $T_{f i}$ $\left({ }^{\circ} \mathrm{C}\right)$, the collector inlet fluid temperature, would then replace $\mathrm{T}_{\mathrm{fm}}$.

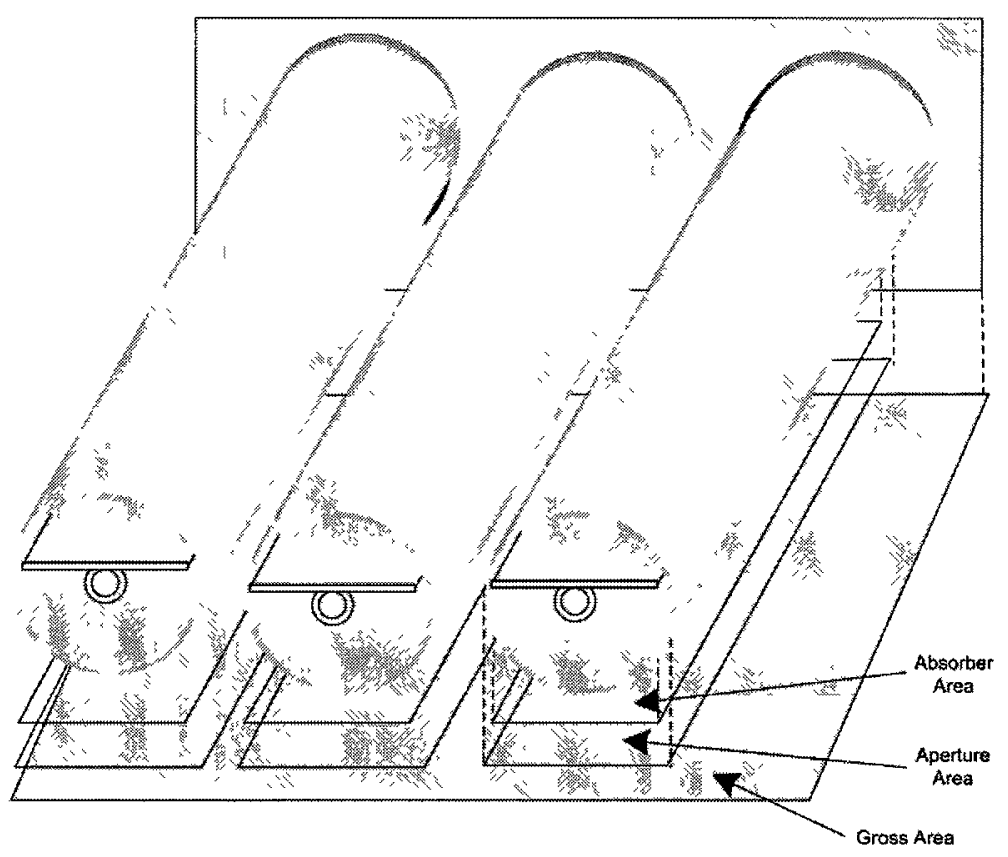

Figure 3-4: Solar collector area definition

The term $\tau \alpha$ is the effective transmittance-absorptance product on the cover and absorber plate, and $\mathrm{U}_{\mathrm{L}}$ is the collector heat loss coefficient $\left(\frac{W}{m^{2} K}\right)$. The term $\mathrm{U}_{\mathrm{L}}$ is further described using additional coefficiencts $\mathrm{J}\left(\frac{W}{m^{2} K}\right)$ and $\mathrm{L}\left(\frac{W}{m^{2} K^{2}}\right)$, in Equation 3-7. The change from $T_{f m}$ to $T_{f}$ also applies to Equation 3-7 when the collector heat removal factor is used.

$$
U_{L}=J-L\left(\mathrm{~T}_{\mathrm{fm}}-\mathrm{T}_{\mathrm{a}}\right)
$$


Type 71 employs the above expressions to align with manufacturer information supplied by the user. Additionally, Type 71 utilizes beam and diffuse IAMs for the performance prediction under actual sky conditions, which account for incident solar angles and overcast conditions. The incidence angle modifier $\left(K_{\alpha \tau}\right)$ is the ratio between the effective transmittance-absorptance at angle $\theta\left[(\tau \alpha)_{e, \theta}\right]$ and the transmittance-absorptance at normal incidence $\left[(\tau \alpha)_{e, n}\right]$, as described in Equation 3-8.

$$
K_{\alpha \tau}=\frac{(\tau \alpha)_{e, \theta}}{(\tau \alpha)_{e, n}}
$$

Evacuated tube collectors have asymmetric incidence angle effects and must be measured from additional angles to fully characterize the IAM. The IAM is estimated by using a transversal IAM $\left[\mathrm{K}_{1}(\Omega)\right]$ at angle $\Omega$ (taken in the plane containing the aperture normal) and a longitudinal IAM $\left[\mathrm{K}_{2}(\Psi)\right]$ at angle $\Psi$ (taken in the plane normal to the collector aperture), as expressed in Equation 3-9. Angles $\Omega$ and $\Psi$ are defined in Figure 3-5.

$$
K_{\alpha \tau}=K_{1}(\Omega) K_{2}(\Psi)
$$




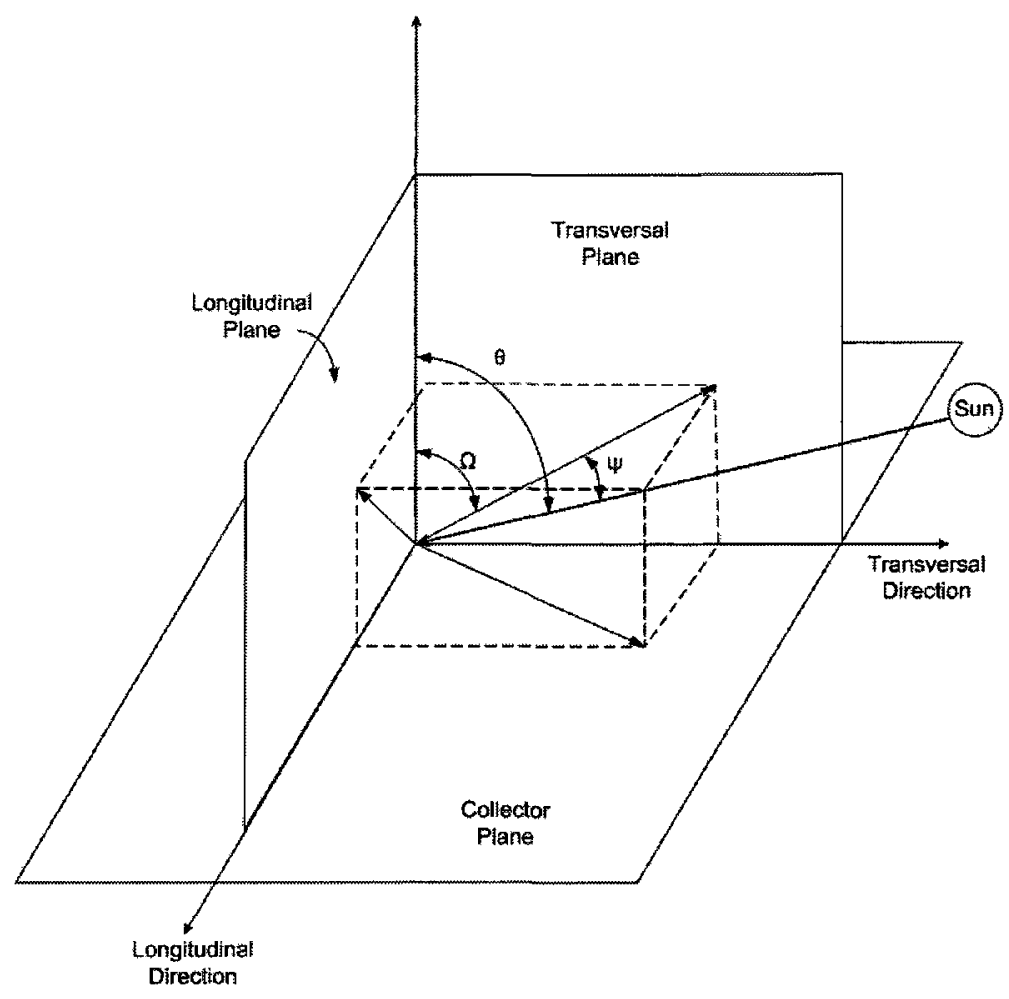

Figure 3-5: Bi-axial incidence angle modifier definitions

Adapted from (Harrison et al., 1993)

The selection of an evacuated tube collector for the model was based on the following criteria:

- Typical gross area between 10 and $100 \mathrm{~m}^{2}$

- IAM information available from the manufacturer

- Efficiency information based on gross area available from the manufacturer

- Nominal efficiency above 0.5

The Wikora Wikosun HP 65-30 evacuated tube collector (Solartechnik Prufung Forschung, 2007) met the above conditions, and was selected for the modelling of the solar collector. The data used for the modelling of the 
Wikora tubes can be found in Table 3-1 and Table 3-2. The efficiency of the Wikora tubes is based on the mean collector fluid temperature, and thus the collector efficiency factor is used.

Table 3-1: Thermal performance coefficients of Wikora tubes

(Solartechnik Prufung Forschung, 2007)

\begin{tabular}{|l|c|}
\hline $\begin{array}{l}\text { Intercept efficiency } \\
\left(\mathrm{F}^{\prime} \tau \alpha\right)\end{array}$ & 0.567 \\
\hline $\begin{array}{l}\text { Negative of first order } \\
\text { efficiency coefficient } \\
\left(\mathrm{F}^{\prime} \mathrm{J}\right)\end{array}$ & 1.21 \\
\hline $\begin{array}{l}\text { Negative of second } \\
\text { order efficiency } \\
\text { coefficient }\left(\mathrm{F}^{\prime} \mathrm{L}\right)\end{array}$ & 0.0008 \\
\hline
\end{tabular}

Table 3-2: IAM data for Wikora tubes

(Solartechnik Prufung Forschung, 2007)

\begin{tabular}{|l|l|l|l|l|l|l|l|}
\hline Direction & $0^{\circ}$ & $15^{\circ}$ & $30^{\circ}$ & $45^{\circ}$ & $60^{\circ}$ & $75^{\circ}$ & $90^{\circ}$ \\
\hline $\begin{array}{l}\text { Transversal } \\
\text { IAM }\end{array}$ & 1.00 & 1.00 & 0.99 & 0.93 & 0.78 & 0.45 & 0.00 \\
\hline $\begin{array}{l}\text { Longitudinal } \\
\text { IAM }\end{array}$ & 1.00 & 1.00 & 0.98 & 0.96 & 0.88 & 0.60 & 0.00 \\
\hline
\end{tabular}

\subsubsection{Type 4a - storage tank; fixed inlets, uniform losses}

Type 4a, a tank with two fixed inlets and uniform losses, was chosen for the modelling of the cold and hot storage tanks. Each of the storage tanks were modelled with 15 nodes. Fifteen nodes provided a reasonable simulation run time, and have also been shown to produce accurate temperature distributions through 
TRNSYS modelling studies (Cruickshank \& Harrison, 2006). A height of $0.9 \mathrm{~m}$ was selected for each tank, based on the height of current domestic hot water tanks (NRCan, 2008b), which resulted in a separation of $0.06 \mathrm{~m}$ between each node.

\subsection{System Sizing}

As described earlier, the three components to be sized using the TRNSYS system were:

- Hot storage tank (volume)

- Cold storage tank (volume)

- Solar collector (area)

The Yazaki specifications provided constraints on the treatment of the flow rates and allowable temperatures of the flows into the chiller. These specifications are detailed in Table 2-1.

The results of Swan et al. (2009b) were used for the required cooling loads for the sizing of the components. These loads were representative of a single detached home in Toronto, Ontario during a typical summer. The house selected for modelling was a two-storey house built in 2000 . The model was used as the base case for the building performance simulations undertaken in ESP-r, further described in Section 5.2. Weather data for the city of Toronto was selected as it is one of Canada's hottest cities, without having a high level of solar radiation compared to other major Canadian cities (Phillips, 2010). The range of cooling loads across different housing sizes and climates were not expected to cause significant variation 
in the sizing of the system components, therefore the results obtained from using a particular house in the Toronto area were considered representative for Ontario houses.

It was desired that the system had high performance for this initial sizing due to the modelling simplifications described, and consequently the system was considered appropriately sized when the cooling loads were met during at least $99 \%$ of the time steps. Meeting $99 \%$ of the cooling loads represents nominally thirty hours during the cooling season with unmet cooling loads. A five minute time step was used for the simulations from May $15^{\text {th }}-$ September $15^{\text {th }}$.

To begin, an analysis was completed to determine the sensitivity of the system's performance to the modification of a number of variables. The following parameters were varied during the sensitivity analysis:

- Solar collector flow rate (1 on Figure 3-1)

- Solar collector area

- Hot storage tank volume

- Cold storage tank volume

- Hot loop flow rate (7 on Figure 3-1)

- Cold loop flow rate (15 on Figure 3-1)

Initial rough calculations using the maximum daily cooling load (215 MJ) and the nominal chiller capacity ( $35 \mathrm{~kW})$ were completed to determine a reasonable baseline for each of the above components. These initial conditions are detailed in 
Table 3-3. Each parameter was varied until changes no longer made a significant difference to the simulation results, or until they reached a value which was physically unreasonable.

Table 3-3: Initial variable conditions

\begin{tabular}{|c|c|c|}
\hline Variable & $\begin{array}{c}\text { Initial } \\
\text { Condition }\end{array}$ & Range Varied \\
\hline Solar Collector Flow Rate & $0.21 \mathrm{~kg} / \mathrm{s}$ & $0.05 \mathrm{~kg} / \mathrm{s}-0.25 \mathrm{~kg} / \mathrm{s}$ \\
\hline Solar Collector Area & $55 \mathrm{~m}^{2}$ & $25 \mathrm{~m}^{2}-70 \mathrm{~m}^{2}$ \\
\hline Hot Storage Tank Volume & $1.3 \mathrm{~m}^{3}$ & $0.8 \mathrm{~m}^{3}-2.0 \mathrm{~m}^{3}$ \\
\hline Cold Storage Tank Volume & $1.7 \mathrm{~m}^{3}$ & $0.75 \mathrm{~m}^{3}-2.2 \mathrm{~m}^{3}$ \\
\hline Hot Loop Flow Rate & $0.26 \mathrm{~kg} / \mathrm{s}$ & $0.05 \mathrm{~kg} / \mathrm{s}-0.4 \mathrm{~kg} / \mathrm{s}$ \\
\hline Cold Loop Flow Rate & $0.44 \mathrm{~kg} / \mathrm{s}$ & $0.3 \mathrm{~kg} / \mathrm{s}-0.9 \mathrm{~kg} / \mathrm{s}$ \\
\hline
\end{tabular}

The rough cold loop flow rate was determined using Equation 3-10 assuming a six degree temperature rise across the house, and a peak load of $11 \mathrm{~kW}\left(\dot{Q}_{\text {peak }}\right)$.

$$
\dot{m}=\frac{\dot{Q}_{\text {peak }}}{C \Delta T}
$$

The storage energy density ( $X_{\text {chill,water }}$ ) of the cold water tank is described by Equation 3-11. Assuming the same resulting temperature rise as previously, the resulting capacity is $28.9 \mathrm{MJ} / \mathrm{m}^{3}$. It was desired that the cold storage tank would be capable of meeting the evening loads, when cooling loads still exist but the solar radiation has subsided. For the initial conditions, a reasonable estimate was made 
that one third of the daily maximum cooling load would occur in this period, resulting in a desired storage capacity of $49.1 \mathrm{MJ}$. Dividing the desired storage capacity $\left(Q_{\text {chill,stored }}\right)$ by the energy density, as shown in Equation 3-12, a nominal tank size $\left(V_{\text {chill }}\right)$ of $1.7 \mathrm{~m}^{3}$ was determined.

$$
\begin{gathered}
X_{\text {chill,water }}=\rho_{\text {chill }} c_{\text {chill }} \Delta T \\
Q_{\text {chill,stored }}=V_{\text {chill }} X_{\text {chill,water }}
\end{gathered}
$$

The hot storage tank was included in order to meet the fluctuating daily solar availability. It was desired that the storage tank would be capable of meeting the house's peak load ( $\left.\dot{Q}_{\text {peak }}\right)$ for 2 hours. Using Equation 3-12, where the heat transfer rate $\left(\dot{Q}_{\text {hotwater }}\right)$ was calculated using Equation 3-13 and a peak load of $11 \mathrm{~kW}$, the hot storage tank size was found to be $1.3 \mathrm{~m}^{3}$.

$$
\dot{Q}_{h o t, w a t e r}=\frac{\dot{Q}_{p e a k}}{C O P_{t h}}
$$

The solar collector area was determined by assuming an ideal heat exchanger between the solar collector and the hot tank, and using an average insolation value for Toronto of $800 \mathrm{~W} / \mathrm{m}^{2}$. To meet the peak load plus $20 \%$, and assuming a $\mathrm{COP}_{\text {th }}$ of 0.6 , the required heat transfer was found to be $22 \mathrm{~kW}$. The resulting solar collector area was determined to be $55 \mathrm{~m}^{2}$. 
The hot loop flow rate was calculated using Equation 3-10, with a heat transfer of $22 \mathrm{~kW}$ and a temperature difference of $20^{\circ} \mathrm{C}$. The resulting flow rate was $0.26 \mathrm{~kg} / \mathrm{s}$. Finally, the solar collector flow rate was determined based on a desired temperature difference of $30^{\circ} \mathrm{C}$, to keep the solar collector losses at a minimum. Using Equation 3-10 with a heat transfer of $22 \mathrm{~kW}$, and a heat capacity of $3,559 \mathrm{~J} / \mathrm{kg}^{\circ} \mathrm{C}$ the solar collector flow rate was found to be $0.21 \mathrm{~kg} / \mathrm{s}$.

For each run of the simulation, all variables were held constant except for one. For instance, for the first iterations, all variables were held constant except for the solar collector flow rate. Multiple simulations were then run, each with a different value for the solar collector flow rate. This process was then repeated for each of the variables. The range over which each variable was changed is found in Table 3-3. This analysis allowed for the determination of the sensitivity of the system to each of the components.

After all iterations of the sensitivity analysis were completed, the best performing size for each variable was then chosen to create a new baseline. The best performance was considered to be the iteration with the lowest value for $2(\%)$, where 2 is described by Equation 3-14.

$Z=$ Percentage of timesteps where the system was not able to meet the 
The outlet water temperature is representative of the interior house temperature, so if the outlet temperature is above $24.5^{\circ} \mathrm{C}$, it indicates that the house temperature is above the upper deadband setpoint. The variation process was then repeated for the new baseline to optimize the sizing of the solar collector array and the storage tanks. The results of the sensitivity analysis and sizing are provided in Sections 3.4.1 through 3.4.4.

\subsubsection{Sensitivity of the solar collector flow rate}

The sensitivity of the solar collector flow rate was expected to be low. The solar collector flow was constrained to a loop containing the solar collector and the heat exchanger. It was expected that as the flow rate increased, the resulting temperature of the flow exiting the solar collector would decrease, but the overall heat transferred to the fluid would be fairly constant. The solar collector performance is related to the flow rate, resulting in some minor fluctuations in system performance with changes in flow. Figure 3-6 shows the relationship between the solar collector flow rate and the number of unmet cooling loads. The solar collector flow rate resulting in the most time steps maintained at the setpoint was found to be $0.1 \mathrm{~kg} / \mathrm{s}$. 


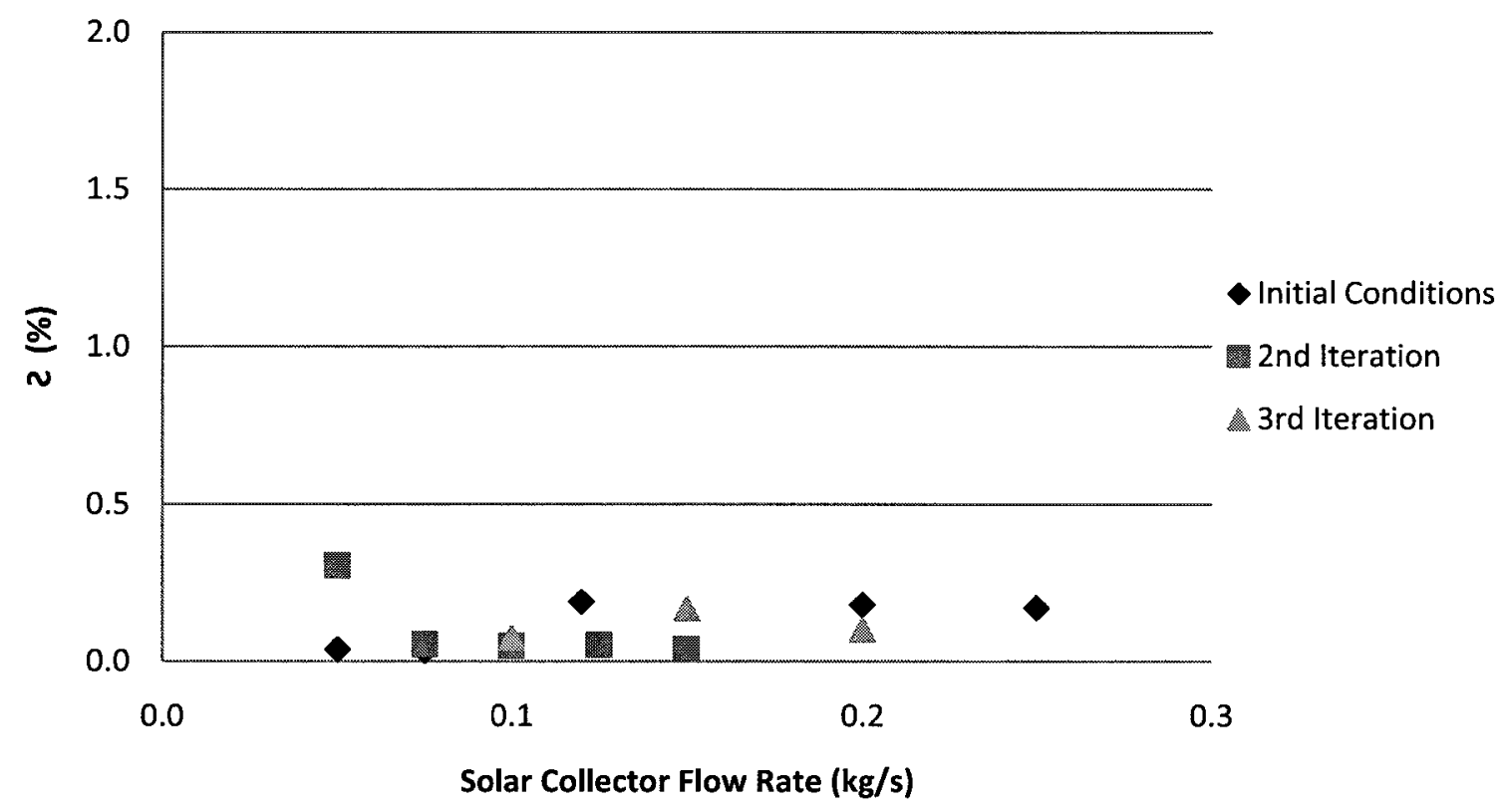

Figure 3-6: Sensitivity of unmet cooling loads to solar collector flow rate

\subsubsection{Hot loop flow rate}

The hot loop flow rate was defined as the flow rate between the hot storage tank and the load side of the heat exchanger. The sensitivity of the hot loop flow rate was expected to be minimal, and was confirmed through the sensitivity analysis. As seen in Figure 3-7, the system performance was mildly dependent on the hot loop flow rate. After three iterations, the flow rate with the least number of time steps above the setpoint was $0.05 \mathrm{~kg} / \mathrm{s}$. 


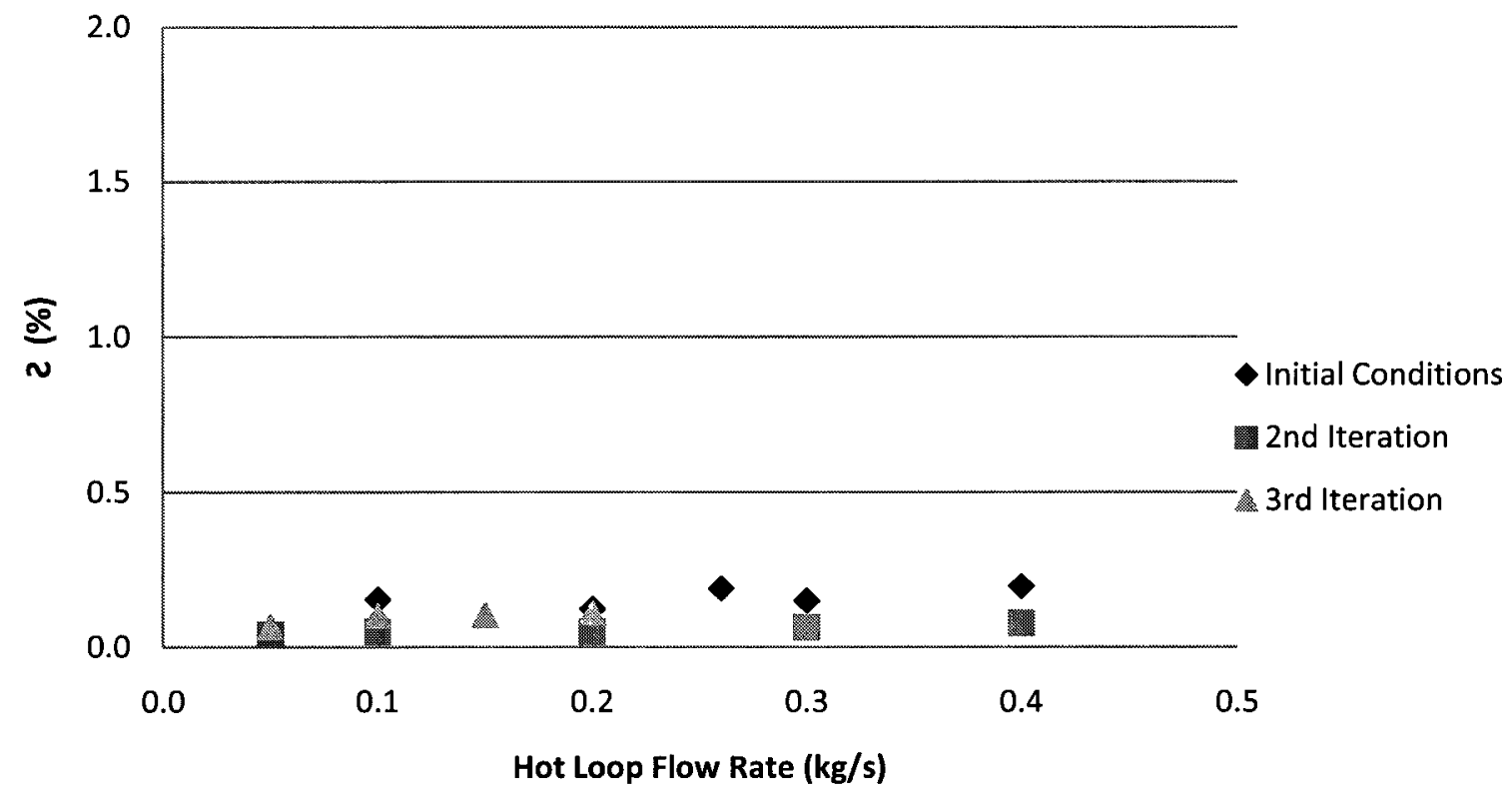

Figure 3-7: Sensitivity of unmet cooling loads to hot loop flow rate

\subsubsection{Cold loop flow rate}

The cold loop flow rate was defined as the flow rate between the cold storage tank and the theoretical house. The performance of the system as modelled was not very sensitive to the cold loop flow rate, though this flow rate was the determining factor for the required mass of chilled water in the cold tank at any given time. Figure 3-8 displays the sensitivity of 2 to the variation of cold loop flow rate during the three iterations. The flow rate at which the cooling setpoint was most often met was selected. A flow rate of $0.9 \mathrm{~kg} / \mathrm{s}$ was found to have the smallest value of 2 for the cold loop. 


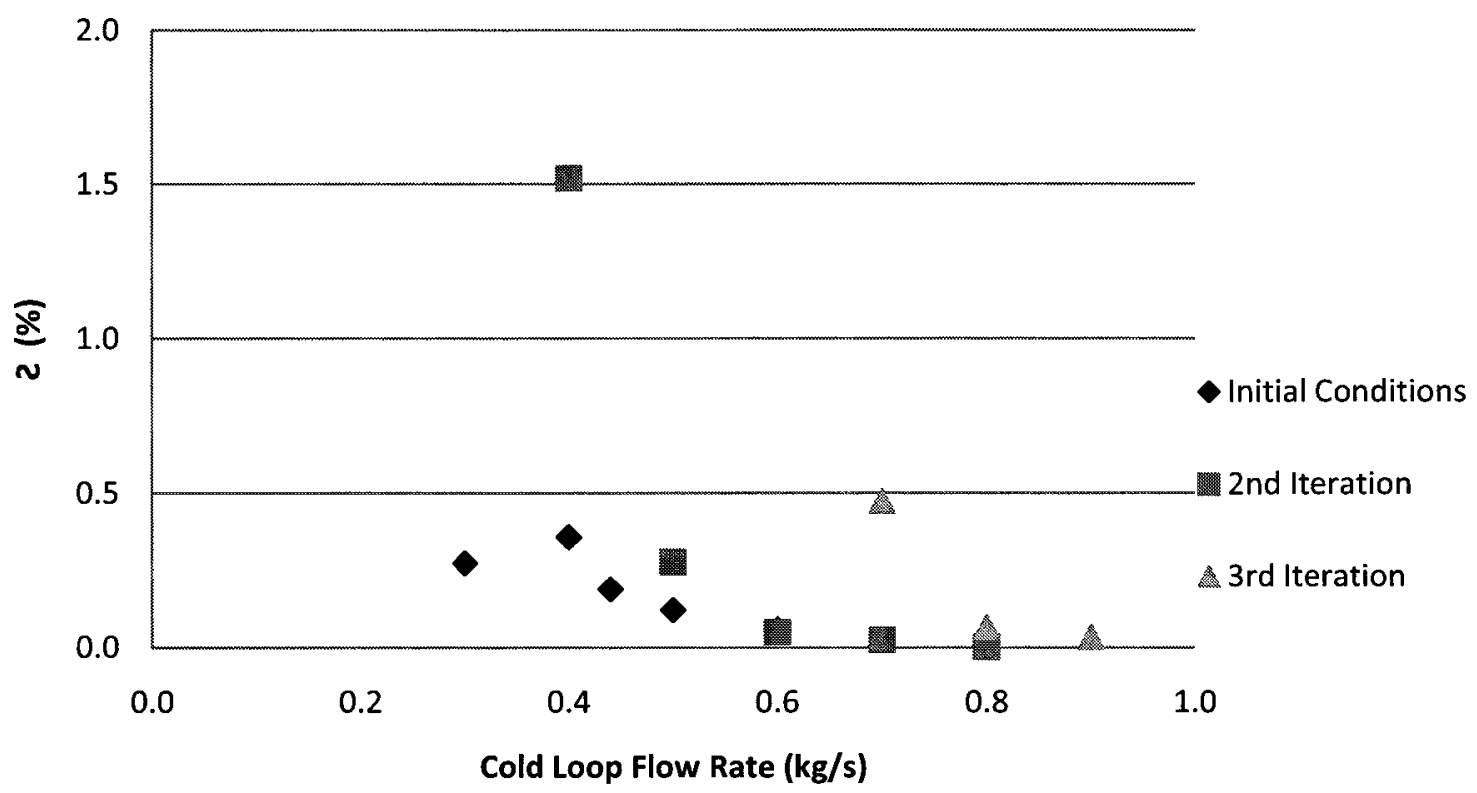

Figure 3-8: Sensitivity of unmet cooling loads to cold loop flow rate

\subsubsection{Component sizing}

After the sensitivity of the extraneous variable values was established, the most favourable sizing of the solar collector area and the cold and hot storage tanks was determined. This process was iterative, with each new sizing of one component being used as the baseline for the following iteration of the other two components.

\section{Solar collector area}

The solar collector area was an important consideration, with increasing collector area providing increased performance, as can be seen in Figure 3-9. The final sizing of the solar collector was completed using the final conditions of the two storage tanks. A solar collector area of $40 \mathrm{~m}^{2}$ or greater was found to result in the temperature setpoint being maintained at least $99.5 \%$ of time steps, and as such $40 \mathrm{~m}^{2}$ was selected as an appropriate trade-off between size and performance. 


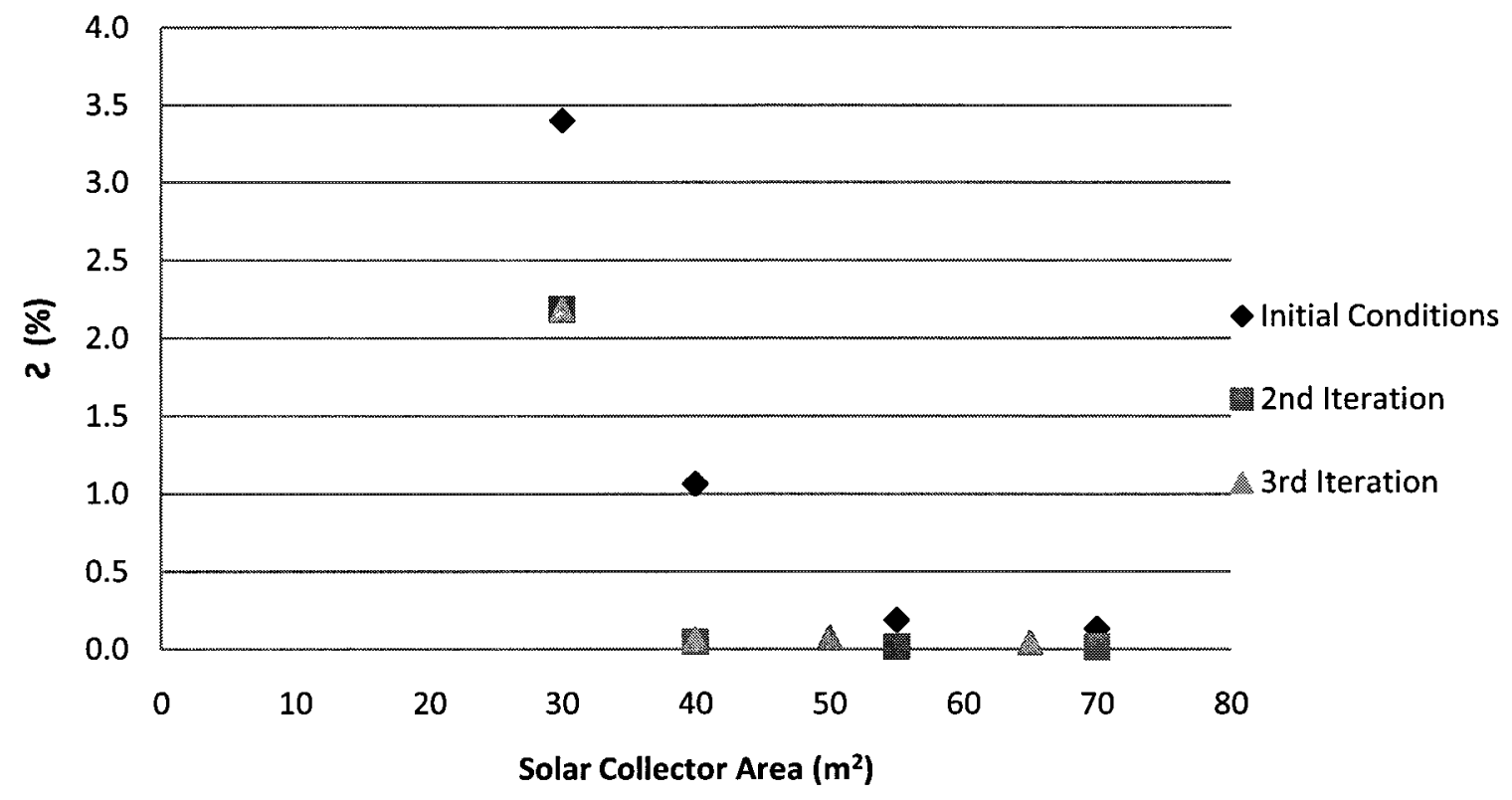

Figure 3-9: Sizing of the solar collectors

\section{Hot and cold storage tanks}

The hot and cold storage tanks both increased overall system performance with increased volume. Figure 3-10 and Figure 3-11 display a general trend of a decrease in 2 with an increase in tank size for the hot storage tank and cold storage tank, respectively. 


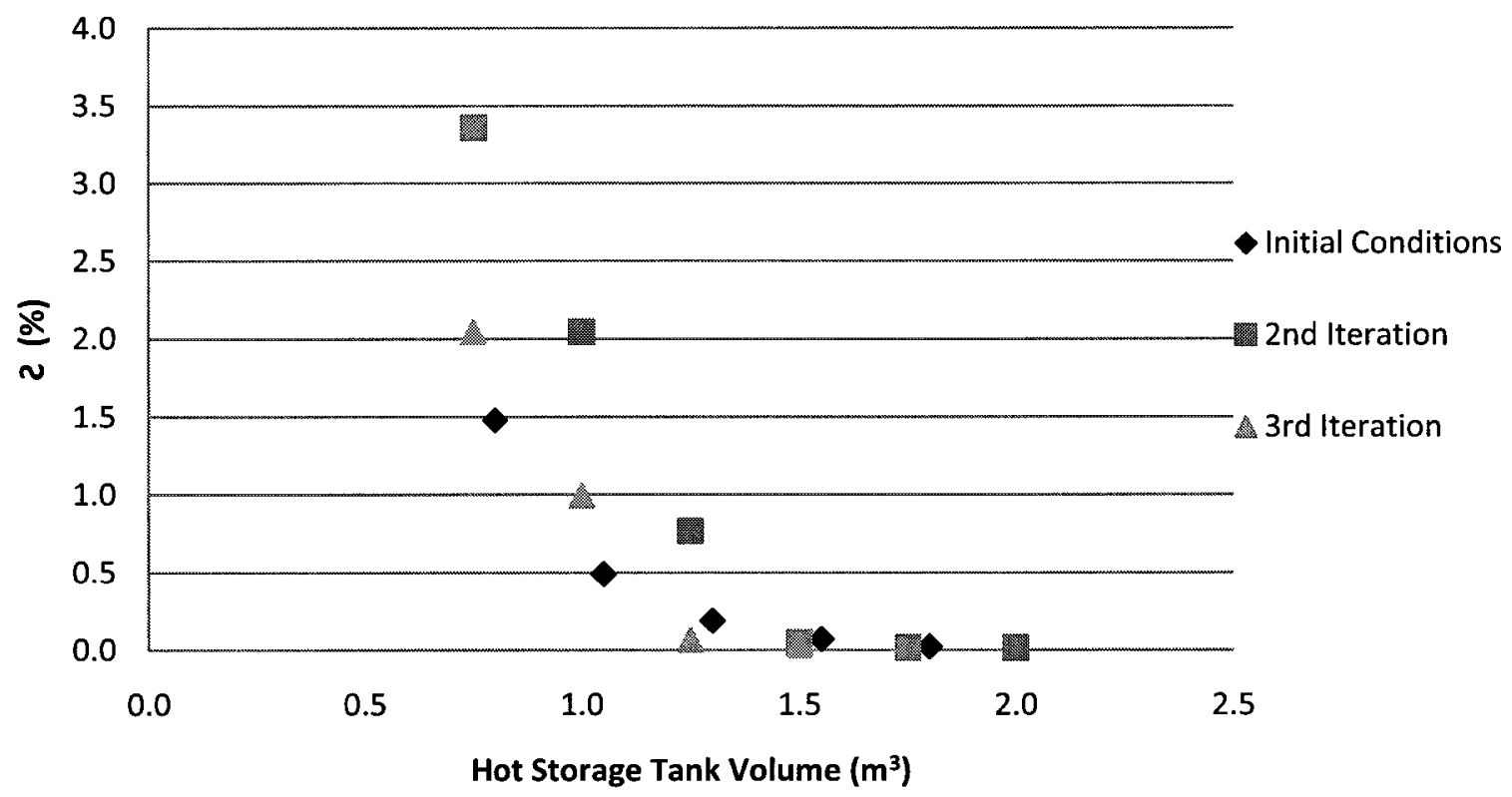

Figure 3-10: Sizing of the hot storage tank

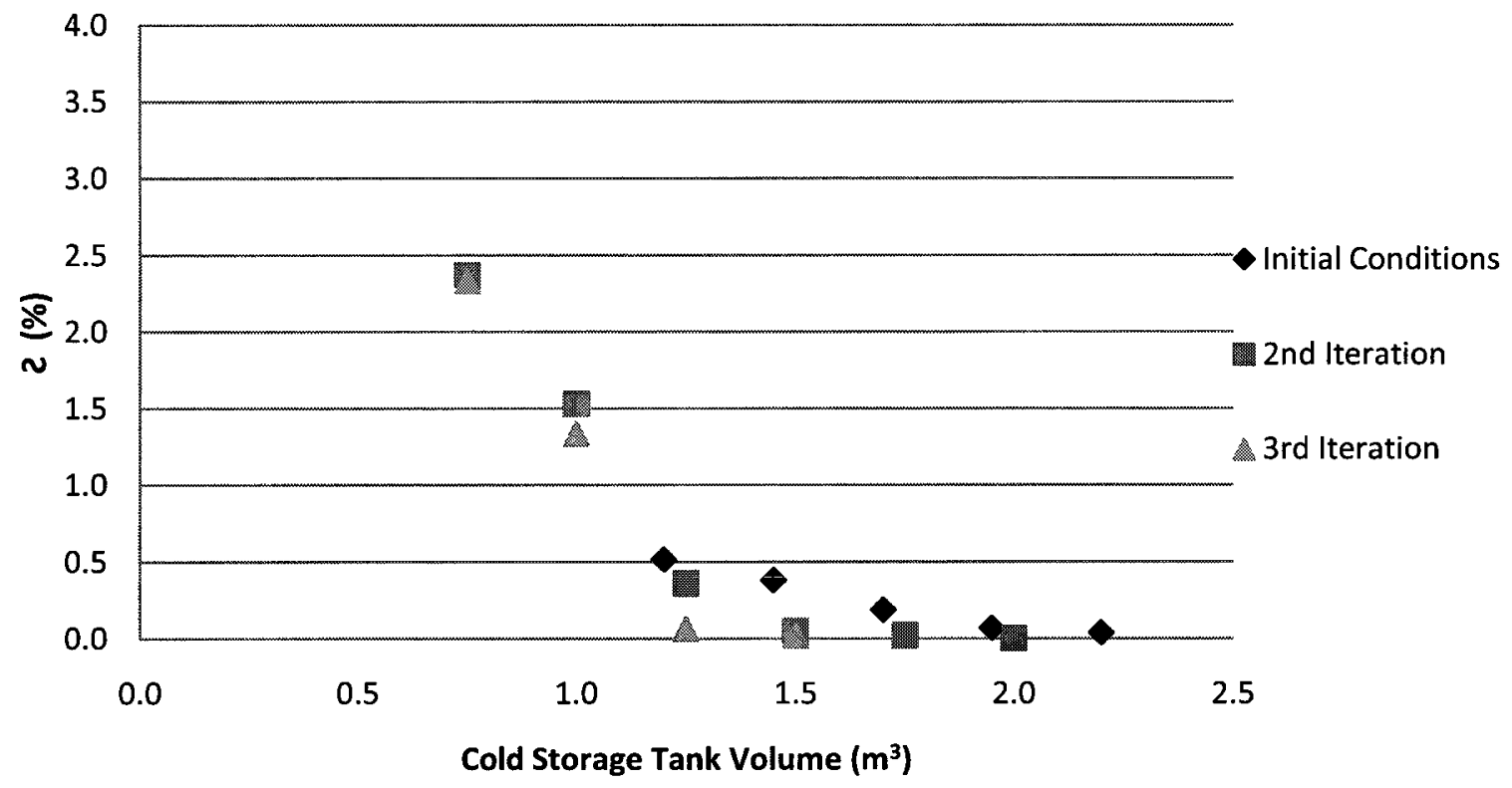

Figure 3-11: Sizing of the cold storage tank

Figure 3-12 shows the relationship between each of the storage tank sizes and 2. As seen in previous figures, 2 is found to be minimal at larger tank sizes. A cold tank 
size of $1.25 \mathrm{~m}^{2}$ and a hot tank size of $1.0 \mathrm{~m}^{3}$ were selected in order to meet a value of 2 above $99 \%$.

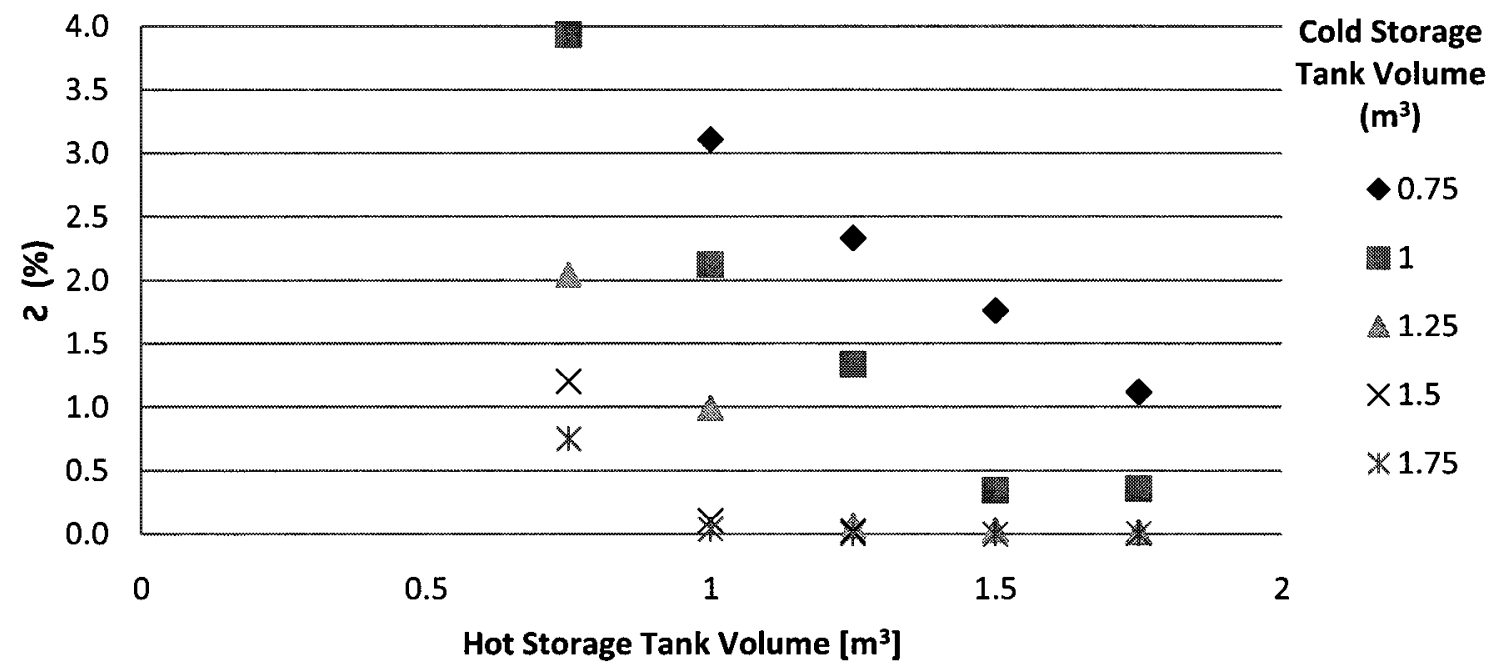

Figure 3-12: Relationship between storage tank sizes and unmet cooling loads

Table 3-4: Final component sizing

\begin{tabular}{|c|c|c|}
\hline Variable & $\begin{array}{c}\text { Initial } \\
\text { Condition }\end{array}$ & Final Sizing \\
\hline Solar Collector Area & $55 \mathrm{~m}^{2}$ & $40 \mathrm{~m}^{2}$ \\
\hline Hot Storage Tank Volume & $1.3 \mathrm{~m}^{3}$ & $1.0 \mathrm{~m}^{3}$ \\
\hline Cold Storage Tank Volume & $1.7 \mathrm{~m}^{3}$ & $1.25 \mathrm{~m}^{3}$ \\
\hline Hot Loop Flow Rate & $0.26 \mathrm{~kg} / \mathrm{s}$ & $0.05 \mathrm{~kg} / \mathrm{s}$ \\
\hline Cold Loop Flow Rate & $0.44 \mathrm{~kg} / \mathrm{s}$ & $0.9 \mathrm{~kg} / \mathrm{s}$ \\
\hline Solar Collector Flow Rate & $0.21 \mathrm{~kg} / \mathrm{s}$ & $0.1 \mathrm{~kg} / \mathrm{s}$ \\
\hline
\end{tabular}

The final sizing for each of the variables is detailed in Table 3-4. The results of the component sizing in TRNSYS are conducive to the physical constraints of a Canadian 
home. A roof capable of accommodating $40 \mathrm{~m}^{2}$ of evacuated tube collector is large, but feasible. While tanks of $1.0 \mathrm{~m}^{3}$ and $1.25 \mathrm{~m}^{3}$ volume are also large for domestic use, they are in the same size range of electric water tanks for large family homes (NRCan, 2008b). The final component sizes were determined for use in the building simulations completed in ESP-r which are further described in Chapter 4. 


\section{Chapter 4}

\subsection{ESP-r Building Performance Simulation Software}

Chapter 3 described the use of TRNSYS for sizing the components of the solar absorption cooling system under consideration. For the sizing of the plant system, a sequential approach to plant modelling was advantageous due to the ability to use different modelling methods for different components, and the ability to rapidly prototype the system layout and sizing. However, once the SAC system is incorporated into a full building simulation, the complexity of the plant and building modelling makes it advantageous to use a simultaneous plant modelling approach. ESP-r simulation software was chosen for the performance simulation of the SAC system in a variety of house designs and climates. While multiple building performance simulation software programs exist (U.S. Department of Energy, 2011), ESP-r was chosen for the work because it is an open-source, non-proprietary simulation software which allows for a high level of customization. Additionally, ESP-r has been well validated and can be used with a high degree of confidence (Strachan, 2008).

The present chapter describes the modelling techniques of the ESP-r simulation software. Section 4.1 will describe the building thermal network modelling, Section 4.2 will describe the plant network modelling, and Section 4.3 will describe 
the control functions. The following description of the simulation techniques integrated in ESP-r is adapted from Clarke (2001).

\subsection{The ESP-r Building Thermal Network}

ESP-r was developed in the 1970s, at the time when numerical methods were beginning to take hold in the BPS industry. ESP-r uses a numerical method with simultaneous solution for solving the building thermal network by representing the model as numerous discretised control volumes. A building is split into separate thermal zones, each made up of a variety of surfaces, plant network interactions, and control functions.

The formulation of a model in ESP-r comprises three stages, beginning with the discretisation of the building system. The discretisation is completed through placing nodes at points of interest throughout the building. Conservation equations are then developed for each node, which include the transfers of mass, energy, and momentum between the node and the surrounding nodes. Based on the present time-row states and prescribed boundary conditions, the resulting set of nodal equations is then solved simultaneously at each time step in order to determine the future time-row variables.

Within an ESP-r building model, thermal zones are defined, each bounded by surfaces containing internal surface nodes and a single air point node in the middle of the zone. The zoning of a building allows for the differentiation between conditioned and unconditioned areas, as well as other varying occupant comfort 
settings and internal gains. For example, a main floor containing a kitchen and washer/dryer will have different heating and cooling setpoints and internal gains than an unconditioned attic.

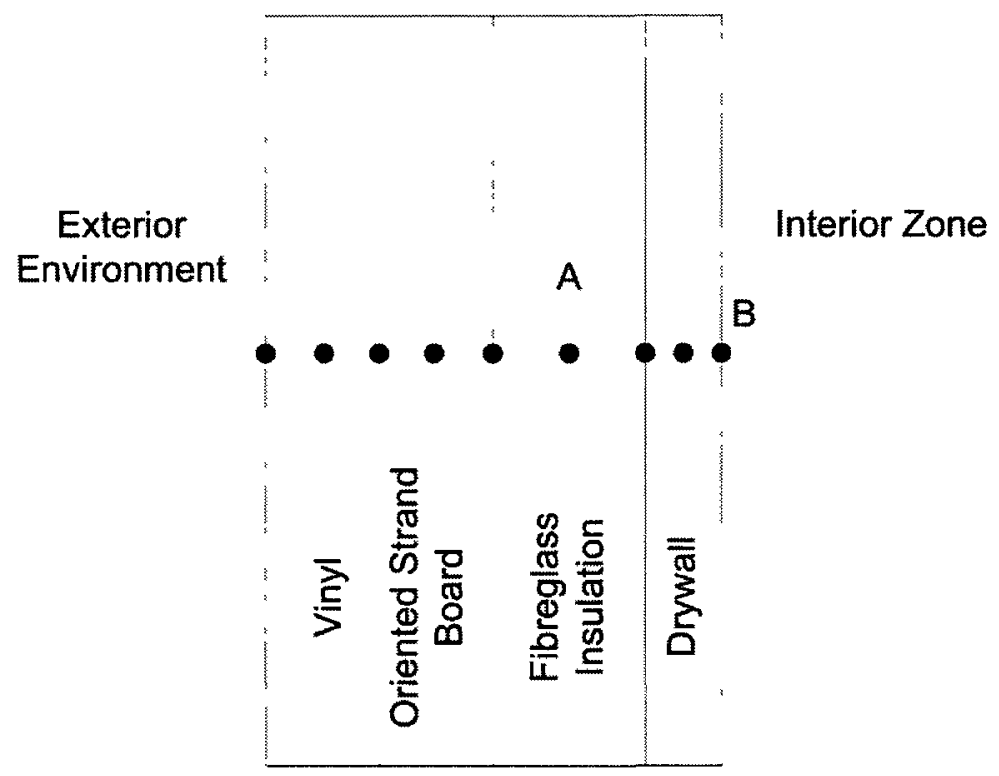

Figure 4-1: Control volume discretisation of an opaque surface Adapted from Beausoleil-Morrison (2000)

Within a zone, each surface and point of interest is discretised into control volumes (nodes). Figure 4-1 shows an opaque surface comprising 4 different materials discretized into nodes. In ESP-r, each construction material has three nodes: an internal surface node (at the intersection between the most internal surface of the material and the internal environment, or the next material, as applicable), an intraconstructional node (at the midsection of the volume), and an external surface node (at the intersection between the material and the external environment, or the next material, as applicable). A study from Clarke (1977) postulates that spatial 
discretisation of a homogeneous element into three or more nodes is considered acceptably accurate (as cited in Clarke (2001)).

Once discretisation has been achieved, governing equations for each node are developed based on the applicable heat transfer. A variety of heat and mass transfer processes can take place within a thermal network. Figure 4-2 outlines some of the most common processes within a building, and also identifies the three nodes just described. The figure depicts heat and mass transfer through infiltration (air flow to and from the external environment through cracks and gaps), internal convection, longwave radiation (both internally and externally), inter-zone airflow, internal gains from occupants and equipment, and exterior convection. Additional sources of heat and mass transfer include HVAC equipment, renewable energy systems, and cogeneration systems.

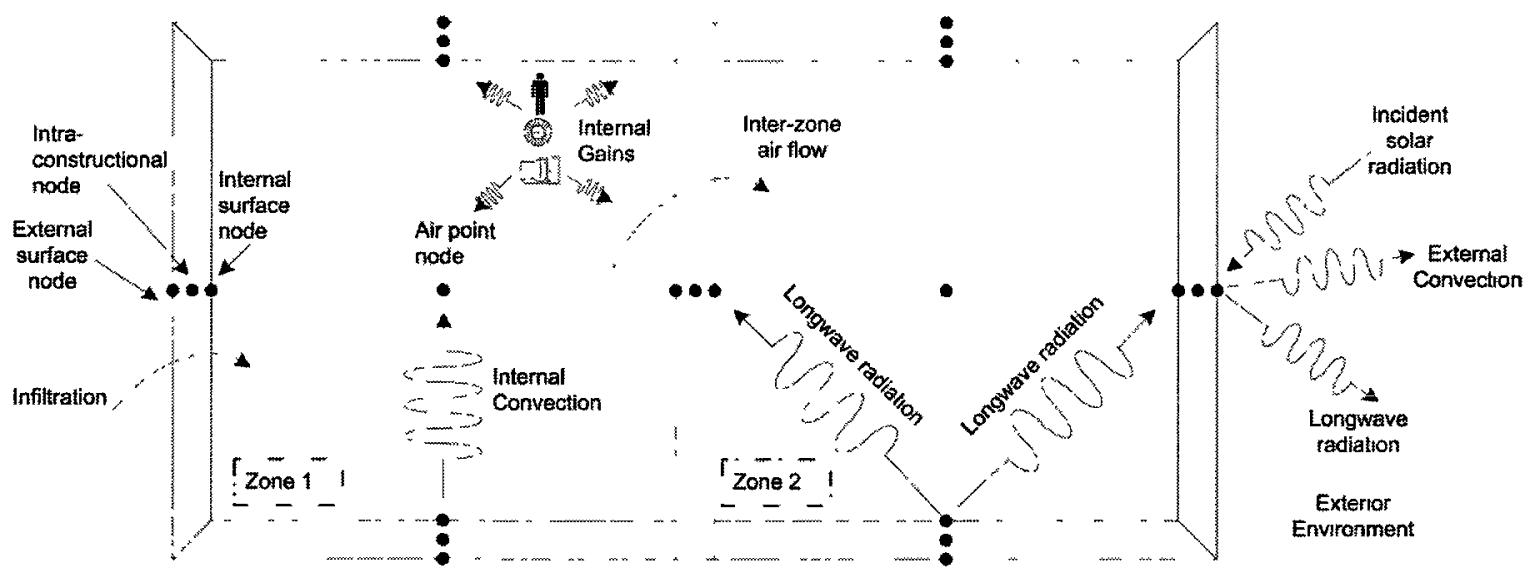

Figure 4-2: Heat and mass transfer processes

Adapted from Beausoleil-Morrison (2000)

Figure 4-3 provides a detailed view of a single opaque surface. For an opaque surface, the energy transfer occurring through the surface will include conduction 
through the solid material, convection within porous materials, as well as radiation. Moisture transfer and contact resistances will also affect the surface, in all three dimensions. In order to model this surface, ESP-r assumes one-dimensional conduction with constant thermophysical properties through the material. This approximation has sufficient accuracy for thin layers of material, and allows for the nodal distribution previously described.

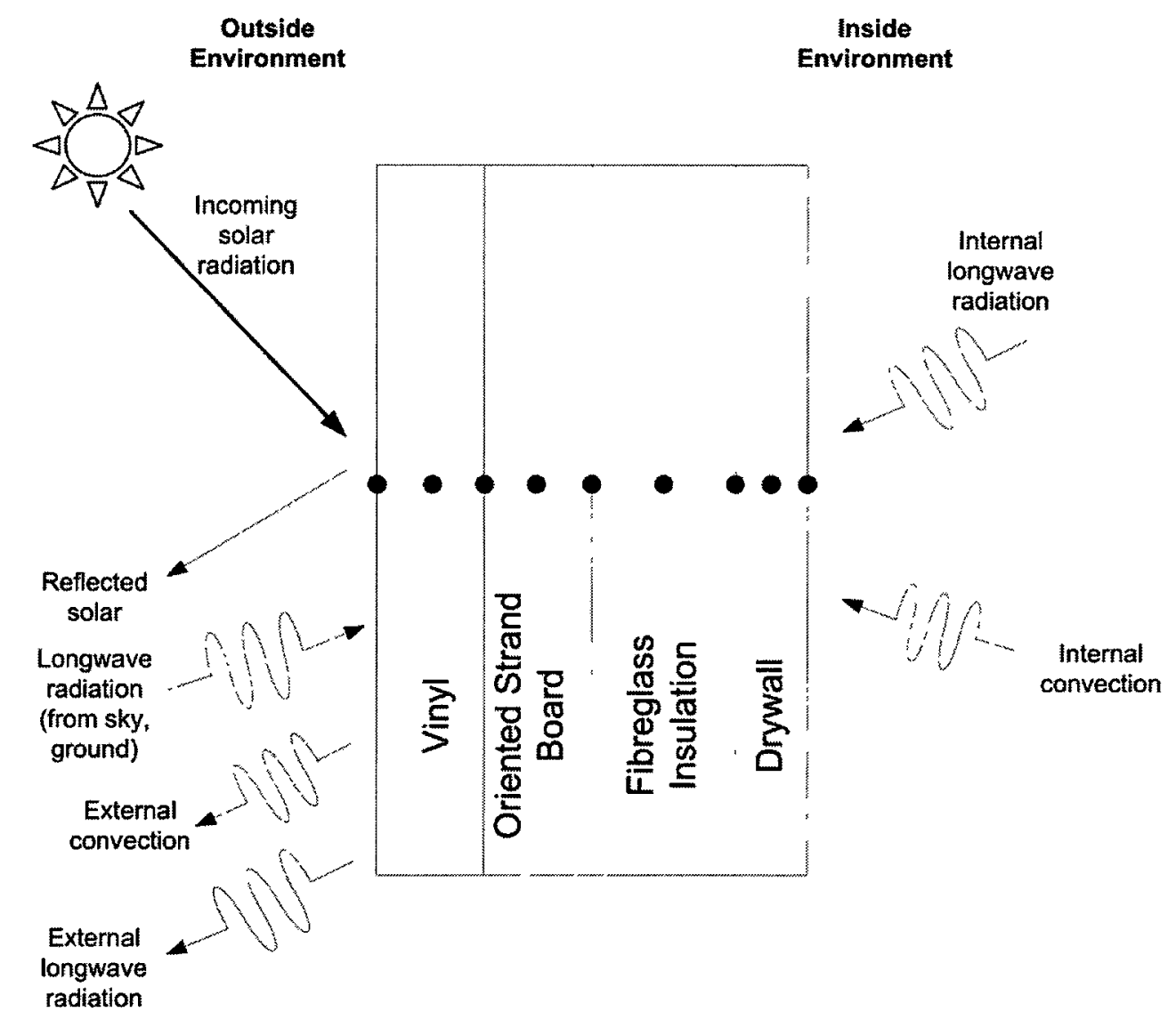

Figure 4-3: Heat and mass transfer processes in an opaque surface Adapted from Beausoleil-Morrison (2000)

For each region (intra-constructional, zone air, etc.), an equation is derived which integrates the thermal interaction with other regions through conduction, 
convection, radiation, and fluid flow. For example, for regions with conduction, the Fourier heat equation is included. These conservation equations are expressed for each of the nodes, approximated using the Taylor Series expansion. ESP-r allows the user to specify the implicit and explicit weighting for the building simulation solutions. A fully explicit solution provides an independent equation for each node. The resulting set of equations may be easily resolved by solving future time-row values at each time step based on the initially prescribed temperatures at $t=0$. A fully implicit solution would present an equation for each node which would contain both present and future time temperatures, related to the surrounding nodes (Clarke, 2001).

For an intra-constructional node such as $A$ in Figure 4-1 the heat balance can be expressed by Equation 4-1:

$$
\rho C_{P} \frac{\partial T}{\partial t}=-\frac{\partial q_{\text {cond }}^{\prime \prime}}{\partial x}+q_{\text {plant }}^{\prime \prime \prime}
$$

where $\rho$ is the density of the material $\left(\mathrm{kg} / \mathrm{m}^{3}\right), C_{p}$ is the specific heat capacity at constant pressure of the material $(\mathrm{J} / \mathrm{kgK}), \frac{\partial T}{\partial t}$ represents the change in temperature with time of the control volume $(\mathrm{K} / \mathrm{s}), q_{\text {plant }}^{\prime \prime \prime}$ is the heat transfer by the plant components per unit volume $\left(\mathrm{W} / \mathrm{m}^{3}\right)$, and $\frac{\partial q_{c o n d}^{\prime \prime}}{\partial x}$ represents the change in heat transfer by conduction per unit area with distance through the control volume $\left(\mathrm{W} / \mathrm{m}^{3}\right)$. 


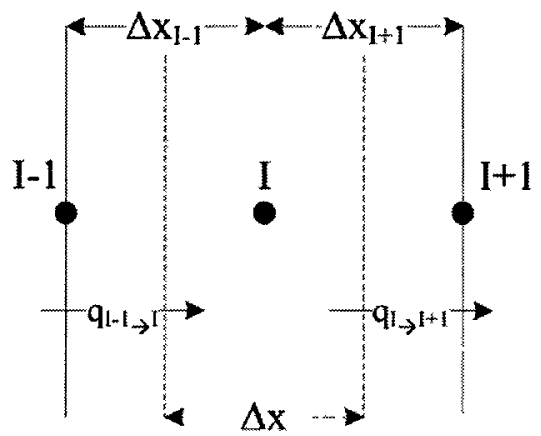

Figure 4-4: Control volume for an intra-constructional node Adapted from Beausoleil-Morrison (2000)

Figure 4-4 provides an example of an intra-constructional control node with related definitions. The $I$ term represents the current node in the centre of the control volume, $I-1$ represents the previous node in space, and $l+1$ represents the next node in space. $\Delta x$ represents the width of the control volume $(\mathrm{m}), \Delta x_{I-1}$ the distance between the current node and the previous node ( $\mathrm{m})$, and $\Delta x_{I+1}$ the distance between the current node and the next node (m). Integrating over space, the fully explicit Taylor series expansion provides Equation 4-2, where the conductive heat transfers $q_{I-1} \rightarrow I(W)$ and $q_{I_{\rightarrow}^{I+1}}(\mathrm{~W})$ are described in Equations 4-3, and 4-4, respectively.

$$
\begin{gathered}
\left(\rho C_{P} \Delta x \Delta y \Delta z\right)_{I} \frac{T_{I}^{t+\Delta t}-T_{I}^{t}}{\Delta t}=q_{I-1 \rightarrow I}-q_{I \rightarrow I+1}+q_{\text {plant }} \\
q_{I-1 \rightarrow I} \approx \frac{k_{I-1} \Delta y \Delta z}{\Delta x_{I-1}}\left(T_{I-1}^{t}-T_{I}^{t}\right) \\
q_{I \rightarrow I+1} \approx \frac{k_{I+1} \Delta y \Delta z}{\Delta x_{I+1}}\left(T_{I}^{t}-T_{I+1}^{t}\right)
\end{gathered}
$$


In these equations, $t+\Delta t$ denotes the future time step, $t$ the current time step, $k$ the thermal conductivity of the material $(\mathrm{W} / \mathrm{mK}), \Delta x$ the width of the control volume (m), $\Delta y$ the height of the control volume (m), and $\Delta z$ the length of the control volume (m).

In order to finalize the conservation equations, the ESP-r user must determine at what ratio to weight the implicit and explicit expressions. A common formulation is the Crank-Nicholson method, which applies a 50\% weighting to each of the implicit and explicit formulations, and is unconditionally stable (Clarke, 2001). The CrankNicholson method was selected for the present work due to its stability. The resulting formulation for intra-constructional control volumes can be seen in Equation 4-5.

$$
\begin{aligned}
& {\left[\frac{2\left(\rho c_{p}\right)_{I}}{\Delta t}+\frac{k_{1-1}}{\Delta x \Delta x_{1-1}}+\frac{k_{I+1}}{\Delta x \Delta x_{I+1}}\right] T_{I}^{t+\Delta t}-\left[\frac{k_{I-1}}{\Delta x \Delta x_{I-1}}\right] T_{I-1}^{t+\Delta t}-\left[\frac{k_{I+1}}{\Delta x \Delta x_{I+1}}\right] T_{I+1}^{t+\Delta t}-\frac{q_{\text {plant }}^{t+\Delta t}}{\Delta x \Delta y \Delta z}=} \\
& {\left[\frac{2\left(\rho c_{p}\right)_{I}}{\Delta t}-\frac{k_{1-1}}{\Delta x \Delta x_{1-1}}-\frac{k_{I+1}}{\Delta x \Delta x_{I+1}}\right] T_{I}^{t}+\left[\frac{k_{I-1}}{\Delta x \Delta x_{I-1}}\right] T_{I-1}^{t}+\left[\frac{k_{I+1}}{\Delta x \Delta x_{I+1}}\right] T_{I+1}^{t}+\frac{q_{\text {plant }}^{t}}{\Delta x \Delta y \Delta z}}
\end{aligned}
$$

Similarly, for an internal surface control volume such as B in Equation 4-1, the control volume would have the form shown in Figure 4-5. The resulting CrankNicholson difference formulation is described by Equation 4-6, where $s$ represents the surface number facing the control volume, and $h_{r a d}$ and $h_{c o n v}$ are the radiative and convective heat transfer coefficients $\left(\mathrm{W} / \mathrm{m}^{2} \mathrm{~K}\right)$, respectively. In the case of the internal surface node, there is also the addition of heat transfer by solar gains, $q_{\text {solar }, I}$ (W), and by radiative casual gains, $q_{c a s-r a d, I}(\mathrm{~W})$. 


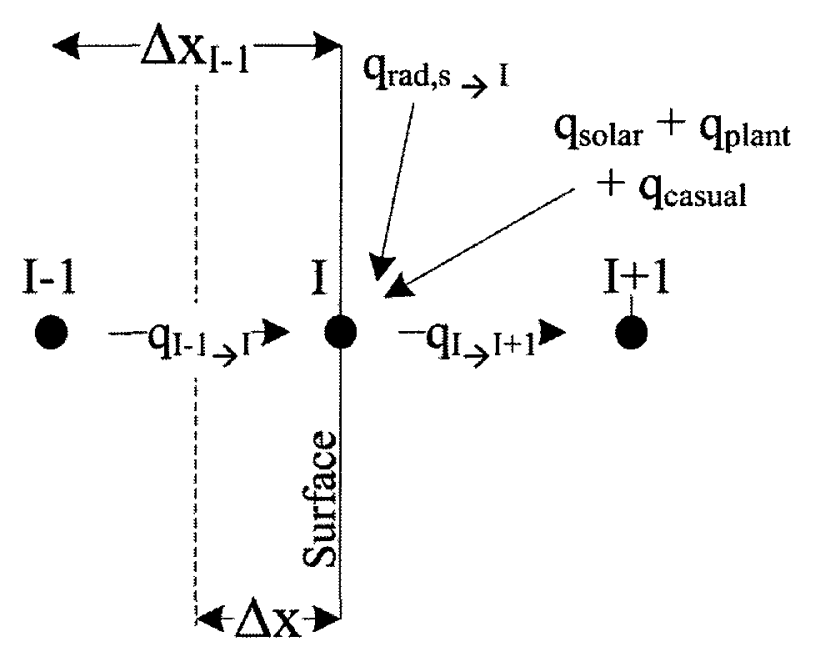

Figure 4-5: Control volume for an internal surface node Adapted from Beausoleil-Morrison (2000)

$\left[\frac{2\left(\rho c_{p}\right)_{I}}{\Delta t}+\frac{k_{1-1}}{\Delta x \Delta x_{1-1}}+\frac{h_{c o n v, I}^{t+\Delta t}}{\Delta x}+\frac{\sum_{s=1}^{N} h_{r a d, s-I}^{t+\Delta t}}{\Delta x}\right] T_{I}^{t+\Delta t}-\left[\frac{k_{I-1}}{\Delta x \Delta x_{I-1}}\right] T_{I-1}^{t+\Delta t}-\left[\frac{h_{c o n v, I}^{t+\Delta t}}{\Delta x}\right] T_{I+1}^{t+\Delta t}-$ 4-6

$\frac{\sum_{s=1}^{N} h_{r a d, s \rightarrow I}^{t+\Delta t} T_{s}^{t+\Delta t}}{\Delta x}-\frac{q_{s o l a r, I}^{t+\Delta t}}{\Delta x \Delta y \Delta z}-\frac{q_{\text {cas }- \text { rad }, I}^{t+\Delta t}}{\Delta x \Delta y \Delta z}-\frac{q_{p l a n t, I}^{t+\Delta t}}{\Delta x \Delta y \Delta z}=\left[\frac{2\left(\rho C_{p}\right)_{I}}{\Delta t}-\frac{k_{1-1}}{\Delta x \Delta x_{1-1}}-\frac{h_{c o n v, I}^{t}}{\Delta x}-\right.$

$\left.\frac{\sum_{s=1}^{N} h_{r a d, s \rightarrow I}^{t}}{\Delta x}\right] T_{I}^{t}+\left[\frac{k_{I-1}}{\Delta x \Delta x_{I-1}}\right] T_{I-1}^{t}+\left[\frac{h_{c o n v, I}^{t}}{\Delta x}\right] T_{I+1}^{t}+\frac{\sum_{s=1}^{N} h_{r a d, s \rightarrow I}^{t} T_{s}^{t}}{\Delta x}+\frac{q_{s o l a r, I}^{t}}{\Delta x \Delta y \Delta z}+\frac{q_{c a s-r a d, I}^{t}}{\Delta x \Delta y \Delta z}+$

$\frac{q_{p l a n t, I}^{t}}{\Delta x \Delta y \Delta z}$

Finally, a zone air control volume, as shown in Figure 4-6, introduces the contribution of advective mass transfer through flow from other zones, as well as infiltration from the exterior through cracks and openings. This contribution is dependent on the mass flow rate as well as the temperature gradient between the zone and the infiltrating zone or exterior. The introduction of advection mass transfer from other zones to air point node $I$ of a zone $\left(\dot{m}_{i j}\right)$ is expressed by Equation 4-7, where $J$ denotes a different zone. 


$$
\dot{m}_{i j}=\sum_{J=1}^{n-1} \dot{m}_{J \rightarrow I}^{t}\left(C_{p}\left(T_{j}^{t}-T_{i}^{t}\right)\right)_{J \neq I}
$$

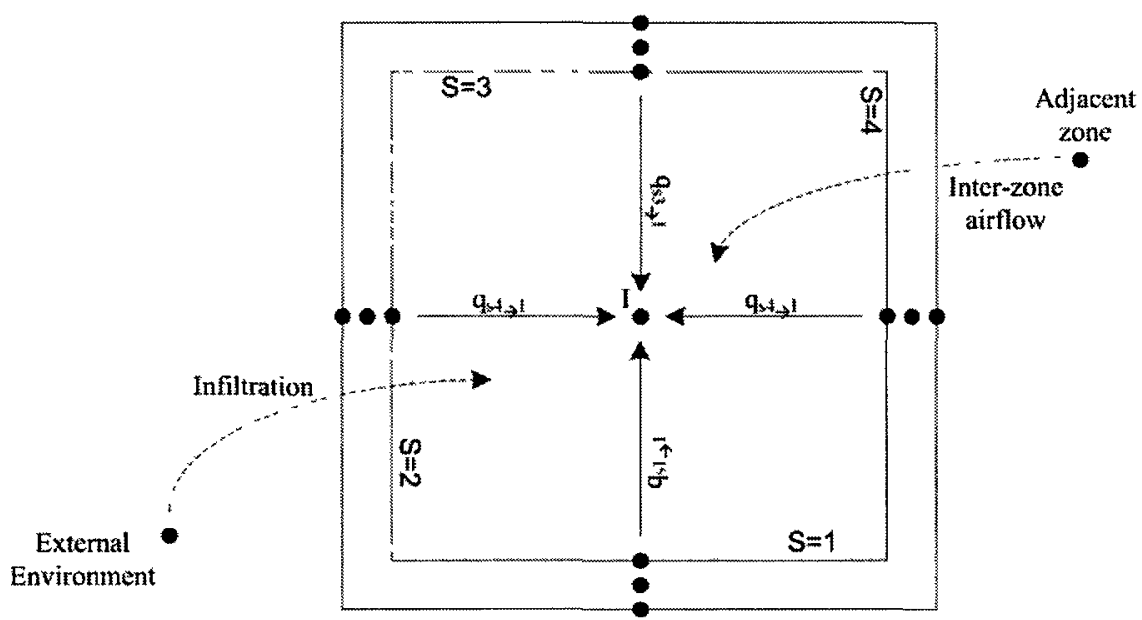

Figure 4-6: Zone air control volume

Adapted from Beausoleil-Morrison (2000)

The transfer from other zones is prescribed by the air flow network, within which users define mechanisms and quantities for the inter-zone air flow. The contribution of infiltration from the exterior $\left(\dot{m}_{i a}\right)$ is similarly expressed by Equation 4-8, where $a$ denotes the exterior.

$$
\dot{m}_{i a}=\dot{m}_{a \rightarrow I}^{t}\left(C_{p}\left(T_{a}^{t}-T_{i}^{t}\right)\right)
$$

In order to determine the mass flow rates infiltrating the zone, ESP-r utilizes the Alberta Infiltration Model (AIM-2) (Walker \& Wilson, 1990). The AIM-2 model relates the weather file information, specifically the wind speed, to the air leakage sites and the pressure difference between the interior and exterior, in order to determine the air infiltration rate. 
First, the user inputs the level of sheltering from the wind based on surrounding trees, buildings, and other objects. This information is used along with the wind speed to determine the force of the wind acting on the building envelope. Second, random infiltration is determined based on the pressure difference across each leakage site on the building envelope. The pressure difference is determined by temperature difference between the interior and exterior, the wind, and appliance operation. The size and location of leakage heavily influence the infiltration rate, and the incorporation of the AIM-2 model into ESP-r has also allowed users to consider the effects of occupants opening and closing windows. The AIM-2 model approximates the numerical solutions of these complex mass balances through algebraic equations which are then included in the overall system equation set (Wang et al., 2009).

Combining Equations 4-7 and 4-8 with the contributions from convective heat transfer from each surface determined by convection coefficient correlations (Beausoleil-Morrison, 2000), a zone air control volume would have the CrankNicholson formulation shown in Equation 4-9, where $V_{\text {room }}$ is the volume of the room containing the air zone node, and $\mathrm{q}_{\text {cas-conv }}$ is the convective casual gain heat transfer $(W)$. 


$$
\begin{aligned}
& {\left[\frac{2\left(\rho C_{p}\right)_{I}}{\Delta t}+\frac{\sum_{s=1}^{N} h_{c, s \rightarrow 1}^{t+\Delta t} A_{s}}{V_{\text {room }}}+\frac{\sum_{J=1}^{M} \dot{m}_{J \rightarrow I}^{t+\Delta t} C_{p}}{V L_{\text {room }}}+\frac{\dot{m}_{a \rightarrow I}^{t+\Delta t} C_{p}}{V O L_{\text {room }}}\right] T_{I}^{t+\Delta t}-\left[\frac{\sum_{s=1}^{N} h_{c, s \rightarrow I}^{t+\Delta t} A_{s} T_{s}^{t+\Delta t}}{V O L_{\text {room }}}\right]-} \\
& {\left[\frac{\sum_{J=1}^{M} \dot{m}_{J \rightarrow I}^{t+\Delta t} C_{p} T_{J}^{t+\Delta t}}{V O L_{\text {room }}}\right]-\left[\frac{\dot{m}_{a \rightarrow I}^{t+\Delta t} C_{p} T_{a}^{t+\Delta t}}{V O L_{\text {room }}}\right]-\frac{q_{c a s-c o n v, I}^{t+\Delta t}}{V O L_{\text {room }}}-\frac{q_{\text {plant }, I}^{t+\Delta t}}{V O L_{\text {room }}}=\left[\frac{2\left(\rho C_{p}\right)_{I}}{\Delta t}-\frac{\sum_{s=1}^{N} h_{c, s \rightarrow I}^{t} A_{s}}{V O L_{\text {room }}}-\right.} \\
& \left.\frac{\sum_{J=1}^{M} \dot{m}_{J \rightarrow I}^{t} C_{p}}{V O L_{\text {room }}}-\frac{\dot{m}_{a \rightarrow I}^{t} C_{p}}{V O L_{\text {room }}}\right] T_{I}^{t}+\left[\frac{\sum_{s=1}^{N} h_{c, s \rightarrow I}^{t} A_{s} T_{s}^{t}}{V O L_{\text {room }}}\right]+\left[\frac{\sum_{J=1}^{M} \dot{m}_{J \rightarrow I}^{t} C_{p} T_{J}^{t}}{V O L_{\text {room }}}\right]+\left[\frac{\dot{m}_{a \rightarrow I}^{t} C_{p} T_{a}^{t}}{V O L_{\text {room }}}\right]+ \\
& \frac{q_{\text {cas-conv }, I}^{t}}{V O L_{\text {room }}}+\frac{q_{\text {plant }, I}^{t}}{V O L_{\text {room }}}
\end{aligned}
$$

Once the set of nodal equations has been determined, the set must be solved at each time step. This solution can be obtained through direct methods or iterative methods. The iterative method was described in Section 3.1 and is the approach taken by TRNSYS. The method used by ESP-r involves the use of rapid direct techniques, with additional iteration of the air flow network when necessary. The interested reader is directed to Clarke (2001) for a full description of the solution approach.

\subsection{The ESP-r Plant Network}

ESP-r includes the option for an explicit or an idealized plant network for modelling heating and cooling systems. The idealized plant network imitates the functionality of the plant energy injection and extraction through simplified, ideal systems with set characteristics, such as cooling capacity. The ideal system uses controllers that manage the heat injection and extraction within the capacity limits of the system, in order to maintain the desired comfort conditions in the conditioned zone. The ideal network has limited functionality and does not sufficiently account for the cyclical nature of actual heating and cooling systems, nor does it allow for high levels of 
customization or component creation. The ideal plant network was not appropriate for the modelling of the SAC system undertaken in the present research, and therefore the explicit plant network was employed. The ideal plant network was used for the electrical modelling of a vapour compression air conditioning system as a comparison to the SAC system, which is further described in Section 7.2.

The explicit plant network creates an additional set of nodes to the thermal network, each node representing one component (or part thereof), of the plant system. The building model energy balances, for example Equation 4-5, include a corresponding entry to the plant network. The plant network can be simplistic or complex, the latter increasing the required computational power.

Individual plant components can have multiple nodes, and node placement carries significance in the way the component is modelled. Plant inputs or extracts which are convective in nature will transfer energy directly with the zone air, and have a fluid nodal location. This placement is appropriate for air conditioning systems, where the cooling flux is convectively added under a control strategy. Inputs or extracts which are both convective and radiant have a surface nodal location. This placement is in accordance with the convective transfer to the proximal fluid volume, and the longwave radiation to the surrounding surfaces. Such a placement is appropriate for components that have explicit surfaces described, such as radiant panels and radiators. Nodes can also be considered as a capacity or insulation node, for systems which would input or extract energy to an intra-material node such as under-floor heating systems. 
Figure 4-7 displays a single-node solar collector, where the node is considered as a fluid node. The collector node interacts with two other plant nodes through energy flow in and out, where $\dot{m}$ is the mass flow rate $(\mathrm{kg} / \mathrm{s})$ and $C_{p}$ is the specific heat capacity $(\mathrm{J} / \mathrm{kgK})$. The collector receives longwave solar radiation, and also has a mass of fluid, $m_{\text {coll }}(\mathrm{kg})$. The outlet temperature can be determined through explicit simulation.

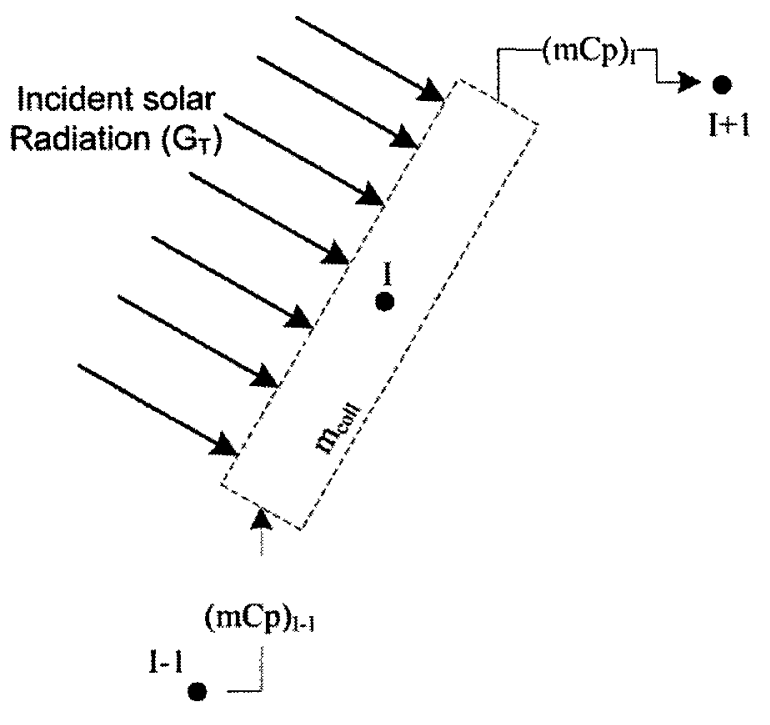

Figure 4-7: Solar collector control volume

A set of conservation equations is described for each node in a component. The number of equations is dependent on the number of phases and properties used. A system of equations can then be created for the plant component network in the same way as for the thermal network described in Section 4.1. This system is combined with the building and fluid flow equation systems and solved numerically. In order to decrease complexity and required processing power, components often include an independent algorithm for internal processes, which allows the overall 
component to be represented by a small number of control volumes. Users provide the required inputs for the characteristic equations, including for example the total component mass and the working fluid heat capacity.

For the solar collector shown in Figure 4-7, the methodology in ESP-r is summarized below. The interested reader is directed to Thevenard et al. (2004) for a more thorough description of the solar collector model. The energy balance for the control volume is described by Equation 4-10 where the left hand side is comprised of the mass of the collector, $\mathrm{m}_{\text {coll }}(\mathrm{kg})$, the average fluid heat capacity, $\bar{c}\left(\mathrm{~kJ} / \mathrm{kg}^{\circ} \mathrm{C}\right)$, and the change of the outlet fluid temperature with respect to time, $\frac{\partial \theta_{\text {out }}}{\partial t}\left({ }^{\circ} \mathrm{C} / \mathrm{s}\right)$.

$$
m_{\text {coll }} \bar{c} \frac{\partial \theta_{\text {out }}}{\partial t}=-\dot{m} C_{p}\left(\theta_{\text {out }}-\theta_{\text {in }}\right)+\eta A G_{T}
$$

The right hand side of the equation includes the energy change through advection, where $\theta$ is the fluid temperature $\left({ }^{\circ} \mathrm{C}\right)$, as well as the heat transfer from the incoming solar radiation, $\mathrm{G}_{\mathrm{T}}\left(\mathrm{W} / \mathrm{m}^{2}\right)$, multiplied by the gross collector area, $\mathrm{A}\left(\mathrm{m}^{2}\right)$, and the solar collector efficiency, $\eta$. The collector efficiency is defined by Equation 4-11, where $\eta_{0}, \eta_{1}$ and $\eta_{2}$ are efficiency coefficients, further described in Section 3.3.3, and $\Delta \theta\left({ }^{\circ} \mathrm{C}\right)$ can either be based on the inlet or average fluid temperature.

$$
\eta=\eta_{0}-\eta_{1} \frac{\Delta \theta}{\mathrm{G}_{\mathrm{T}}}-\eta_{2} \frac{\Delta \theta^{2}}{\mathrm{G}}
$$


As with the thermal network, conservation equations can be determined using the flux through the control volume at the present and future time steps. These equations can then be integrated using a Taylor Series expansion for the future time row. For the modelling of the solar collector in ESP-r, Equation 4-11 is rearranged in terms of $\theta_{\text {out, }}$ rather than $\theta_{\text {avg }}$ or $\theta_{\text {in. }}$. The reader is directed to (Thevenard et al., 2004) for the complete steps of the transformation. With this rearrangement, the future time row of the European collector balance, is expressed by Equation $4-12$ where $\Delta \mathrm{T}\left({ }^{\circ} \mathrm{C}\right)$ is the difference between the mean fluid and ambient temperatures, $\delta \mathrm{t}$ is the time step (s), and $\theta_{\mathrm{a}}$ is the ambient temperature $\left({ }^{\circ} \mathrm{C}\right)$. Similarly, the present time row can be expressed by Equation 4-13.

$$
\begin{aligned}
& {\left[-\dot{m}(t+\delta t) C_{p}(t+\delta t)-A \frac{\left(\eta_{1}+\eta_{2} \Delta T(t)\right)}{2}-\frac{m \bar{c}}{\delta t}\right] \theta_{\text {out }}(t+\delta t)+\left[\dot{m}(t+\delta t) C_{p}(t+\right.} \\
& \left.\delta t)-A \frac{\left(\eta_{1}+\eta_{2} \Delta T(t)\right)}{2}\right] \theta_{\text {in }}(t+\delta t)=-A \frac{\left(\eta_{1}+\eta_{2} \Delta T(t)\right)}{2} \theta_{a}(t+\delta t)-A \eta_{0} G(t+\delta t)- \\
& \frac{m \bar{c}}{\delta t} \theta_{\text {out }}(t) \\
& -\frac{m \bar{c}}{\delta t} \theta_{\text {out }}(t+\delta t)=\left[\dot{m}(t) C_{p}(t)+A \frac{\left(\eta_{1}+\eta_{2} \Delta T(t)\right)}{2}-\frac{m \bar{c}}{\delta t}\right] \theta_{\text {out }}(t) \\
& -\dot{m}(t) C_{p}(t) \theta_{\text {in }}(t)-A \frac{\left(\eta_{1}+\eta_{2} \Delta T(t)\right)}{2} \theta_{a}(t)-A \eta_{0} G(t)
\end{aligned}
$$

Combining Equations 4-12 and 4-13, Equation 4-14 provides the conservation equation for the solar collector, where $\alpha$ represents the explicit weighting, and (1- $\alpha)$ is the implicit weighting. 
$\left[-\alpha\left(\dot{m}(t+\delta t) C_{p}(t+\delta t)+A \frac{\left(\eta_{1}+\eta_{2} \Delta T(t)\right)}{2}\right)-\frac{m \bar{c}}{\delta t}\right] \theta_{\text {out }}(t+\delta t)+\alpha[\dot{m}(t+$

$\left.\delta t) C_{p}(t+\delta t)-A \frac{\left(\eta_{1}+\eta_{2} \Delta T(t)\right)}{2}\right] \theta_{i n}(t+\delta t)=$

$\left[(1-\alpha)\left(\dot{m}(t) C_{p}(t)+A \frac{\left(\eta_{1}+\eta_{2} \Delta T(t)\right)}{2}\right)-\frac{m \bar{c}}{\delta t}\right] \theta_{\text {out }}(t)-(1-\alpha) \dot{m}(t) C_{p}(t) \theta_{\text {in }}(t)-$

$\alpha\left(A \frac{\left(\eta_{1}+\eta_{2} \Delta T(t)\right)}{2} \theta_{a}(t+\delta t)+A \eta_{0} G(t+\delta t)\right)-(1-\alpha)\left(A \frac{\left(\eta_{1}+\eta_{2} \Delta T(t)\right)}{2} \theta_{a}(t)-\right.$

$\left.A \eta_{0} G(t)\right)$

The solution of the building thermal network described in Section 4.1 can now be completed using the resulting expression of Equation 4-14 for the solar collector plant component. The function of the ESP-r plant network is prescribed by the control systems described in the following section.

\subsection{Control Systems}

The approach taken in ESP-r for control systems is a collection of control loops, each consisting of a sensor, response, and actuator, as shown in Figure 4-8.
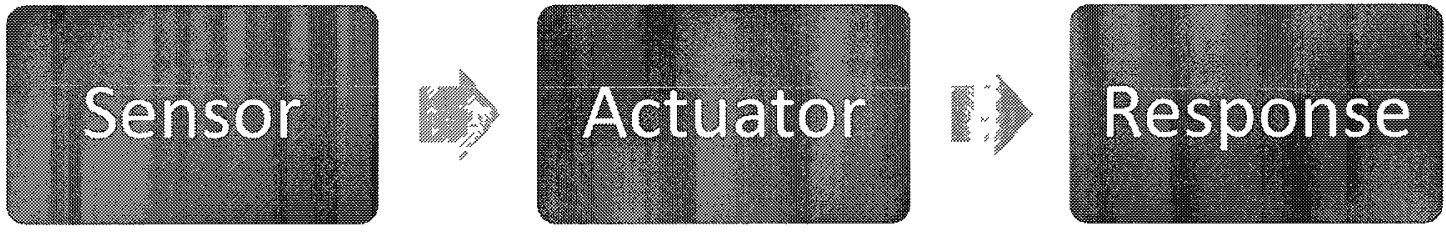

Figure 4-8 Control loop methodology in ESP-r

The sensor measures a parameter which determines when actuation will occur.

This parameter could be the temperature of a zone, the ambient temperature, 
incoming solar radiation, or any other parameter which may affect the operating conditions of the house. Once the sensed parameter has been selected, the user may select the details of the actuator for delivery of the action. The actuation includes both location details and the characteristics of the actuation. For instance, actuation could occur at a point in a zone, or at a surface or intra-constructional node, or in the case of a plant component actuation would occur at a component node.

Once the sensor and actuator details have been selected, the response details are described, which characterise the control action based on the sensed condition. The user may then determine various control strategies for user-prescribed time blocks. Controllers include on/off controllers, free-floating conditions for non-conditioned areas, and flux laws. For instance, the user could sense the temperature of the zone (sensor), and describe that between 9:00 am and 4:00 pm the zone could be freefloating, and from 4:00 pm to 10:00 pm the cooling fan should actuate whenever the temperature exceeds $25^{\circ} \mathrm{C}$.

The conditions of the system are sensed at each time step and are delivered to the controller response algorithm. This algorithm then modifies the model parameters before the final matrix equation is solved. Multiple control types can be combined and incorporated into the overall control strategy.

The ESP-r control strategy approach does not allow the actuation of multiple plant components simultaneously based on a single sensor, and was not sufficient for the control needs of the present research. In order to meet the control strategy outlined 
in Section 2.8, an independent control file was created that was read by the building performance simulator of ESP-r prior to solving the plant network. The control file included the sensing of the main zone temperature, ambient air temperature, the temperature of the hot and cold storage tanks, and the chilled and hot stream temperatures into the chiller. Based on these temperatures, the various pumps, cooling fan, and chiller were actuated based on the control logic prescribed in Section 2.8 .

\subsection{Climatic Considerations}

ESP-r requires climatic conditions in order to simulate the environmental effects on building performance. The dry bulb temperature is required for heat transfer by conduction, and radiation between the building and the surroundings. The dry bulb temperature can also be used to determine the soil temperature, which accounts for the heat loss from the foundation. Direct and diffuse solar radiation is required for the assessment of the absorption, transmission, and reflection of solar radiation through building surfaces. The wind speed and direction are used in the AIM-2 modelling to determine the ambient-zone air leakage, and finally the relative humidity is used for the determination of the wet-bulb temperature used in the absorption chiller control, as well as the changes in latent load and air density and specific heat values (Swan, 2010).

ESP-r's thermal and plant networks, when combined with customized control strategies, and detailed climatic information, allow for a highly customizable and accurate modelling of housing and HVAC performance. The detailed plant network, 
selected houses and modelling strategy used for BPS in ESP-r are described in Chapter 5. 


\section{Chapter 5}

\subsection{ESP-r Modelling Methods}

The performance assessment of the SAC system for houses in Ontario was completed in the ESP-r simulation environment. The ESP-r system developed was of similar format to the system developed in TRNSYS, and included a hot loop, a chilled loop, and a load loop. A schematic of the system is provided in Figure 5-1. The most significant deviation from the TRNSYS model discussed in Chapter 3 was the additional thermal modelling of a single-detached house, which included the implementation of a cooling coil and fan in the plant network.

The accuracy of any building performance simulation is dependent on the quality of the underlying system data and parameters. The subsequent sections discuss the selected parameter definitions for the modelling of the absorption chiller, along with the additional changes to the SAC system. Section 5.1 discusses the plant network, Section 5.2 discusses the house models, Section 5.3 describes the selection of the climatic information, Section 5.4 describes the sizing of the system, and finally Section 5.5 describes the simulation strategies employed in ESP-r. 


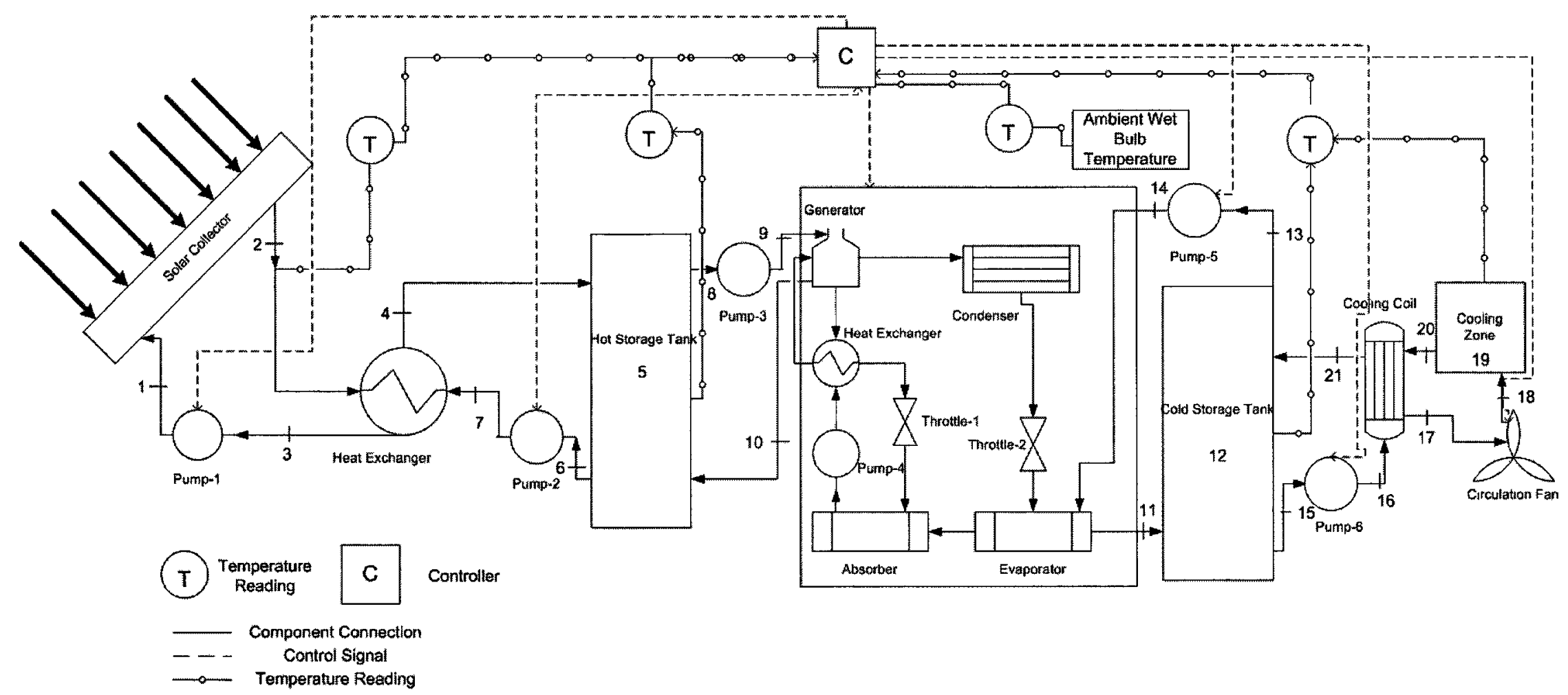

Figure 5-1: Schematic of ESP-r plant network representing the SAC system 


\subsection{Plant Network Description}

The plant network was composed of existing components from the ESP-r source code, with minor adjustments, and it also included a novel customized controller component, described in Section 5.1.1. An existing absorption chiller component was modified for use and is described in Section 5.1.2. The employed solar collector model was similar to the TRNSYS model previously described in Section 4.2. The reader is directed to the ESP-r source code for the underlying mathematical models for the remaining components (ESRU, 2002). The description of the system components and associated inputs can be found in Appendix B.

The solar collector model utilized had a flow rate limitation which impeded the use of the desired flow rate. A lower flow rate was used, which resulted in a slightly lower solar collector efficiency, but the overall heat transfer to the system was minimally affected. The resulting solar fractions and overall performance are thus considered a slightly conservative estimate of the system's performance.

\subsubsection{Controller component}

In order to control multiple plant components simultaneously, a customized controller component was created using FORTRAN for use in the ESP-r system. The controller followed the described control parameters in Section 2.8, and thus controlled the actuation of the solar collector pump, hot loop pump, absorption chiller and associated pumps, cold loop pump, cooling coil, and circulation fan. The 
control file was read in prior to the solution of the plant components at each time step.

The control of the absorption chiller component was altered from Section 2.8.3 in order to align with experimental results from Johnson (2011), as described in Table 5-1. The lower limit of the condenser inlet temperature in the experimental work completed by Johnson (2011) was $26.7^{\circ} \mathrm{C}$. It was expected that a decrease in condenser inlet temperature would increase the performance of the chiller, however no experimental data was available for validation. In the event that the condenser inlet temperature was below $26.7^{\circ} \mathrm{C}$, the chiller model assumed the inlet temperature was equal to $26.7^{\circ} \mathrm{C}$, leading to a conservative estimation of the chiller performance. Similarly, the Yazaki chiller being modelled is able to function with generator inlet temperatures up to $95.0^{\circ} \mathrm{C}$, but Johnson's experimental work only provided inlet temperatures up to $86.6^{\circ} \mathrm{C}$. In the event that the chiller inlet temperature was greater than $86.6^{\circ} \mathrm{C}$, the heat transfer rate calculations were completed with a generator inlet temperature of $86.6^{\circ} \mathrm{C}$.

Table 5-1 Temperature ranges for chiller experimental data

(Johnson, 2011)

\begin{tabular}{|c|c|c|}
\hline Component & $\begin{array}{c}\text { Minimum Temperature } \\
\text { Tested }\left({ }^{\circ} \mathbf{C}\right)\end{array}$ & $\begin{array}{c}\text { Maximum Temperature } \\
\text { Tested }\left({ }^{\circ} \mathbf{C}\right)\end{array}$ \\
\hline $\begin{array}{c}\text { Chilled Water Inlet } \\
\text { (Temperature 14) }\end{array}$ & 10.8 & 22.2 \\
\hline Heat Rejection Water Inlet & 26.7 & 32.7 \\
\hline $\begin{array}{c}\text { Heat Medium Inlet } \\
\text { (Temperature 9) }\end{array}$ & 73.6 & 86.6 \\
\hline
\end{tabular}


The lowest evaporator inlet temperature examined by Johnson was $10.8^{\circ} \mathrm{C}$, and therefore $10.8^{\circ} \mathrm{C}$ was selected as the lowest allowable evaporator inlet temperature. Finally, the minimum generator inlet temperature for chiller operation was shifted from $70.0^{\circ} \mathrm{C}$ to $73.6^{\circ} \mathrm{C}$, the lowest temperature examined by Johnson.

\subsubsection{Absorption chiller component}

The absorption chiller model in ESP-r was created by Beausoleil-Morrison et al. (2004) and was designed for calibration with experimental data. This model has three nodes: the water-side of the generator, the water-side of the evaporator, and the air-side of the condenser. The model was created to use an experimentally obtained $\mathrm{COP}_{\text {th }}$ characteristic equation based on the difference between actual and standard conditions for each node inlet. The use of the derived COP th equation also required the user attribution of the temperature of the generator at the refrigerant inlet and the generator efficiency. In order to reduce the number of assumptions and the compounded experimental error from the $\mathrm{COP}_{\text {th }}$ calculations, the model was modified such that it is based on experimentally derived relationships for the generator and evaporator heat transfers.

The chiller model is controlled using the custom controller described in Section 5.1.1 and therefore has no internal control mechanisms. The inlet temperatures, inlet flow rates, and ambient wet bulb temperature are supplied to the chiller component. The condenser inlet temperature $\left(\mathrm{T}_{\text {con,in }}\right)$ is determined by adding a two degree buffer to the ambient wet bulb temperature $\left(\mathrm{T}_{\mathrm{a}, \mathrm{wb}}\right)$ as shown in 
Equation 5-1. A two degree buffer was assumed to be an appropriate approximation of the local heating effects surrounding the condenser given the structure of the component source code and the nature of the present research (BeausoleilMorrison et al., 2004).

$$
T_{\text {con,in }}=T_{a, w b}+2.0
$$

After determining the condenser inlet temperature, the chiller model must evaluate the heat transfer that occurs at the generator and evaporator. The generator and evaporator heat transfer rates were determined through characteristic equations based on the inlet temperatures from Johnson's experimental work (Johnson, 2011). The data used for the regressions can be found in Appendix C. Multiple configurations of the generator heat transfer characteristic equation were assessed to determine the most appropriate form for the correlation. Three of the equation forms can be seen in Figure 5-2. 


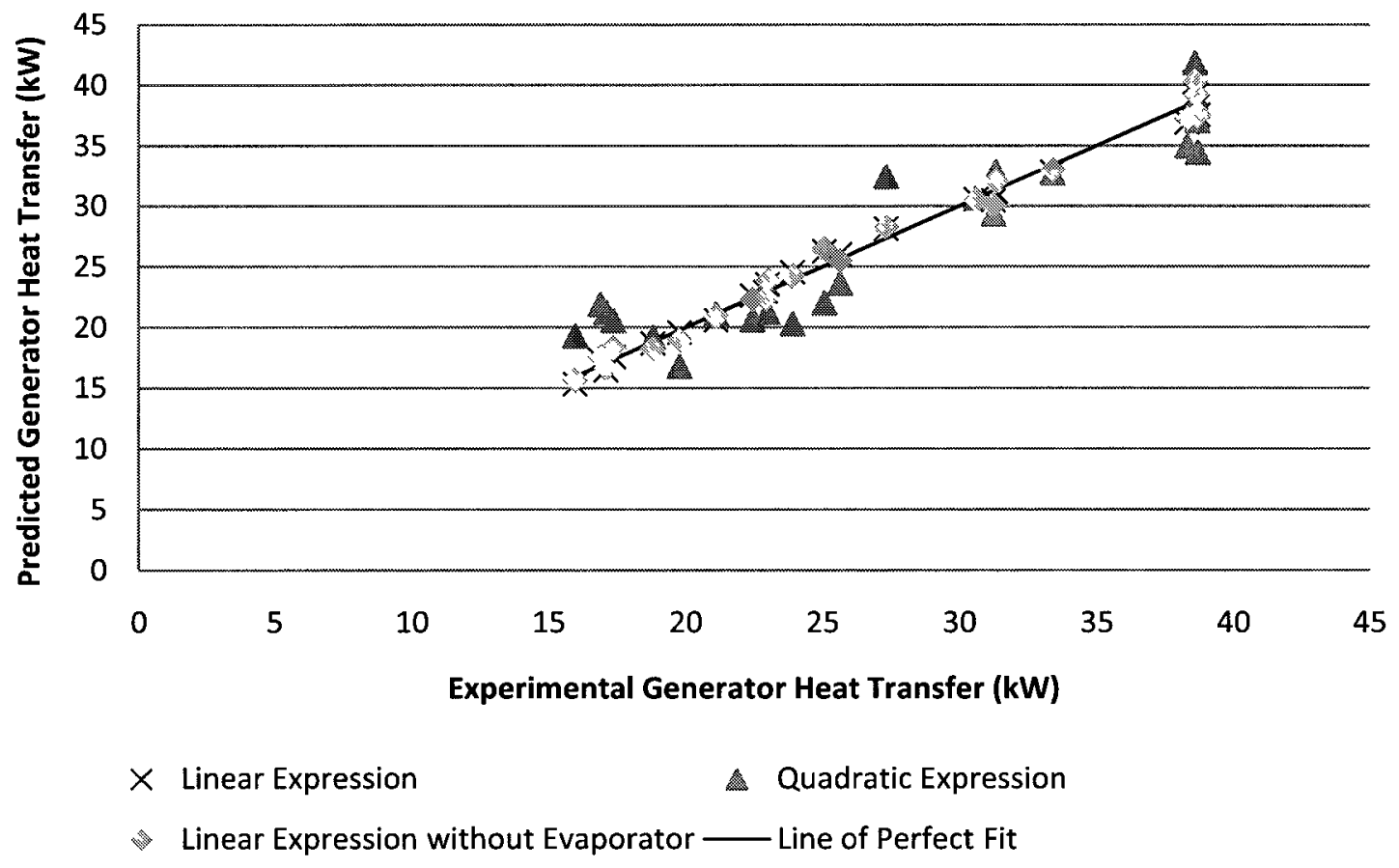

Figure 5-2: Comparison of the predicted and experimental generator heat transfer rates

The characteristic equations for the "linear expression", "quadratic expression", and "linear expression without evaporator" are described in Equations 5-2, 5-3, and 5-4 respectively. In these equations, $\dot{Q}_{g e n}$ is the generator heat transfer rate $(\mathrm{W}), \mathrm{T}$ is the temperature $\left({ }^{\circ} \mathrm{C}\right)$, the subscripts for gen,in, evap,in, and con,in are the inlet conditions for the generator, evaporator, and condenser, respectively, and the remaining variables are coefficients to be determined.

$$
\dot{Q}_{g e n}=a_{0}+a_{1} * T_{\text {gen_inlet }}+a_{2} * T_{\text {evap_inlet }}+a_{3} * T_{\text {cond_inlet }}
$$




$$
\begin{array}{rl}
\dot{Q}_{g e n}=b_{0}+b_{1} & * T_{g e n_{-} \text {inlet }}+b_{2} * T_{\text {evap_inlet }}+b_{3} * T_{\text {cond_inlet }}+b_{4} * T_{\text {gen_inlet }}^{2} \\
& +b_{5} * T_{\text {evap_inlet }}^{2}+b_{6} * T_{\text {cond_inlet }}^{2}+b_{7} * T_{\text {gen_inlet }} * T_{\text {evap_inlet }} \\
& +b_{8} * T_{\text {gen_inlet }} * T_{\text {cond_inlet }}+b_{9} * T_{\text {evap_inlet }} * T_{\text {cond_inlet }}
\end{array}
$$

$$
\dot{Q}_{g e n}=c_{0}+c_{1} * T_{g e n \_ \text {inlet }}+c_{2} * T_{\text {cond_inlet }}
$$

A linear expression based on the inlet temperature at all Equation 5-5 provides the selected expression. The p-values for each of the retrieved coefficients for the generator heat transfer are found in Table 5-2.

$$
\dot{Q}_{g e n}=-70.387+1.9269 * T_{\text {gen,in }}+0.16366 * T_{\text {evap,in }}-1.8824 * T_{\text {con,in }}
$$

Table 5-2: Generator heat transfer coefficients

\begin{tabular}{|c|c|c|}
\hline & Regression Coefficient & $p$-value \\
\hline$a_{0}$ & -70.387 & $1.924 \mathrm{E}-11$ \\
\hline $\mathrm{a}_{1}$ & 1.9269 & $1.069 \mathrm{E}-19$ \\
\hline $\mathrm{a}_{2}$ & 0.16366 & $2.360 \mathrm{E}-02$ \\
\hline $\mathrm{a}_{3}$ & -1.8824 & $1.028 \mathrm{E}-12$ \\
\hline
\end{tabular}

The p-value is a statistical parameter that characterises the significance of each term in an expression. The p-value is obtained by setting each coefficient to zero and contrasting the result with that obtained when the coefficient is non-zero. The p-value is then compared to a selected level of significance, in this case 0.05 , to 
determine whether the term has any statistical significance. The interested reader is directed to (Kutner et al., 2004) for a thorough description of the p-value.

The obtained $\mathrm{p}$-values for the generator heat transfer were all significantly below 0.05 , which affirms that each term in the selected linear expression holds statistical significance. The least significant term in the expression was found to be the evaporator inlet temperature, corresponding to coefficient $\mathrm{a}_{2}$.

Similar expressions were investigated for the evaporator heat transfer characteristic equation, with $\dot{Q}_{g e n}$ being replaced by $\dot{Q}_{\text {evap }}$ in Equations 5-1 through 5-4. The predicted evaporator heat transfer is plotted against the experimentally retrieved values in Figure 5-3.

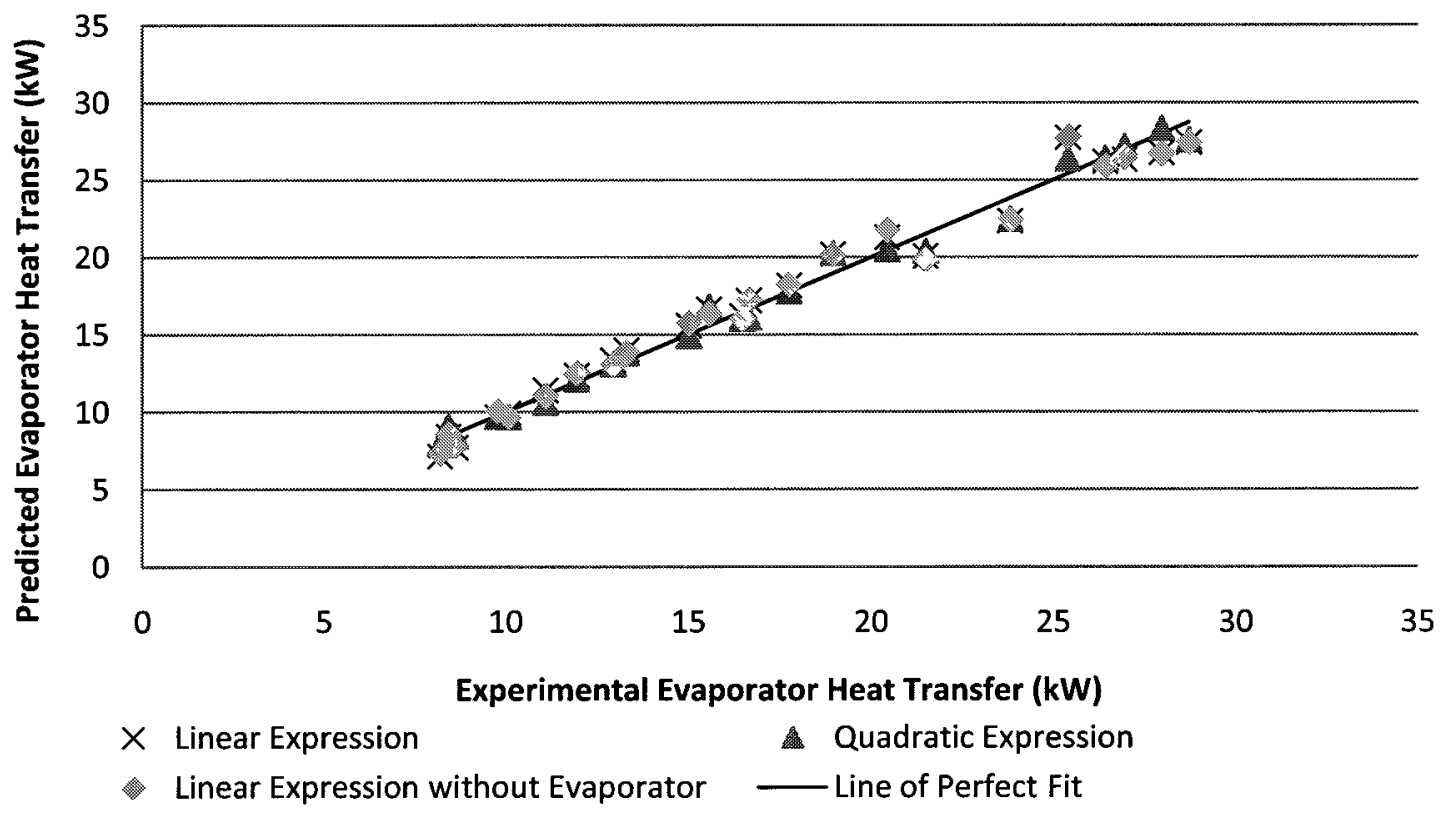

Figure 5-3: Comparison of the predicted and experimental evaporator heat transfers 
The linear expression was found to best represent the evaporator heat transfer. Table 5-3 provides the coefficients and p-values for the expression. The evaporator inlet temperature, with coefficient $a_{2}$, was found to be marginally statistically insignificant based on the p-value. The predicted values of the linear expression and the linear expression without evaporator temperature were compared, and the minimally better predictions from the full linear expression were found to be worth any additional computing power required by the extra term. The linear expression was selected for use and is described by Equation 5-6.

Table 5-3: Evaporator heat transfer linear expression coefficients

\begin{tabular}{|c|c|c|}
\hline & Regression Coefficient & $\mathrm{p}$-value \\
\hline $\mathrm{a}_{0}$ & -46.765 & $1.1449 \mathrm{E}-06$ \\
\hline $\mathrm{a}_{1}$ & 1.5296 & $1.4926 \mathrm{E}-15$ \\
\hline $\mathrm{a}_{2}$ & 0.08963 & $3.2192 \mathrm{E}-01$ \\
\hline $\mathrm{a}_{3}$ & -1.9135 & $1.0584 \mathrm{E}-10$ \\
\hline
\end{tabular}

$$
\dot{Q}_{\text {evap }}=-46.765+1.5296 * T_{\text {gen,in }}+0.08963 * T_{\text {evap, in }}-1.9135 * T_{\text {con, in }}
$$

After the heat transfer occurring at the evaporator and at the generator has been determined, an energy balance is completed on the chiller as a whole. The resulting 
condenser heat transfer, $\dot{Q}_{c o n}$, is determined using Equation 5-7, where $P_{a u x}$ is the user-specified auxiliary pump power.

$$
\dot{Q}_{c o n}=\dot{Q}_{g e n}+\dot{Q}_{e v a p}+P_{a u x}
$$

The thermal coefficient of performance is calculated using Equation 5-8.

$$
\operatorname{COP}_{t h}=\frac{\dot{Q}_{\text {evap }}}{\dot{Q}_{\text {gen }}}
$$

The matrix equation for each of the nodes is then described for the simultaneous solution of the outlet nodal temperatures of the chiller along with the remaining plant components, based on a simple nodal energy balance of the form shown in Equation 5-9.

$$
\dot{Q}=\dot{m} C_{p}\left(T_{\text {outlet }}-T_{\text {inlet }}\right)
$$

\subsection{House Models}

To accurately assess the performance of the SAC system in Ontario houses, a number of house models were utilized. Swan et al. (2009a) developed a database of representative houses across Canada, called the Canadian Stock of Single-Detached, Double, and Row Houses Database (CSDDRD). The house models include a high level of detail, including required inputs for full thermal analysis in ESP-r simulations. From this database of over 16,000 houses, four house models were 
selected for use in the present research. The criteria for the house model selection are described in Table 5-4.

Table 5-4: Criteria for house model selection

\begin{tabular}{|c|c|c|c|c|}
\hline House Name & House 1 & House 2 & House 3 & House 4 \\
\hline Vintage & 1955 & 1976 & $1976-$ LW & 2000 \\
\hline Locale & $\begin{array}{c}\text { Greater Toronto } \\
\text { Area }\end{array}$ & $\begin{array}{c}\text { Greater } \\
\text { Toronto Area }\end{array}$ & $\begin{array}{c}\text { Greater Toronto } \\
\text { Area }\end{array}$ & $\begin{array}{c}\text { Greater Toronto } \\
\text { Area }\end{array}$ \\
\hline Cooling System & Central Air & Central Air & Central Air & Central Air \\
\hline $\begin{array}{c}\text { Main Living } \\
\text { Area }\end{array}$ & $\begin{array}{c}\text { Average floor } \\
\text { area for houses } \\
\text { meeting the } \\
\text { above criteria }\end{array}$ & $\begin{array}{c}\text { Average floor } \\
\text { area for } \\
\text { houses } \\
\text { meeting the } \\
\text { above criteria }\end{array}$ & $\begin{array}{c}\text { Average floor } \\
\text { area for houses } \\
\text { meeting the } \\
\text { above criteria }\end{array}$ & $\begin{array}{c}\text { Average floor } \\
\text { area for houses } \\
\text { meeting the } \\
\text { above criteria }\end{array}$ \\
\hline $\begin{array}{c}\text { Fenestration } \\
\text { Area }\end{array}$ & $\begin{array}{c}\text { Average } \\
\text { fenestration } \\
\text { area for houses } \\
\text { meeting the } \\
\text { above criteria }\end{array}$ & $\begin{array}{c}\text { Average } \\
\text { fenestration } \\
\text { area for } \\
\text { houses } \\
\text { meeting the } \\
\text { above criteria }\end{array}$ & $\begin{array}{c}\text { Above average } \\
\text { fenestration } \\
\text { area for houses } \\
\text { meeting the } \\
\text { above criteria }\end{array}$ & $\begin{array}{c}\text { Average } \\
\text { fenestration } \\
\text { area for houses } \\
\text { meeting the } \\
\text { above criteria }\end{array}$ \\
\hline
\end{tabular}

In order to capture the diversity in building styles present across Ontario, houses across three vintage periods were selected. The Greater Toronto Area (GTA) was selected as the main region for the assessment due to the high population and high summer temperatures present in Toronto. After selecting houses that met the vintage and regional requirements, houses with central air were selected, since these are the homes that would benefit from a SAC system. Following this selection, the house with the main living floor area and window area most similar to the 
average of the remaining houses was selected for each vintage. Finally, a house meeting the previous criteria, but also possessing a significantly larger window area, was selected in order to simulate the high solar gains associated with large fenestration. The following sections describe the geometry and envelope characteristics, air flow, and internal gain strategies for each of the houses. The interested reader is directed to work by Swan (2009a, 2009b, 2010) for further information on the CSDDRD, and its modelling in ESP-r.

\subsubsection{Geometry and envelope characteristics}

The CSDDRD defines three types of thermal zones: foundation, main levels, and attic or roof spaces. A foundation generally represents a basement or a crawl space. For the present research, neither basements nor crawl spaces are regarded as part of the main living space, and are consequently unconditioned zones. The foundation level is treated through specific descriptions to the BASEIMP model in ESP-r which estimates the heat loss for each unique foundation type.

Main levels represent the primarily occupied levels in a house and receive heating and cooling. These levels can range from one to three distinct storeys above the foundation zone. The attic or roof space levels are unconditioned spaces located above the highest main level. The zoning of the house into distinct regions has important implications in the treatment of air flow between each zone and the exterior environment, as discussed in the following section. 
The geometric and envelope characteristics of each of the houses are described in Table 5-5. Sketches are provided for each house in Figure 5-4 through Figure 5-7. The 1955 and 2000 houses have two main living zones, while the 1976 and 1976-LW houses each have one.

In addition to the geometric differences between the houses, each house has a different main wall building material composition. The width of each wall layer and its corresponding insulation R-value (RSI) determines the resistance of the material to conductively transfer heat to the adjoining layer, and as a whole these characteristics determine the conductive flow of heat through the wall. The 2000 vintage house has the highest RSI value for the main walls, which would impede heat transfer from incident solar radiation through the walls, but it also results in heat being unable to exit the living space to the exterior.

The 1955, 1976, and 2000 houses have similar window areas, while the 1976-LW house has twice the fenestrated area. The 1976-LW is the only house which has low emissivity, argon gap windows, but the house also has over $15 \mathrm{~m}^{2}$ of windows with the same properties as the other houses. The resulting solar gain in the 1976-LW house was expected to be much higher, requiring a more robust cooling system. 
Table 5-5: House characteristics

\begin{tabular}{|c|c|c|c|c|c|c|c|c|}
\hline House & $\begin{array}{c}\text { Main } \\
\text { floors }\end{array}$ & $\begin{array}{c}\text { Livable } \\
\text { Floor Area } \\
\left(\mathbf{m}^{2}\right)\end{array}$ & $\begin{array}{l}\text { Window } \\
\text { Area }\left(m^{2}\right)\end{array}$ & Window Type & $\begin{array}{l}\text { Main Walls Building Materials } \\
\text { (exterior to interior) }\end{array}$ & $\begin{array}{c}\text { Main } \\
\text { walls RSI } \\
\left(\mathrm{Km}^{2} / \mathrm{W}\right)\end{array}$ & $\begin{array}{c}\text { Air } \\
\text { Changes } \\
\text { per Hour }\end{array}$ & $\begin{array}{c}\text { Appliance } \\
\text { and } \\
\text { Lighting }\end{array}$ \\
\hline 1955 & 2 & 144.75 & 21.04 & $\begin{array}{c}\text { Double glaze } \\
(3 \mathrm{~mm}) \\
13 \mathrm{~mm} \text { air gap } \\
\mathrm{U}=1.877 \\
\mathrm{~W} / \mathrm{m}^{2} \mathrm{~K} \\
\end{array}$ & $\begin{array}{c}\text { Brick (RSI 0.1) } \\
\text { Brick (RSI 0.3) } \\
\text { Expanded Polystyrene (RSI 0.7) } \\
\text { Drywall (RSI 0.1) }\end{array}$ & 1.20 & 14.05 & Low \\
\hline 1976 - LW & 1 & 128.67 & 15.90 & $\begin{array}{c}\text { Double glaze } \\
(3 \mathrm{~mm}) \\
\text { 13mm air gap } \\
\mathrm{U}=1.877 \\
\mathrm{~W} / \mathrm{m}^{2} \mathrm{~K} \\
\text { Double glaze } \\
(3 \mathrm{~mm}) \\
\text { Inside pane low- } \\
\text { Emissivity } \\
9 \mathrm{~mm} \text { argon gap } \\
\mathrm{U}=2.703 \\
\mathrm{~W} / \mathrm{m}^{2} \mathrm{~K} \\
\end{array}$ & $\begin{array}{c}\text { Vinyl (RSI 0.0) } \\
\text { Oriented Strand Board (RSI 0.1) } \\
\text { Fibreglass Batt (RSI 2.2) } \\
\text { Drywall (RSI 0.1) }\end{array}$ & 2.39 & 4.66 & Low \\
\hline 2000 & 2 & 186.49 & 21.52 & $\begin{array}{c}\text { Double glaze } \\
(3 \mathrm{~mm}) \\
13 \mathrm{~mm} \text { air gap } \\
\mathrm{U}=1.877 \\
\mathrm{~W} / \mathrm{m}^{2} \mathrm{~K}\end{array}$ & $\begin{array}{c}\text { Vinyl (RSI 0.0) } \\
\text { Oriented Strand Board (RSI 0.1) } \\
\text { Fibreglass Batt (RSI 2.9) } \\
\text { Drywall (RSI 0.1) }\end{array}$ & 3.05 & 4.95 & Medium \\
\hline
\end{tabular}




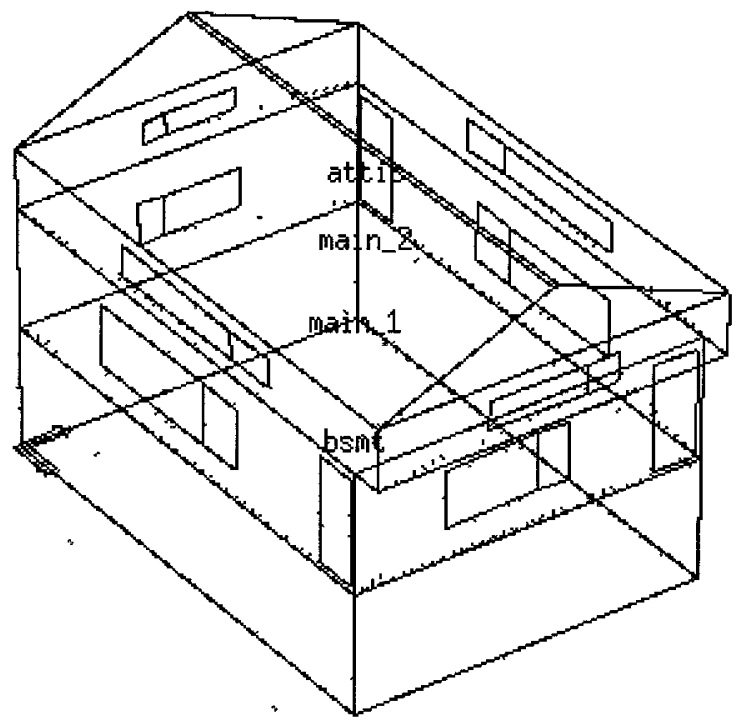

Figure 5-4: Wireframe diagram of the 1955 house

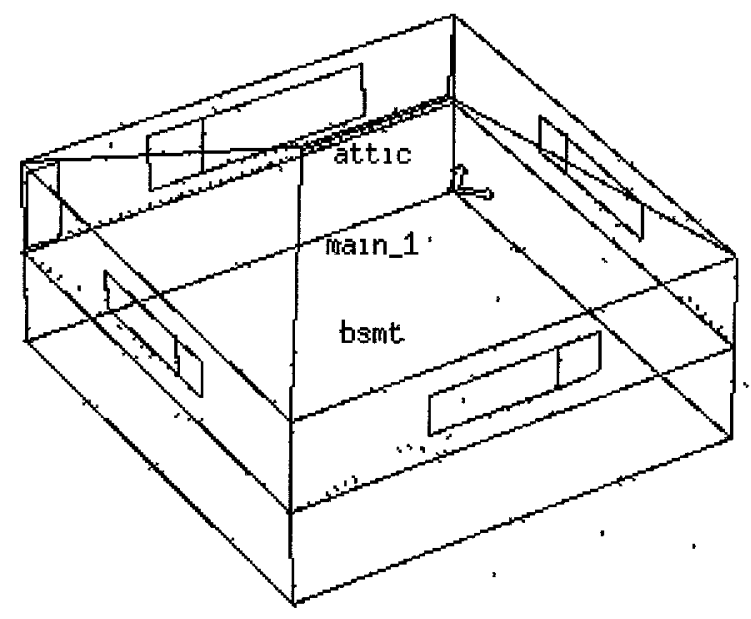

Figure 5-5: Wireframe diagram of the 1976 house 


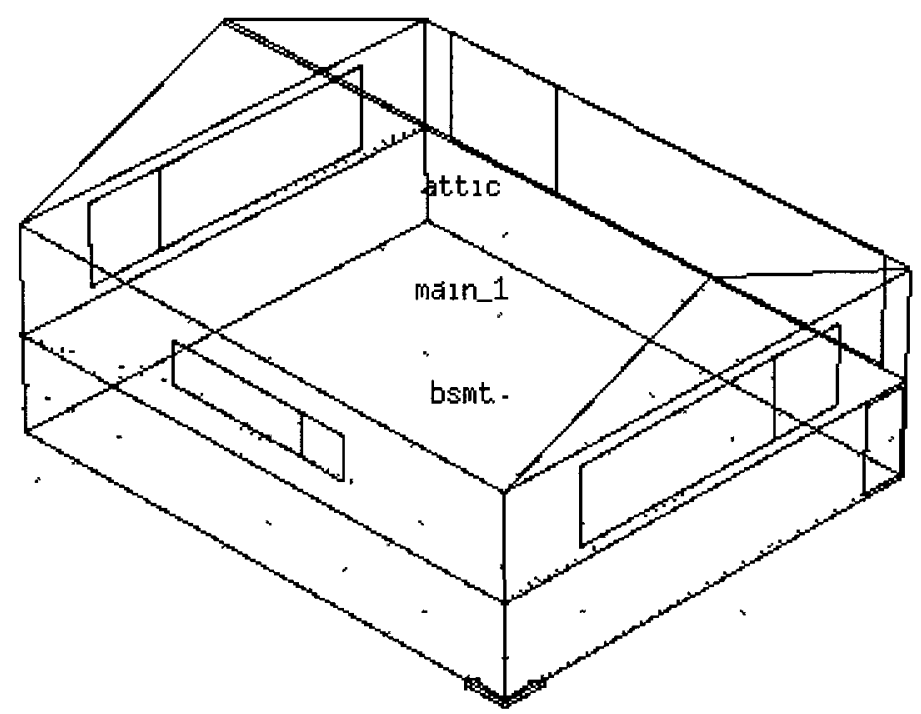

Figure 5-6: Wireframe diagram of the 1976-LW house

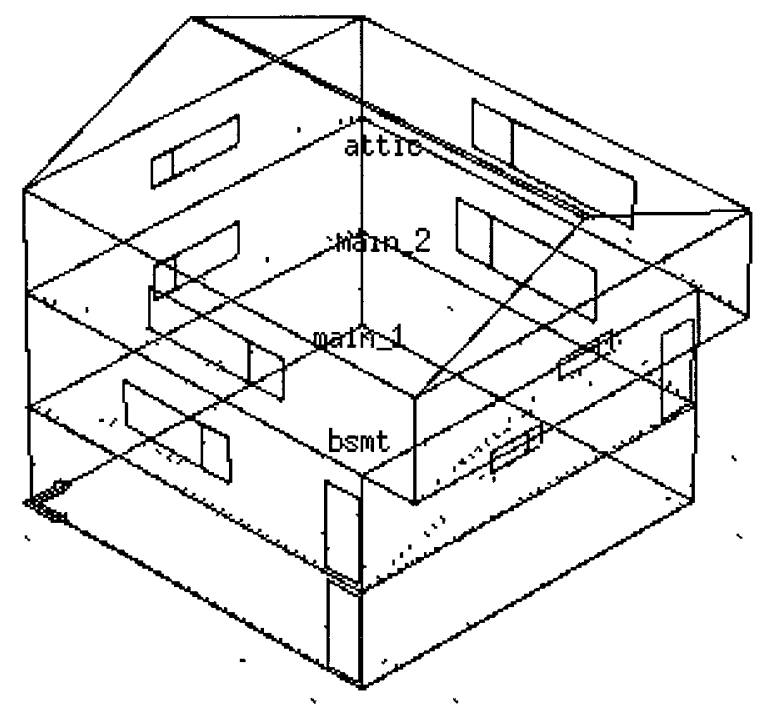

Figure 5-7: Wireframe diagram of the 2000 house 


\subsubsection{Air flow}

As described in Section 4.1, ESP-r has multiple manners of addressing air flow within a building. The CSDDRD houses utilise an air flow network for inter-zone air flow (forced and free); the AIM-2 model for natural zone-ambient air exchange through cracks and gaps; and mechanical ventilation for fan-driven zone-ambient air exchange. The air flow network is also used for large zone-ambient air flows through windows or large gaps such as attics (Swan L. G., 2010). Cooling was injected solely into the main zone of each house, with the cooling of additional zones being accomplished through inter-zone air flow. The air flow rates between main living zones were varied in the 1955 and 2000 houses to determine the optimal setting to model centrally-dịstributed cooling.

\subsubsection{Internal gains}

The internal gains present in a house affect the cooling load due to the addition of heat to the living spaces. The CSDDRD houses include appliance and lighting energy consumption (AL), the bulk of which results in heat addition to the zones (Swan et al., 2009a). Swan et. al. (2009b) used 5 minute time step load profiles from the International Energy Agency's Energy Conservation in Building and Community Systems Program (IEA, 2010), to create hourly integrated profiles. Three profiles of $\mathrm{AL}$ consumption were produced to reflect different $\mathrm{AL}$ usage rates: low (12.2 GJ/year), medium (21.8 GJ/year), and high (35.7 GJ/year). Each house has a specified AL distribution, including a multiplier to match the occupant usage for 
each house. The 1955 and 1976-LW house had low AL profiles, while the 2000 and 1976 houses had medium and high profiles, respectively.

The AL energy resultant from the clothes dryer is assumed to be exhausted to the exterior, while energy addition from all other AL sources is assumed to become a mix of $50 \%$ convective and $50 \%$ radiative sensible load to the zones. The domestic hot water (DHW) volume draw is not treated as an internal gain in the CSDDRD models (Swan, 2010).

\subsection{Climatic information}

The base case for the assessment of the SAC system was the Canadian Weather for Energy Calculations (CWEC) Toronto (Numerical Logics, 1999) weather file. CWEC files are derived from hourly weather information for Canada from 1953 to 1995 and are representative of conditions which would result in approximately average cooling loads in buildings, based on statistically comparing various climatic conditions (Environment Canada, 2011). CWEC weather files for Windsor and Ottawa were also used in the research. Finally, to further investigate the suitability of the system across multiple years, Canadian Weather Energy and Engineering Datasets (CWEEDS) were employed for Toronto from 1999 to 2008. CWEEDS datasets provide 21 weather elements at specific locations on an hourly basis.

\subsection{System Configuration}

The simulation of the house models in ESP-r was undertaken first with the base sizing determined in TRNSYS, as described in Chapter 3. As described in 
Section 5.1.2, the ESP-r system used experimentally-derived parametric equations for the generator and evaporator heat transfers, while the TRNSYS model assumed a constant COPth of 0.6. Additionally, the static cooling loads used in TRNSYS did not take into consideration the effect unmet cooling loads at a given time step would have on the subsequent time step. The chiller inlet flow rates were much higher in TRNSYS due to correspondence to Yazaki specifications, while in ESP-r these values were based on the experimental flow rates. These variations meant that the sizing completed in TRNSYS provided a good starting point for the system modelling in ESP-r, but the system had to be further refined to find appropriate sizing in ESP-r. Once implemented in ESP-r, the system was altered to simulate a variety of tank sizes, solar collector areas, and inter-zone flow rates to determine the most favourable model setup for the performance of the system in ESP-r.

Each of the parameters described in Section 3.4, as well as the tilt angle of the solar collector, were varied at small increments in ESP-r to find the most favourable conditions. The performance of the system was based on the variable $\mathcal{N}(\%)$, described by Equation 5-10, where $n$ is the number of conditioned zones. The setpoint of the system was $24+/-0.5^{\circ} \mathrm{C}$. The two minute time step used resulted in minor increases above $24.5^{\circ} \mathrm{C}$ in a single time step before the chiller system would actuate. In order to only count time steps when the SAC was unable to meet cooling demands, zone temperatures above $25.0^{\circ} \mathrm{C}$ were considered to be above the setpoint. 


$$
\mathcal{N}=\frac{\sum_{i=1}^{n} \text { Number of timesteps zone temperature above } 25.0^{\circ} \mathrm{C}}{\text { Number of timesteps } * n} * 100
$$

The desired performance of the best system was a value of $\mathcal{N}$ below $5 \%$, while maintaining practical sizing of components. Five percent of time steps results in approximately 150 hours of the summer with unmet cooling setpoints, and was selected as an appropriate target for assessing feasibility of the system. The sizing was completed using the 2000 vintage house model described in the previous section, which was also used for cooling load determination in the TRNSYS simulations described in Chapter 3. The Toronto CWEC weather file was used for the weather information.

To begin, the tilt angle of the solar collector was varied from 0 to $90^{\circ}$ from the horizontal. The resulting value of $\mathcal{N}$, is shown by month in Figure 5-8. It was observed that a tilt angle above $50^{\circ}$ from the horizontal produced very poor system performance, and therefore these results have not been included in the figure. A dashed line is provided to show the desired performance characteristic of the system (setpoint maintained $95 \%$ of the time steps). The system was able to meet the cooling load in July marginally more frequently with a solar collector tilt angle of $10^{\circ}$, but a tilt angle of $20^{\circ}$ performed significantly better in August. 


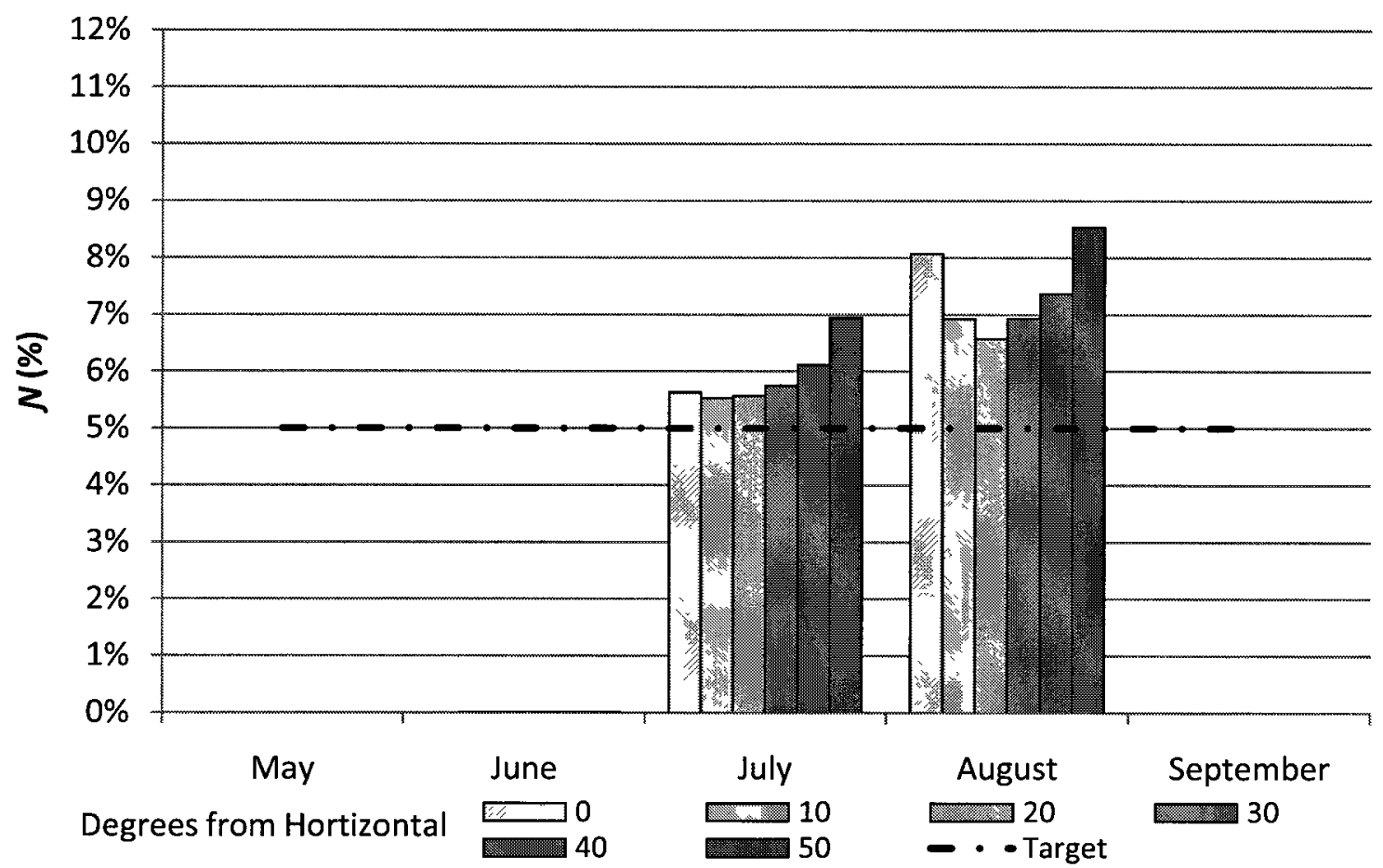

Figure 5-8: Percentage of unmet cooling loads by month for different solar collector tilt angles

Figure 5-9 shows the solar collector efficiency for each collector tilt angle, where the efficiency is calculated using Equation 4-11. The efficiencies of the collectors with tilt angles between 0 and $50^{\circ}$ from the horizontal were found to be similar, with minor deviations across each month. A tilt angle of $20^{\circ}$ from the horizontal was selected due to its higher performance in maintaining the desired setpoint. 


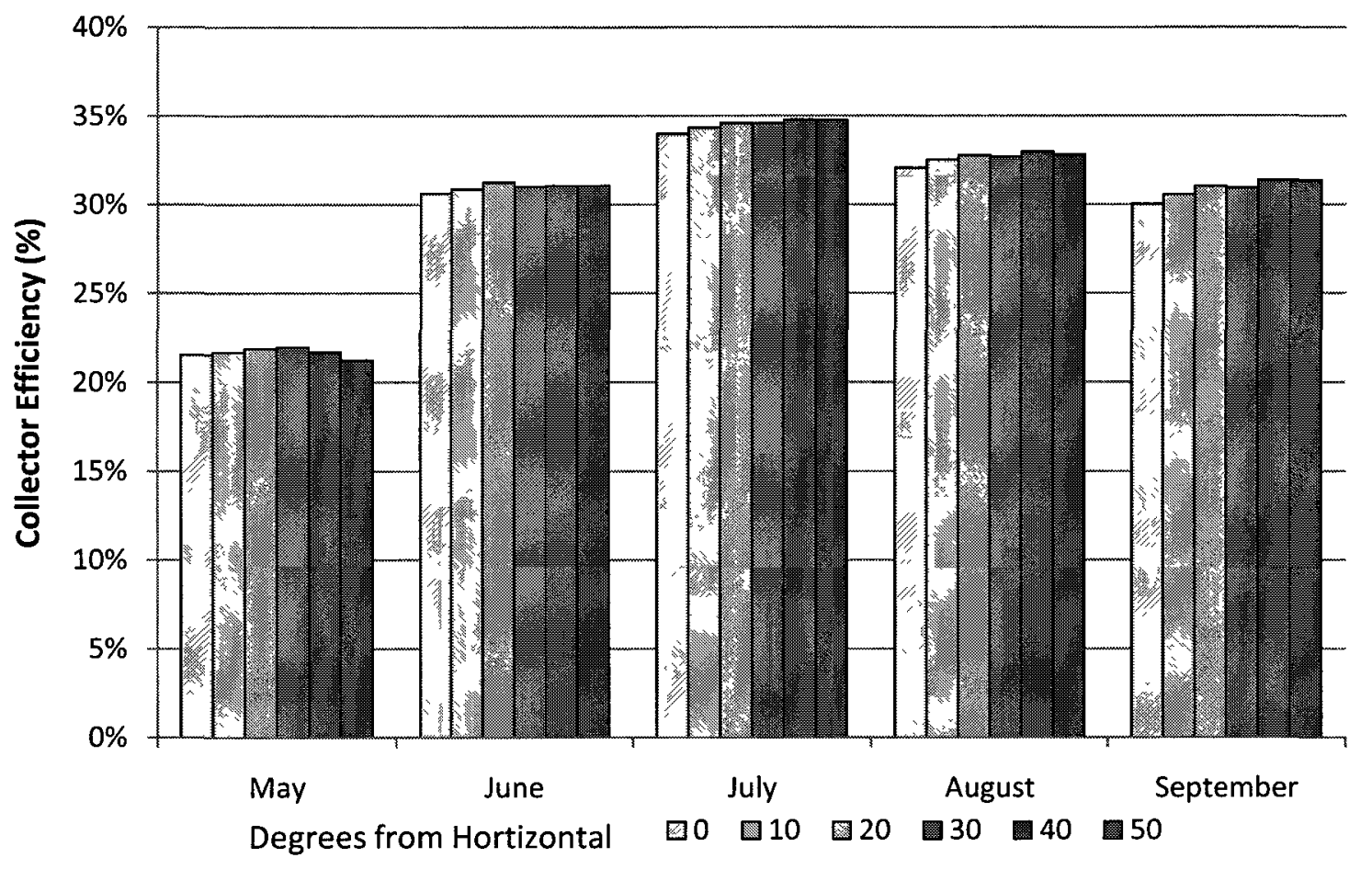

Figure 5-9: Monthly solar collector efficiency for different tilt angles

With the selected tilt angle of the solar collector, the size of the solar collectors and water tanks were varied to determine the optimal configuration. The hot storage tank size was found to increase the performance of the system with increased size, but this performance increase stagnated at $0.5 \mathrm{~m}^{3}$. The high flow rate requirement of the absorption chiller hot medium flow results in the majority of the usable solar energy being directed immediately to the chiller. This direct transfer of energy results in a minimal availability of solar energy for storage on days with high chiller activation. A hot storage tank volume of $0.5 \mathrm{~m}^{3}$ was found to provide an appropriate level of thermal storage.

The performance of the system was found to be very sensitive to the volume of the cold tank and solar collector area. The $\mathcal{N}$ term is displayed for various tank and 
collector configurations in Figure 5-10. Increases in the cold storage tank size and the solar collector size were both found to increase the performance of the system, with a diminishing gain for each consecutive increase of either component. A solar collector area of at least $30 \mathrm{~m}^{2}$ was required for a value of $\mathcal{N}$ of $5 \%$. However, even the smallest cold storage tank size, $0.75 \mathrm{~m}^{3}$, was able to meet the setpoint $95 \%$ of the time with a large enough solar collector area.

The maximum air temperature of the main living zone is shown for a variety of solar collector areas and tank sizes in Figure 5-11. Increasing the size of the solar collector and the cold tank decreased the maximum zone temperature, but all configurations had a maximum zone temperature above $26^{\circ} \mathrm{C}$.

Due to the considerable increase in performance with a larger solar collector, a final collector area of $50 \mathrm{~m}^{2}$ was utilized in the remainder of the study. Figure 5-12 shows the monthly performance of the system with a $50 \mathrm{~m}^{2}$ solar collector and a variety of tank sizes. None of the cold tank sizes were able to meet the cooling loads in August, but tank volumes of $1.5 \mathrm{~m}^{3}$ and greater were able to meet at least $95 \%$ of the cooling loads in all other months. A cold tank size of $1.5 \mathrm{~m}^{3}$ was selected as the final size for the SAC system. 


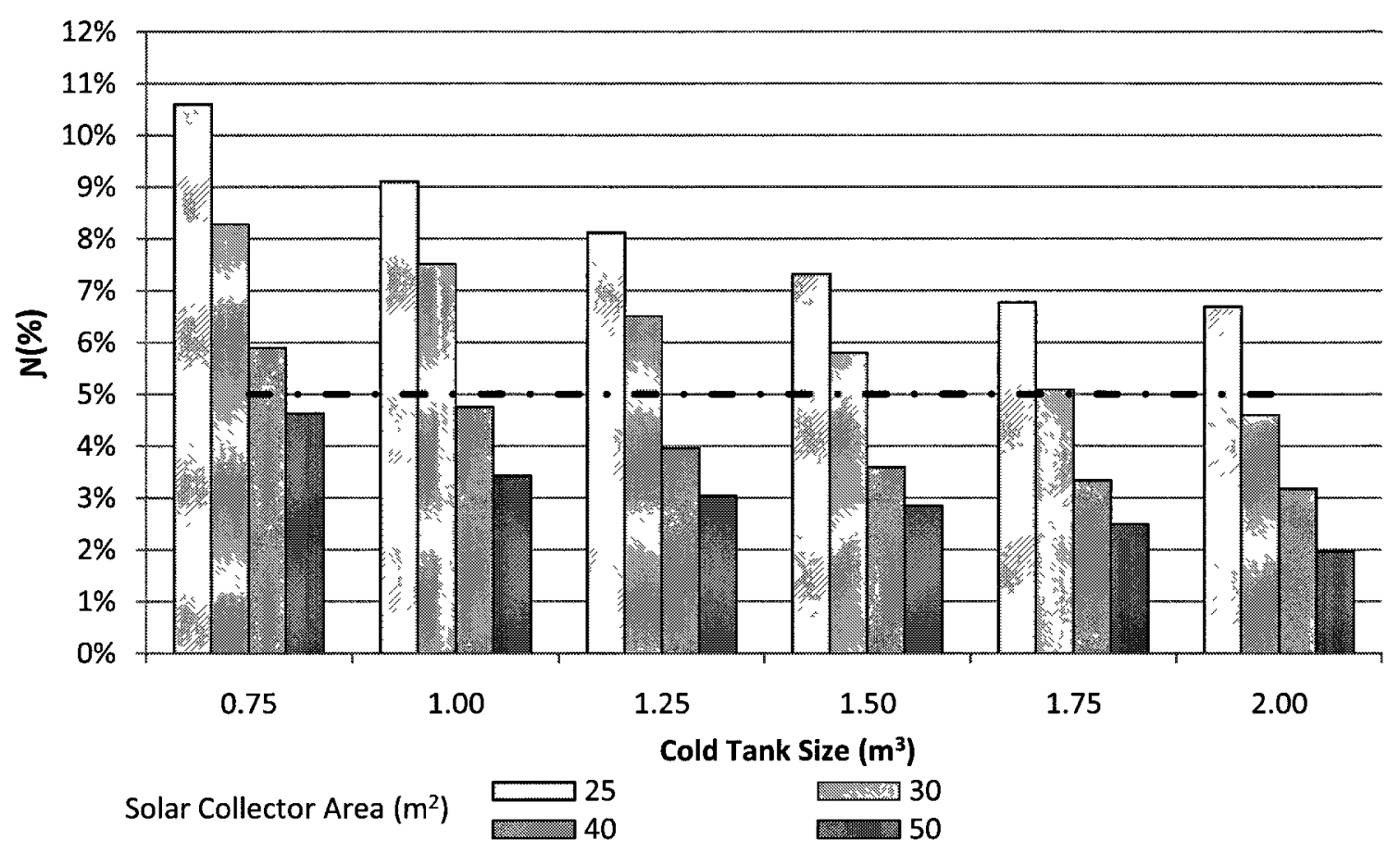

Figure 5-10: Percentage of cooling loads unmet with various cold tank and solar collector sizes

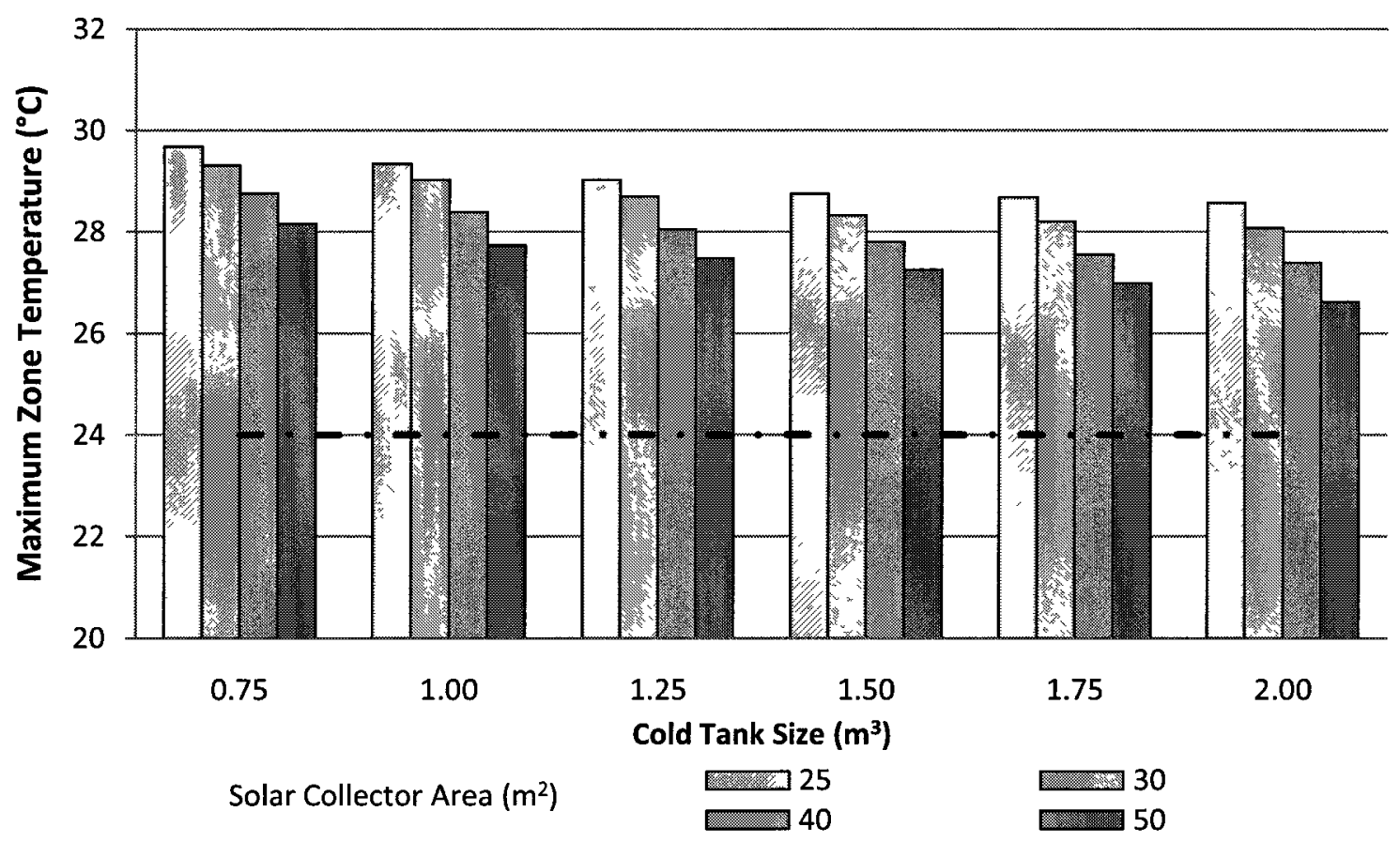

Figure 5-11: Maximum main living zone temperature for various solar collector and cold tank sizes 


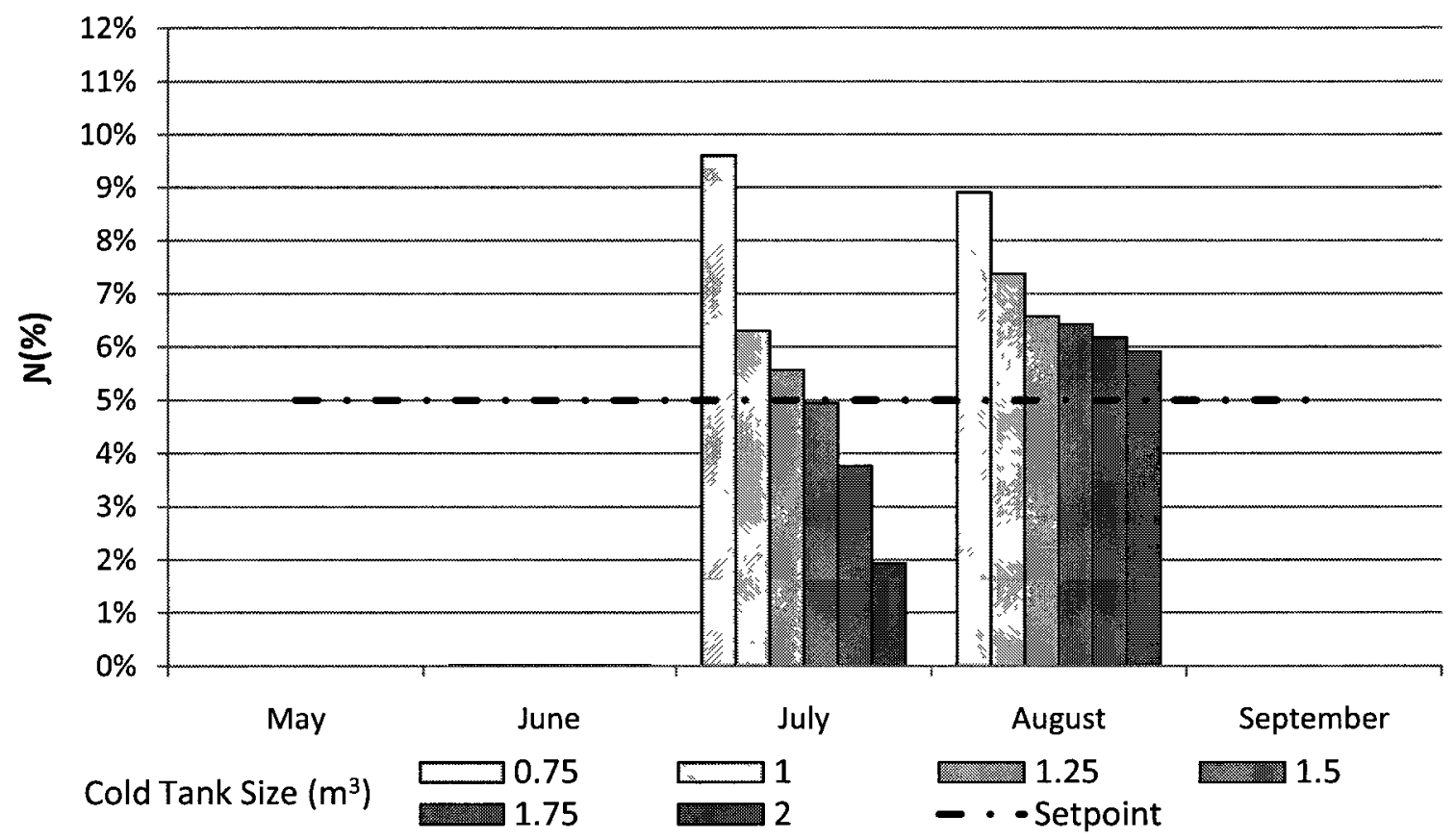

Figure 5-12: Percentage of monthly unmet cooling loads for various cold tank sizes with a solar collector area of $50 \mathrm{~m}^{2}$

The final sizing of the tanks and solar collector are summarized in Table 5-6. With the varying $\mathrm{COP}$ and cumulative heating effect of the final model, a larger solar collector and cold storage tank were needed to meet the cooling demands of the house than initially determined in the TRNSYS simulations. With the final sizing of the system components completed, the system was implemented in multiple house models with different configurations, as described in the following section.

Table 5-6: Tank and solar collector sizing

\begin{tabular}{|c|c|c|}
\hline Variable & Preliminary Sizing & Final Sizing \\
\hline Solar Collector Area & $40 \mathrm{~m}^{2}$ & $50 \mathrm{~m}^{2}$ \\
\hline Hot Storage Tank Volume & $1.0 \mathrm{~m}^{3}$ & $0.5 \mathrm{~m}^{3}$ \\
\hline Cold Storage Tank Volume & $1.25 \mathrm{~m}^{3}$ & $1.5 \mathrm{~m}^{3}$ \\
\hline
\end{tabular}




\subsection{Simulation Strategy}

The performance of the SAC system was simulated with the 2000 house and the Toronto CWEC weather file as the system base case. The 2000 house was selected as the base model because of the potential for the residential application of SAC in the future, particularly in newer housing developments. The modelling was accomplished at a two-minute time step in order to suit the small time constant of the solar collector and to obtain accurate representations of the plant system response. Once the base case simulations were completed, the performance of the SAC was simulated with a variety of changes to test the robustness of the system. The simulation cases examined can be seen in Table 5-7.

To begin, simulations were completed with the four different house models described in Section 5.2. These simulations were completed to represent the breadth of current housing design in Ontario. Next, the system was simulated with the base house in different regions, namely Windsor, Ontario, and Ottawa, Ontario. Windsor consistently has one of the highest summer temperatures in Canada, high humidity, and also has considerably high night-time temperatures. Ottawa is also a high temperature city in Ontario (Environment Canada, 2010b), and provided an additional test climate. It was assumed that the design of the GTA houses was representative of urban Ontario houses and that they were appropriate for testing in the Windsor and Ottawa municipalities. 
Table 5-7: Simulation cases

\begin{tabular}{|c|c|c|c|c|}
\hline Run \# & House & Climate & $\begin{array}{c}\text { Cooling } \\
\text { Set-point }\left({ }^{\circ} \mathrm{C}\right) \\
(+/-0.5)\end{array}$ & $\begin{array}{c}\text { Min. } \\
\text { Generator } \\
\text { Temp. }\left({ }^{\circ} \mathrm{C}\right)\end{array}$ \\
\hline 1 & 2000 & Toronto CWEC & 24 & 73.6 \\
\hline 2 & 1955 & Toronto CWEC & 24 & 73.6 \\
\hline 3 & 1976 & Toronto CWEC & 24 & 73.6 \\
\hline 4 & 1976 - LW & Toronto CWEC & 24 & 73.6 \\
\hline 5 & 2000 & Windsor CWEC & 24 & 73.6 \\
\hline 6 & 2000 & Ottawa CWEC & 24 & 73.6 \\
\hline 7 & 2000 & Toronto 1999 & 24 & 73.6 \\
\hline 8 & 2000 & Toronto 2000 & 24 & 73.6 \\
\hline 9 & 2000 & Toronto 2001 & 24 & 73.6 \\
\hline 10 & 2000 & Toronto 2002 & 24 & 73.6 \\
\hline 11 & 2000 & Toronto 2003 & 24 & 73.6 \\
\hline 12 & 2000 & Toronto 2004 & 24 & 73.6 \\
\hline 13 & 2000 & Toronto 2005 & 24 & 73.6 \\
\hline 14 & 2000 & Toronto 2006 & 24 & 73.6 \\
\hline 15 & 2000 & Toronto 2007 & 24 & 73.6 \\
\hline 16 & 2000 & Toronto 2008 & 24 & 73.6 \\
\hline 17 & 2000 & Toronto CWEC & 23 & 73.6 \\
\hline 18 & 2000 & Toronto CWEC & Varying $24 / 26$ & 73.6 \\
\hline 19 & 2000 & Toronto CWEC & 24 & 70.0 \\
\hline 20 & 2000 & Toronto CWEC & 24 & 75.0 \\
\hline 21 & 2000 & Toronto CWEC & 24 & 80.0 \\
\hline
\end{tabular}


The 2000 house model was also simulated with the Toronto Pearson International Airport CWEEDS data from 1999 to 2008 in order to assess the ability of the system to meet cooling loads across the temporal variance of an individual city.

The performance of the system was assessed with a lower cooling setpoint $\left(23^{\circ} \mathrm{C}\right)$, and a varying system with a day-time setpoint of $24^{\circ} \mathrm{C}$ and a night-time setpoint of $26^{\circ} \mathrm{C}$. Different setpoints were investigated in order to determine the ability of the system to meet different occupant comfort preferences. All setpoints included a one degree deadband.

The minimum generator inlet temperature for activation of the chiller based on Yazaki specifications (Aroace, 2010) is $70^{\circ} \mathrm{C}$. Johnson (2011) showed that higher inlet temperatures result in a higher COP, however reaching a higher temperature can be difficult on days with lower available solar radiation. In order to assess the impact of the generator inlet temperature, the SAC system was simulated with four different minimum temperatures: $70^{\circ} \mathrm{C}, 73.6^{\circ} \mathrm{C}, 75^{\circ} \mathrm{C}$, and $80^{\circ} \mathrm{C}$. The base case for all other simulations was $73.6^{\circ} \mathrm{C}$, as it was the lowest inlet temperature tested by Johnson (2011).

Occupant behaviour such as the operation of blinds and windows was not included in the present research. The potential for the inclusion of occupant behaviour is described in Chapter 8.

For each variation, the performance of the system was determined in terms of the ability of the system to maintain the cooling setpoint during the time period from 
May $15^{\text {th }}$ through September $15^{\text {th }}$. The results of these assessments are found in Chapter 6. Following the simulations, an analysis of greenhouse gas emissions was completed in comparison to typical vapour compression systems and is presented in Chapter 7. 


\section{Chapter 6}

\subsection{Results and Analysis}

In order to determine the suitability of solar absorption cooling to Ontario households, the SAC system was modelled with a variety of constraints and environmental conditions. The baseline case observed was the 2000 vintage house with the Toronto CWEC weather data, from May $15^{\text {th }}$ to September $15^{\text {th }}$. The results of the building performance simulations undertaken are described in the following sections. For houses with two conditioned zones, $\mathcal{N}$ denotes the average percentage of time steps that the cooling setpoint was unmet in each zone, though the inter-zone air flow was such that the two zones had nearly identical temperatures. All results are plotted against standard time. Full results are provided in Appendix D.

To begin, the performance of the system in relation to a house without cooling is investigated in Section 6.1. The overall performance of the base case is provided in Section 6.2. The significance of building geometry and construction is then assessed in Section 6.3 through the comparison of the four different house models. The effect of climate on the system performance is then explored in Section 6.4 through simulations in different climates and across multiple years. Finally, Section 6.5 describes the impact of different control strategies. 


\subsection{Comparison to Free Floating Conditions}

In order to assess the performance of the SAC system, the system was first compared to a free floating (no cooling system) house model. The 2000 vintage house was simulated with the Toronto CWEC weather data, with and without the SAC system. The daily maximum temperature in the main living zone, referred to as Zone 1, for July and August is plotted for both the free floating and conditioned states in Figure 6-1. The cooling setpoint $\left(24^{\circ} \mathrm{C}\right)$ of the conditioned house is shown by a dashed line.

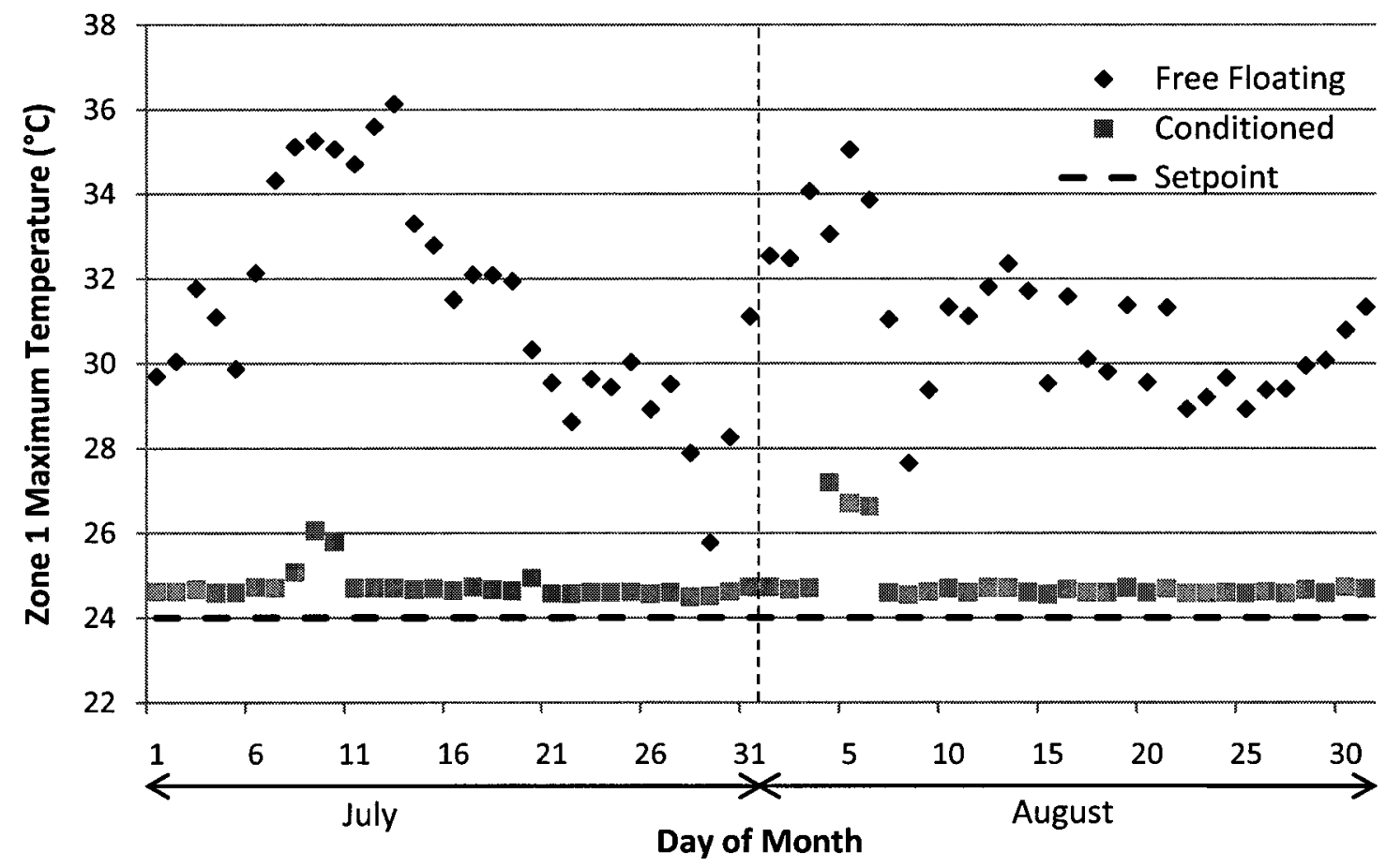

Figure 6-1: Maximum daily temperature in Zone 1 for July and August

As expected, the free-floating house has much higher peak temperatures than the conditioned house. The maximum temperature reached in the free floating case is $36.1^{\circ} \mathrm{C}$, whilst the maximum temperature in the conditioned case is $27.2^{\circ} \mathrm{C}$. The 
maximum daily temperature for both the free-floating and conditioned cases are above the setpoint of $24+/-0.5^{\circ} \mathrm{C}$.

The average daily temperature in Zone 1 is shown in Figure 6-2 for July and August. The average daily temperature of the conditioned house is centrered around the setpoint of $24^{\circ} \mathrm{C}$, as expected, with deviations up to a maximum of $25.9^{\circ} \mathrm{C}$. The free floating house is seen to vary significantly due to shifts in climatic conditions, with a maximum average temperature of $33.6^{\circ} \mathrm{C}$ and an average temperature of $28^{\circ} \mathrm{C}$ or higher more than $50 \%$ of the time.

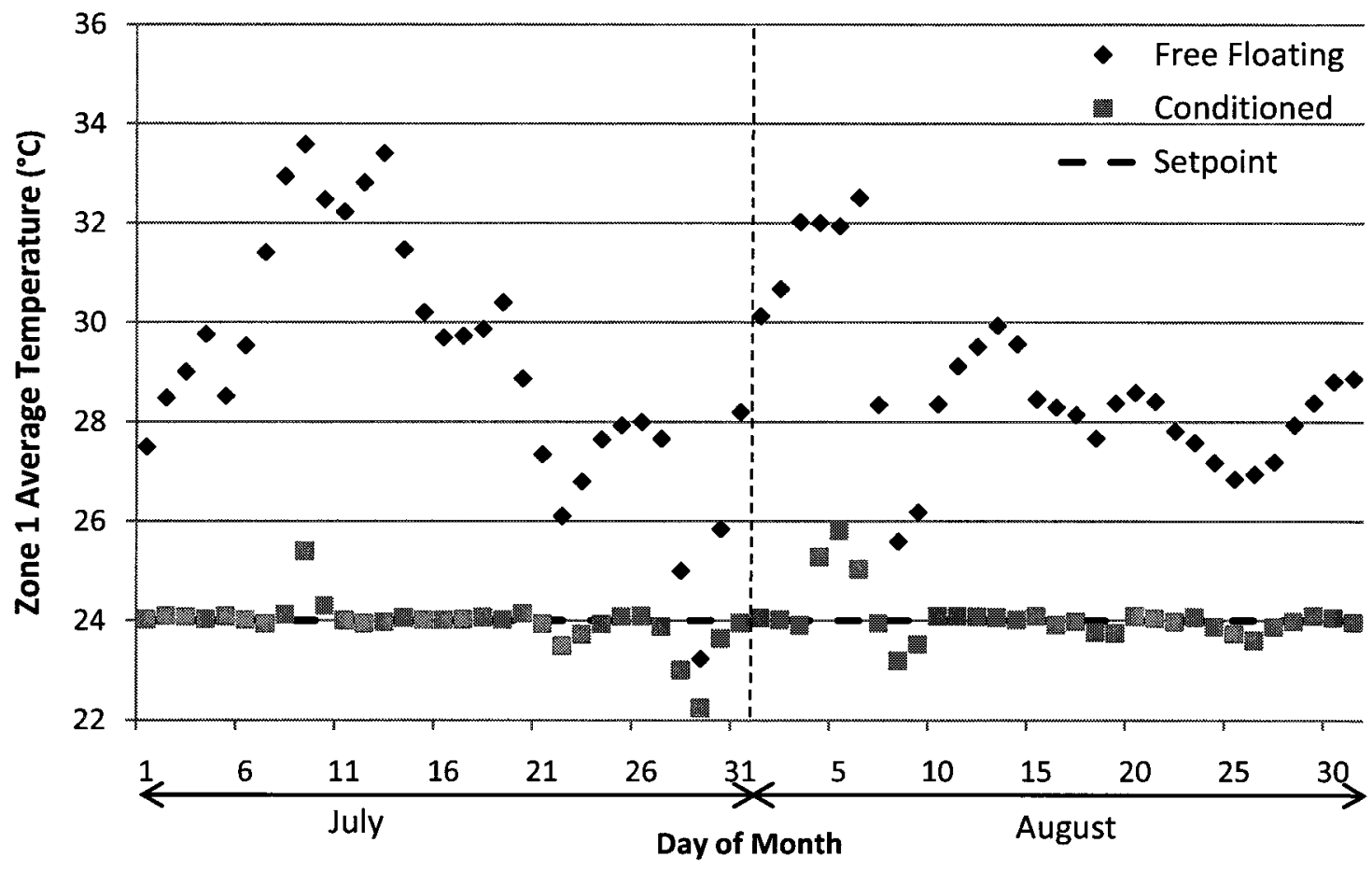

Figure 6-2: Average daily temperature in Zone 1 for July and August

The free floating case demonstrates the need for space-cooling in order to meet the desired comfort conditions. While the base case still experiences maximum zone 
temperatures $4^{\circ} \mathrm{C}$ above the setpoint, it is still able to maintain a comfortable average temperature. The general performance of the SAC system will be assessed in the next section.

\subsection{System Performance}

The SAC system was modelled in the 2000 vintage house with the Toronto CWEC climate from May $15^{\text {th }}-$ September $15^{\text {th }}$ to act as the reference system for future comparisons. The summary of the system's performance is presented in Table 6-1. The system was able to meet the $24+/-0.5^{\circ} \mathrm{C}$ cooling setpoint $97.5 \%$ of the time, with a peak zone temperature of $27.2^{\circ} \mathrm{C}$.

Table 6-1: Summary of performance characteristics

\begin{tabular}{|c|c|c|c|c|c|}
\hline Climate & $\begin{array}{c}\text { Average } \\
\text { Ambient } \\
\text { Temp. }\left({ }^{\circ} \mathrm{C}\right)\end{array}$ & $\begin{array}{c}\text { Number of } \\
\text { hours } \\
\text { ambient } \\
\text { Temp. } \\
\text { above } 30^{\circ} \mathrm{C}\end{array}$ & $\mathcal{N}(\%)$ & $\begin{array}{c}\text { Max. } \\
\text { Zone } \\
\text { Temp. } \\
\left.\mathbf{(}^{\circ} \mathrm{C}\right)\end{array}$ & $\begin{array}{c}\text { Avg. Zone } \\
\text { Temp. }\left({ }^{\circ} \mathrm{C}\right)\end{array}$ \\
\hline Toronto CWEC & 18.3 & 31 & 2.5 & 27.2 & 23.4 \\
\hline
\end{tabular}

The temperature trends for the hot and cold tanks on a typical day (July $4^{\text {th }}$ ) are shown in Figure 6-3. The blocks correspond to the time steps where the chiller is activated. Figure 6-4 shows the zone temperature, ambient temperature, and available solar radiation on the same day. The morning hours serve as a time to 


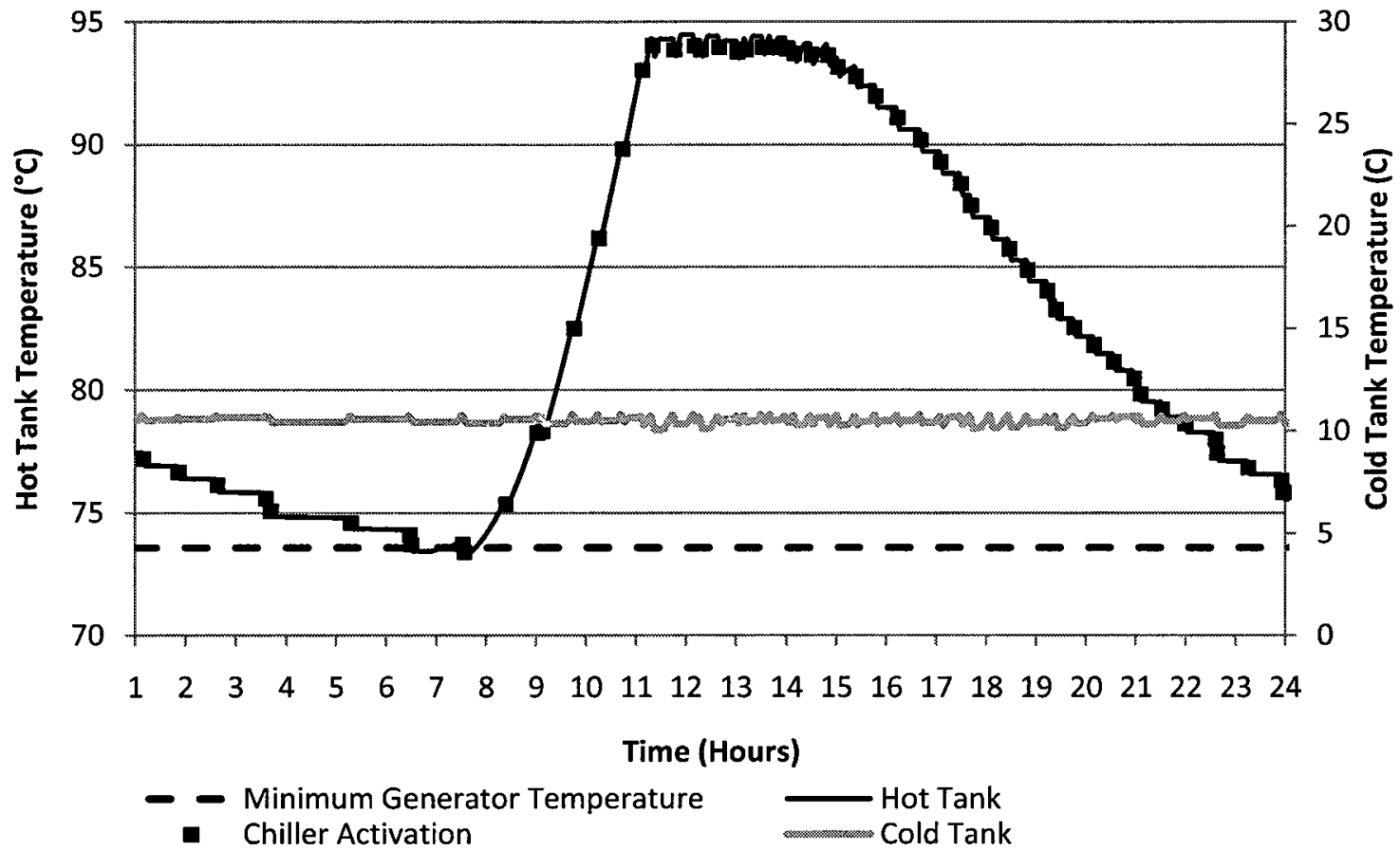

Figure 6-3: Tank temperatures and chiller activation on July $4^{\text {th }}$

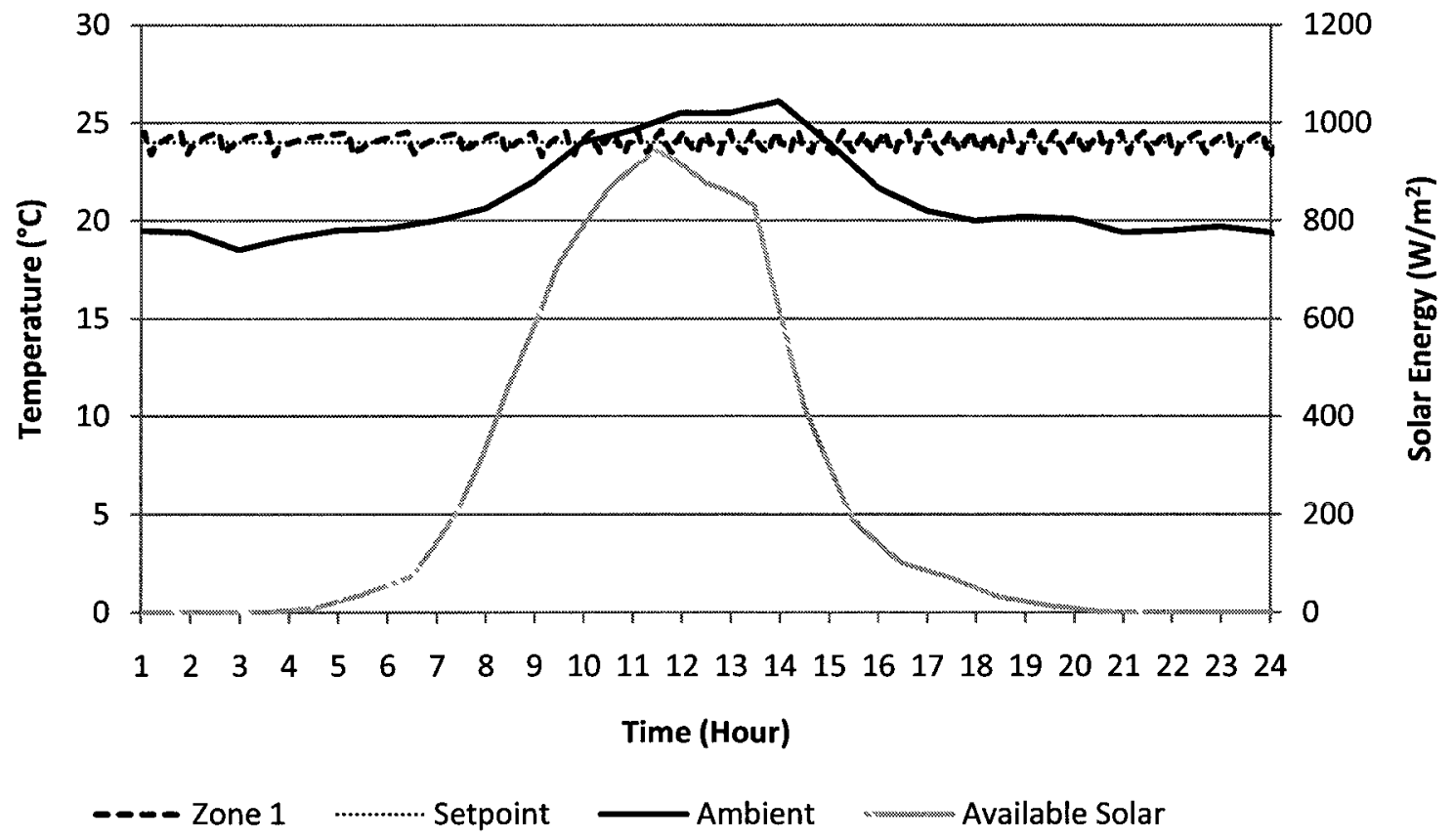

Figure 6-4: Zone and ambient temperatures on July $4^{\text {th }}$ 
charge the hot tank to the maximum generator operating temperature. The chiller activates throughout the day, with more frequent activations in the afternoon and evening hours. The zone temperature fluctuates between $23.5^{\circ} \mathrm{C}$ and $24.5^{\circ} \mathrm{C}$, corresponding to the cooling deadband.

Similar plots are shown for the day with the peak zone temperature, August $4^{\text {th }}$, in Figure 6-5 through Figure 6-7. For ease of viewing the fluctuation of the hot tank temperature, it has been plotted with an amplified temperature axis in Figure 6-6. Immediately it can be seen that the cold tank begins the day at a much higher temperature than on July $4^{\text {th }}$. The ambient temperature on August $4^{\text {th }}$ was in a similar range as that of July $4^{\text {th }}$, but the solar radiation was significantly lower.

This low radiation resulted in the hot storage tank being unable to maintain the minimum generator inlet temperature. Once the tank reached the minimum generator inlet temperature, the chiller immediately activated, drawing the hot storage tank temperature down and consequently cycling the chiller off. The hot storage tank then recharged until the setpoint and again the chiller activated immediately. The low solar radiation meant that by 3:00 pm the hot tank could no longer be charged and the chiller remained inactive. This inactivity resulted in a steadily increasing cold tank temperature, and consequentially a steadily increasing zone temperature. Zone 1 reached a peak temperature of $27.2^{\circ} \mathrm{C}$ in the late evening. 


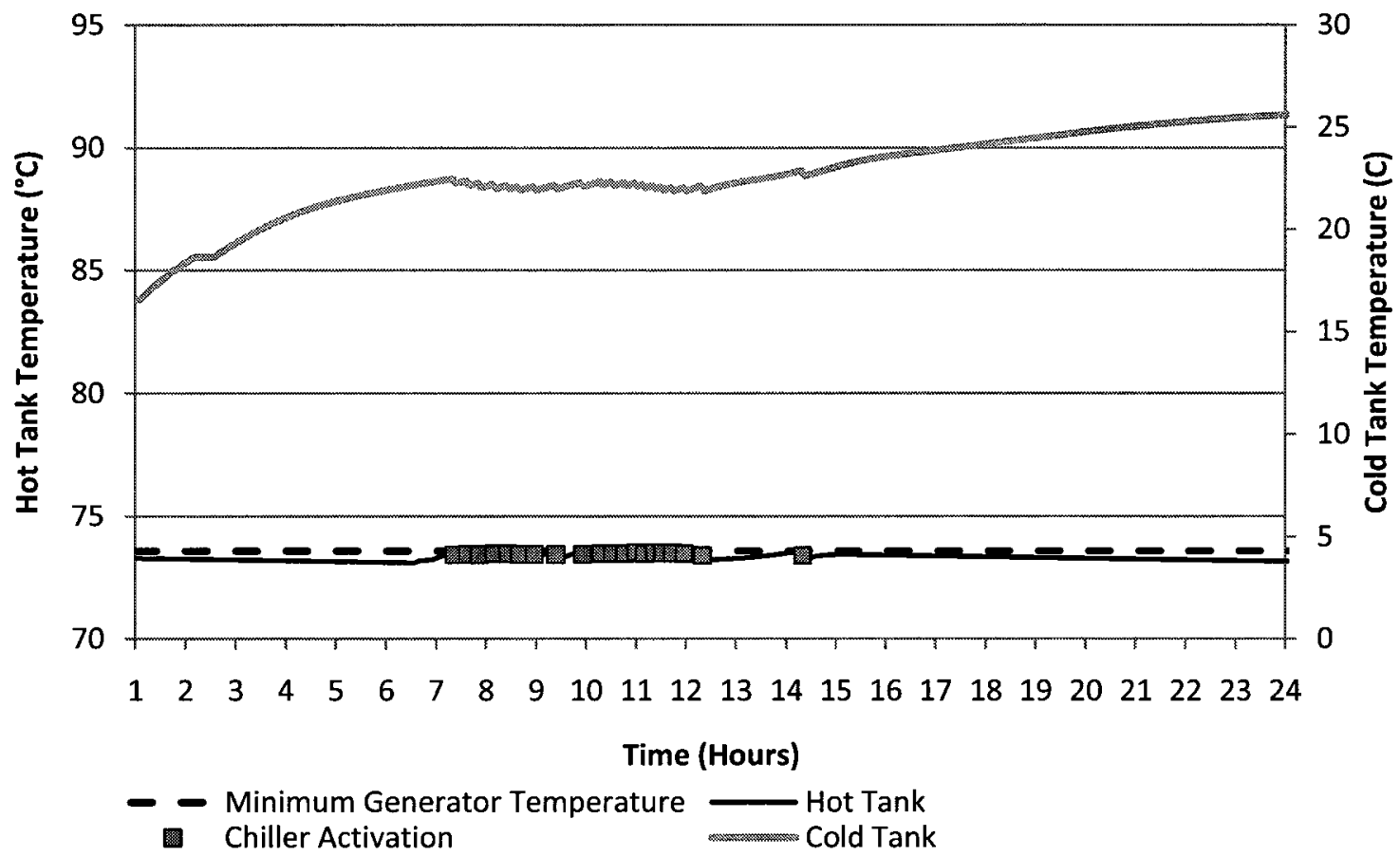

Figure 6-5: Tank temperatures and chiller activation on August $4^{\text {th }}$

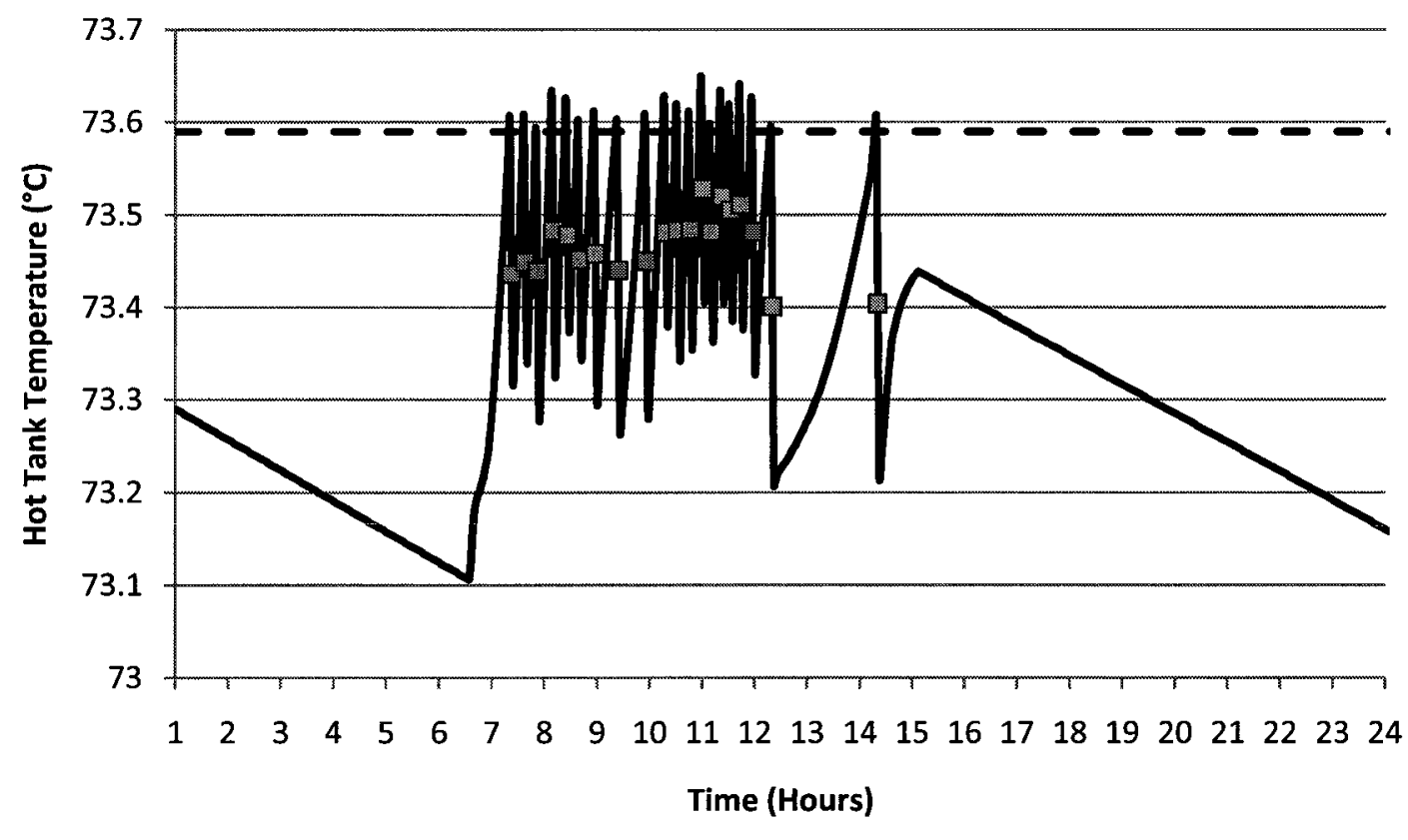

- Minimum Generator Temperature Hot Tank Chiller Activation

Figure 6-6: Hot tank temperature variation on August $4^{\text {th }}$ 


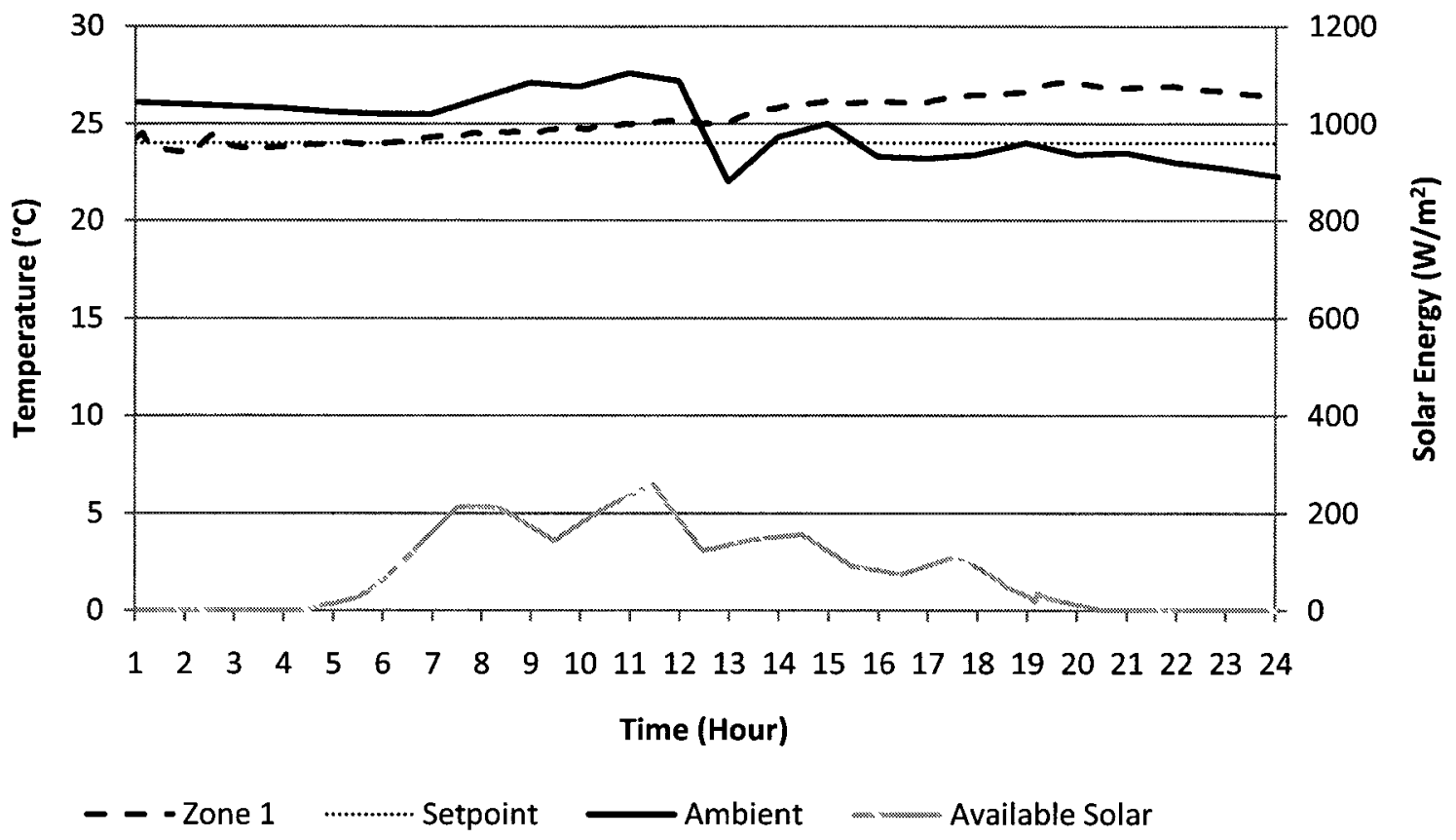

Figure 6-7: Zone and ambient temperatures on August $4^{\text {th }}$

Plots of the hot tank, cold tank, and zone temperatures on a cool and sunny day, May $17^{\text {th }}$, are shown in Figure 6-8 and Figure 6-9. The ambient temperature throughout the day is below the setpoint, resulting in cooler zone temperatures in the morning, and steadily charged hot and cold tanks. The zone temperature increases steadily with the increase of solar radiation, causing two evening chiller activations to bring the cold tank back down to the setpoint. 


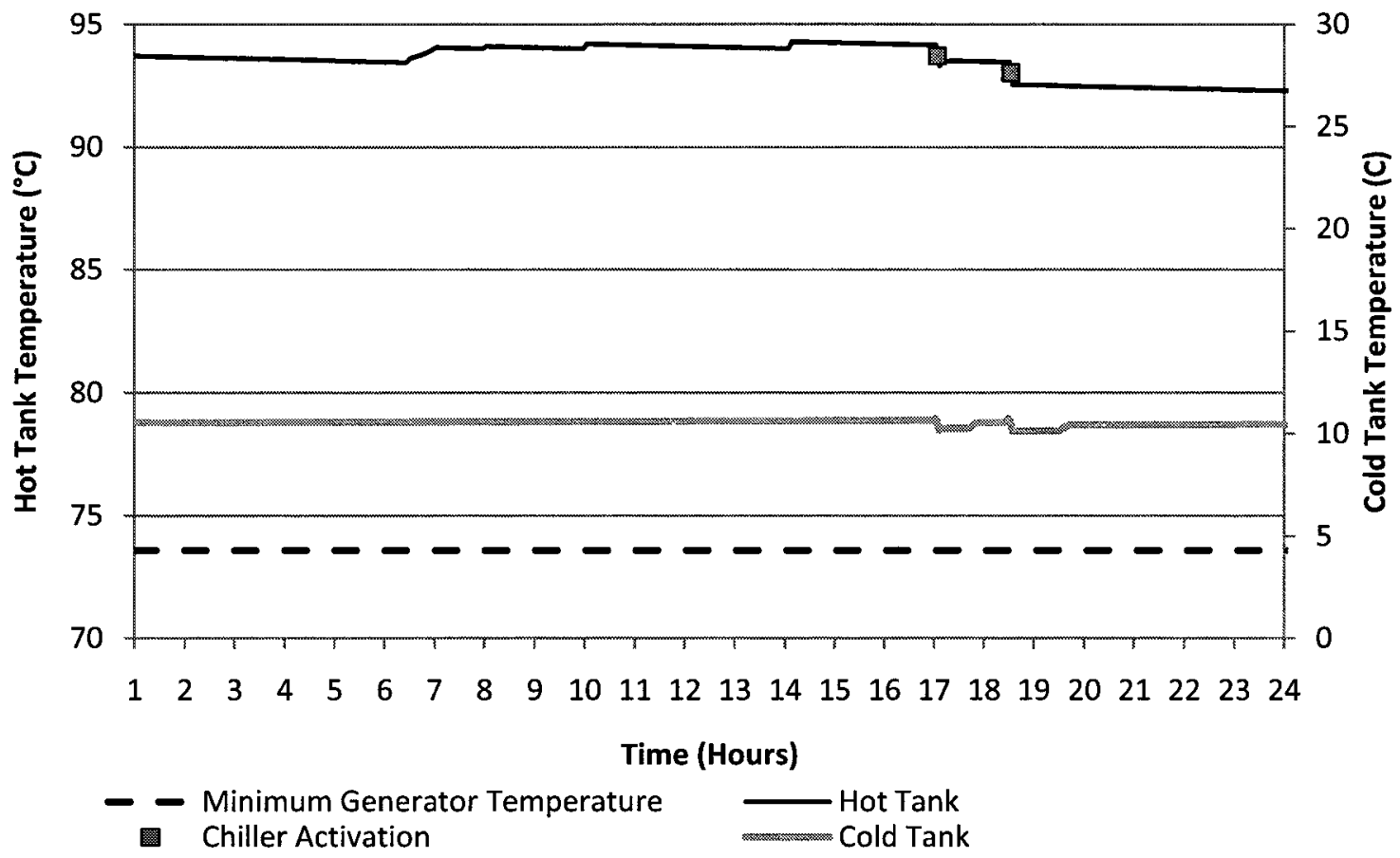

Figure 6-8: Tank temperatures and chiller activation on May 17th

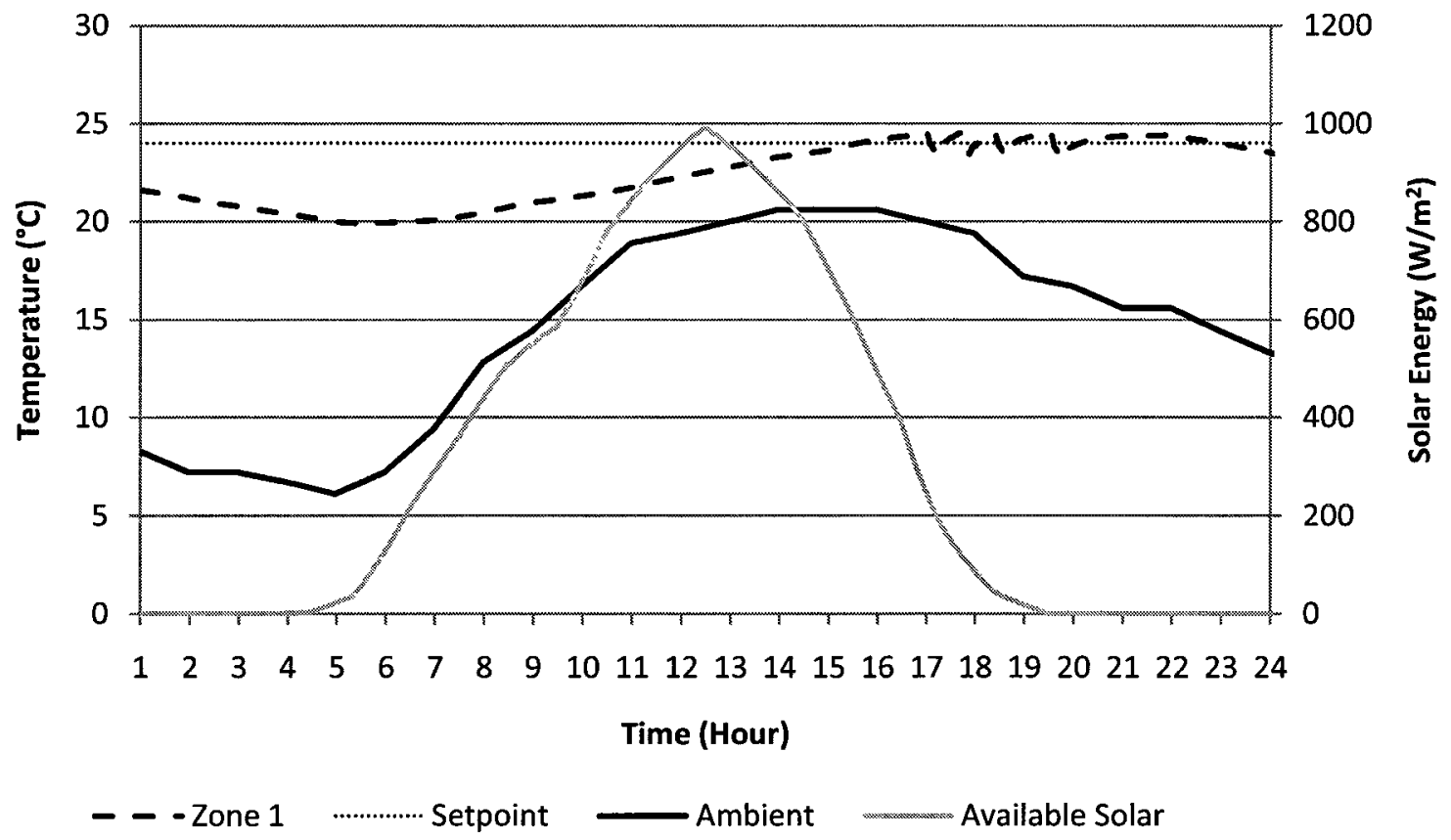

Figure 6-9: Zone and ambient temperatures on May 17 th 
The following parameters were determined for the chiller and system performance, where $P_{\text {elec }}$ is the electrical power (MJ) consumed:

$$
Q_{\text {captured }}=\text { solar energy captured by solar collector (MJ) }
$$

Equation 6-1 defines the amount of solar energy that is transferred to the working fluid that is circulating through the solar collector.

$$
\begin{gathered}
\mathrm{Q}_{\text {avail }_{\text {on }}}=\text { incident solar energy on collector at time steps when } \\
\text { solar collector loop is activated (MJ) }
\end{gathered}
$$

Equation 6-2 defines the amount of solar energy that is incident upon the solar collector during the time steps when working fluid is circulating through the solar collector.

$$
\mathrm{MSF}_{\text {chiller }}=\frac{\mathrm{Q}_{\text {evap }}}{\mathrm{Q}_{\text {captured }}}
$$

$\mathrm{MSF}_{\text {chller }}$ is the modified solar fraction and is equal to the ratio of the heat transferred at the chiller's evaporator to the solar energy captured by the solar collector.

$$
\mathrm{SF}_{\text {chiller }}=\frac{\mathrm{Q}_{\text {evap }}}{\mathrm{Q}_{\text {availon }}}
$$

$\mathrm{SF}_{\text {chlller }}$ is the solar fraction and is equal to the ratio of the heat transferred at the chiller's evaporator to the solar energy available during time steps the solar collector loop is active.

$$
\operatorname{COP}_{\text {elec-chiller }}=\frac{Q_{\text {evap }}}{P_{\text {elec-chiller }}}
$$

Equation 6-5 provides the electrical COP of the chiller, which is equal to the ratio of the heat transferred at the chiller's evaporator to the electrical power input to the chiller. 


$$
\mathrm{MSF}_{\text {system }}=\frac{\mathrm{Q}_{\text {cooling }}}{\mathrm{Q}_{\text {captured }}}
$$

$\mathrm{MSF}_{\text {system }}$ is the modified solar fraction of the system and is equal to the ratio of the cooling energy removed from the zone to the solar energy captured by the solar collector.

$$
\mathrm{SF}_{\text {system }}=\frac{\mathrm{Q}_{\text {cooling }}}{\mathrm{Q}_{\text {availon }}}
$$

$\mathrm{SF}_{\text {system }}$ represents the solar fraction of the system and is equal to the ratio of the cooling energy removed from the zone to the solar energy available when the solar collector loop is active.

$$
\text { COP }_{\text {elec-system }}=\frac{Q_{\text {cooling }}}{P_{\text {elec-system }}}
$$

Equation 6-8 describes the electrical COP of the system and is equal to the ratio of the cooling energy removed from the zone to the electrical power supplied to the system.

The average value of the system performance parameters on July $4^{\text {th }}$ between 9:30 am and 5:00 pm are provided in Table 6-2. The electrical power consumption of system components used in determining the $\mathrm{COP}_{\text {elec }}$ is described more fully in Section 7.1. The average chiller $\mathrm{COP}_{\text {th }}$ value of 0.74 is in line with the range observed by Johnson (2011). The system has an overall solar fraction $\left(\mathrm{SF}_{\text {system }}\right)$ of $11 \%$, with significant losses occurring across the solar collector. The COP $\mathrm{Plec}_{\text {-chiller }}$ is high, due to the high evaporator heat transfer and low electrical input, which does not include the cooling tower or associated components. 
Table 6-2: Average performance indicators for the SAC system on July $4^{\text {th }}$

\begin{tabular}{|c|c|}
\hline Parameter & Average value between 9:30 am and 5:00 pm \\
\hline $\mathrm{COP}_{\text {th }}$ & 0.74 \\
\hline $\mathrm{MSF}_{\text {chiller }}$ & 0.51 \\
\hline $\mathrm{SF}_{\text {chlller }}$ & 0.19 \\
\hline $\mathrm{COP}_{\text {elec-chiller }}$ & 163.8 \\
\hline $\mathrm{MSF}_{\text {system }}$ & 0.50 \\
\hline $\mathrm{SF}_{\text {system }}$ & 0.11 \\
\hline $\mathrm{COP}_{\text {elec-system }}$ & 12.3 \\
\hline
\end{tabular}

The overall monthly performance of the chiller is described in Table 6-3. The average daily cooling was found to be $86 \mathrm{MJ} /$ day, with a maximum daily average cooling of $139 \mathrm{MJ} /$ day occurring in July. The chiller was able to meet all of the loads in May, June, and September, while the system was unable to maintain the setpoint for a portion of both July and August. A significant finding is the number of days where temperatures above the setpoint occur - only three sequential days in each July and August. This suggests that while the chiller failed to maintain the cooling setpoint $2.5 \%$ of the time steps, these time steps were concentrated on very few days, rather than being a frequent occurrence. 
Table 6-3: Monthly performance summary of base case

\begin{tabular}{|c|c|c|c|c|c|c|}
\hline & May & June & July & Aug. & Sept. & Total \\
\hline $\begin{array}{c}\text { Incident Solar Energy } \\
\text { (MJ) }\end{array}$ & 18660 & 33252 & 34220 & 30599 & 12984 & 129715 \\
\hline $\begin{array}{c}\text { Solar Energy } \\
\text { Captured (M)) }\end{array}$ & 233 & 2870 & 6194 & 5035 & 1321 & 15653 \\
\hline Cooling Energy (MJ) & 95 & 1955 & 4181 & 3419 & 838 & 10488 \\
\hline $\begin{array}{c}\text { Average Daily Cooling } \\
\text { (MJ/day) }\end{array}$ & 11 & 70 & 139 & 110 & 70 & 85 \\
\hline N(\%) & 0.0 & 0.0 & 3.5 & 5.8 & 0.0 & 2.5 \\
\hline $\begin{array}{c}\text { Days with unmet } \\
\text { cooling loads }\end{array}$ & 0 & 0 & 3 & 3 & 0 & 6 \\
\hline $\begin{array}{c}\text { COP } \\
\text { th }\end{array}$ & 0.74 & 0.72 & 0.69 & 0.70 & 0.73 & 0.70 \\
\hline COP elec-chiller $_{\text {SF }}$ & 169 & 149 & 106 & 110 & 148 & 117 \\
\hline system & 0.09 & 0.21 & 0.24 & 0.22 & 0.20 & 0.20 \\
\hline COP $_{\text {elec-system }}$ & 6.9 & 9.3 & 8.0 & 7.7 & 9.1 & 8.2 \\
\hline $\begin{array}{c}\text { Days Chiller in } \\
\text { Operation/Days } \\
\text { Simulated }\end{array}$ & $9 / 17$ & $28 / 30$ & $30 / 31$ & $31 / 31$ & $12 / 15$ & $110 / 124$ \\
\hline
\end{tabular}

The time steps where the system failed to maintain the setpoint are shown for July $7^{\text {th }}$ through $9^{\text {th }}$ in Figure $6-10$ and for August $4^{\text {th }}$ through $6^{\text {th }}$ in Figure $6-11$. A day before and after the days with unmaintained setpoints is included in each case to provide additional context. The ambient temperature on July $6^{\text {th }}$ was quite high, but was matched by high solar radiation. Lower solar radiation and higher ambient temperatures resulted in the hot and cold storage draining on July $7^{\text {th }}$. Persistently high evening ambient temperatures resulted in an overheated zone temperature. 


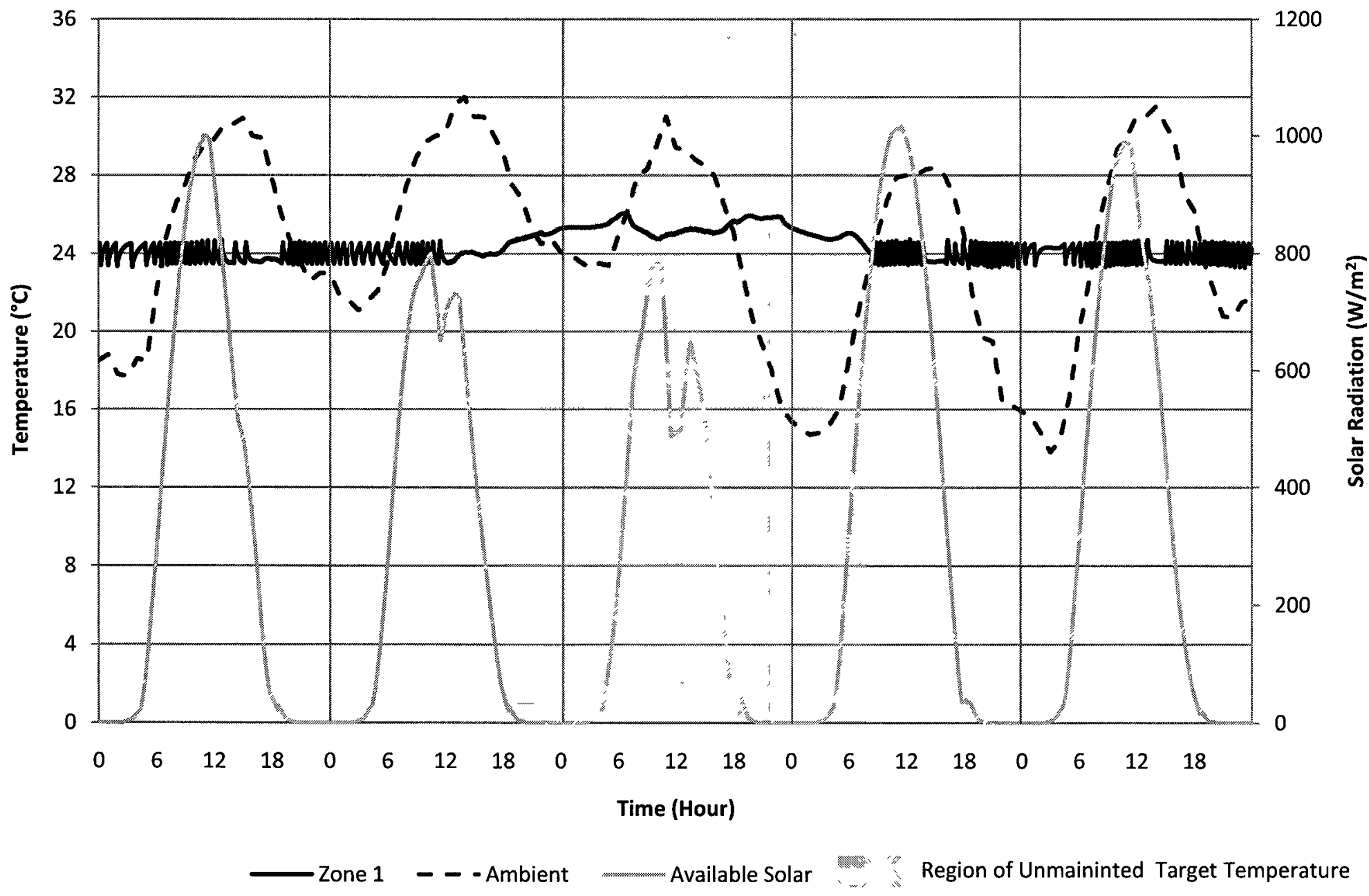

Figure 6-10: Zone temperature and ambient conditions during time of unmet cooling setpoint from July $6^{\text {th }}$ to July $10^{\text {th }}$ 


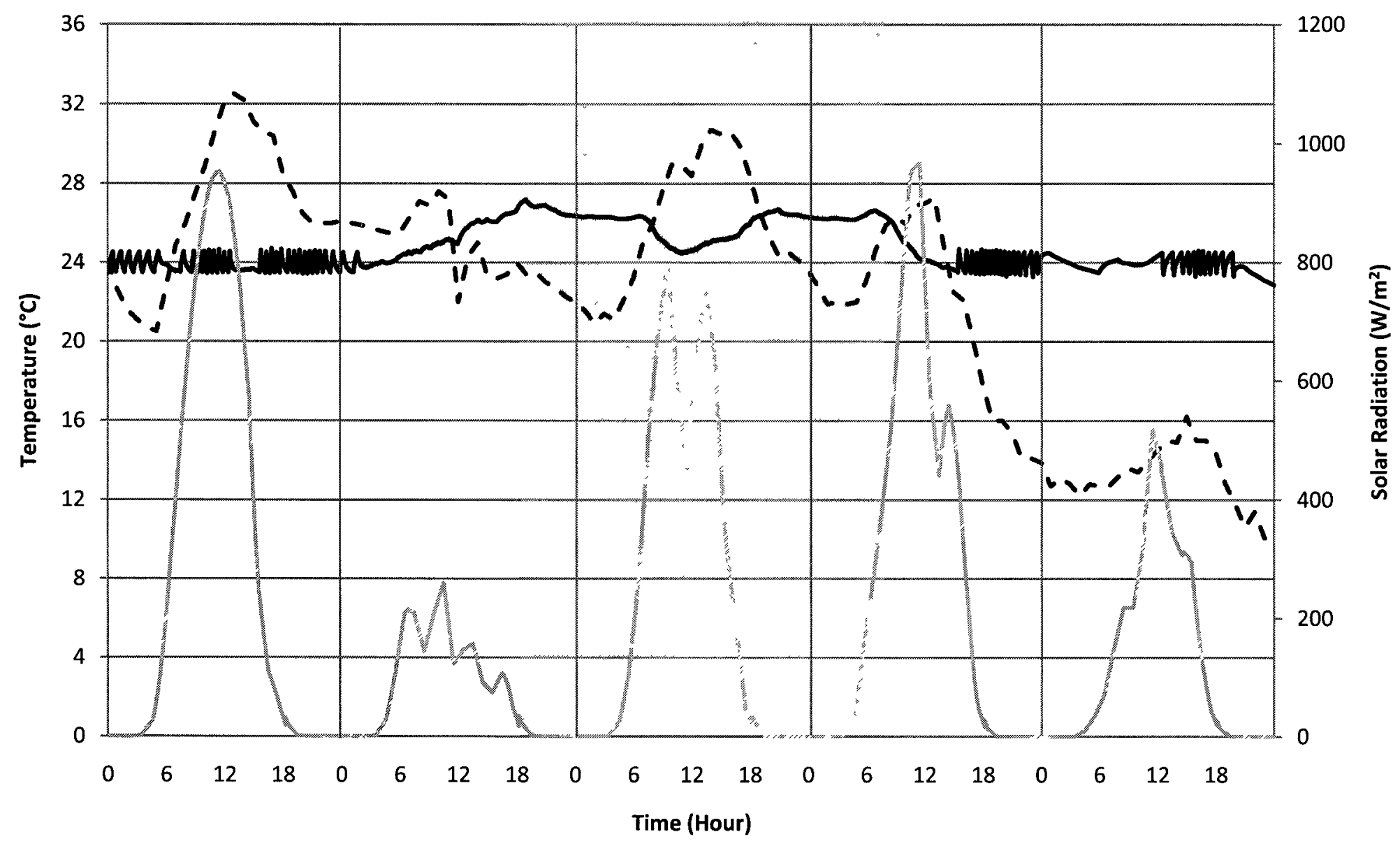

Zone 1 - - Ambient Available Solar Region of Unmaininted Target Temperature

Figure 6-11: Zone temperature and ambient conditions during time of unmet cooling setpoint from August $3^{\text {rd }}$ to August $7^{\text {th }}$ 
The following day presented average radiation and sustained high ambient temperatures, resulting in the system being unable to bring the zone back to the setpoint temperature. Finally, on July $9^{\text {th }}$, the high levels of solar radiation and slightly lower ambient temperatures enabled the system to bring the zone temperature back to the setpoint in the morning hours.

In August, while the setpoint was well maintained on August $3^{\text {rd }}$, a day of very low solar radiation resulted in the peak zone temperature on August $4^{\text {th }}$, causing a lasting effect for another 36 hours, described earlier.

The $\mathrm{COP}_{\text {th }}$ of the chiller was fairly consistent throughout the summer, with a maximum monthly average in May. The chiller activated less frequently in May, resulting in higher generator inlet temperatures, which improved the chiller performance. The chiller was in operation 114 out of the 124 days simulated, with daily operation occurring in August.

The instantaneous values of the performance parameters fluctuate considerably due to the multi-stage nature of the cooling process. The time at which solar radiation is available results in greater available cooling, with some delay due to the charging of the hot and cold storage tanks. The daily performance parameters for the chiller and system for the weeks of June $27^{\text {th }}-$ July $10^{\text {th }}$ are shown in Figure 6-12 and Figure 6-13, respectively. 


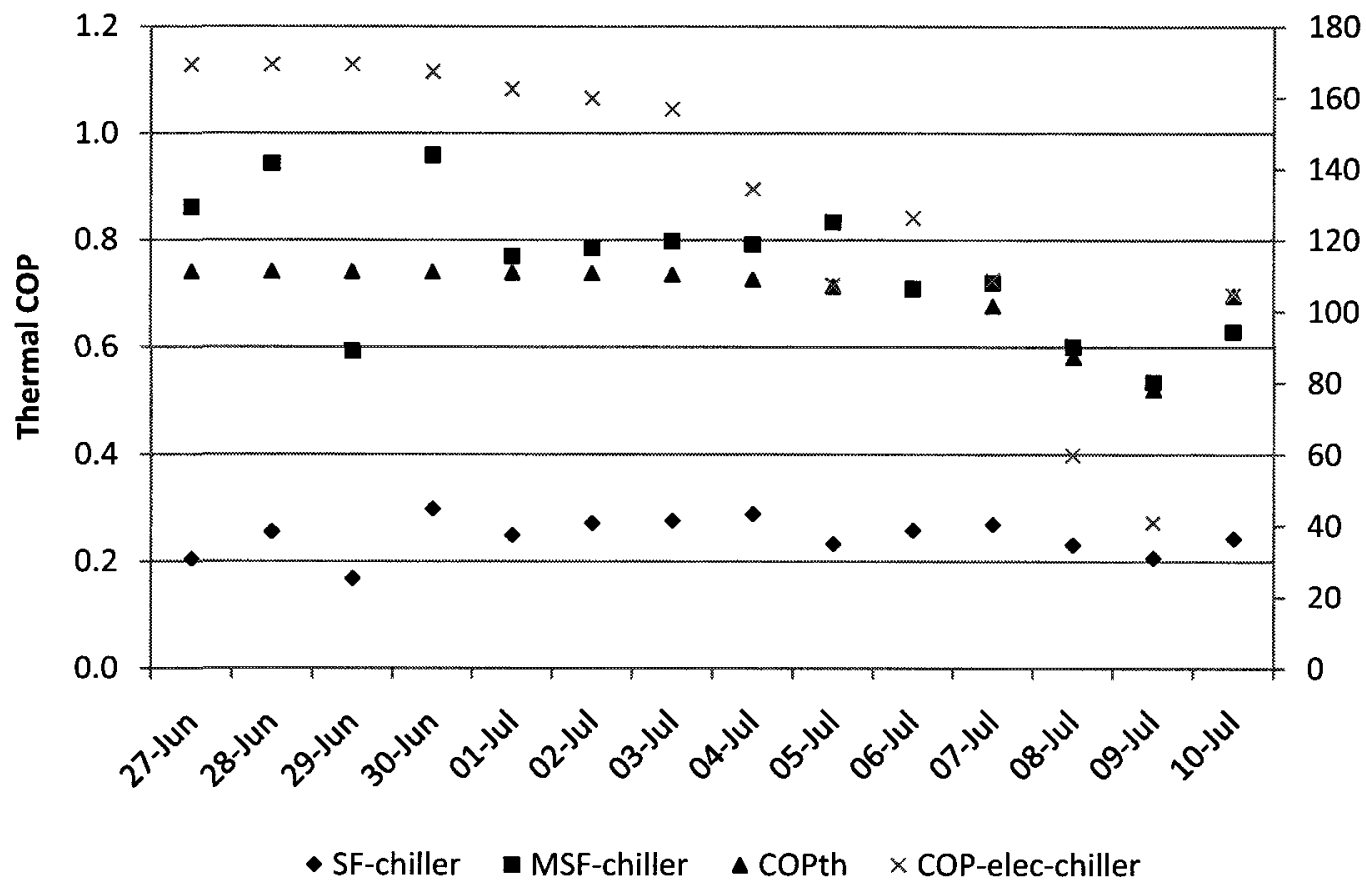

Figure 6-12: Chiller performance parameters from 9:30 am-5:30 pm over a two week period

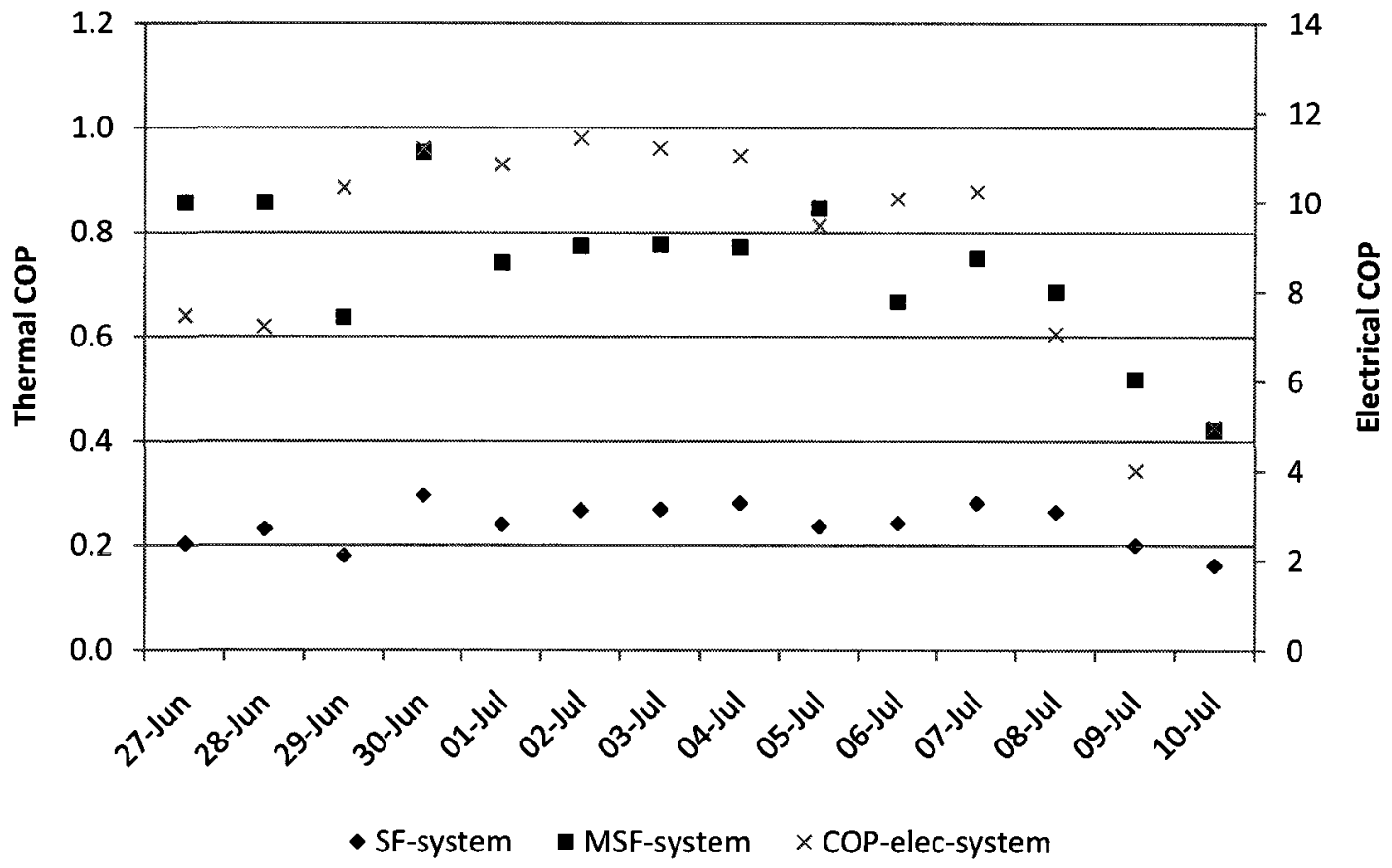

Figure 6-13: System performance parameters from 9:30 am-5:30 pm over a two week period 
The chiller and system as a whole show high electrical $\operatorname{COP}_{\text {elec }}$ at the beginning of the simulation period, where temperatures were more moderate and the tanks were better able to charge and maintain stored energy. As the weather grew hotter, the $\mathrm{COP}_{\text {elec }}$ decreased with frequent activation of the solar components, cooling loop and the chiller. The $\mathrm{COP}_{\text {th }}$ stayed within the range of 0.5 to 0.75 , with increased performance at the beginning of the week where higher evaporator inlet conditions were more frequent. The $\mathrm{SF}_{\text {system }}$ was also fairly constant, with peaks nearing $30 \%$, while the $\mathrm{SF}_{\text {chiller }}$ varied considerably with changing weather patterns.

The energy flow for a typical day, July $4^{\text {th }}$, is shown on Figure 6-14. The available solar energy for the day is $1050.9 \mathrm{MJ}$, only about $22 \%$ of which is absorbed for use in the SAC system due to sporadic solar collector pump activation and solar collector inefficiencies. The resultant energy is available to the generator, along with $27.8 \mathrm{MJ}$ from the hot storage tank, which allows 189.4 MJ of energy to be removed through the evaporator. The resulting cooling output is $184.7 \mathrm{MJ}$, along with $0.5 \mathrm{MJ}$ of additional storage in the cold tank. The diagram shows the heat loss in the hot storage tank and heat gain in the cold storage tank, as well as the auxiliary power input. The major loss of available solar energy occurs from the sporadic activation of the solar collector loop and the coefficient of performance of the chiller. 


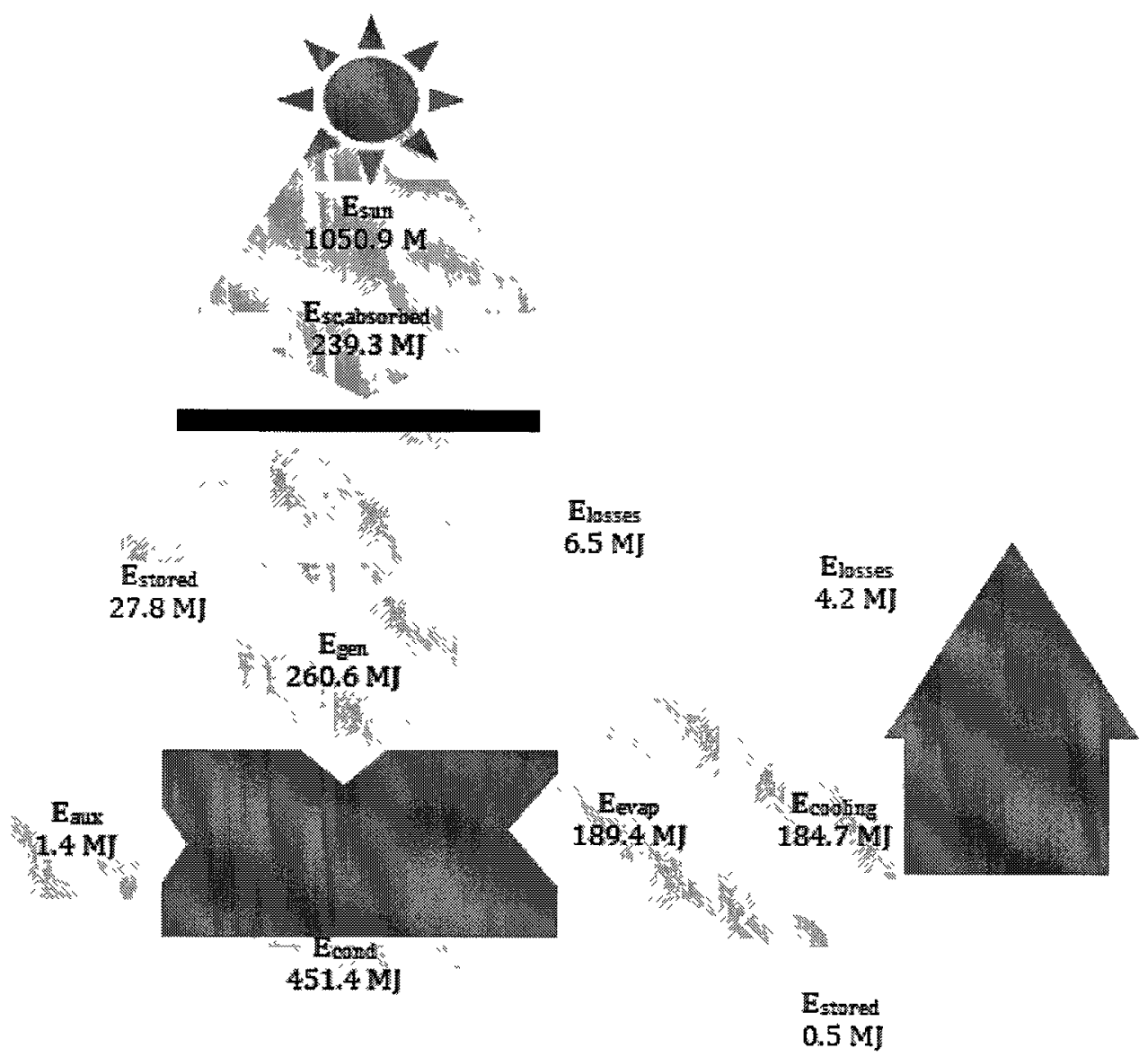

Figure 6-14: Energy flow for the SAC system on a typical day (July $4^{\text {th }}$ )

The allowable generator inlet temperature of the chiller had a range of $73.6^{\circ} \mathrm{C}$ to $95.0^{\circ} \mathrm{C}$. This wide range affected the chiller performance, and consequently the overall operation of the system. The performance and characteristics of the system with different generator inlet temperatures over August $1^{\text {st }}$ and $2^{\text {nd }}$ are shown in Table 6-4. From the table, it can be seen that the highest generator inlet temperatures occur at higher average solar radiation. Higher generator inlet temperatures result in a higher $\mathrm{COP}_{\text {th }}$ and a significant evaporator heat transfer, resulting in a decreased outlet temperature of the chiller cold stream. 
Table 6-4: System performance at different operating conditions for two hot days (August $1^{\text {st }}-2^{\text {nd }}$ ) with peak solar radiation of $937 \mathrm{~W} / \mathrm{m} 2$

\begin{tabular}{|c|c|c|c|c|c|c|}
\hline \multirow{2}{*}{ Parameter } & \multicolumn{5}{|c|}{ Generator Inlet Temperature $\left({ }^{\circ} \mathrm{C}\right)$} & \multirow{2}{*}{$\begin{array}{c}\text { Average } \\
\text { values }\end{array}$} \\
\hline & $<75$ & $75-80$ & $80-85$ & $85-90$ & $>95$ & \\
\hline $\begin{array}{c}\text { Solar Irradiation } \\
\left(\mathrm{W} / \mathrm{m}^{2}\right)\end{array}$ & 148.6 & 224.9 & 212.6 & 221.8 & 655.5 & 321.3 \\
\hline $\begin{array}{c}\text { Ambient } \\
\text { Temperature } \\
\left({ }^{\circ} \mathrm{C}\right) \\
\end{array}$ & 24.1 & 23 & 20.7 & 23.6 & 25.0 & 23.6 \\
\hline $\begin{array}{l}\text { Chiller Hot Outlet } \\
\left.\qquad{ }^{\circ} \mathrm{C}\right)\end{array}$ & 70.6 & 73.2 & 76.8 & 79.1 & 85.4 & 76.3 \\
\hline $\begin{array}{c}\text { Chiller Cold Inlet } \\
\left({ }^{\circ} \mathrm{C}\right)\end{array}$ & 11.3 & 10.6 & 10.6 & 10.5 & 10.5 & 10.8 \\
\hline $\begin{array}{l}\text { Chiller Cold } \\
\text { Outlet }\left({ }^{\circ} \mathrm{C}\right) \\
\end{array}$ & 9.2 & 7.8 & 6.3 & 4.7 & 4.3 & 6.9 \\
\hline Hot Tank $\left({ }^{\circ} \mathrm{C}\right)$ & 73.5 & 77.4 & 82.6 & 87.1 & 93.6 & 84.4 \\
\hline Cold Tank $\left({ }^{\circ} \mathrm{C}\right)$ & 11.7 & 10.6 & 10.4 & 10.5 & 10.5 & 11.1 \\
\hline Coil Air Inlet $\left({ }^{\circ} \mathrm{C}\right)$ & 24.0 & 24.0 & 24.0 & 24.0 & 24.0 & 24.0 \\
\hline $\begin{array}{l}\text { Coil Air Outlet } \\
\left.\qquad{ }^{\circ} \mathrm{C}\right)\end{array}$ & 13.6 & 12.6 & 12.2 & 11.9 & 11.6 & 12.3 \\
\hline $\begin{array}{c}\text { Cooling Power } \\
(\mathrm{kW})\end{array}$ & 5.4 & 5.9 & 5.5 & 5.2 & 4.9 & 5.3 \\
\hline Chiller COP th & 0.60 & 0.63 & 0.69 & 0.73 & 0.74 & 0.66 \\
\hline $\begin{array}{c}\text { Chiller Electrical } \\
\text { COP }\end{array}$ & 55.2 & 76.8 & 115.7 & 156.4 & 164.8 & 104.0 \\
\hline
\end{tabular}

Higher generator inlet temperatures denote a higher charging of the hot tank from solar radiation, and less frequent chiller activation. This results in a lower cooling power output, while high activation of the chiller at low generator inlet temperatures result in higher cooling output. The chiller COP and electrical COP are seen to increase significantly with higher generator inlet temperatures due to the 
dependence of the evaporator and generator heat transfers on generator inlet temperature.

The histogram shown in Figure 6-15 displays the frequency of the occurrence of each level of evaporator heat transfer on August $1^{\text {st. }}$ The high frequency of evaporator heat transfers over $32.5 \mathrm{~kW}$ results in the low chiller cold outlet temperatures seen in Table 6-4.

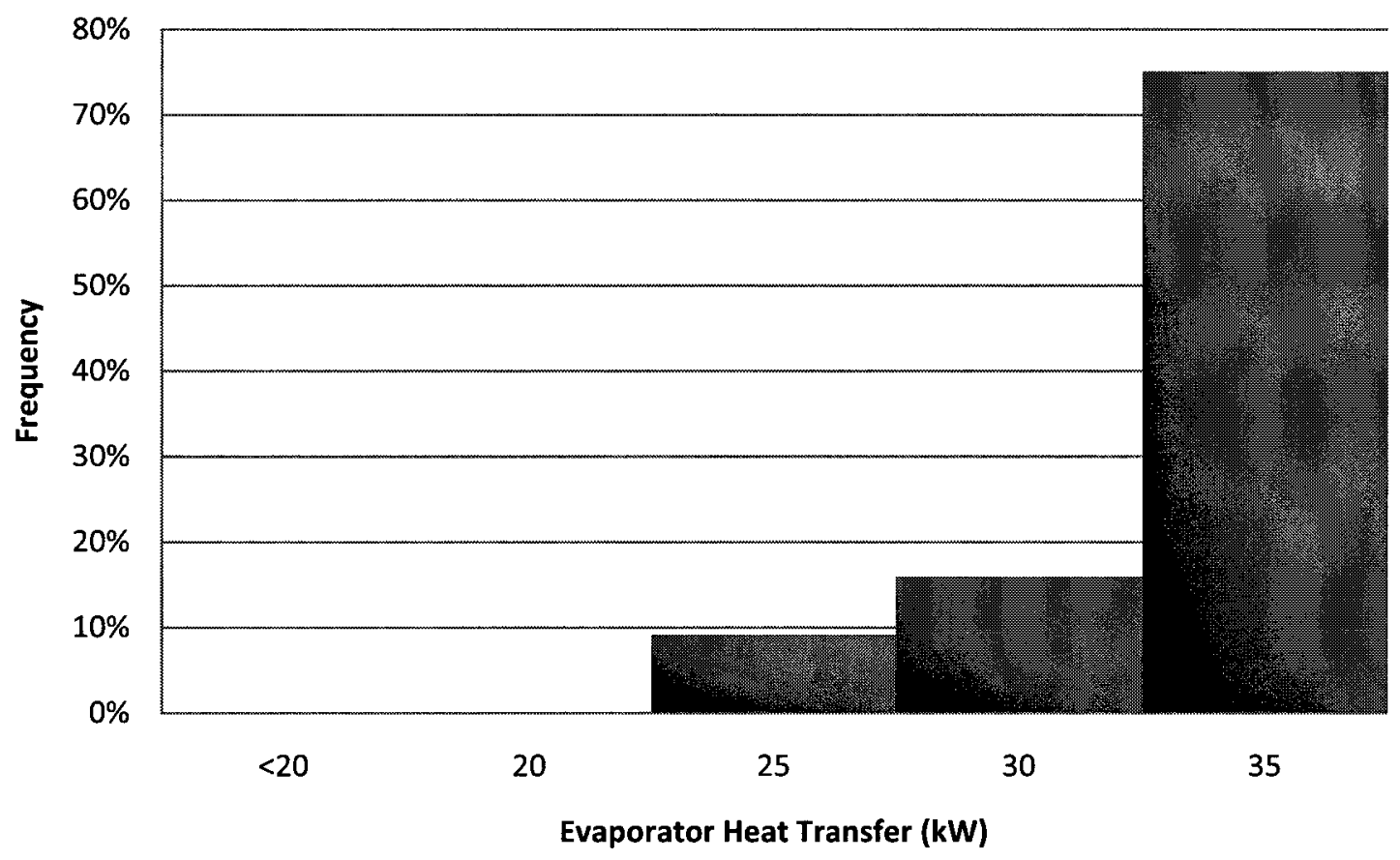

Figure 6-15: Histogram of the evaporator heat transfer on August 1st, a typical hot day 


\subsubsection{Summary of findings}

The findings for the general performance of the SAC system are as follows:

- The SAC system is able to perform well on warm days with high solar radiation, and on days with cooler ambient temperatures.

- The SAC system is unable to maintain the desired setpoint on hot days with low solar radiation.

- The system was unable to meet the cooling setpoint on two periods of three sequential days each, where a trend of high ambient temperatures was followed by a day with lower than average solar radiation. The peak Zone 1 temperature was $27.2^{\circ} \mathrm{C}$.

- The $\mathrm{SF}_{\text {system }}$ increases as the day progresses due to the energy availability in the storage tank in the late afternoon and evening when the solar radiation has decreased.

- The chiller $\mathrm{COP}_{\text {th }}$ remains fairly constant throughout the day, and falls within the range of 0.5 to 0.75 .

- The biggest sources of energy loss in the system are the collector efficiency, and the chiller inefficiencies.

- The chiller has an evaporator heat transfer of $32.5 \mathrm{~kW}$ or greater more than $50 \%$ of the time that it operates over the full summer. 
The performance of the 2000 vintage house with Toronto CWEC climate data reference case will now be compared to cases with different house constructions, climatic conditions, and control strategies.

\subsection{Significance of Housing Construction and Geometry}

The significance of the construction and geometry of houses on the performance of the SAC system was determined through the modelling of four different houses. These houses represented three different house vintages and two different window areas. The full details of the modelled houses are described in Table 5-5 on page 93. Each house was modelled with the SAC system in the Toronto CWEC climatic conditions, and the summary of performance results for each house is provided in Table 6-5. The system was able to meet at least $95 \%$ of the loads in all cases except for the 1976-LW house.

Table 6-5: Summary of results for four houses

\begin{tabular}{|c|c|c|c|}
\hline House & $\mathcal{N}(\%)$ & $\begin{array}{c}\text { Max. Zone } \\
\text { Temp. }\left({ }^{\circ} \mathrm{C}\right)\end{array}$ & $\begin{array}{c}\text { Avg. Zone } \\
\text { Temp. }\left({ }^{\circ} \mathrm{C}\right)\end{array}$ \\
\hline 1955 & 3.3 & 28.2 & 22.8 \\
\hline 1976 & 3.9 & 28.7 & 23.0 \\
\hline $1976-\mathrm{LW}$ & 22.7 & 34.6 & 23.9 \\
\hline 2000 & 2.5 & 27.2 & 23.4 \\
\hline
\end{tabular}


The maximum monthly temperature for the main zone of each house is shown in Figure 6-16. The width of each slice represents the fraction of the summer simulated in that month, for instance only the final 17 days of May were included, while June through August had full months of simulation. The radius of each slice represents the maximum temperature that was reached in the zone. The centre of the circle represents $19^{\circ} \mathrm{C}$, and each subsequent ring denotes one additional degree. The results indicate that the vintages with average window areas had similar maximum zone temperatures, peaking in August. The 1976 vintage had the highest temperature of the three houses, with a peak of nearly $29^{\circ} \mathrm{C}$ in August.

The 1976-LW house, with large windows, had significantly higher peak temperatures, reaching a maximal temperature of $34.6^{\circ} \mathrm{C}$ in July. The marginally higher zone temperature in July rather than August for 1976-LW can be attributed to the higher solar radiation occurring in July. The increase in solar radiation increases the performance of the SAC system for each house, but was not enough to offset the higher solar gains of the house with large window area.

The average monthly temperature of the main zone for each house is displayed in Figure 6-17. The three house constructions with average window area have similar average monthly zone temperatures, and in this case the 1976-LW house is similarly aligned, with average temperatures within a degree of the 2000 house, and within a degree and a half of the 1955 and 1976 houses. 

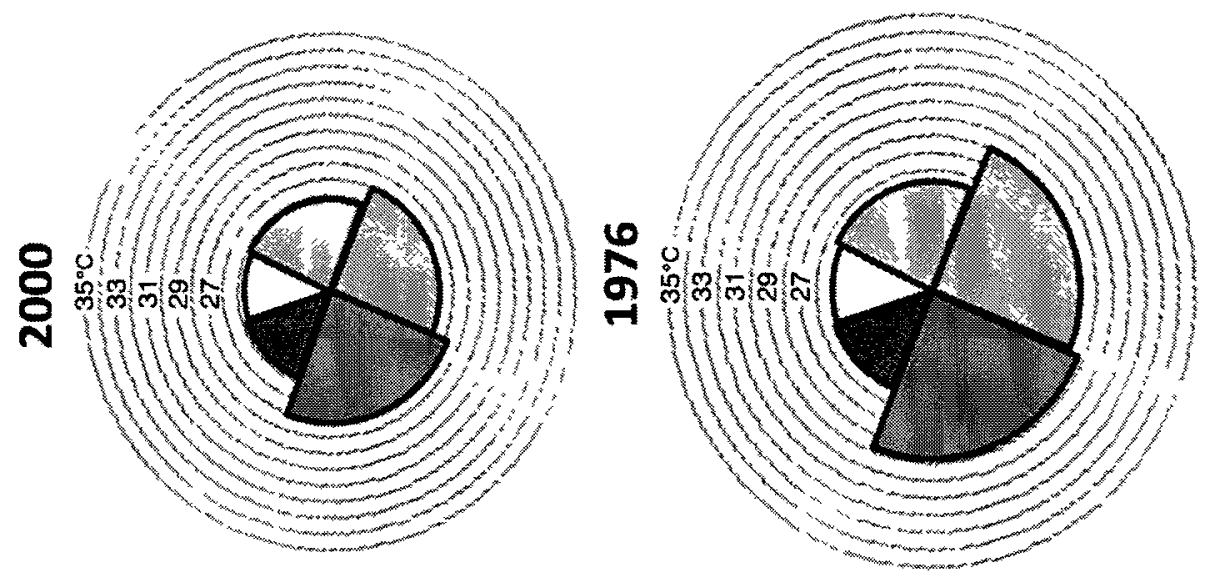

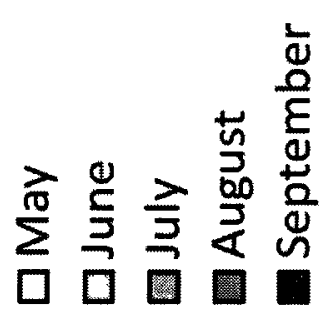
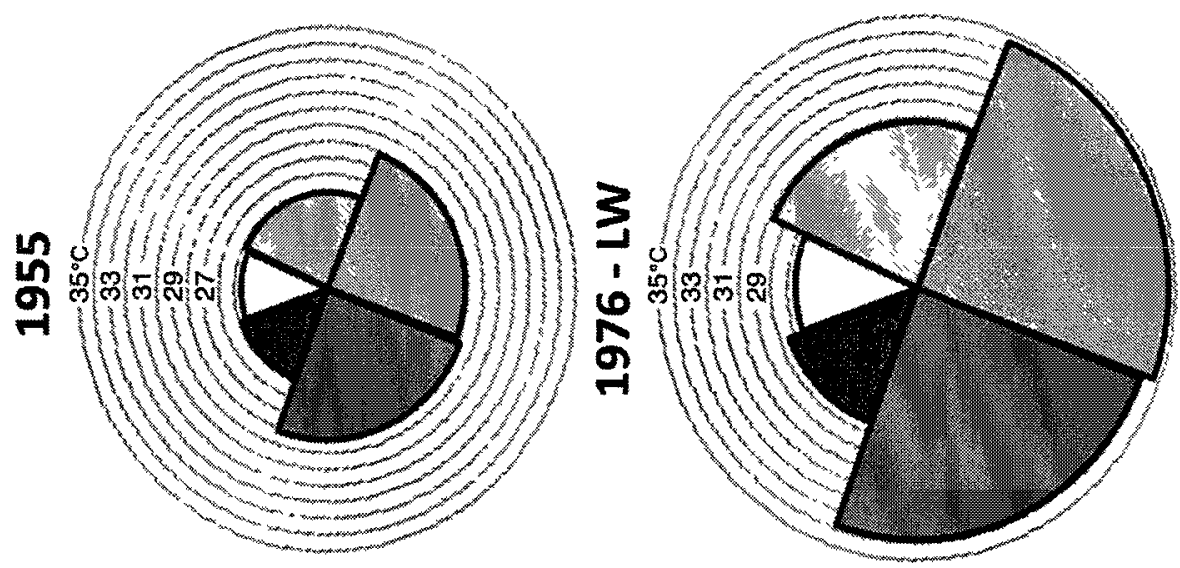

$m$ 

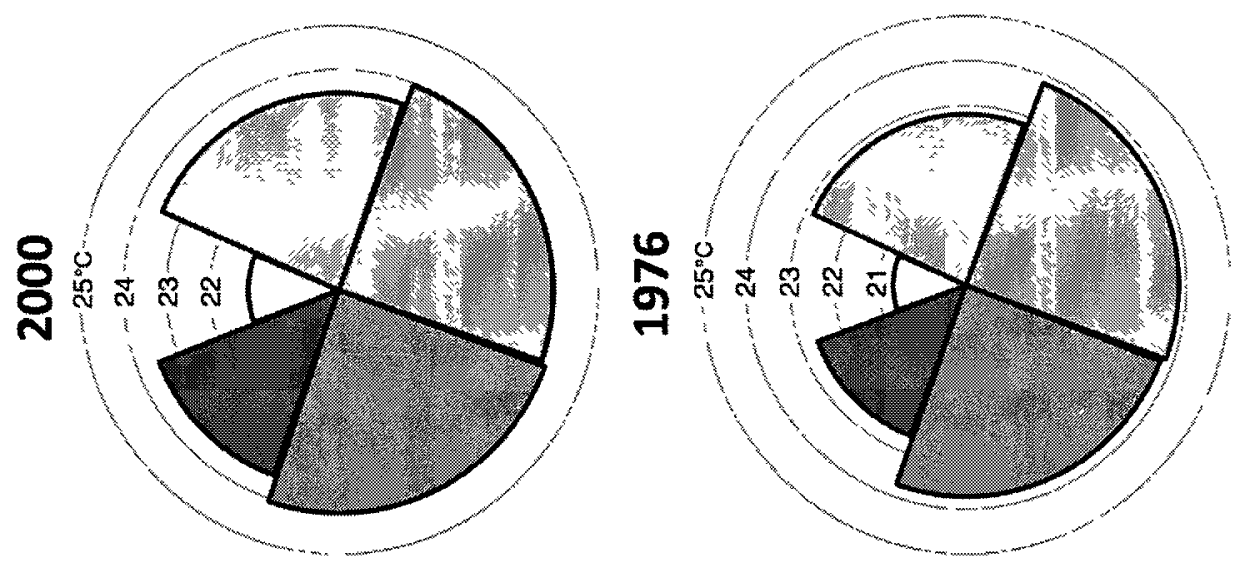

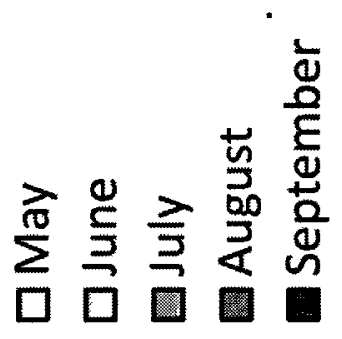
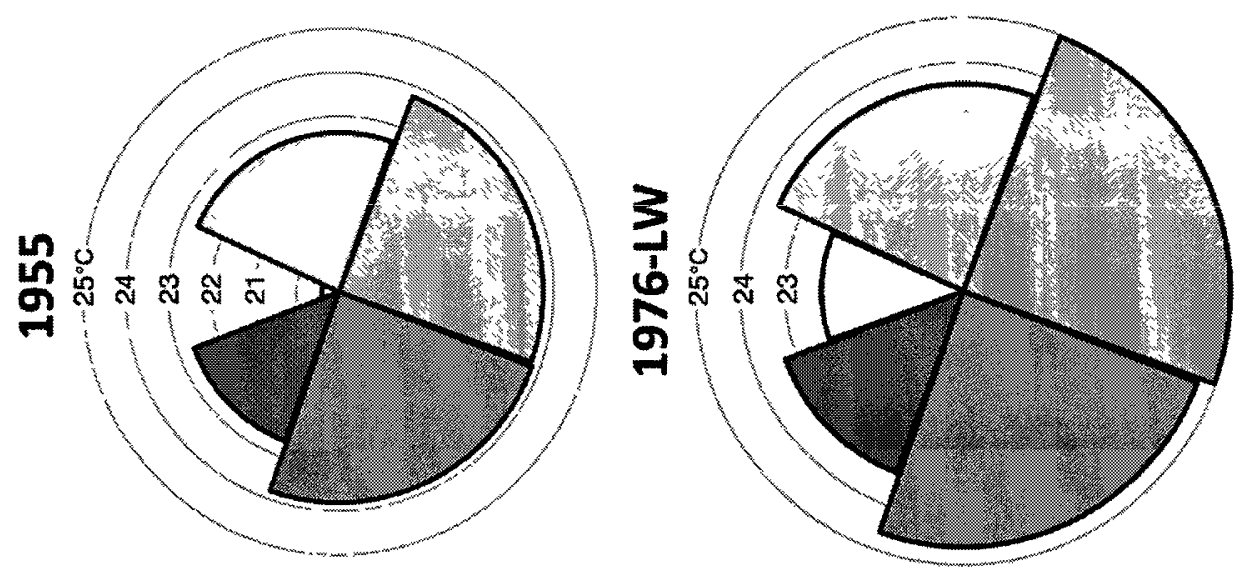

m 
The fraction of $\mathcal{N}$ that occurs during each of the time periods for each house is shown in Figure 6-18. The figure shows that the unmet loads for the 1955, 1976, and 2000 houses occur throughout the day with fairly even distribution. The majority of unmet cooling loads in the 1976-LW house, however, occur between 9:00 am and 4:59 pm, due to the reduced storage in the morning period, and the high solar gains through the large window area. This phenomenon is shown on July $30^{\text {th }}$ in Figure 6-19 and Figure 6-20. While both the 1976 and 1976-LW house cold storage tanks increase in temperature as the sun rises, the higher solar gains in the 1976-LW house causes the zone temperature of the house to increases more rapidly, surpassing the setpoint from 7:00am onwards.

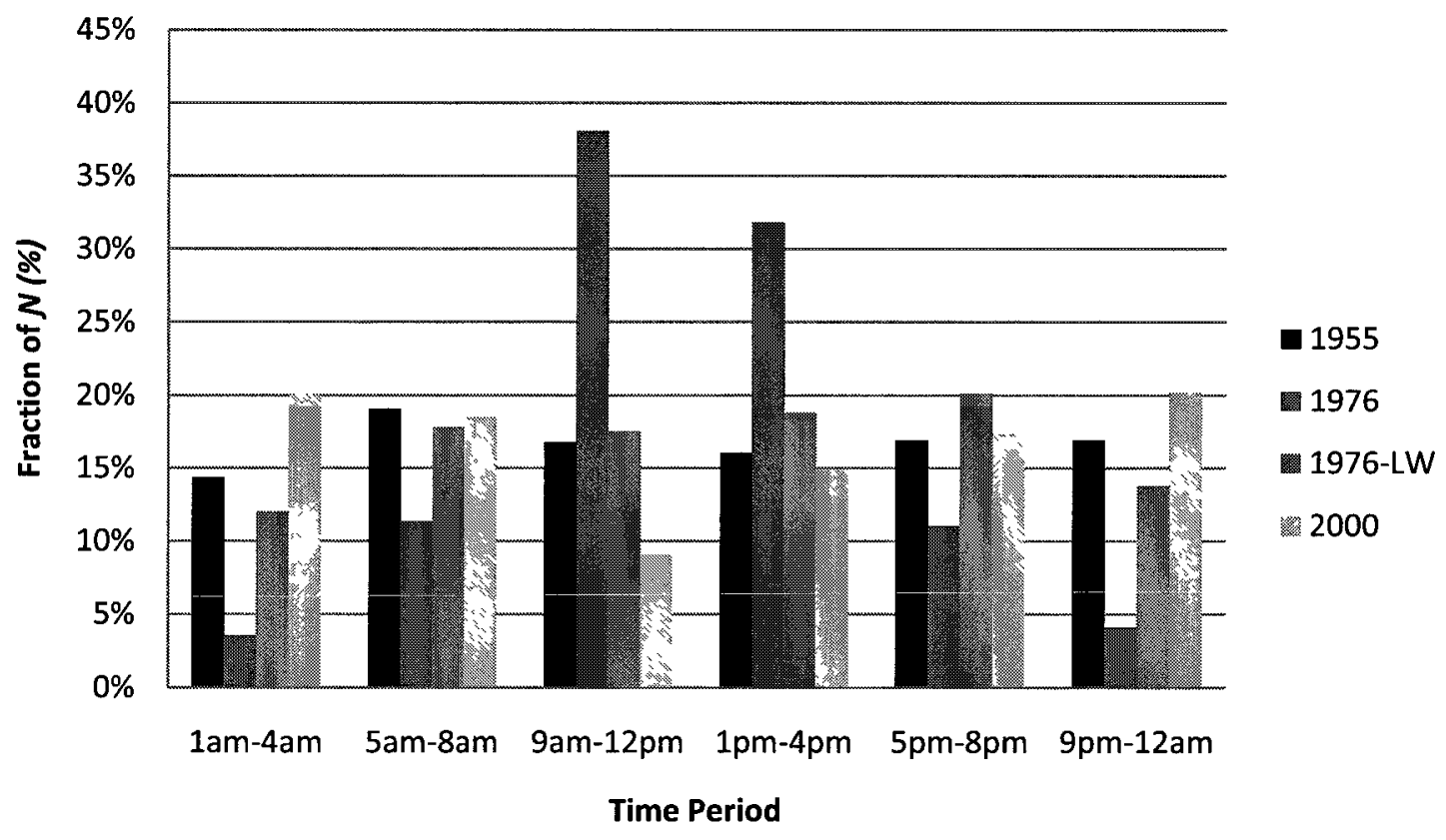

Figure 6-18: Breakdown of unmet cooling loads by time period 


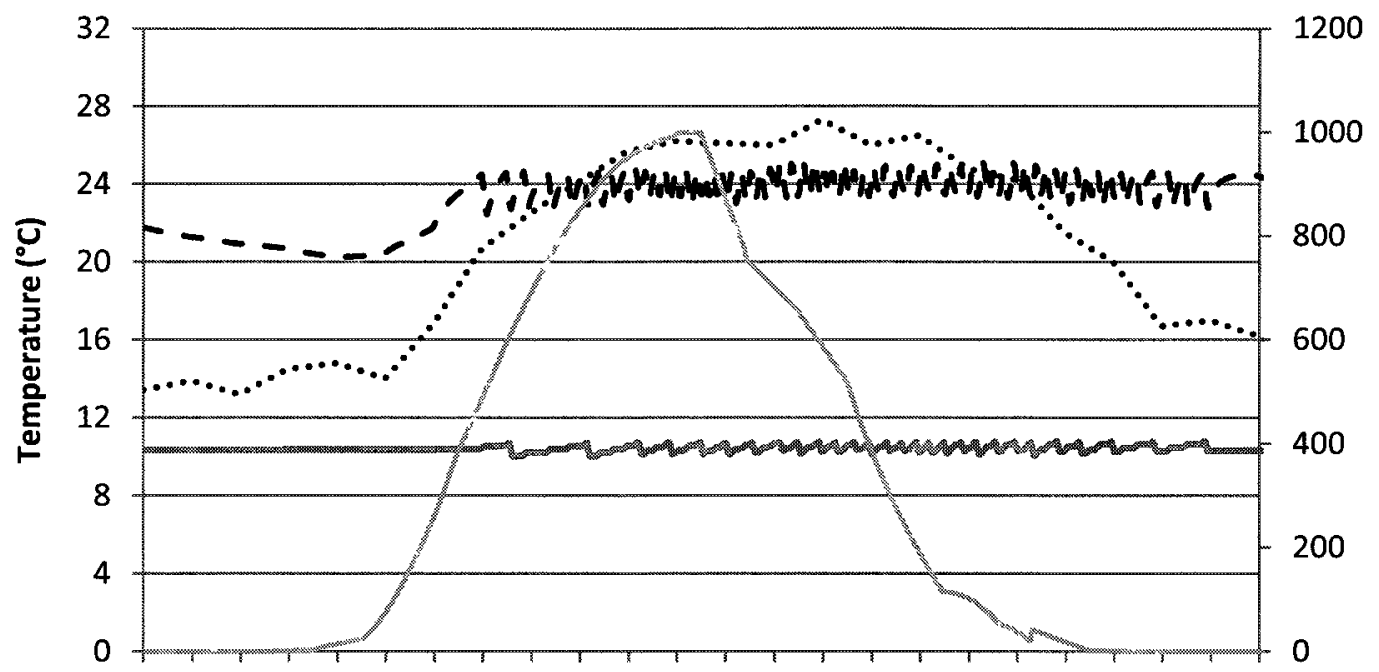

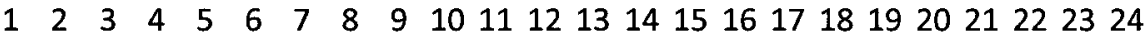

Time (Hour)

Cold Tank ....... Ambient $\quad$ - - - Zone $1 \quad$ Available Solar

Figure 6-19: Temperature fluctuation of the 1976 house on July $30^{\text {th }}$

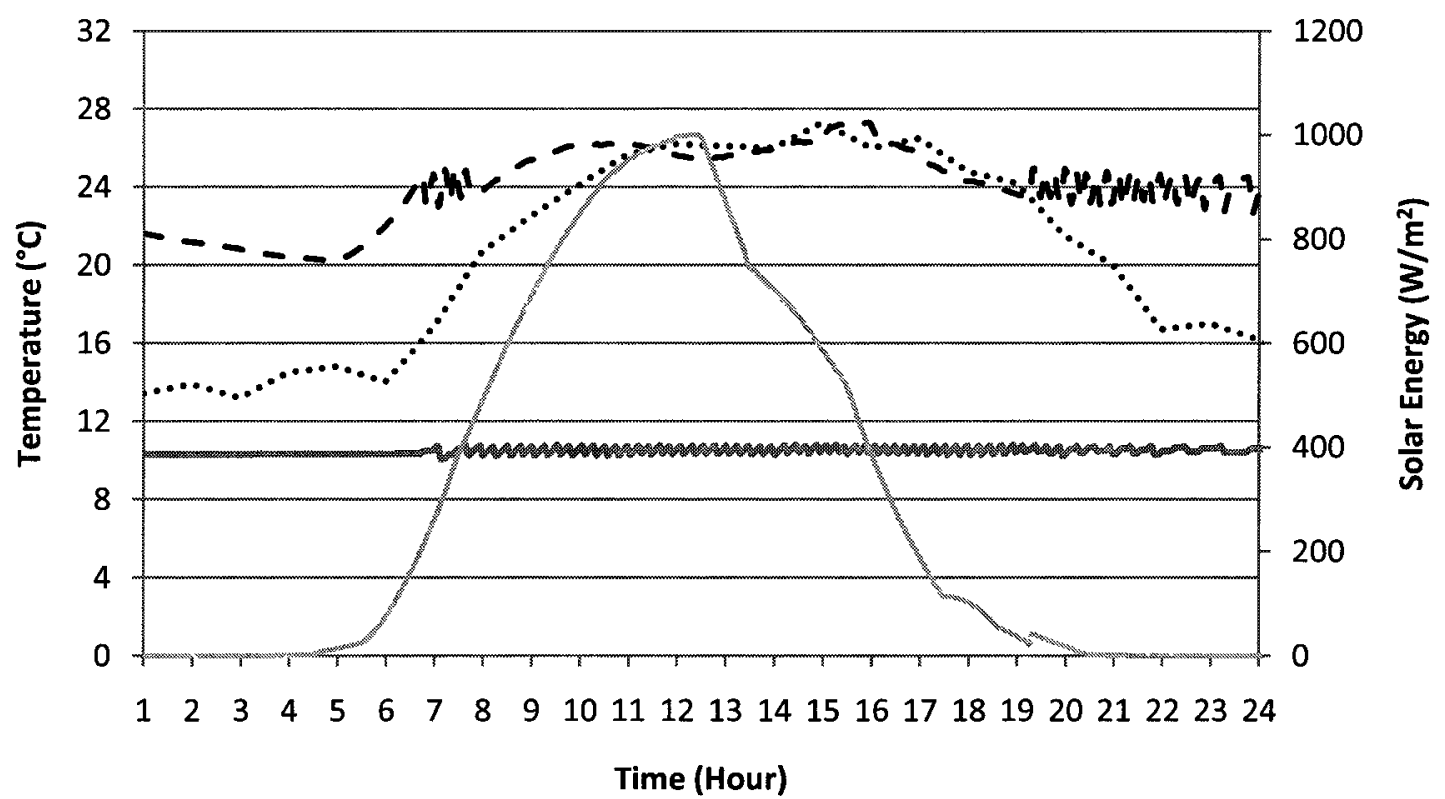

$\longrightarrow$ Cold Tank ....... Ambient - - - Zone $1 \quad$ Available Solar

Figure 6-20: Temperature fluctuation of the 1976-LW house on July $30^{\text {th }}$ 
With reference to Figure 6-18 again, the 1955 and 2000 houses both show a trend with lowest frequency of unmet loads occurring during the peak daylight hours, while the 1976 and 1976-LW have the highest frequency of unmet loads at this time. The 1955 and 2000 have two main living zones, while the other houses have single main living zones. It is estimated that the cooling loads overnight for the 1955 and 2000 houses may be greater due to the larger volume of livable zone. The higher external wall surface area of the two story houses causes greater thermal build up across the walls during the day, which is then released over night, causing additional thermal loading. This increased cooling load has a greater effect overnight when the sun has set and there is limited storage available, but does not affect the performance of the system when solar energy is rampant.

The monthly flow of energy from incident solar energy to useful cooling power for each house is shown in Figure 6-21. The 1976-LW house has the highest cooling loads of the four houses, which results in a more rapid reduction of both the hot and cold storage tanks, and a more frequent actuation of the solar collector pump, chiller, and cooling loop. The frequent actuation of the pump results in more solar energy absorbed for the 1976-LW house than any of the others. The differences between the remaining three houses are minimal, with slightly higher cooling energy supplied by the 1976 house. 


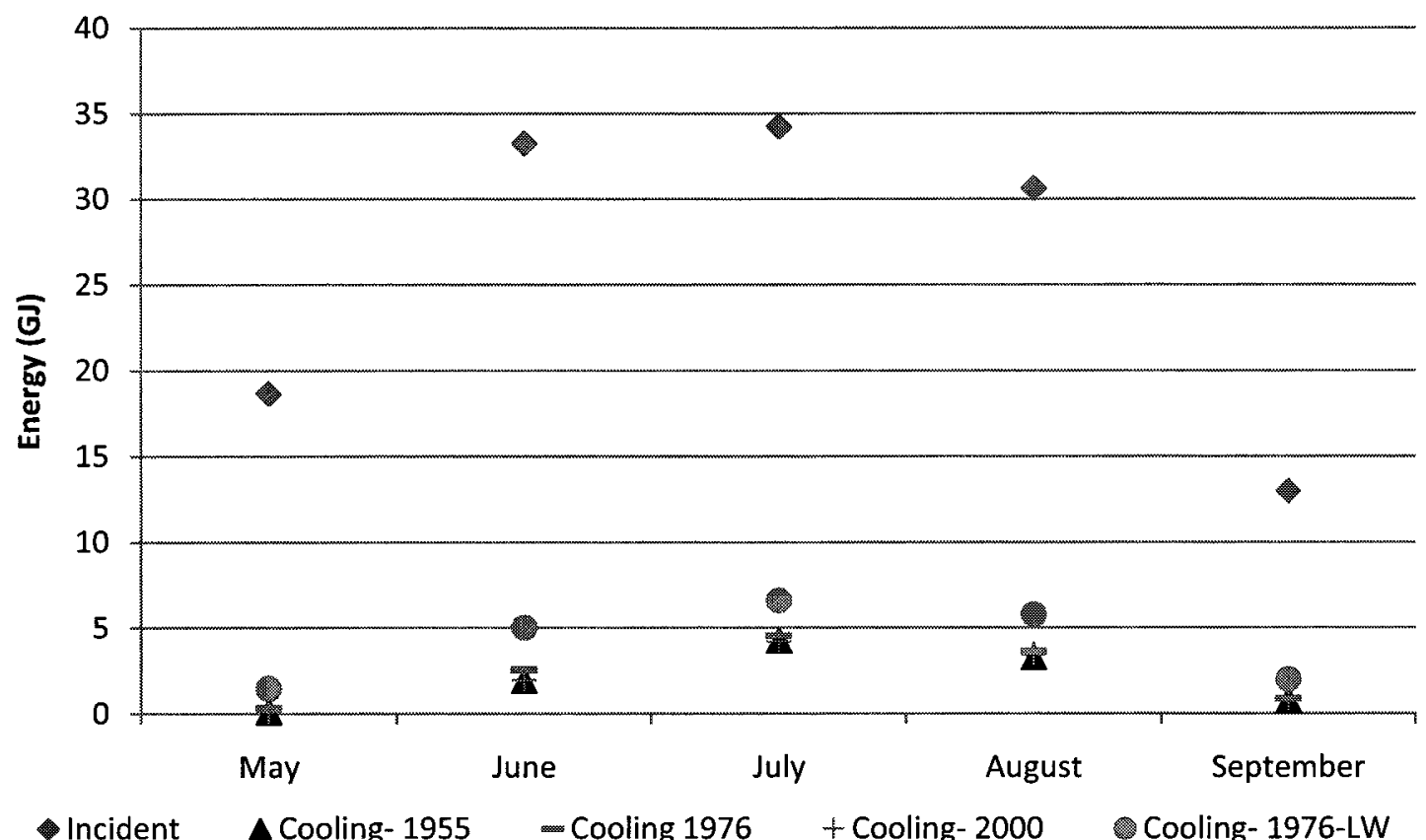

Figure 6-21: Monthly energy flow for each house

\subsubsection{Summary of findings}

The results of the variation in housing geometry and construction are as follows:

- The geometry and vintage of a house can cause moderate variations in the performance of the SAC system.

- The window area can cause significant variations in the performance of the SAC system. In particular, the peak temperature of the zone and the number of timesteps with unmet cooling loads are seen to be highly affected by the window area. 
- The peak loads for a house with high window area tend to occur in the early hours of solar gain before the chiller has begun to function.

- Houses with larger cooling loads have higher solar fraction due to the more frequent actuation of solar collector components. A higher solar fraction does not necessarily indicate a better system performance overall.

- Absorbed radiation peaks in the late morning/early afternoon hours for most houses due to the charging of the hot and cold storage tanks, which then deactivates the solar loop pump.

- Houses with two storeys tend to have more unmet loads than single-storey houses during the night time hours. The night time loads may be due to the convective release of the thermal mass of the walls into the house.

\subsection{Effect of Climate and Weather Conditions}

The three houses with average window sizes were found to have similar SAC system performance. To determine the effect of the climatic conditions on the system performance, the operation of the SAC system in the 2000 house was simulated in three Ontario climates using CWEC data (Numerical Logics, 1999), as described in Section 6.4.1. The SAC system was also simulated with ten Toronto Pearson International CWEEDS weather files, as discussed in Section 6.4.2.

\subsubsection{Regional considerations}

The simulations undertaken across Ontario used CWEC climate files from Toronto, Windsor, and Ottawa. The results of these simulations are shown in Table 6-6. The 
Windsor climate has a lower number of days above $30^{\circ} \mathrm{C}$, but a higher overall average ambient temperature than the other two climates. The average Zone 1 temperature for each house was similar, with slightly higher peak temperatures in Toronto and Windsor.

Table 6-6: Summary of results for Toronto, Windsor, and Ottawa simulations

\begin{tabular}{|c|c|c|c|c|c|}
\hline Climate & $\begin{array}{c}\text { Average } \\
\text { Ambient } \\
\text { Temp. }\left({ }^{\circ} \mathrm{C}\right)\end{array}$ & $\begin{array}{c}\text { Number of } \\
\text { Hours } \\
\text { Ambient } \\
\text { Temp. } \\
\text { above 30 }{ }^{\circ} \mathrm{C}\end{array}$ & $\mathcal{N}(\%)$ & $\begin{array}{c}\text { Max. } \\
\text { Zone } \\
\text { Temp. } \\
\left({ }^{\circ} \mathrm{C}\right)\end{array}$ & $\begin{array}{c}\text { Avg. Zone } \\
\text { Temp. }\left({ }^{\circ} \mathrm{C}\right)\end{array}$ \\
\hline $\begin{array}{c}\text { Toronto } \\
\text { baseline) }\end{array}$ & 18.3 & 31 & 2.5 & 27.2 & 23.4 \\
\hline Windsor & 19.8 & 25 & 2.4 & 26.2 & 23.7 \\
\hline Ottawa & 17.9 & 20 & 0.9 & 28.2 & 23.3 \\
\hline
\end{tabular}

The breakdown of when the unmet cooling loads occur in each house is shown in Figure 6-22, along with the average temperature for each climate during each time period. The Windsor climate has unmet loads occurring most frequently overnight, which is a result of the higher average night time temperatures, which causes the storage tanks to be drained of energy once solar energy is no longer available. 


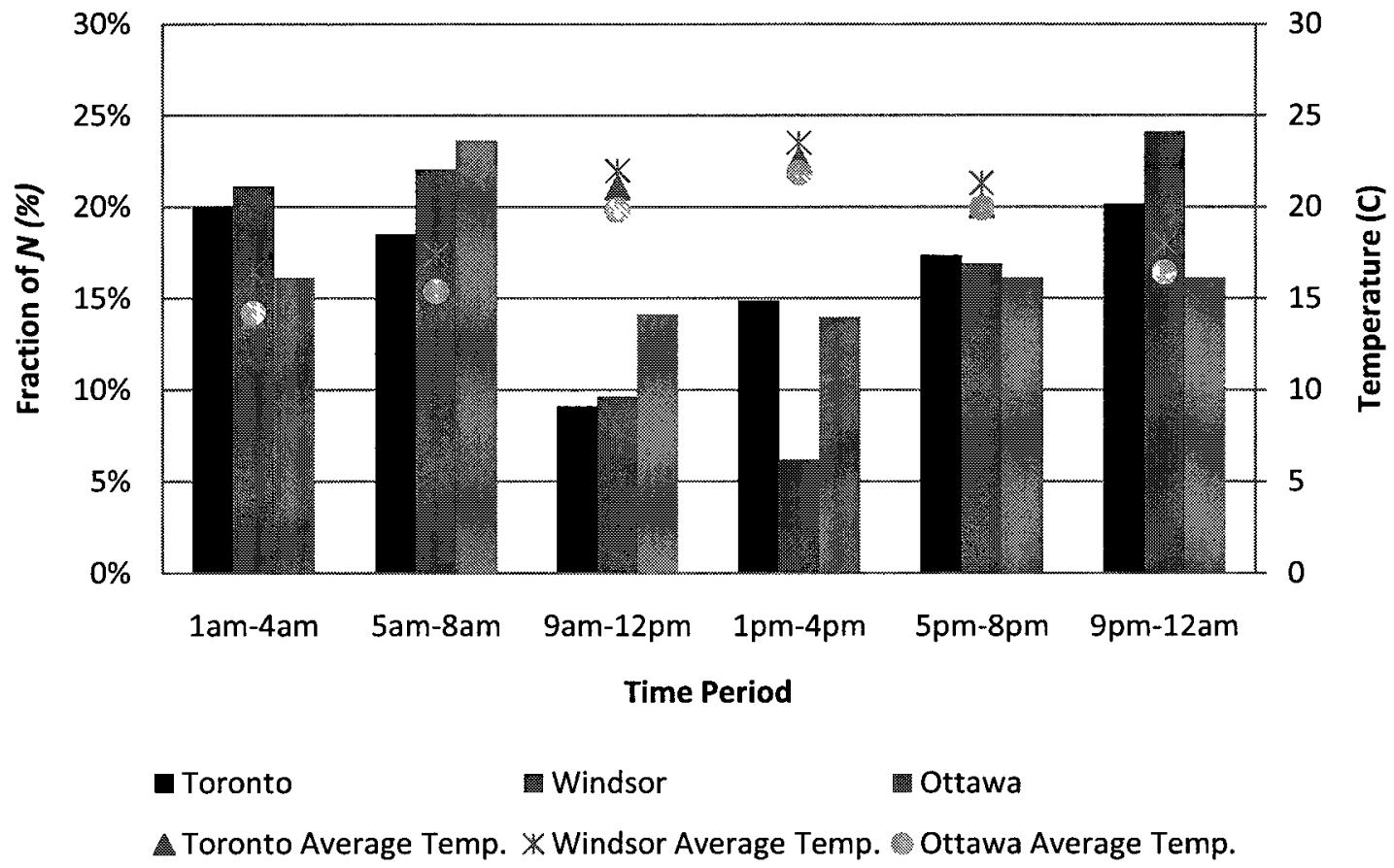

Figure 6-22: Breakdown of unmet cooling loads across four hour periods in three climates

The Toronto and Windsor climates show a decrease in unmet cooling loads during the hours with available solar energy. The Ottawa climate, however, has the highest fraction of unmet cooling loads during the 5:00 am-8:59 am period. This difference is explained by the higher incident solar radiation in the Toronto and Windsor climates, causing these systems to more quickly meet the daytime cooling loads than the house in the Ottawa climate.

Figure 6-23 and Figure 6-24 show the maximum monthly and average Zone 1 temperatures, respectively, for the 2000 house for each climate. The maximum monthly Zone 1 temperatures occurring in each climate were found to be similar, with a slightly higher peak in Toronto in August, and a significant peak of 
$28.2^{\circ} \mathrm{C}$ in July in Ottawa. This maximal temperature corresponds to July $20^{\text {th }}$, the climax of a hot week in Ottawa.

The temperatures of various component streams throughout this hot day are shown in Figure 6-25. The high temperature of the cold tank at the start of the day and the high ambient temperature resulted in all of the available solar energy being used directly in the absorption chiller, with no usable cold or hot storage available after the sunset. The result was an evening with high Zone 1 temperatures, where the system was unable to meet the load for $60 \%$ of the day. The Windsor climate was found to result in a higher temperature in September than the other two climates, corresponding to a particularly hot September $1^{\text {st }}$ day. 


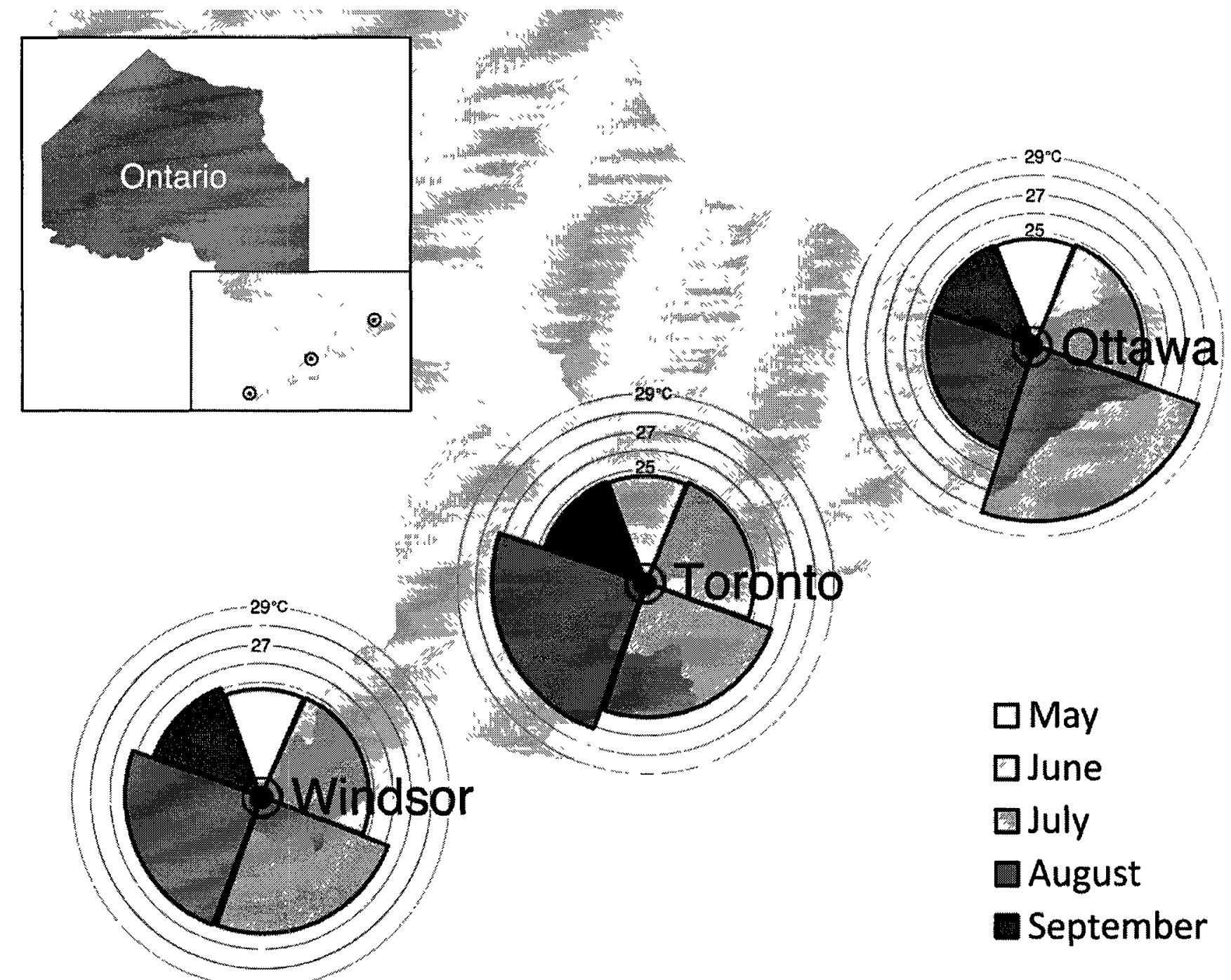

Figure 6-23: Maximum monthly Zone 1 temperature for three Ontario climates 


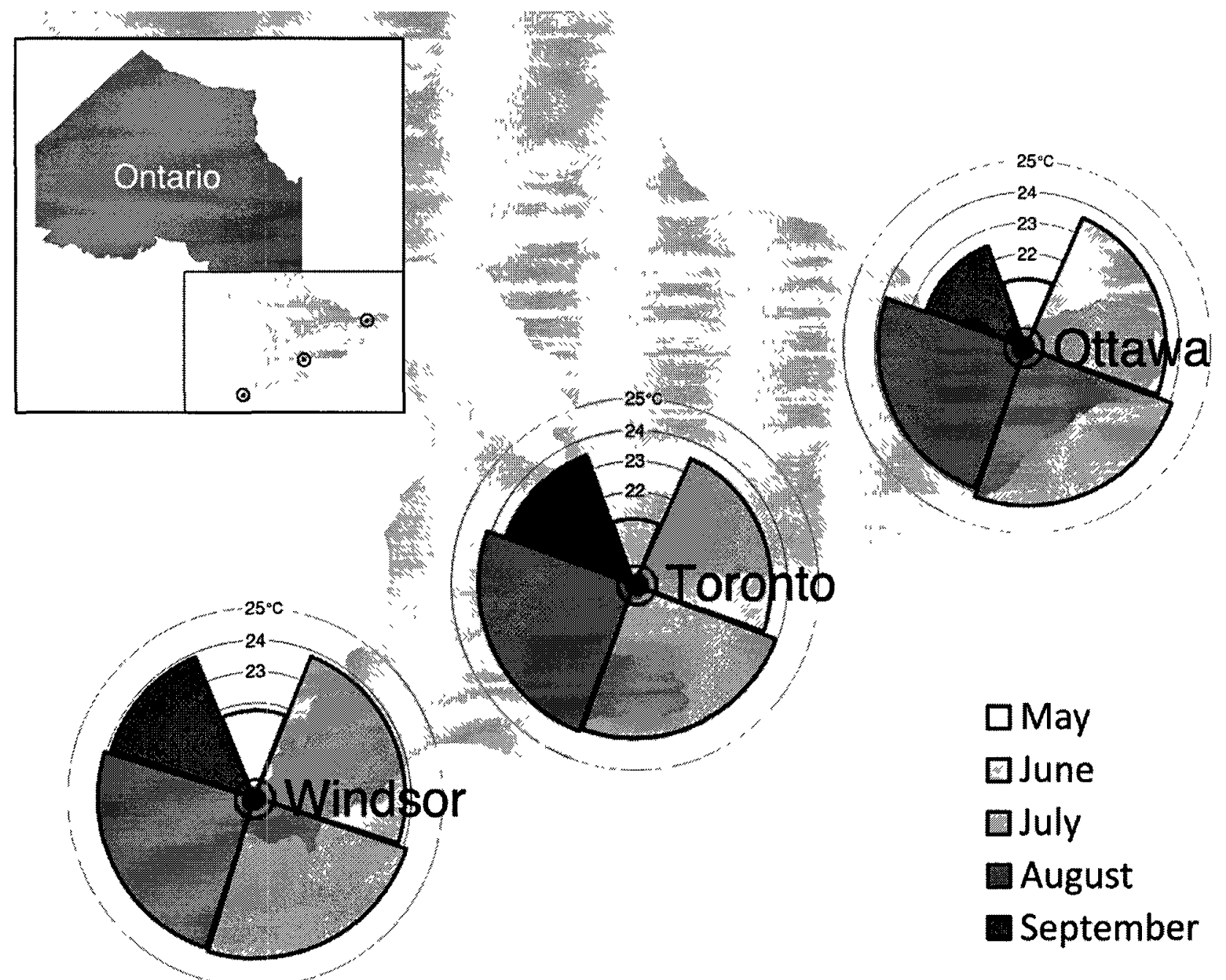

Figure 6-24: Average monthly Zone 1 temperatures across three Ontario climates 


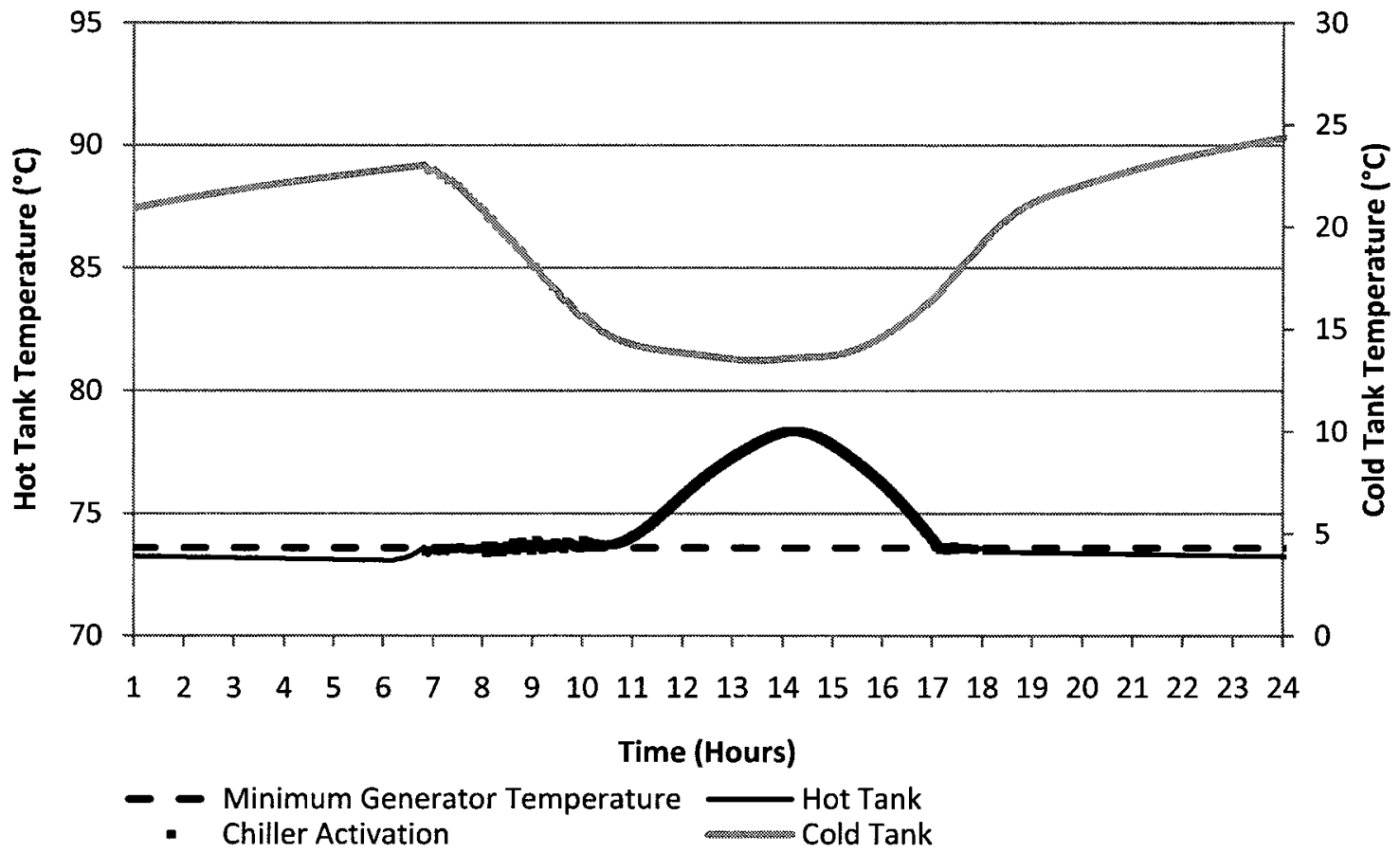

Figure 6-25: Component temperatures on hottest day (July $20^{\text {th }}$ ) in Ottawa

The average temperatures for May through August were found to be within one degree of each other for all three climates, however Windsor was found to have a mildly warmer September in relation to the other climates. The average Zone 1 temperature in Windsor in September was $23.9^{\circ} \mathrm{C}$, which corresponds to the higher average ambient temperature of $18.1^{\circ} \mathrm{C}$ in Windsor, compared to $17.6^{\circ} \mathrm{C}$ in Toronto and $15.4^{\circ} \mathrm{C}$ in Ottawa.

The temperature of the hot storage tank and cold storage tank for August $1^{\text {st }}$ is shown for each of the three climates in Figure 6-26. While the weather conditions in each of the three cities were different on August $1^{\text {st }}$, it was a hot day with high solar radiation in all three regions. The hot tank begins at a high enough temperature for 
the chiller to activate in Ottawa and Toronto, while the Windsor tank needs to be charged throughout the early morning before reaching the minimum required temperature. The cold tanks for all three climates are able to maintain the chiller setpoint temperature throughout the day.

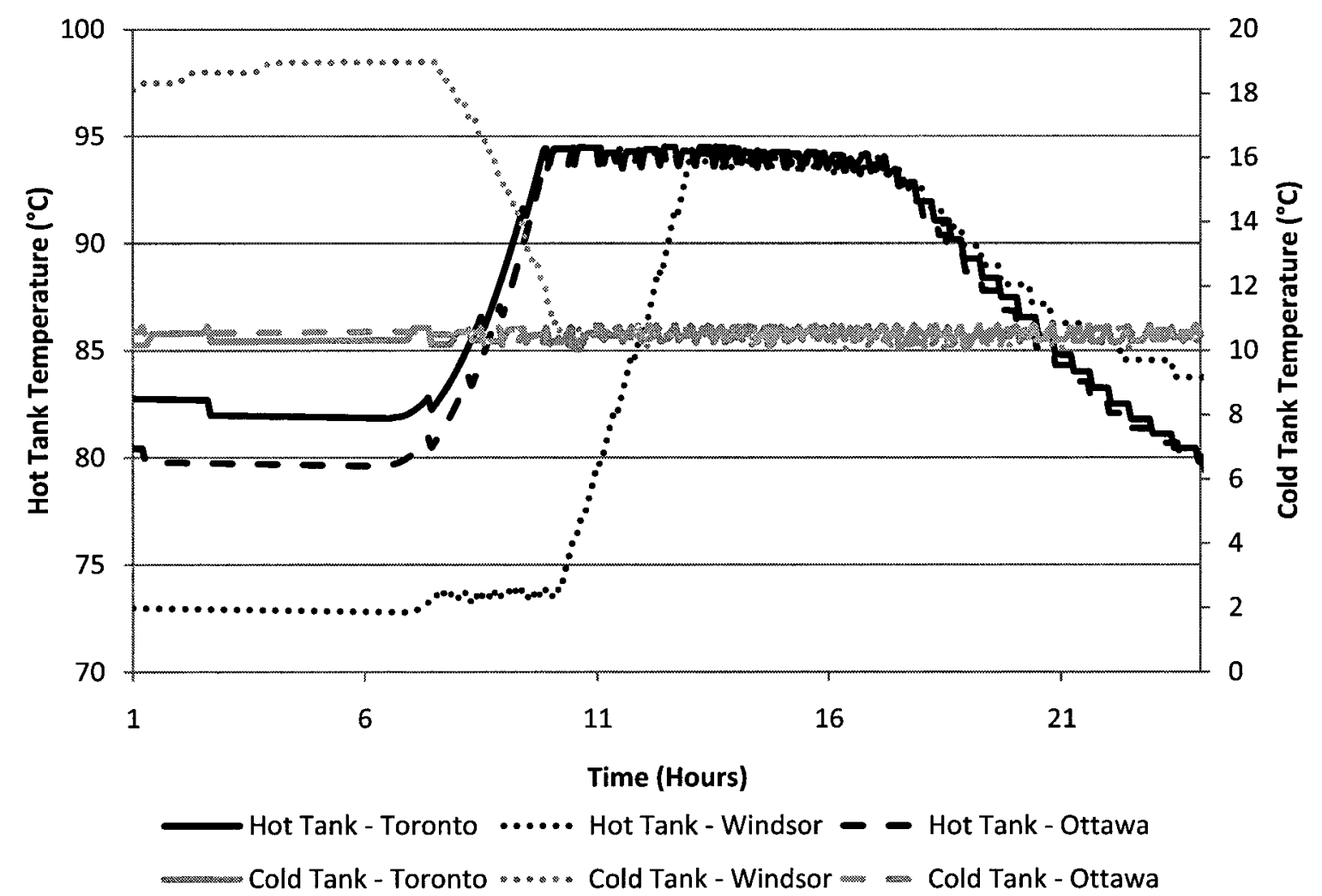

Figure 6-26: Storage tank temperatures for three Ontario climates on August $1^{\text {st }}$

The system performance variation in a single climate across a number of years is presented in the following section. A summary of findings for climatic and weather conditions is subsequently presented. 


\subsubsection{Temporal considerations}

Given the variation of temperatures and humidity of a particular climate each year, the performance of the SAC system in the 2000 house was modelled from 1999 to 2008 in the Toronto region using CWEEDS weather files. Figure 6-27 shows the resulting percentage of unmet cooling loads for each summer, as well as the maximum occurring and average temperatures for Zone 1. Table 6-7 displays weather information about each of the years. The hot summers of 2002 and 2005 in Toronto resulted in the highest frequency of zone temperatures above the setpoint of $24^{\circ} \mathrm{C}$, but the highest peak zone temperature occurs in 2006 .

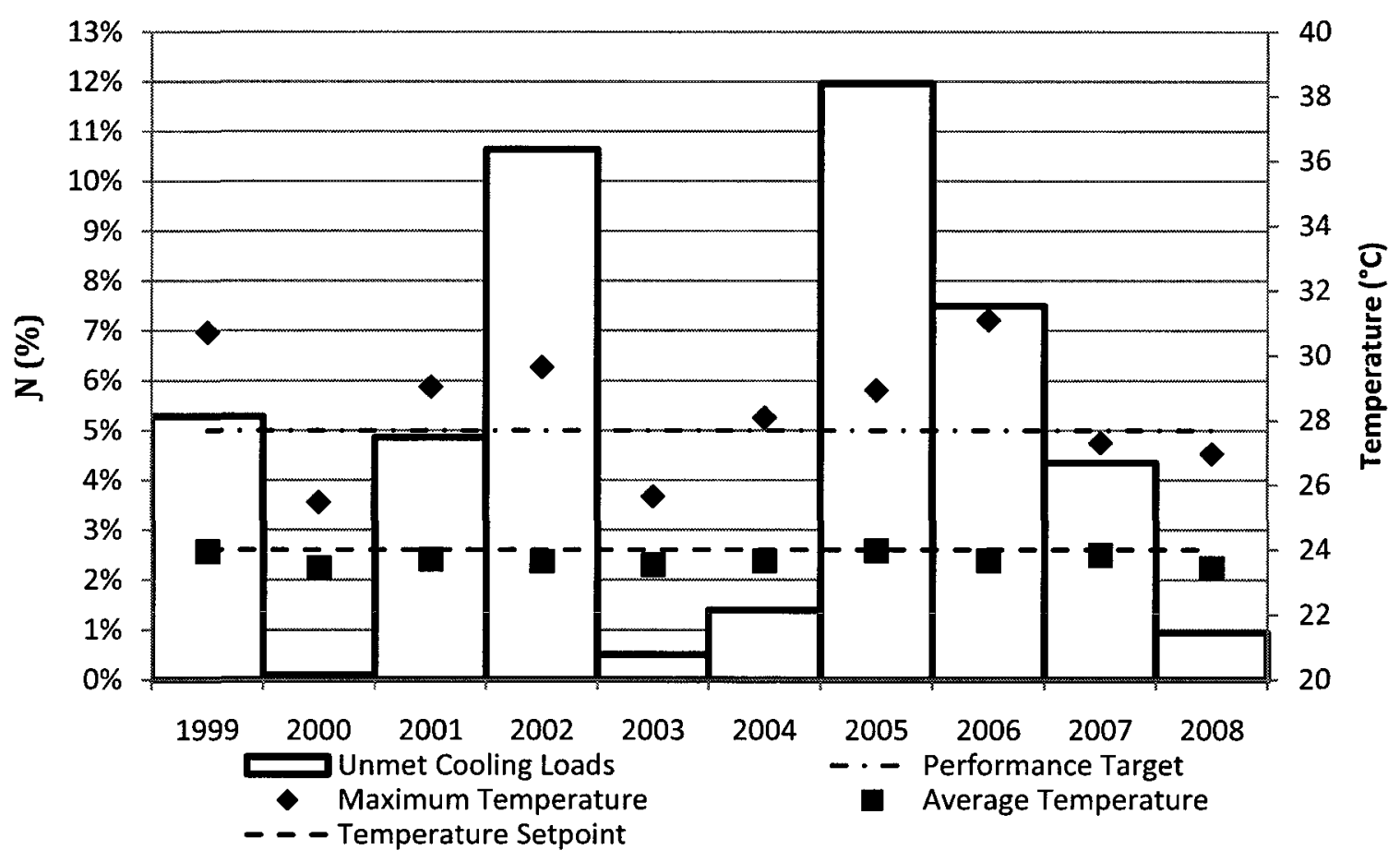

Figure 6-27: Unmet cooling loads and maximum and average zone temperatures in Toronto from 1999-2008 
The SAC system was able to meet the cooling loads and maintain the desired comfort conditions at least $95 \%$ of the time for six of the summers investigated. The remaining four summers had over-heated living zones between $5.3 \%$ and $12.0 \%$ of the time. The decade-long simulations show that while changes in weather do not affect the average zone temperature, they do significantly affect the peak temperature and frequency of peak temperatures.

Comparing $\mathcal{N}$ in Table 6-7 shows that the peak number of unmet cooling loads coincides with the years with the highest number of hours with high ambient temperatures and low solar radiation. While these occurrences don't account for all unmet cooling loads, it does affirm the finding in Section 6.2 that the system performs most poorly on hot days with low solar radiation. This finding may also explain the higher number of unmet cooling loads in 2006, despite the higher average ambient temperature and solar radiation in 2007. 
Table 6-7: Summary of weather and performance variables for Toronto Pearson International Airport for 1999-2008

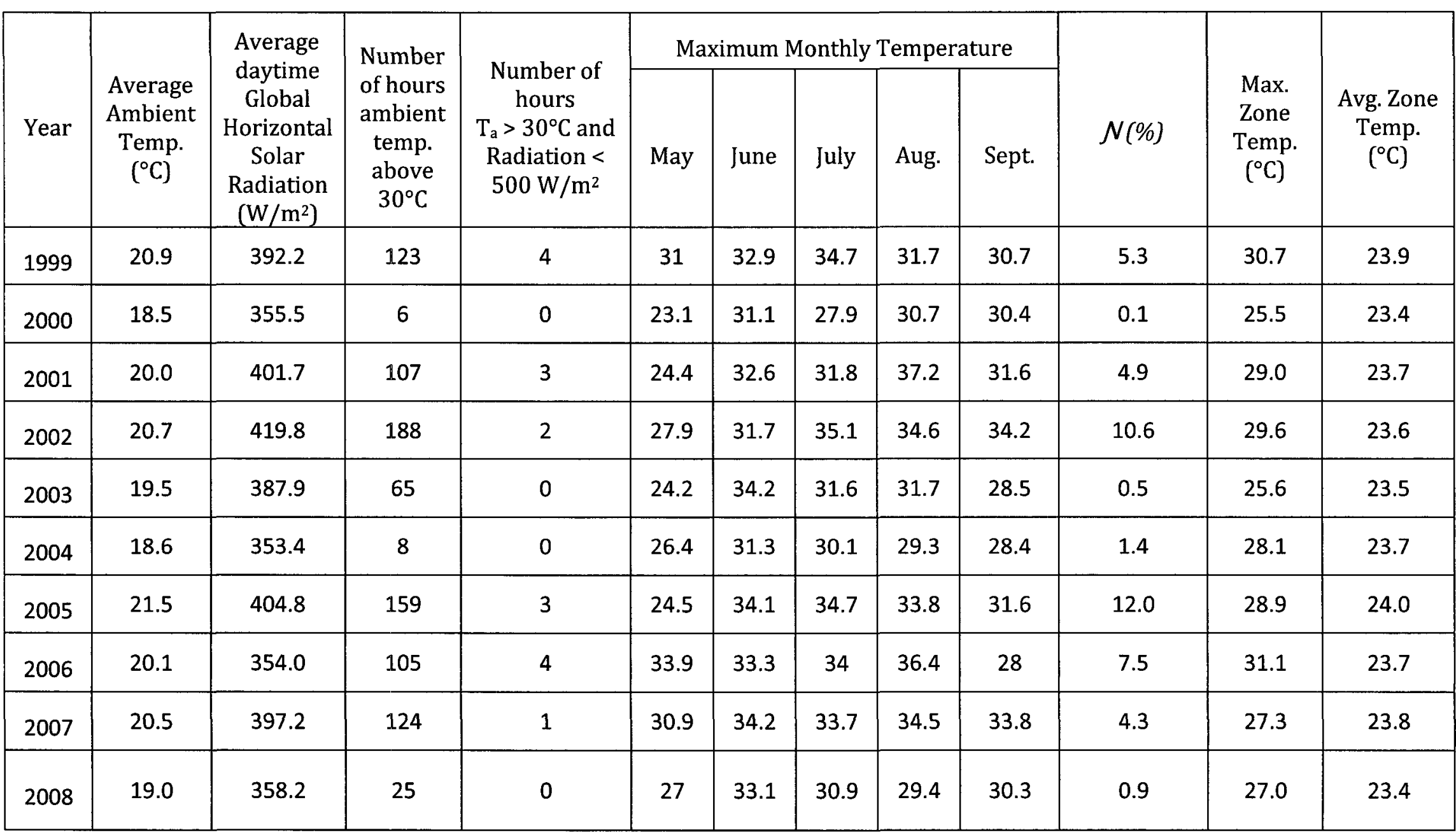




\subsubsection{Summary of findings}

The analysis of climatic and weather conditions is as follows:

- Climatic and weather conditions create variations in peak zone temperatures, and mildly affect the average temperatures.

- Climatic conditions affect the prevalence of peak Zone 1 temperatures, and subsequently the number of hours the system is unable to maintain the zone setpoint.

- The SAC system is able to maintain the cooling setpoint at least $95 \%$ of the time for average cooling years in Toronto, Windsor, and Ottawa.

- The frequency of hot ambient days is a key indicator of the system performance, however the frequency of hot days with low solar radiation was found to be the strongest predictor of the inability of the system to meet cooling loads.

- The SAC system is able to meet the loads $60 \%$ of the years between 1999 and 2008 in Toronto.

\subsection{Control Strategies}

The performance of the SAC system in the 2000 house with Toronto CWEC data was assessed with different control strategies, including changes to the zone setpoint temperature, and the minimum generator inlet temperature for the absorption chiller. The results of the zone setpoint simulations are described in Section 6.5.1, 
and the results of the generator inlet temperature simulations are discussed in Section 6.5.2.

\subsubsection{Zone cooling setpoint}

To begin, the system was modelled with three different zone temperature setpoints: 1) $24+/-0.5^{\circ} \mathrm{C}$ at all hours, 2) $23+/-0.5^{\circ} \mathrm{C}$ at all hours, and 3) $24+/-0.5^{\circ} \mathrm{C}$ from 8:00 am - 7:59 pm, $26+/-0.5^{\circ}$ from 8:00 pm - 7:59 am (varying setpoint). The summary of results for the three simulations is found in Table 6-8. The varying setpoint case provided the least number of time steps above the desired setpoint, and all systems were able to meet at least $95 \%$ of the loads.

Table 6-8: Summary of results for different zone cooling setpoints

\begin{tabular}{|c|c|c|c|c|}
\hline Setpoint & $\begin{array}{l}\% \text { of time } \\
\text { steps above } \\
\text { setpoint }\end{array}$ & $\begin{array}{l}\% \text { of time steps } \\
\text { above } 25^{\circ} \mathrm{C} \text { from } \\
8: 00 \text { am- } 7: 59 \mathrm{pm}\end{array}$ & $\begin{array}{l}\text { Max. Zone } \\
\text { Temp. }\left({ }^{\circ} \mathrm{C}\right)\end{array}$ & $\begin{array}{l}\text { Avg. Zone } \\
\text { Temp. }\left({ }^{\circ} \mathrm{C}\right)\end{array}$ \\
\hline 24 (baseline) & 2.5 & 1.0 & 27.2 & 23.4 \\
\hline 23 & 2.8 & 1.1 & 27.2 & 22.7 \\
\hline $\begin{array}{c}24 \text { - 8:00 am- } \\
7: 59 \mathrm{pm} \\
23-8: 00 \mathrm{pm}- \\
\text { 7:59 am }\end{array}$ & 1.5 & 1.0 & $\begin{array}{l}27.2 \\
27.1\end{array}$ & $\begin{array}{l}23.6 \\
23.7\end{array}$ \\
\hline
\end{tabular}

The resulting cold tank and zone temperatures for each control strategy on August $4^{\text {th }}$, the day with the peak Zone 1 temperature, is shown in Figure 6-28. The varying setpoint case begins the day with a cold tank maintained at the chiller 
setpoint temperature overnight. The other two cold tanks begin the day at nearzone temperatures. On this particular hot day, the three cold tanks are drained throughout the day, and none are able to maintain the zone temperature at $24^{\circ} \mathrm{C}$ in the evening. The varying setpoint case is able to maintain a cooler temperature throughout the day.

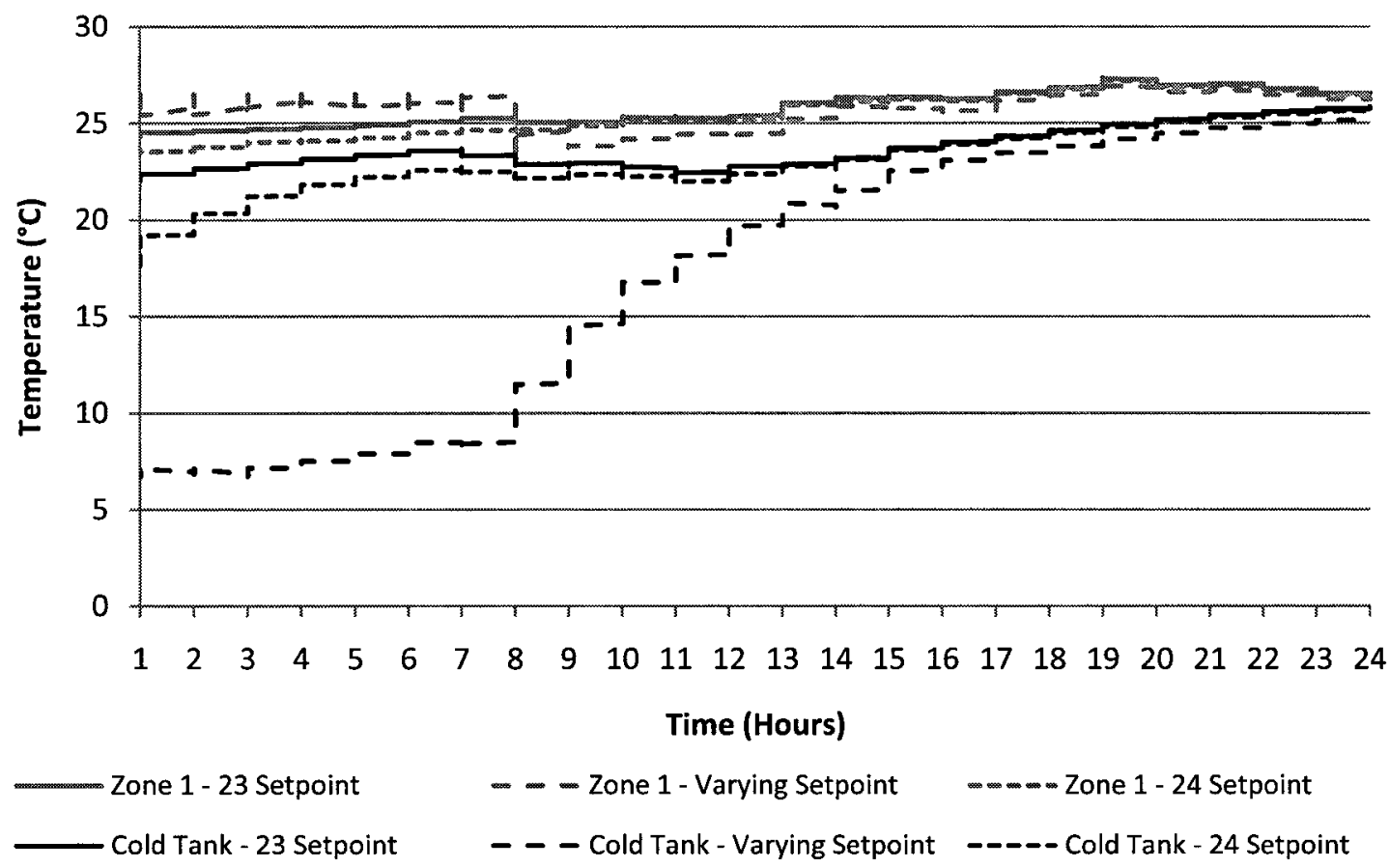

Figure 6-28: Cold storage tank and zone temperatures for different cooling setpoints on August $4^{\text {th }}$

\subsubsection{Minimum generator inlet temperature}

The SAC system was simulated with four different minimum generator inlet temperatures: $70^{\circ} \mathrm{C}, 73.6^{\circ} \mathrm{C}, 75^{\circ} \mathrm{C}$, and $80^{\circ} \mathrm{C}$. The summary of the results of these simulations can be seen in Table 6-9. The increase in minimum generator inlet temperature resulted in a lower number of time steps that the system was unable to 
meet the cooling setpoint. The improved performance of the system diminished once the minimum generator inlet temperature was $80^{\circ} \mathrm{C}$. This result is most likely due to evening hours when high ambient temperatures persist, without available solar radiation to maintain the tank at the minimum generator inlet temperature.

The increase in generator inlet temperature resulted in an increase of the average $\mathrm{COP}_{\text {th }}$, as expected. The increased $\mathrm{COP}_{\text {th }}$ resulted in an increase in evaporator heat transfer and ultimately an increase in the ability of the system to maintain the cooling setpoint in Zone 1 . The increase also led to fewer days with chiller activation, though the frequency of activation was similar for all four cases.

Table 6-9: Summary of results for different minimum generator inlet temperatures

\begin{tabular}{|c|c|c|c|c|c|c|}
\hline $\begin{array}{c}\text { Minimum } \\
\text { Generator } \\
\text { Inlet } \\
\text { Temperature } \\
\left({ }^{\circ} \mathrm{C}\right)\end{array}$ & $\mathcal{N}(\%)$ & $\begin{array}{c}\text { Maximum } \\
\text { main zone } \\
\text { temperature } \\
\left({ }^{\circ} \mathrm{C}\right)\end{array}$ & $\begin{array}{c}\text { Average } \\
\text { main zone } \\
\text { temperature } \\
\left({ }^{\circ} \mathrm{C}\right)\end{array}$ & $\begin{array}{c}\text { Average } \\
\text { COP }\end{array}$ & $\begin{array}{c}\text { \% of time } \\
\text { steps } \\
\text { chiller } \\
\text { activated }\end{array}$ & $\begin{array}{c}\text { Number } \\
\text { of days } \\
\text { chiller } \\
\text { activated }\end{array}$ \\
\hline 70 & 2.9 & 27.3 & 23.4 & 0.63 & 4.8 & 109 \\
\hline 73.6 & 2.5 & 27.2 & 23.4 & 0.67 & 4.2 & 110 \\
\hline (baseline) & 2.3 & 27.2 & 23.4 & 0.69 & 3.9 & 111 \\
\hline 75 & 2.3 & 27.3 & 23.4 & 0.71 & 3.8 & 112 \\
\hline 80 & & & & & & \\
\hline
\end{tabular}




\subsubsection{Summary of findings}

The results of the variation of the cooling setpoint and minimum generator inlet temperature are as follows:

- A higher overnight cooling setpoint increases the daytime performance of the system due to higher storage capacity available in the early morning hours.

- The SAC was still able to meet a reduced cooling setpoint of $23+/-0.5^{\circ} \mathrm{C} 95 \%$ of the time, and the peak zone temperature was not significantly affected by the change in setpoint.

- Increasing the minimum generator inlet temperature increases the overall performance of the system, including the $\mathrm{COP}_{\text {th }}$ and the number of time steps the zones are maintained at the cooling setpoint.

- The peak and average zone temperatures are not significantly affected by changing the minimum generator inlet temperature.

\subsection{Summary of Results}

The thermal performance of the SAC system was tested in a variety of houses and climates, and with varied control strategies. The system proved to be capable of maintaining a setpoint of $24+/-0.5^{\circ} \mathrm{C}$ at least $95 \%$ of the time for typical summers in Toronto, Windsor, and Ottawa; and within houses with average window area. The system failed to meet the desired cooling loads in a house with extremely large window area, and on days with high ambient temperatures and low solar radiation. 
For the base case, this resulted in 3 sequential days in both July and August with an unmaintained cooling setpoint.

These results indicate that SAC is a technically feasible option for cooling residential houses in Ontario. The resulting electrical performance of the system will be assessed in Chapter 7. Further potential for optimization of the system is explored in Chapter 8. 


\section{ChAPTER 7}

\subsection{Electrical Results and Greenhouse Gas Emissions}

One of the primary motivations for the use of solar absorption cooling is to reduce the peak load on the electrical grid during the summer months. Peak loads are supplied by GHG intensive energy generation sources, and therefore a decrease in peak loads would result in a decrease in GHG emissions. The performance of the 2000 house was simulated both with the inclusion of the SAC system and with an ideal plant model of a vapour-compression system in ESP-r (see Section 4.2). The electrical consumption of each case was compared, and the resulting reduction in GHG emissions of the SAC system was determined.

The description of the electrical loads of the SAC system is provided in Section 7.1. The electrical performance, including the overall electrical consumption of the SAC and the vapour-compression systems is discussed in 7.2. The GHG emission determination was completed using Farhat \& Ugursal (2010), and is described in Section 7.3. Finally, the resulting GHG reduction is presented in 7.4.

\subsection{System Electrical Loads}

The electrical consumption of each component in the SAC system is provided in Table 7-1. The pumping power of Pump-1 (Figure 5-1), $P_{1}(\mathrm{~W})$, was considered to be the power required to pump water across the height differential from the heat exchanger at ground level to the rooftop solar collector, z (m), at the mass flow rate, 
$\dot{m}(\mathrm{~kg} / \mathrm{s})$, as expressed in $7-1$. The acceleration due to gravity is denoted by $g\left(\mathrm{~m} / \mathrm{s}^{2}\right)$.

$$
P_{1}=\dot{m} g z
$$

Table 7-1: Electrical consumption by component of SAC system

\begin{tabular}{|c|c|}
\hline Component & $\begin{array}{c}\text { Electrical } \\
\text { Consumption (W) }\end{array}$ \\
\hline Heat Exchanger - Solar Collector Pump (Pump-1) & 8 \\
\hline Hot Water - Heat Exchanger Pump (Pump-2) & 10 \\
\hline Hot Water -Chiller Pump (Pump-3) & 130 \\
\hline Cold Water - Chiller Pump (Pump-5) & 74 \\
\hline Chiller Auxiliary Power & 210 \\
\hline Cold Water - Cooling Coil Pump (Pump-6) & 32 \\
\hline Circulation Fan & 250 \\
\hline Cooling Tower and Associated Components & 500 \\
\hline
\end{tabular}

The electrical consumption of Pump-3, $P_{3}(\mathrm{~W})$ and Pump-5, $P_{5}(\mathrm{~W})$, was determined by Equation $7-2$, using the pressure losses $(\Delta p)$ provided in the Yazaki specifications (Aroace, 2010). Equations 7-1 and 7-2 ignore pump and motor irreversibilities, but provide a reasonable base electrical draw for comparison.

$$
P_{3}=\frac{\dot{m}}{\rho} \Delta p
$$


The chiller auxiliary power was also stipulated in the Yazaki specifications (Aroace, 2010). The circulation fan power was determined by the electrical consumption of the circulation fan used in the vapour-compression unit in Swan (2009a), in order to accurately compare the two cooling systems. The remaining pumps (Pump-2 and Pump-6) were determined using Equation 7-2 and estimated pressure drops from commercially available components. The cooling tower electrical consumption was conservatively estimated by scaling the findings of Fong et al. (2010) to the flow rate of the condenser water stream. The final electrical consumption was compared to the absorption chiller electrical analysis by Fong et al. (2010) to confirm that the values were appropriate.

The electrical consumption of the vapour compression air conditioning unit was determined using the existing ideal HVAC model included in the CSDDRD (Swan et al., 2009a) for the house under investigation. The system size was appropriate to meet the cooling setpoint at least $95 \%$ of the time, and was representative of a traditional vapour compression air conditioning unit used in the house.

Both systems provided cooling centrally in the main zone and used inter-zone air flow to distribute cooling to the second living zone. The modelled electrical consumption of the inter-zone fan was not included in the electrical analysis, however it would be the same for both cases. 


\subsection{Electrical Performance}

The total electrical consumption of the SAC system in each of the four houses from May $15^{\text {th }}$ to September $15^{\text {th }}$ for the Toronto CWEC and Toronto 2006 CWEEDS climates is provided in Table 7-2. The electrical consumption with a conventional vapour-compression air conditioner set to meet the cooling setpoint of $24+/-0.5^{\circ} \mathrm{C}$ at least $95 \%$ of the time is also provided. None of the SAC systems assessed with the 2006 Toronto climate, nor with the 1976-LW house were able to meet the desired level of cooling $(N=95 \%)$, so these values do not represent a direct comparison to the conventional air conditioning system.

Table 7-2: Total summer electrical draw for four houses with conventional and solar absorption cooling systems

\begin{tabular}{|c|c|c|c|c|}
\hline House & Climate & $\mathcal{N}(\%)$ & $\begin{array}{c}\text { SAC System } \\
\text { Electrical } \\
\text { Consumption (M) }\end{array}$ & $\begin{array}{c}\text { Conventional Air } \\
\text { Conditioner } \\
\text { Electrical } \\
\text { Consumption } \\
\text { (M)) }\end{array}$ \\
\hline 1955 & Toronto CWEC & 3.3 & 1,129 & 5,772 \\
\hline 1976 & Toronto CWEC & 3.9 & 1,291 & 6,635 \\
\hline $1976-\mathrm{LW}$ & Toronto CWEC & 22.7 & $2,446^{*}$ & 10,896 \\
\hline $\begin{array}{c}2000 \\
\text { (baseline) }\end{array}$ & Toronto CWEC & 2.5 & 1,155 & 5,384 \\
\hline 1955 & Toronto 2006 & 11.7 & $2,121^{*}$ & 8,962 \\
\hline 1976 & Toronto 2006 & 10.8 & $2,239^{*}$ & 9,224 \\
\hline $1976-\mathrm{LW}$ & Toronto 2006 & 29.2 & $3,507^{*}$ & 13,472 \\
\hline 2000 & Toronto 2006 & 7.5 & $1,856^{*}$ & 7,564 \\
\hline
\end{tabular}

* Cases where the cooling setpoint was not maintained for a minimum of $95 \%$ of time steps 
In all cases, the SAC system consumes considerably less electrical energy than the conventional system. For the typical Toronto CWEC climate, the reduction in electrical consumption is over $75 \%$ for the 1955,1976 , and 2000 systems. A SAC system sized to adequately meet the cooling loads experienced in Toronto in 2006 would require greater electrical consumption than is listed, however it is expected that the consumption would still be lower than the conventional system.

The 1976-LW house is included to highlight the significant electrical draw required to cool the highly-fenestrated house. The SAC system was unable to meet the cooling loads for this house, but it is expected that the electrical consumption of an optimized system for the house would be significantly higher than for the other houses. As previously discussed, a house with large cooling loads, such as the 1976-LW house, resulted in more frequent activation of all system components. This activation created a higher electrical draw, even though the system can still fail to fully meet the cooling loads. The 1976-LW house had higher electrical consumption than all other houses and had the worst performance.

For all four houses, the proportion of the electricity use for each component is similar and is shown for the 2000 house in Figure 7-1. The largest electrical demand is due to the circulation fan, and consequently the pump between the cooling coil and the cold tank also consumes a significant portion of the electricity. 


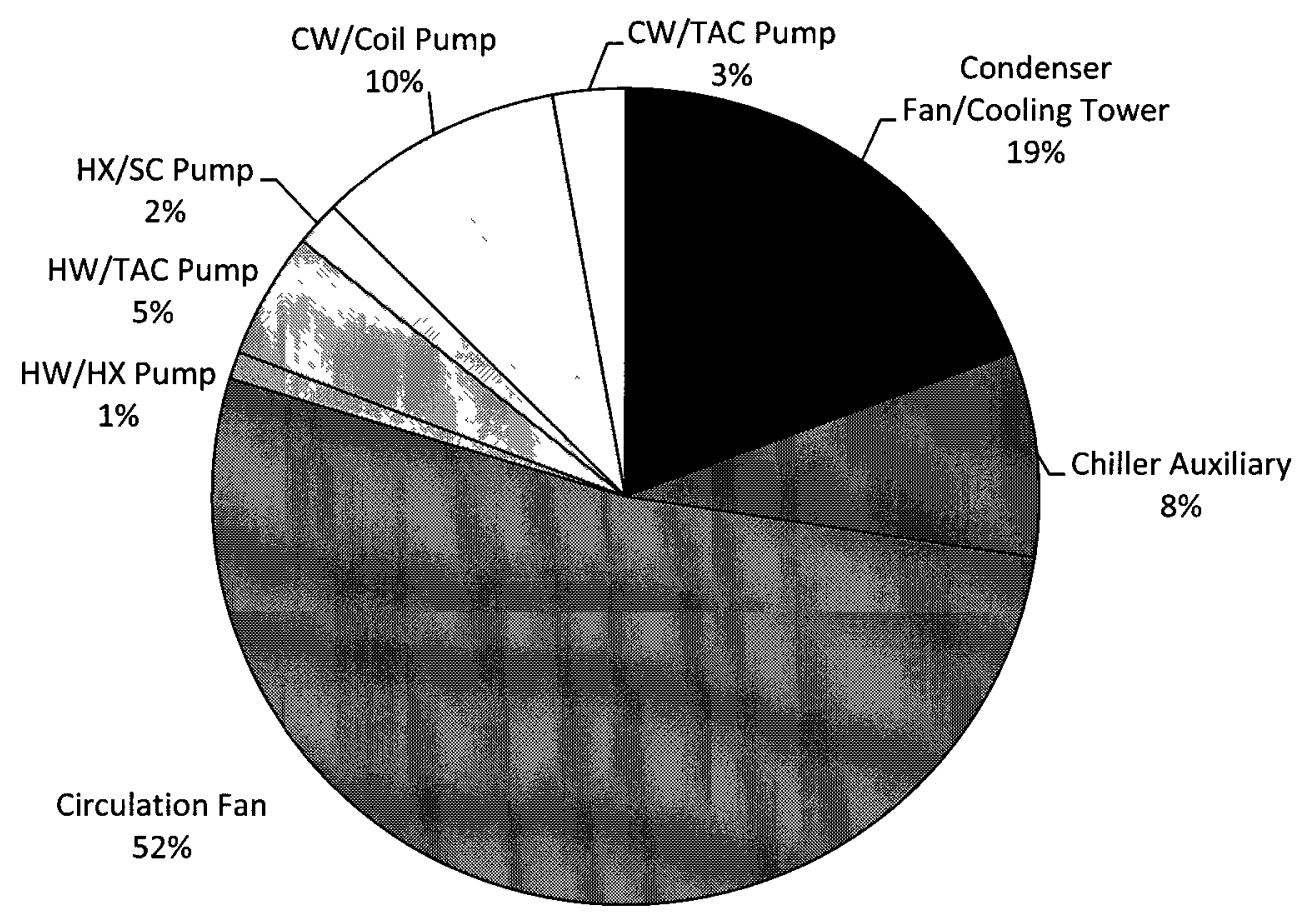

Figure 7-1: Electrical breakdown for 2000 house

The methodology for determining the GHG emission reduction for the SAC system is provided in the following section, followed by the resulting GHG performance of the system.

\subsection{Determination of Greenhouse Gas Emissions}

The determination of greenhouse gas emissions from electrical consumption is dependent on the source of electrical energy. The breakdown of electricity generation by source in Ontario is nuclear (50\%), hydro (21\%), coal (18\%), natural gas (8\%), and wind (1\%) (Farhat \& Ugursal, 2010). For simplicity, wind, hydro, and nuclear generators are not considered to have any greenhouse gas emissions. The electricity grid is powered by a combination of plants to meet base loads, 
intermediate loads, and peak loads. The quantity of each of the three plant types is determined strategically in order to meet the variable power needs, while minimizing the cost of power generation (Farhat \& Ugursal, 2010).

Base load plants are those which generate power at full capacity continuously. They are characterized by having high fixed costs and low operational costs. In Ontario, the primary base load plants are nuclear and hydroelectric plants. Intermediate load plants have moderate fixed costs, and their operational costs are higher than the base load plants. The purpose of intermediate load plants is to meet the demand between the daytime base loads and peak loads. Intermediate plants are selected because their output can change more rapidly than base plants.

Peak generation plants are selected because their output can be altered quickly to meet demand fluctuations. They have low capital cost and the highest operational cost, and are thus the most expensive to employ. In Ontario, the intermediate and peak plants are coal, natural gas, oil, and hydroelectric generators with storage. Ontario also has minor wind generation, which is considered a non-dispatchable source and is fed into the grid whenever the power is available (Farhat \& Ugursal, 2010).

The primary GHGs released during the combustion of fossil-fuels are carbon dioxide $\left(\mathrm{CO}_{2}\right)$, methane $\left(\mathrm{CH}_{4}\right)$, water $\left(\mathrm{H}_{2} \mathrm{O}\right)$, and nitrous oxide $\left(\mathrm{N}_{2} \mathrm{O}\right)$. Water is generally not considered as having a human-induced global warming effect due to its atmospheric regulation through precipitation. $\mathrm{As}^{\mathrm{CO}_{2}}$ is the gas of primary interest for global 
warming, the global warming potential (GWP) relates the impact of other gases to that of $\mathrm{CO}_{2}$ through $\mathrm{CO}_{2}$ equivalence. The GWP is a measure of the contribution to global warming of a given gas over a period of 100 years, where $\mathrm{CO}_{2}$ is defined to have a value of 1.0. The gases $\mathrm{CH}_{4}$ and $\mathrm{N}_{2} \mathrm{O}$ have GWPs of 25 and 298, by mass, respectively, indicating a much greater impact by mass than $\mathrm{CO}_{2}$ (Farhat \& Ugursal, 2010).

In order to determine the reduction in the GHG emissions of the solar absorption cooling system, greenhouse gas intensity factors (GHGIF) were employed. The work of Farhat \& Ugursal (2010) was selected due to their extensive work in determining accurate GHGIFs for intermediate and peak generation for the Ontario region at a monthly and seasonal level. This analysis is well-suited to the assessment of cooling systems due to the coincidence of high electrical cooling loads with the use of intermediate and peak generation facilities.

The GHG emission reduction was determined by comparing the electrical consumption of the CSDDRD house (Swan et al., 2009a) modelled with the vapourcompression system and the solar absorption cooling system. This comparison was completed using Equation 7-3 and the monthly marginal GHGIFs and transmission losses determined by Farhat and Ugursal (2010) for Ontario, listed in Table 7-3. 


$$
=\left(\frac{\text { reduction in on }- \text { site electricity consumption }(k W h)}{1-\frac{\% \text { losses }}{100}}\right) \times G H G I F
$$

Table 7-3: Marginal greenhouse gas intensity factors

(Farhat \& Ugursal, 2010)

\begin{tabular}{|c|c|}
\hline Month & $\begin{array}{c}\text { Marginal GHGIF } \\
\left.\text { (gCO }_{\text {2eq }} \text { /kWh }\right)\end{array}$ \\
\hline May & 501 \\
\hline June & 514 \\
\hline July & 489 \\
\hline August & 491 \\
\hline September & 455 \\
\hline \% losses & 6 \\
\hline
\end{tabular}

\subsection{Greenhouse Gas Emission Results}

Once the reduction in electricity consumption for the 2000 house with Toronto CWEC climate was determined with the implementation of the SAC system, the GHG emission reduction was calculated. Table $7-4$ provides the monthly reduction in electricity consumption of the SAC system relative to the traditional vapourcompression system, and the resulting GHG emission reduction. The total GHG emissions of the house's cooling system were reduced by $614 \mathrm{~kg} \mathrm{CO}_{2 \text { eq. }}$ The average Canadian was responsible for 22.04 tonnes of $\mathrm{CO}_{2 \mathrm{eq}}$ in 2008 , with 1.3 tonnes from 
residential sources (Environment Canada, 2010a). The implementation of a SAC system for a household of four would account for an approximate reduction of $12 \%$ of the household's annual residential GHG emissions.

Table 7-4: Monthly greenhouse gas emission reduction

\begin{tabular}{|c|c|c|}
\hline Month & $\begin{array}{c}\text { Reduction in on-site } \\
\text { electricity consumption } \\
\text { (M) }\end{array}$ & $\begin{array}{c}\text { GHG Emission Reduction } \\
\left.\text { (kgCO }_{\text {2eq }}\right)\end{array}$ \\
\hline May & 95 & 14 \\
\hline June & 856 & 130 \\
\hline July & 1528 & 221 \\
\hline August & 1360 & 197 \\
\hline September & 390 & 52 \\
\hline Total & $\mathbf{4 2 2 9}$ & $\mathbf{6 1 4}$ \\
\hline
\end{tabular}

The total residential sector central air space-cooling energy use in Ontario was 12.1 PJ in 2008 (NRCan, 2010). Each of the systems described in Table 7-2 resulted in over $75 \%$ reduction in electrical consumption for the SAC system relative to the vapour compression system. Estimating a $75 \%$ reduction in electrical consumption for the adoption of SAC systems in place of existing systems, a rough approximation can be made for the total GHG emissions reduction for central air space-cooling in Ontario.

Farhat and Ugursal (2010) presented an annual GHGIF for Ontario of $407 \mathrm{gCO}_{2 \mathrm{eq}} / \mathrm{kWh}$ when monthly energy reduction information is unavailable. Using 
Equation 7-3 and the estimated energy reduction in Table 7-5, the annual GHG emission reduction was determined for Ontario central air space-cooling for different levels of provincial SAC adoption. The data in the table are meant as an approximation and are not recommended for use beyond the discussion in the present research.

As presented in the table, a $1 \%$ adoption rate of the SAC technology in Ontario residential households could roughly produce a reduction of 10 kilotonnes of $\mathrm{CO}_{2 \mathrm{eq}}$ annually, a significant reduction. The data presented provides incentive for continued research into the reduction of barriers to the adoption of SAC for residential space-cooling.

Table 7-5: Approximation of annual Ontario central air space-cooling GHG emission reduction for different levels of SAC adoption

\begin{tabular}{|c|c|c|}
\hline SAC Adoption Rate & Energy Reduction (T) & $\begin{array}{c}\text { GHG Emission Reduction } \\
\left.\text { (kilotonnes } \mathrm{CO}_{2 \mathrm{eq}}\right)\end{array}$ \\
\hline $1 \%$ & 91 & 10 \\
\hline $5 \%$ & 454 & 51 \\
\hline $10 \%$ & 907 & 103 \\
\hline $25 \%$ & 2269 & 256 \\
\hline $50 \%$ & 4538 & 513 \\
\hline
\end{tabular}

The BPS of the SAC system showed a considerable reduction in electrical consumption of over $75 \%$, compared to a traditional vapour compression system. Due to the reliance on GHG-intensive fuels for intermediate and peak loads, this 
electrical reduction translated into a reduction of $614 \mathrm{~kg}$ of GHG emissions. These results demonstrate that SAC is not only technically feasible in Ontario, but also would provide much needed relief from peak electrical grid loading and provincial GHG emissions. Conclusions about the assessment of SAC for Ontario as well as recommendations for future work are provided in the following Chapter. 


\section{ChAPTER 8}

\subsection{Conclusions and Recommendations for Future Work}

Residential space-cooling accounts for a significant level of electricity use during the summer months in Canada. This work has shown that solar absorption cooling could reduce the electrical draw for space-cooling, and positively impact the electricity grid during the peak summer season in Ontario. This reduction in electrical draw could consequently reduce the emissions from greenhouse gasintensive peak demand energy sources. The assessment of the suitability of solar absorption cooling as an alternative to traditional vapour compression cooling was undertaken for a representative sample of Ontario residences. This research was the second phase of a larger performance assessment; the first phase involved experimental testing of a small-scale absorption chiller.

The research objectives were to create an accurate model of a full, appropriatelysized solar absorption cooling system for use in building performance simulation software. The system was designed and first sized using TRNSYS 17 software, and later implemented in a full building model in the ESP-r simulation environment. The performance of the system was assessed within different house geometries, operating conditions, and climatic regions. The system was found to perform well with a large solar collector area of $50 \mathrm{~m}^{2}$, and two water storage tanks totalling $2.0 \mathrm{~m}^{3}$. 
The system was able to maintain a cooling setpoint of $24+/-0.5^{\circ} \mathrm{C}$ at least $95 \%$ of the time from May $15^{\text {th }}-$ September $15^{\text {th }}$ for typical summers in Toronto, Windsor, and Ottawa. The system was robust enough to successfully maintain a lower cooling setpoint of $23+/-0.5^{\circ} \mathrm{C}$. The system failed to meet the cooling setpoint on days with high temperatures and low incident solar radiation, and in houses with particularly high window areas. The fluctuation of weather conditions from year to year for Toronto affected the performance of the system.

The electrical draw for the SAC system was less than $25 \%$ than that of a vapour compression system, resulting in a substantial reduction in greenhouse gas emissions. These results affirmed the feasibility and environmental benefits of using a solar absorption cooling system for space-cooling in Ontario.

The results of the research attest to the potential use for solar absorption cooling in Ontario climates, while also providing motivation for further research into the application and reduction of barriers of SAC systems.

\subsection{Recommendations for System Optimization}

The system used for the base analysis in the research utilized a large evacuated tube collector area, which represents a high initial investment cost. In addition, the $1.5 \mathrm{~m}^{3}$ cold storage tank is rather large for residential applications. Future research should address opportunities to reduce the high capital cost required to implement the SAC system. These opportunities could involve grants from government bodies 
for renewable energy systems, as well as options for reducing the required size of these system components.

The inclusion of occupant behaviour strategies in future research work could result in much lower required storage and solar collector area. Many occupants actuate blinds and utilize operable windows within their residences that could significantly reduce the cooling loads of a house. The work of Saldanha (2010), for example, could be incorporated into building simulation to determine the reduction in loads from various occupant control strategies.

Additionally, the research demonstrated the sensitivity of the system to the generator setpoint temperature. Further experimental research on the absorption chiller across a wider range of operating conditions would bring about a greater level of accuracy to future simulations, including a variety of flow rates for each of the chiller streams. Experimental research to determine accurate electrical consumption of all components and in particular the cooling tower, would also prove to be beneficial for further investigations.

Finally, the Yazaki chiller (Aroace, 2010) used was selected due to the available recent experimental results. However, the chiller has a $35 \mathrm{~kW}$ capacity, which is much greater than the peak loads experienced by most residential houses. The effect of the oversized chiller was frequent cycling on and off of the chiller during simulations. This cycling was due to the immediate draw of the hot tank temperature below the minimum generator temperature. A smaller chiller could 
result in less frequent cycling and higher chiller efficiencies. This change would also better utilize the hot storage as it would be less frequently drawn down, and better align available cooling to the times with greatest cooling need.

\subsection{Recommendations for Future Simulation Work}

For future solar absorption cooling research involving simulations, it is recommended that the associated ESP-r components are further refined. For the absorption chiller model, it is suggested that a dynamically calculated temperature buffer based on experimental data is employed in order to more accurately reflect local heating conditions, as suggested by Beausoleil-Morrison et al. (2004). The evacuated tube solar collector model in ESP-r should also be revised to allow for a wider range of flow rates to be evaluated. These changes, though minimal in their effects, would allow for more accurate simulation of component performance.

The greenhouse gas emission predictions in the present research were reliant on the GHGIFs determined by Farhat and Ugursal (2010). The provincial fuel mix and GHGIFs shift each year due to the fluctuations in electrical production and efficiencies of the marginally producing power plants. Additionally, the Ontario government has projected that coal plants will be phased out and replaced with increased base loads provided by nuclear and intermediate and peak natural gas production by 2014 , which will significantly affect the monthly GHGIF for Ontario. It is advised that future work in this area uses updated IESO data to determine appropriate GHGIFs. 


\section{REFERENCES}

Abadie, M., Deblois, J., \& Mendes, N. (2005). A comparison exercise for calacuting heat and moisture transfers using TRNSYS and PowerDomus. Curitiba, Brazil: Pontifical Catholic University of Parana.

Aroace. (2010). Water Fired Single-Effect Absorption Chiller and Chille-Heater. Plano Texas: Yazaki Energy Systems, Inc.

Asrubali, F., Baldinelli, G., \& Presciutti, A. (2009). An Experimental Solar Cooling System with a Small Size Absorption Chiller: Design and First Measurements. 3rd International Conference Solar Air-Conditioning. Palermo: OTTI.

Balaras, C., Grossman, G., Henning, H.-M., Infante Ferreira, C., Podesser, E., Wang, L., et al. (2007). Solar air conditioning in Europe - an overview. Renewable \& Sustainable Energy Reviews , 299-314.

Balghouthi, M., Chahbani, M., \& Guizani, A. (2005). Solar Powered air conditioning as a solution to reduce environmental pollution in Tunisia. Desalination , 105-110.

Bansal, N. K., \& Bhandari, M. S. (1996). Comparison of the periodic solution method with TRNSYS and SUNCODE for thermal building simulation. Solar Energy, 57 (1), 918. 
Beausoleil-Morrison, I. (2000). The Adaptive Coupling of Heat and Air Flow Modelling Within Dynamic Whole-Building Simulation. Glasgow: Energy Systems Research Unit, University of Strathclyde.

Beausoleil-Morrison, I., Mottillo, M., Brandon, R., Sears, P., \& Ferguson, A. (2004). The Simulation of a Residential Space-Cooling System Powered by the Thermal Output of a Cogeneration Device. ESim - The Canadian Conference on Building Energy Simulation (p. 163). Vancouver: IBPSA-Canada.

Bong, T., Ng, K. C., \& Tay, A. (1987). Performance Study of a Solar-Powered AirConditioning System. Solar Energy , 39 (3), 173-182.

Bongs, C., Dalibard, A., Kohlenbach, P., Marc, O., Gurruchaga, I., \& Tsekouras, P. (2010). Simulation Tools for Solar Cooling Systems - Comparison for a Virtual Chilled Water System. EuroSun 2010: International Conference on Solar Heating, Cooling, and Buildings. Graz.

Clarke, J. A. (2001). Energy Simulation in Building Design. Oxford: ButterworthHenemann.

Clarke, J. A. (1977). Environmental Systems Performance. Glasgow: University of Sstrathclyde. 
Cristina, S., Soutullo, S., Enriquez, R., Ferrer, J., \& Heras, M. (2010). NEW

SIMULATION MODEL OF ABSORPTION PUMP WITH INTERNAL STORAGE. ESim 2010 (pp. 40-47). Winnipeg: IBPSA Canada.

Cruickshank, C. A., \& Harrison, S. (2006). Simulation and Testing of Stratified MultiTank, Thermal Storages for Solar Heating Systems. Eurosun. Glasgow.

Dincer, I., Edin, M., \& Ture, I. E. (1996). Investigation of Thermal Performance of a Solar Powered Absorption Refrigeration System. Energy Conservation Management, $37(1), 51-58$.

Duffie, J. A., \& Beckman, W. A. (2006). Solar Engineering of Thermal Processes (3rd Edition ed.). Hoboken: John Wiley \& Sons, Inc.

Environment Canada. (2010a). Greenhouse Gas Emissions Data. Retrieved 06 20, 2011, from Environment Canada: http://www.ec.gc.ca/indicateursindicators/default.asp?lang=en\&n=BFB1B398-1\#ghg7_en

Environment Canada. (2010b). National Climate Data and Information Archive. Retrieved 05 2011, from Canadian Cities are Weather Winners!: http://www.currentresults.com/Weather-Extremes/Canada/hottest-citiessummer.php 
Environment Canada. (2011). National Climate Data and Information Archive. Retrieved 06 17, 2011, from Environment Canada: http://climate.weatheroffice.gc.ca/prods_servs/index_e.html ESRU. (2002). The ESP-r system for building energy simulation: user guide version 10 series. Retrieved from Energy Systems Research Unit: www.esru.strath.ac.uk ESTIF. (2006). Solar assisted cooling - state of the art. Report of project key issues for renewable heat in Europe. ESTIF.

Farhat, A. A., \& Ugursal, V. I. (2010). Greenhouse gas emission intensity factors for marginal electricity generation in Canada. International Journal of Energy Research , 1309-1327.

Florides, G. A., Kalogirou, S. A., Tassou, S., \& Wrobel, L. (2002a). Modelling and simulation of an absorption solar cooling system for cyprus. Solar Energy , 43-51.

Florides, G., Kalogriou, S., Tassou, S., \& Wrobel, L. (2002b). Modelling, simulation and warming impact assessment of a domestic-size absorption solar cooling system. Applied Thermal Energy , 1313-1325.

Fong, K., Chow, T., Lee, C., Lin, Z., \& Chan, L. (2010). Solar Energy. ScienceDirect, 84 (2), 227-244.

Ghaddar, N., Shihab, M., \& Bdeir, F. (1997). Modeling and simulation of solar absorption system performance in Beirut. Renewable Energy , 539-558. 
Grossman, G. (2002). Solar-Powered Systems for Cooling, Dehumidification and airconditioning. Solar Energy , 53-62.

Harrison, S., Rogers, B., Soltau, H., \& Wood, B. (1993). The Characterization and Testing of Solar Collector Thermal Performance. Kingston: Solar Calorimetry Laboratory, Queen's University.

Henning, H.-M. (2007b). Solar assisted air conditioning of buildings - an overview. Applied Thermal Engineering , 1734-1749.

Henning, H.-M. (2007a). Solar-Assisted Air-Conditioning in Buildings (2nd Revised Edition ed.). New York: Springer-Verlag Wien NewYork.

IEA. (2010). IEA Conservation in Buildings \& Community Systems. Retrieved 0620 , 2011, from The ECBCS Research Programme: http://www.ecbcs.org/

IEA/SCH Task 25. (2002). ONGOING RESEARCH RELEVANT FOR SOLAR ASSISTED AIR CONDITIONING SYSTEMS. IEA/SCH Task 25: Solar-assisted air-conditioning of buildings.

Johnson, G. (2011). Design and Commissioning of an Experiment to Characterize the Performance of a Lithium-Bromide Absorption Chiller. Ottawa: Carleton University.

Keiholz, W., Kummert, M., \& Riederer, P. (2003). CSTB. Retrieved 05 2011, from Type 155 - a new TRNSYS type for coupling TRNSYS and MATLAB: Example of using 
Matlab controllers with TRNSYS components:

http://kheops.champs.cstb.fr/simbadlab/workshop/Presentation4.pdf

Kim, D., \& Ferreira, I. (2008). Solar refrigeration options - a state-of-the-art review. International Journal of Refrigeration , 3-15.

Kutner, M., Nachtsheim, C., \& Neter, J. (2004). Applied Linear Regression Models (4th Edition ed.). McGraw-Hill.

LA Audubon. (2008). Centre of Audubon Chapter Activity in the Los Angeles Area. Retrieved 03 08, 2010, from Video - Air Conditioning System at Debs Park Audubon Environmental Center, Link:

http://losangelesaudubon.org/index.php?option=com_content\&task=view\&id=306 \&Itemid $=131$

Mateus, R., \& Oliveira, A. (2009). Energy and Economic Analysis of an Integrated Solar Absorption Cooling and Heating System in Different Building Types and Climates. Applied Energy, 86 (6), 949-957.

NRCan. (2008a). Natural Resources Canada. Retrieved 09 20, 2009, from Economic Scan of Canada's Energy Sector: Residential Sector: http://www.sst.gc.ca/default.asp?lang=En\&n=AADC6287-1\&offset=3\&toc=show 
NRCan. (2008b). Office of Energy Efficiency. Retrieved November 2010, from Water Usage and Sizing: http://oee.nrcan.gc.ca/residential/personal/water-usagesizing.cfm?attr $=4$

NRCan. (2010). Office of Energy Efficiency. Retrieved 06 10, 2011, from Residential Sector: Ontario:

http://oee.nrcan.gc.ca/corporate/statistics/neud/dpa/tablestrends2/res_on_27_e_ 4.cfm?attr $=0$

Numerical Logics. (1999). Canadian Weather for Energy Calculations, Users Manual and CD-ROM. Downsview, Ontario: Environment Canada.

Phillips, D. (2010). National Climate Data and Information Archive. Retrieved 121 , 2010, from Canadian Cities are Weather Winners!:

http://www.climate.weatheroffice.gc.ca/winners/intro_e.html

Riley, J. M., \& Probert, S. (1998). Carbon-dioxide emissions from an integrated smallscale CHP and absorption chiller system. Applied Energy , 193-207.

Saldanha, N. (2010). Towards the assessment of a residential electric storage system: analysis of Canadian residential electricity use and the development of a lithium-ion battery model. Ottawa: Carleton University.

SEIA. (2010). SEIA Solar Directory. Retrieved 03 08, 2010, from Solar Air Conditioning Search Results: 
http://seiasolardirectory.com/results.php?category=Installers+/+System+Integrato rs+for+Consumers\&heading $=248 \&$ category_id $=2703$

Solartechnik Prufung Forschung. (2007). Solar Collector Factsheet: Wikora Wikosun HP 65-30. Rapperswil: SPF Testing.

Sparber, W., Napolitano, A., \& Melograno, P. (2007). OVERWIEW ON WORLD WIDE INSTALLED SOLAR COOLING SYSTEMS. 2nd International Conference Solar Air Conditioning (pp. 1-6). Tarragona: Institute for Renewable Energy, EURAC Research of Bolzano.

Stephenson, \& Mitalas. (1967). Cooling load calculations by thermal response factor method. ASHRAE Transactions [0001-2505], 73 (1), 7.

Strachan, P. (2008). History and development of validation with the ESP-r simulation program. Building and Environment, 43 (4), 601.

Swan, L. G. (2010). Residential Sector Energy and GHG Emissions Model for the Assessment of New Technologies. Halifax: Dalhousie University.

Swan, L., Ugursal, V., \& Beausoleil-Morrison, I. (2009a). A database of house descriptions representative of the Canadian housing stock for coupling to building energy performance simulation. Journal of Building Performance Simulation , 2 (2), 75-84. 
Swan, L., Ugursal, V., \& Beausoleil-Morrison, I. (2009b). Implementation of a

Canadian residential energy end-use model for assessing new technology impacts. Proceedings of the IBPSA Building Simulation 2009 (pp. 1429-1436). Glasgow: IBPSA.

Thevenard, D., Haddad, K., \& Purdy, J. (2004). Development of a new solar collector model in ESP-r. Canadian Solar Building Conference. Montreal.

Tsoutsos, T., Aloumpi, E., Gkouskos, Z., \& Karagiorgas, M. (2010). Design of a solar absorption cooling system in a Greek hospital. Energy and Buildings , 265-272.

U.S. Department of Energy. (2011). Energy Efficiency and Renewable Energy.

Retrieved 02 08, 2011, from Building Energy Software Tools Directory: http://apps1.eere.energy.gov/buildings/tools_directory/

Underwood, C. (1997). A Comparative Assessment of Two HVAC Plant Modelling Programs. Building Simulation. Prague: IBPSA.

University of Wisconsin. (2010). TRNSYS 17 Documentation. Madison: Solar Energy Lab.

Vanek, F., \& Albright, L. (2008). Energy Systems Engineering. USA: McGraw-Hill.

Vidal, H., Escobar, R., \& Colle, S. (2009). Simulation and Optimization of a Solar Driven Air Conditioning System for a House in Chile. ISES Solar World Congress (pp. 844-853). Johannesburg: ISES. 
Walker, I., \& Wilson, D. (1990). The Alberta air infiltration model: AIM-2. Edmonton: The University of Alberta, Department of Mechnical Engineering.

Wang, W., Beausoleil-Morrison, I., \& Reardon, J. (2009). Evaluation of the Alberta air infiltration model using measurements and inter-model comparisons. Building and Environment , 309-318.

Zhai, X. Q., \& Wang, R. Z. (2009a). A review for absorbtion and adsorbtion solar cooling systems in China. Renewable and Sustainable Energy Reviews , 1523-1531.

Zhai, X., \& Wang, R. (2009b). Experimental investigation and theoretical analysis of the solar adsorption cooling system in a green building. Applied Thermal Engineering, 17-27. 


\title{
APPENDIX A: TRNSYS Deck File
}

\author{
VERSION 17 \\ * Model "Type99-Weather File" (Type 99) \\ $*$
}

UNIT 21 TYPE 99 Type99-Weather File

*\$UNIT_NAME Type99-Weather File

*\$MODEL . \Weather Data Reading and Processing \User Format \Type99.tmf *\$POSITION 134255

*\$LAYER Main \#

PARAMETERS 3

55

4

1

INPUTS 3

0,0 ! [unconnected] Ground reflectance

0,0 ! [unconnected] Slope of surface

0,0 ! [unconnected] Azimuth of surface

$* * *$ INITIAL INPUT VALUES

0.200

* Model "Type9a - Cooling Loads" (Type 9)

$*$

UNIT 20 TYPE 9 Type9a-Cooling Loads

*\$UNIT_NAME Type9a - Cooling Loads

*\$MODEL . \Utility \Data Readers \Generic Data Files $\backslash$ First Line is Simulation

Start \Free Format \Type9a.tmf

*\$POSITION 650202

*\$LAYER Main \#

PARAMETERS 10

2

0

1

1

1

1

0

1

57

$-1$

! 1 Mode

! 2 Header Lines to Skip

! 3 No. of values to read

! 4 Time interval of data

! 5 Interpolate or not?

! 6 Multiplication factor

17 Addition factor

! 8 Average or instantaneous value

! 9 Logical unit for input file

*

! 10 Free format mode 
* Model "Type4a - Cold Tank" (Type 4)

UNIT 26 TYPE 4 Type4a - Cold Tank

*\$UNIT_NAME Type4a - Cold Tank

*\$MODEL.$\backslash$ Thermal Storage $\backslash$ Stratified Storage Tank $\backslash$ Fixed Inlets $\backslash$ Uniform

Losses $\backslash$ Type4a.tmf

*\$POSITION 511383

* \$LAYER Main \#

PARAMETERS 34

1

0.5

4.19

1000

3.0

.06

.06

.06

.06

.06

.06

.06

.06

.06

.06

.06

.06

.06

.06

.06

1

1

1

150

5

0

1

1

150

5

0

0

20

100

!1 Fixed inlet positions

! 2 Tank volume

! 3 Fluid specific heat

! 4 Fluid density

! 5 Tank loss coefficient

! 6 Height of node-1

! 7 Height of node-2

! 8 Height of node- 3

! 9 Height of node-4

! 10 Height of node-5

! 11 Height of node- 6

! 12 Height of node-7

! 13 Height of node-8

! 14 Height of node-9

! 15 Height of node- 10

! 16 Height of node-11

! 17 Height of node-12

! 18 Height of node-13

! 19 Height of node-14

! 20 Height of node-15

! 21 Auxiliary heater mode

! 22 Node containing heating element 1

! 23 Node containing thermostat 1

! 24 Set point temperature for element 1

! 25 Deadband for heating element 1

! 26 Maximum heating rate of element 1

! 27 Node containing heating element 2

! 28 Node containing thermostat 2

! 29 Set point temperature for element 2

! 30 Deadband for heating element 2

! 31 Maximum heating rate of element 2

! 32 Not used (Flue UA)

! 33 Not used (Tflue)

!34 Boiling point 
INPUTS 7

22,4

11,2

9,3

temperature

9,4

21,1 temperature

0,0

0,0

$* * *$ INITIAL INPUT VALUES

20100.000799105496 .5990072211

DERIVATIVES 15

50

50

50

50

50

50

50

50

50

50

50

50

50

50

50

\section{$*$}

* Model "Type4a-2-Hot Tank" (Type 4)

UNIT 25 TYPE 4 Type4a-2-Hot Tank

*\$UNIT_NAME Type4a-2-Hot Tank

*\$MODEL . \Thermal Storage \Stratified Storage Tank \Fixed Inlets \Uniform Losses $\backslash$ Type4a.tmf

*\$POSITION 243500

*\$LAYER Main \#

PARAMETERS 34

1

0.5

4.19

1000

3.0

! 1 Fixed inlet positions

! 2 Tank volume

!3 Fluid specific heat

! 4 Fluid density

! 5 Tank loss coefficient 


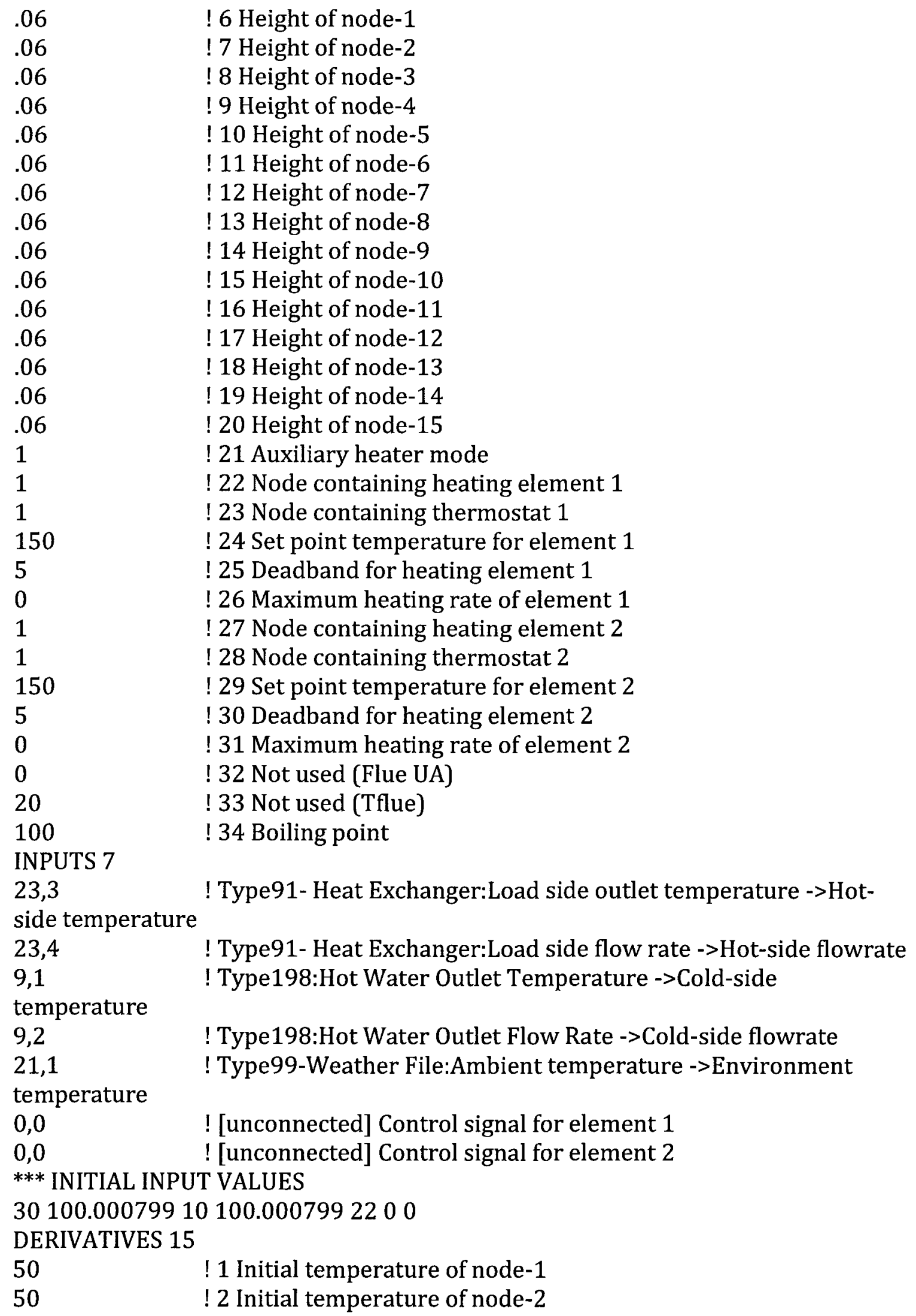


50

50

50

50

50

50

50

50

50

50

50

50

50

! 3 Initial temperature of node-3

! 4 Initial temperature of node-4

! 5 Initial temperature of node-5

! 6 Initial temperature of node-6

! 7 Initial temperature of node-7

! 8 Initial temperature of node-8

! 9 Initial temperature of node-9

! 10 Initial temperature of node-10

! 11 Initial temperature of node-11

! 12 Initial temperature of node-12

! 13 Initial temperature of node-13

! 14 Initial temperature of node-14

! 15 Initial temperature of node-15

* Model "Type71-Solar Collector" (Type 71)

UNIT 3 TYPE 71 Type71-Solar Collector

*\$UNIT_NAME Type71-Solar Collector

*\$MODEL . \Solar Thermal Collectors \Evacuated Tube Collector \Type71.tmf

*\$POSITION 276319

*\$LAYER Main \#

PARAMETERS 11

1

40

3.559

2

69.55

0.576

4.356

0.00288

54

7

7

INPUTS 10

23,1

temperature

23,2

21,1

temperature

21,18

radiation

0,0

0,0

! 1 Number in series

! 2 Collector area

! 3 Fluid specific heat

! 4 Efficiency mode

! 5 Flow rate at test conditions

! 6 Intercept efficiency

! 7 Negative of first order efficiency coeficient

! 8 Negative of second order efficiency coeficient

! 9 Logical unit of file containing biaxial IAM data

! 10 Number of longitudinal angles for which IAMs are provided

! 11 Number of transverse angles for which IAMs are provided

! Type91- Heat Exchanger:Source-side outlet temperature ->Inlet

! Type91- Heat Exchanger:Source side flow rate ->Inlet flowrate

! Type99-Weather File:Ambient temperature ->Ambient

! Type99-Weather File:total radiation on tilted surface ->Incident

! [unconnected] Incident diffuse radiation

! [unconnected] Solar incidence angle 


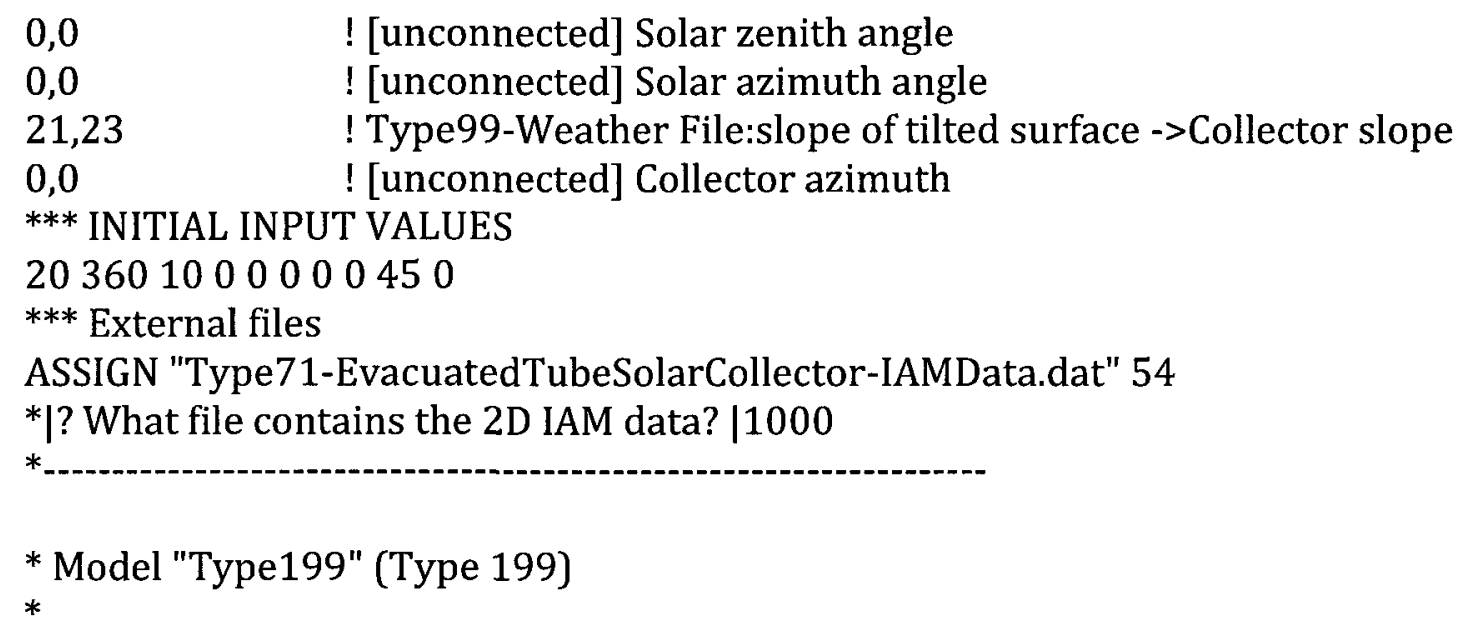

UNIT 22 TYPE 199

Type199

*\$UNIT_NAME Type199

*\$MODEL . \Controllers \Absorption Chiller Controller \Type199.tmf

*\$POSITION 75150

*\$LAYER Main \#

INPUTS 7
25,1 ! Type4a-2-Hot Tank:Temperature to heat source ->TempBaseHT
25,3 ! Type4a-2-Hot Tank:Temperature to load ->TempTopHT
26,1 ! Type4a - Cold Tank:Temperature to heat source ->TempBaseCT
3,1 ! Type71-Solar Collector:Outlet temperature $>$ TempExtSC
20,1 ! Type9a-Cooling Loads:Output $1>$ Cooling Load
11,2 ! Type3b-5 Pump:Outlet flow rate ->FlowExCT
21,1 ! Type99-Weather File:Ambient temperature $\rightarrow$ Tamb
$* * *$ INITIAL INPUT VALUES
000000000

* Model "Type3b-5 Pump" (Type 3)

$*$

UNIT 11 TYPE 3 Type3b-5 Pump

*\$UNIT_NAME Type3b-5 Pump

*\$MODEL .\Hydronics\Pumps\Single Speed \Type3b.tmf

*\$POSITION 468276

* \$LAYER Main \#

PARAMETERS 5

2880

4.19

60.001192

0.05

0.5

! 1 Maximum flow rate

! 2 Fluid specific heat

! 3 Maximum power

!4 Conversion coefficient

! 5 Power coefficient 
INPUTS 3

26,1

! Type4a - Cold Tank:Temperature to heat source ->Inlet fluid temperature

26,2

! Type4a - Cold Tank:Flowrate to heat source ->Inlet mass flow

rate

0,0 ! [unconnected] Control signal

*** INITIAL INPUT VALUES

201001

* Model "Type3b-6-Pump" (Type 3)

*

UNIT 17 TYPE 3 Type3b-6-Pump

*\$UNIT_NAME Type3b-6-Pump

*\$MODEL . \Hydronics \Pumps\Single Speed \Type3b.tmf

*\$POSITION 562532

*\$LAYER Main \#

PARAMETERS 5

5472

4.19

!1 Maximum flow rate

60.001192

! 2 Fluid specific heat

0.05

! 3 Maximum power

0.5

! 4 Conversion coefficient

INPUTS 3

26,3

! 5 Power coefficient

temperature

26,4

0,0

*** INITIAL INPUT VALUES

! Type4a - Cold Tank:Temperature to load ->Inlet fluid

20100.0007991

* Model "Type3b-Pump" (Type 3)

*

UNIT 7 TYPE 3 Type3b-Pump

*\$UNIT_NAME Type3b-Pump

*\$MODEL . \Hydronics \Pumps\Single Speed \Type3b.tmf

*\$POSITION 123415

*\$LAYER Water Loop \#

PARAMETERS 5

180.0

4.19

! 1 Maximum flow rate

60.001192

! 2 Fluid specific heat

! 3 Maximum power 
$0.05 \quad ! 4$ Conversion coefficient

$0.5 \quad$ ! 5 Power coefficient

INPUTS 3

25,1

! Type4a-2-Hot Tank:Temperature to heat source ->Inlet fluid temperature

25,2

! Type4a-2-Hot Tank:Flowrate to heat source ->Inlet mass flow rate

22,1 ! Type199:CS Hot Pump Cycle ->Control signal

*** INITIAL INPUT VALUES

20100.0007991

* Model "Type3b-4-Pump" (Type 3)

$*$

UNIT 15 TYPE 3 Type3b-4-Pump

*\$UNIT_NAME Type3b-4-Pump

*\$MODEL.$\backslash$ Hydronics $\backslash$ Pumps $\backslash$ Single Speed $\backslash$ Type3b.tmf

*\$POSITION 252628

* \$LAYER Main \#

PARAMETERS 5

8640

4.19

60.001192

! 1 Maximum flow rate

0.05

0.5

! 2 Fluid specific heat

! 3 Maximum power

!4 Conversion coefficient

INPUTS 3

! 5 Power coefficient

25,3

! Type4a-2-Hot Tank:Temperature to load ->Inlet fluid

temperature

25,4

! Type4a-2-Hot Tank:Flowrate to load ->Inlet mass flow rate

0,0

! [unconnected] Control signal

*** INITIAL INPUT VALUES

85100.0007991

* Model "Type91- Heat Exchanger" (Type 91)

*

UNIT 23 TYPE 91 Type91- Heat Exchanger

*\$UNIT_NAME Type91- Heat Exchanger

*\$MODEL . \Heat Exchangers \Constant Effectiveness \Type91.tmf

*\$POSITION 342404

* \$LAYER Main \#

PARAMETERS 3

1.0

! 1 Heat exchanger effectiveness 
3.559

4.19

INPUTS 4

3,1 temperature

3,2

7,1 temperature

7,2 *** INITIAL INPUT VALUES

90360.070100 .000

* Model "Type198" (Type 198)

*

UNIT 9 TYPE 198 Type198

*\$UNIT_NAME Type198

*\$MODEL . \HVAC \Absorption Chiller (Hot-Water Fired, Single Effect) \Type198.tmf *\$POSITION 426682

* \$LAYER Main \#

INPUTS 10

15,1

Temperature

15,2

17,1

Temperature

17,2

0,0

0,0

0,0

0,0

22,5

21,1

*** INITIAL INPUT VALUES

85500.00039912 .22500 .0003990 .6755 .999921710
! Type3b-4-Pump:Outlet fluid temperature ->Hot Water Inlet

! Type3b-4-Pump:Outlet flow rate ->Hot Water Inlet Flow rate

! Type3b-6-Pump:Outlet fluid temperature ->Chilled Water Inlet

! Type3b-6-Pump:Outlet flow rate ->Chilled Water Inlet Flowrate

! [unconnected] COP

! [unconnected] Auxiliary Power

! [unconnected] Chiller Control Signal

! [unconnected] Chiller Set Point

! Type199:Cooling Season ->CoolingSeason

! Type99-Weather File:Ambient temperature ->TempAmb

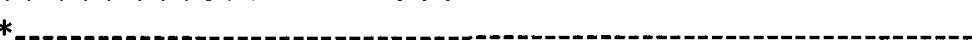




\section{APPENDIX B: ESP-r Plant Network Description and Inputs}

\# Total no. of specified components and simulation type

\section{3}

\#-> 1, variable speed domestic WCH pump; 1 node model

pump_hw_hx 15

1 \# Component has 1 control variable(s).

5.0000 \# 1 Component total mass $(\mathrm{kg})$

4185.0 \# 2 Mass weighted average specific heat $(\mathrm{J} / \mathrm{kgK})$

0.20000 \# 3 UA modulus from wall to environment $(\mathrm{W} / \mathrm{K})$

6.000 \# 4 Rated total absorbed power (W)

$0.50000 \mathrm{E}-04$ \# 5 Rated volume flow rate $\left(\mathrm{m}^{\wedge} 3 / \mathrm{s}\right)$

$0.70000 \# 6$ Overall efficiency $(-)$

\#-> 2, Generic 2-node fluid fluid heat exchanger with multiple flow regimes

heat_exchanger 52

0 \# Component has 0 control variable(s).

1.0000 \# 1 Mass of encapsulated fluid on 'hot' side (kg)

1.0000 \# 2 Mass of encapsulated fluid on the "cold" side (kg)

$6000.0 \# 3$ Overall heat transfer coefficient $\left(\mathrm{W} / \mathrm{m}^{\wedge} 2 \mathrm{~K}\right)$

$1.0000 \quad \# 4$ Heat transfer surface area $\left(\mathrm{m}^{\wedge} 2\right)$

0.0000 \# 5 UA modulus for component $(\mathrm{W} / \mathrm{K})$

2.0000 \# 6 Flow arrangement index $(-)$

\#-> 3, variable speed domestic WCH pump; 1 node model

pump_hx_sc 15

1 \# Component has 1 control variable(s).

5.0000 \# 1 Component total mass $(\mathrm{kg})$

3558.8 \# 2 Mass weighted average specific heat $(\mathrm{J} / \mathrm{kgK})$

0.20000 \# 3 UA modulus from wall to environment $(\mathrm{W} / \mathrm{K})$

10.000 \# 4 Rated total absorbed power (W)

$0.96061 \mathrm{E}-04$ \# 5 Rated volume flow rate $\left(\mathrm{m}^{\wedge} 3 / \mathrm{s}\right)$

$0.70000 \quad \# 6$ Overall efficiency $(-)$ 
\#-> 4, Simplified flat plate solar collector, 1 node model solar_collect 84

0 \# Component has 0 control variable(s).

$50.0000 \quad \# 1$ Collector area $(\mathrm{m} 2)$

2.0000 \# 2 Type of efficiency equ. (1=North-American,2=European)

$0.57600 \# 3$ Constant coef. of efficiency equ. (-)

$1.2100 \quad \# 4$ Linear coef. of efficiency equ. (W/m2/C)

$0.0008 \# 5$ Quadratic coef. of efficiency equ. (W/m2/C2)

$0.68576 \mathrm{E}-01$ \# 6 Collector test flow rate $(\mathrm{kg} / \mathrm{s})$

$3860.0 \quad \# 7$ Heat capacitance of fluid used for test $(\mathrm{J} / \mathrm{kg} / \mathrm{C})$

$2.0000 \# 8$ Inc. angle correction (=1 Fit, $=2$ Interpolation)

$0.20000 \# 9$ Inc. angle equation linear term coef. $(-)$

$0.0000 \# 10$ Inc. angle equation quadratic term coef. ( - )

1.0000 \# 11 Number of data pairs for inc angle correction (-)

0.0000 \# 12 1st inc. angle correction data pair angle (Deg)

1.0000 \# 131 st inc. angle correction data pair factor (-)

$0.0000 \quad \#$ 14 2nd inc. angle correction data pair angle (Deg)

$1.0000 \# 15$ 2nd inc. angle correction data pair factor $(-)$

0.0000 \# 16 3rd inc. angle correction data pair angle (Deg)

1.0000 \# 17 3rd inc. angle correction data pair factor

$0.0000 \quad \# 18$ 4th inc. angle correction data pair angle (Deg)

1.0000 \# 19 4th inc. angle correction data pair factor (-)

0.0000 \# 20 5th inc. angle correction data pair angle (Deg)

1.0000 \# 21 th inc. angle correction data pair factor $(-)$

$0.0000 \# 22$ 6th inc. angle correction data pair angle (Deg)

1.0000 \# 23 6th inc. angle correction data pair factor (-)

$0.0000 \# 247$ th inc. angle correction data pair angle (Deg)

$1.0000 \# 257$ th inc. angle correction data pair factor $(-)$

$0.0000 \# 26$ 8th inc. angle correction data pair angle (Deg)

$1.0000 \# 278$ th inc. angle correction data pair factor $(-)$

$0.0000 \# 28$ 9th inc. angle correction data pair angle (Deg) 
$1.0000 \quad \# 29$ 9th inc. angle correction data pair factor $(-)$

0.0000 \# 30 10th inc. angle correction data pair angle (Deg)

$1.0000 \quad \# 31$ 10th inc. angle correction data pair factor (-)

20.000 \# 32 Collector slope (deg. from horizontal)

180.00 \# 33 Collector azimuth (deg., N=0, E=90)

$50.000 \quad$ \# 34 Mass fraction of propylene glycol (\%)

0.0000 \# 35 Mass of collector $(\mathrm{kg})$

3559.00 \# 36 Collector average capacitance (J/kg-C)

\#-> 5, 1-node tank for TAC work

hw_tank 60

0 \# Component has 0 control variable(s).

500.0 \# 1 Component total mass $(\mathrm{kg})$

1.1750 \# 2 Tank heat gain coefficient $(\mathrm{W} / \mathrm{k})$

$4185.0 \quad \# 3$ Specific heat of water in tank $(\mathrm{J} / \mathrm{kgK})$

\#-> 6, variable speed domestic WCH pump; 1 node model

pump_hw_tac 15

1 \# Component has 1 control variable(s).

5.0000 \# 1 Component total mass $(\mathrm{kg})$

$4185.0 \quad \# 2$ Mass weighted average specific heat $(\mathrm{J} / \mathrm{kgK})$

0.20000 \# 3 UA modulus from wall to environment $(\mathrm{W} / \mathrm{K})$

130.000 \# 4 Rated total absorbed power (W)

$0.14400 \mathrm{E}-02$ \# 5 Rated volume flow rate $\left(\mathrm{m}^{\wedge} 3 / \mathrm{s}\right)$

$1.0000 \quad \# 6$ Overall efficiency $(-)$

\#-> 7, 3-node description of a TAC unit

TAC 61

2 \# Component has 2 control variable(s).

$55.000 \quad \# 1$ temperature of refrigerant at generator inlet (oC)

$0.80000 \# 2$ generator heat exchanger effectiveness (e)

$0.10133 \mathrm{E}+06 \# 3$ water pressure in $\mathrm{FC}$ - $\operatorname{cogen} \mathrm{h} / \mathrm{x}$ - generator inlet loop $(\mathrm{Pa})$

0.62544 \# 4 nominal COP at standard operating conditions (a)

$-0.17194 \mathrm{E}-02$ \# 5 COP generator temp 1st order polynomial coefficient (b1) 
-0.27549E-02 \# 6 COP condenser temp 1st order polynomial coefficient (b2)

$0.70038 \mathrm{E}-02$ \# 7 COP evaporator temp 1st order polynomial coefficient (b3)

-0.53193E-03 \# 8 COP generator temp 2nd order polynomial coefficient (c1)

$0.28771 \mathrm{E}-02$ \# 9 COP condenser temp 2nd order polynomial coefficient ( $c$ 2)

$-0.17200 \mathrm{E}-04$ \# $10 \mathrm{COP}$ evaporator temp 2 nd order polynomial coefficient (c3)

$0.50710 \mathrm{E}-03$ \# 11 COP gen-conden temp 2 nd order polynomial coefficient (d1)

$0.46441 \mathrm{E}-03$ \# 12 COP gen-evap temp 2 nd order polynomial coefficient ( $\mathrm{d} 2$ )

$-0.17481 \mathrm{E}-02$ \# 13 COP cond-evap temp 2nd order polynomial coefficient (d3)

88.000 \# 14 generator standard operating temperature $(\mathrm{oC})$

$31.000 \quad \# 15$ condenser standard operating temperature (oC)

$7.0000 \quad \# 16$ evaporator standard operating temperature (oC)

210.000 \# $17 \mathrm{TAC}$ refrigerant pump power (W)

1.0000 \# 18 mass flow rate of air through condenser $(\mathrm{kg} / \mathrm{s})$

$500.00 \quad \# 19$ condenser fan power (W)

$2.0000 \quad \# 20$ temperature rise at condenser inlet (oC)

$0.10000 \mathrm{E}+08 \# 21$ Limit on heat input to generator at std conditions (W)

\#-> 8, variable speed domestic WCH pump; 1 node model

pump_cw_tac 15

1 \# Component has 1 control variable(s).

5.0000 \# 1 Component total mass $(\mathrm{kg})$

4185.0 \# 2 Mass weighted average specific heat $(\mathrm{J} / \mathrm{kgK})$

0.20000 \# 3 UA modulus from wall to environment (W/K)

74.000 \# 4 Rated total absorbed power (W)

$0.13300 \mathrm{E}-02$ \# 5 Rated volume flow rate $\left(\mathrm{m}^{\wedge} 3 / \mathrm{s}\right)$

0.70000 \# 6 Overall efficiency $(-)$

\#-> 9, 1-node tank for TAC work

cw_tank 60

0 \# Component has 0 control variable(s).

3

1500.0 \# 1 Component total mass (kg)

1.1750 \# 2 Tank heat gain coefficient $(\mathrm{W} / \mathrm{k})$ 
4185.0 \# 3 Specific heat of water in tank $(\mathrm{J} / \mathrm{kgK})$

\#-> 10, variable speed domestic WCH pump; 1 node model pump_tank_coil 15

1 \# Component has 1 control variable(s).

$5.0000 \# 1$ Component total mass $(\mathrm{kg})$

4185.0 \# 2 Mass weighted average specific heat $(\mathrm{J} / \mathrm{kgK})$

0.20000 \# 3 UA modulus from wall to environment $(\mathrm{W} / \mathrm{K})$

46.000 \# 4 Rated total absorbed power (W)

$0.80000 \mathrm{E}-03$ \# 5 Rated volume flow rate $\left(\mathrm{m}^{\wedge} 3 / \mathrm{s}\right)$

$0.70000 \# 6$ Overall efficiency $(-)$

\#-> 11, air cooling coil fed by WCH system; 3 node model

cooling_coil 20

0 \# Component has 0 control variable(s).

0.20000 \# 1 Component total mass (kg)

$800.00 \# 2$ Average specific heat of solids $(\mathrm{J} / \mathrm{kgK})$

6.0000 \# 3 UA modulus (node 1 to surroundings) $(\mathrm{W} / \mathrm{K})$

0.20000 \# 4 Mass of water encapsulated in component (kg)

5.6450 \# 5 Coil outside (air) heat transfer area $\left(\mathrm{m}^{\wedge} 2\right)$

$1.0000 \# 6$ Coil inside (water) heat transfer area $\left(\mathrm{m}^{\wedge} 2\right)$

$0.20000 \# 7$ Coil face area $\left(\mathrm{m}^{\wedge} 2\right)$

$0.10000 \mathrm{E}-04 \# 8$ Metal thermal resistance $\left(\mathrm{m}^{\wedge} 2 \mathrm{~K} / \mathrm{W}\right)$

$0.11500 \mathrm{E}-01$ \# 9 Internal tube diameter $(\mathrm{m})$

\#-> 12, centrifugal fan, 1 node model ; flow control

circ_fan 3

1 \# Component has 1 control variable(s).

0.10000 \# 1 Component total mass (kg)

1000.0 \# 2 Mass weighted average specific heat $(\mathrm{J} / \mathrm{kgK})$

0.0000 \# 3 UA modulus $(\mathrm{W} / \mathrm{K})$

250.000 \# 4 Rated total absorbed power (W)

0.2500 \# 5 Rated volume flow rate $\left(\mathrm{m}^{\wedge} 3 / \mathrm{s}\right)$

$0.70000 \# 6$ Overall efficiency $(-)$ 
\# The following is a list of component connections.

17 \# Total number of connections

\# receiving node conncn sending node diversion suppl1 suppl2

\# component type component ratio

solar_collect 143 pump_hx_sc $\quad 1 \quad 1.000 \quad \# 1$

pump_hw_hx $\quad \begin{array}{llllll}1 & 3 & \text { hw_tank } & 1 & 0.500 & \# 2\end{array}$

pump_hx_sc $\quad 1 \quad 3$ heat_exchanger $111.000 \quad$ \# 3

heat_exchanger 113 solar_collect $111.000 \quad$ \# 4

heat_exchanger $25 \quad 3$ pump_hw_hx $11.000 \quad$ \# 5

TAC $\quad 1 \quad 3$ pump_hw_tac $11.000 \quad$ \# 6

$\begin{array}{lllllll}\text { hw_tank } & 1 & 3 & \text { heat_exchanger } & 2 & 1.000 & \# 7\end{array}$

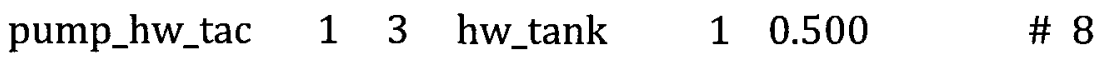

$\begin{array}{lllllll}\text { cw_tank } & 1 & 3 & \text { TAC } & 2 & 1.000 & \# 9\end{array}$

TAC $\quad 2 \quad 3 \quad$ pump_cw_tac 11000 \#

$\begin{array}{lllllll}\text { hw_tank } & 1 & 3 & \text { TAC } & 1 & 1.000 & \# 11\end{array}$

pump_cw_tac $\quad 1 \quad 3 \quad$ cw_tank $\quad \begin{array}{llll}1 & 0.500 & \text { \# } 12\end{array}$

pump_tank_coil $1 \quad 3 \quad$ cw_tank $\quad \begin{array}{llll}1 & 0.500 & \text { \# } 13\end{array}$

cooling_coil $2 \begin{array}{llllllll} & 4 & \text { circ_fan } & 1 & 1.000 & 1.00\end{array}$ \# 14

$\begin{array}{lllllll}\text { cw_tank } & 1 & 3 & \text { cooling_coil } & 3 & 1.000\end{array}$

cooling_coil $3 \quad 3$ pump_tank_coil $111.000 \quad$ \# 16

$\begin{array}{lllllll}\text { circ_fan } & 1 & 3 & \text { cooling_coil } & 2 & 1.000\end{array}$

\# The following is a list of containment temperatures.

$5 \quad$ \# Total number of containments

\# Component cont type suppl1 suppl2 suppl3

$\begin{array}{llllll}\text { cw_tank } & 3 & 1.00000 & 0.00000 & 0.00000\end{array}$

$\begin{array}{lllll}\text { hw_tank } & 3 & 1.00000 & 0.00000 & 0.00000\end{array}$

$\begin{array}{lllll}\text { solar_collect } & 0 & 0.00000 & 0.00000 & 0.00000\end{array}$

$\begin{array}{llllll}\text { cooling_coil } & 3 & 1.00000 & 0.00000 & 0.00000\end{array}$

$\begin{array}{lllll}\text { circ_fan } & 3 & 1.00000 & 0.00000 & 0.00000\end{array}$ 


\section{APPENDIX C: Experimental Data Used for Regression Analysis}

The following data is a summary of data gathered by Johnson (2011) from his experimental investigations of the absorption chiller performance. This data was used to determine expressions for the evaporator and generator heat transfer rates based on inlet conditions. For full experimental data, the interested reader is directed to Johnson (2011).

\begin{tabular}{|c|c|c|c|c|}
\hline Trial & $\begin{array}{c}\text { Generator Inlet } \\
\text { Temperature }\left({ }^{\circ} \mathrm{C}\right)\end{array}$ & $\begin{array}{c}\text { Evaporator Inlet } \\
\text { Temperature }\left({ }^{\circ} \mathrm{C}\right)\end{array}$ & $\begin{array}{c}\text { Condenser Inlet } \\
\text { Temperature } \\
\left({ }^{\circ} \mathrm{C}\right)\end{array}$ & COP \\
\hline 1 & 81.58 & 12.86 & 27.63 & 0.704 \\
\hline 2 & 81.7 & 15.03 & 27.6 & 0.723 \\
\hline 3 & 74.6 & 14.74 & 27.74 & 0.654 \\
\hline 4 & 74.84 & 18.75 & 27.8 & 0.692 \\
\hline 5 & 80.08 & 10.79 & 28.96 & 0.653 \\
\hline 6 & 80.78 & 15.09 & 29.17 & 0.714 \\
\hline 7 & 84.03 & 15.27 & 29.12 & 0.744 \\
\hline 8 & 74.82 & 16.22 & 29.67 & 0.565 \\
\hline 9 & 75.2 & 19.75 & 29.28 & 0.593 \\
\hline 10 & 76.93 & 20.51 & 29.32 & 0.607 \\
\hline 11 & 73.59 & 22.16 & 29.47 & 0.562 \\
\hline 12 & 74.21 & 14.5 & 30.5 & 0.566 \\
\hline
\end{tabular}

\begin{tabular}{|c|c|c|c|c|}
\hline Trial & $\begin{array}{c}\text { Generator Inlet } \\
\text { Temperature }\left({ }^{\circ} \mathrm{C}\right)\end{array}$ & $\begin{array}{c}\text { Evaporator Inlet } \\
\text { Temperature }\left({ }^{\circ} \mathrm{C}\right)\end{array}$ & $\begin{array}{c}\text { Condenser Inlet } \\
\text { Temperature } \\
\left({ }^{\circ} \mathrm{C}\right)\end{array}$ & COP \\
\hline 13 & 85.64 & 15.11 & 30.23 & 0.658 \\
\hline 14 & 80.03 & 17 & 29.78 & 0.62 \\
\hline 15 & 83.84 & 19.18 & 29.8 & 0.6833 \\
\hline 16 & 79.72 & 19.19 & 29.7 & 0.689 \\
\hline 17 & 81.13 & 17.78 & 32.26 & 0.611 \\
\hline 18 & 74.17 & 17.98 & 31.96 & 0.519 \\
\hline 19 & 75.41 & 19.17 & 32.72 & 0.506 \\
\hline 20 & 77.05 & 22.12 & 31.22 & 0.568 \\
\hline 21 & 74.88 & 22.24 & 31.27 & 0.539 \\
\hline 22 & 75.73 & 18.99 & 32.58 & 0.501 \\
\hline 23 & 75.03 & 14.74 & 26.74 & 0.709 \\
\hline
\end{tabular}




\section{APPENDIX D: LIST OF RESULTS}

\begin{tabular}{|c|c|c|c|c|c|c|c|}
\hline $\begin{array}{c}\text { Run } \\
\#\end{array}$ & House & Climate & $\begin{array}{l}\text { Cooling } \\
\text { Setpoint }\end{array}$ & $\begin{array}{c}\text { Min. } \\
\text { Generator } \\
\text { Temp. }\left({ }^{\circ} \mathrm{C}\right)\end{array}$ & $\mathcal{N}(\%)$ & $\begin{array}{c}\text { Max. } \\
\text { Zone } \\
\text { Temp. } \\
\left({ }^{\circ} \mathrm{C}\right)\end{array}$ & $\begin{array}{c}\text { Avg. } \\
\text { Zone } \\
\text { Temp. } \\
\left({ }^{\circ} \mathrm{C}\right)\end{array}$ \\
\hline 1 & 2000 & Toronto CWEC & 24 & 73.6 & 2.5 & 27.2 & 23.4 \\
\hline 2 & 1955 & Toronto CWEC & 24 & 73.6 & 3.3 & 28.2 & 22.8 \\
\hline 3 & 1976 & Toronto CWEC & 24 & 73.6 & 3.9 & 28.7 & 23.0 \\
\hline 4 & $1976-\mathrm{LW}$ & Toronto CWEC & 24 & 73.6 & 22.7 & 34.6 & 23.9 \\
\hline 5 & 2000 & Windsor CWEC & 24 & 73.6 & 2.4 & 26.2 & 23.7 \\
\hline 6 & 2000 & Ottawa CWEC & 24 & 73.6 & 0.9 & 28.2 & 23.3 \\
\hline 7 & 2000 & Toronto 1999 & 24 & 73.6 & 5.3 & 30.7 & 23.9 \\
\hline 8 & 2000 & Toronto 2000 & 24 & 73.6 & 0.1 & 25.5 & 23.4 \\
\hline 9 & 2000 & Toronto 2001 & 24 & 73.6 & 4.9 & 29.0 & 23.7 \\
\hline 10 & 2000 & Toronto 2002 & 24 & 73.6 & 10.6 & 29.6 & 23.6 \\
\hline 11 & 2000 & Toronto 2003 & 24 & 73.6 & 0.5 & 25.6 & 23.5 \\
\hline 12 & 2000 & Toronto 2004 & 24 & 73.6 & 1.4 & 28.1 & 23.7 \\
\hline 13 & 2000 & Toronto 2005 & 24 & 73.6 & 12.0 & 28.9 & 24.0 \\
\hline 14 & 2000 & Toronto 2006 & 24 & 73.6 & 7.5 & 31.1 & 23.7 \\
\hline 15 & 2000 & Toronto 2007 & 24 & 73.6 & 4.3 & 27.3 & 23.8 \\
\hline 16 & 2000 & Toronto 2008 & 24 & 73.6 & 0.9 & 27.0 & 23.4 \\
\hline 17 & 2000 & Toronto CWEC & 23 & 73.6 & 2.8 & 27.3 & 22.7 \\
\hline 18 & 2000 & Toronto CWEC & $\begin{array}{c}\text { Varying } \\
24 / 26\end{array}$ & 73.6 & 1.5 & 27.2 & 23.6 \\
\hline 19 & 2000 & Toronto CWEC & 24 & 70.0 & 2.9 & 27.3 & 23.4 \\
\hline 20 & 2000 & Toronto CWEC & 24 & 75.0 & 2.3 & 27.2 & 23.4 \\
\hline 21 & 2000 & Toronto CWEC & 24 & 80.0 & 2.3 & 27.3 & 23.4 \\
\hline
\end{tabular}

